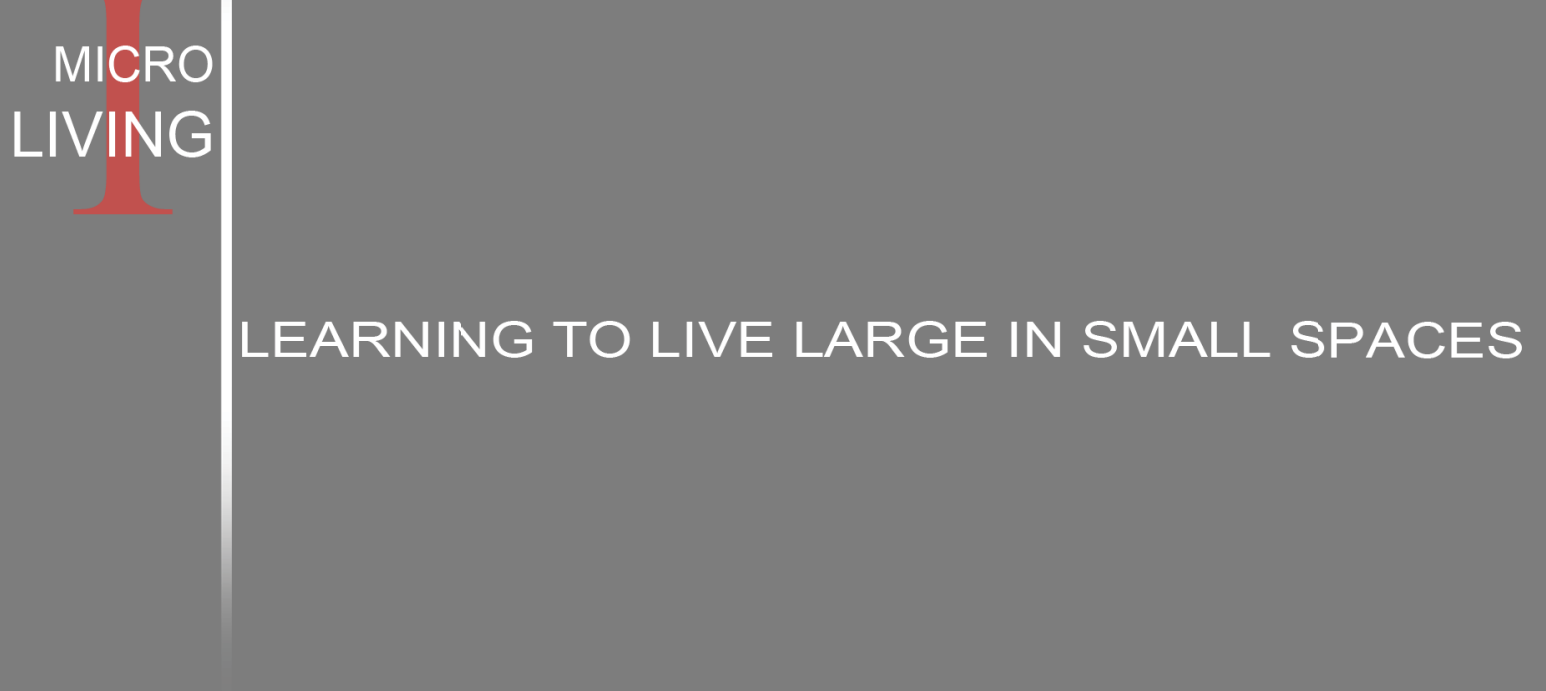

LEARNING TO LIVE LARGE IN SMALL SPACES$$
\text { - }
$$
40

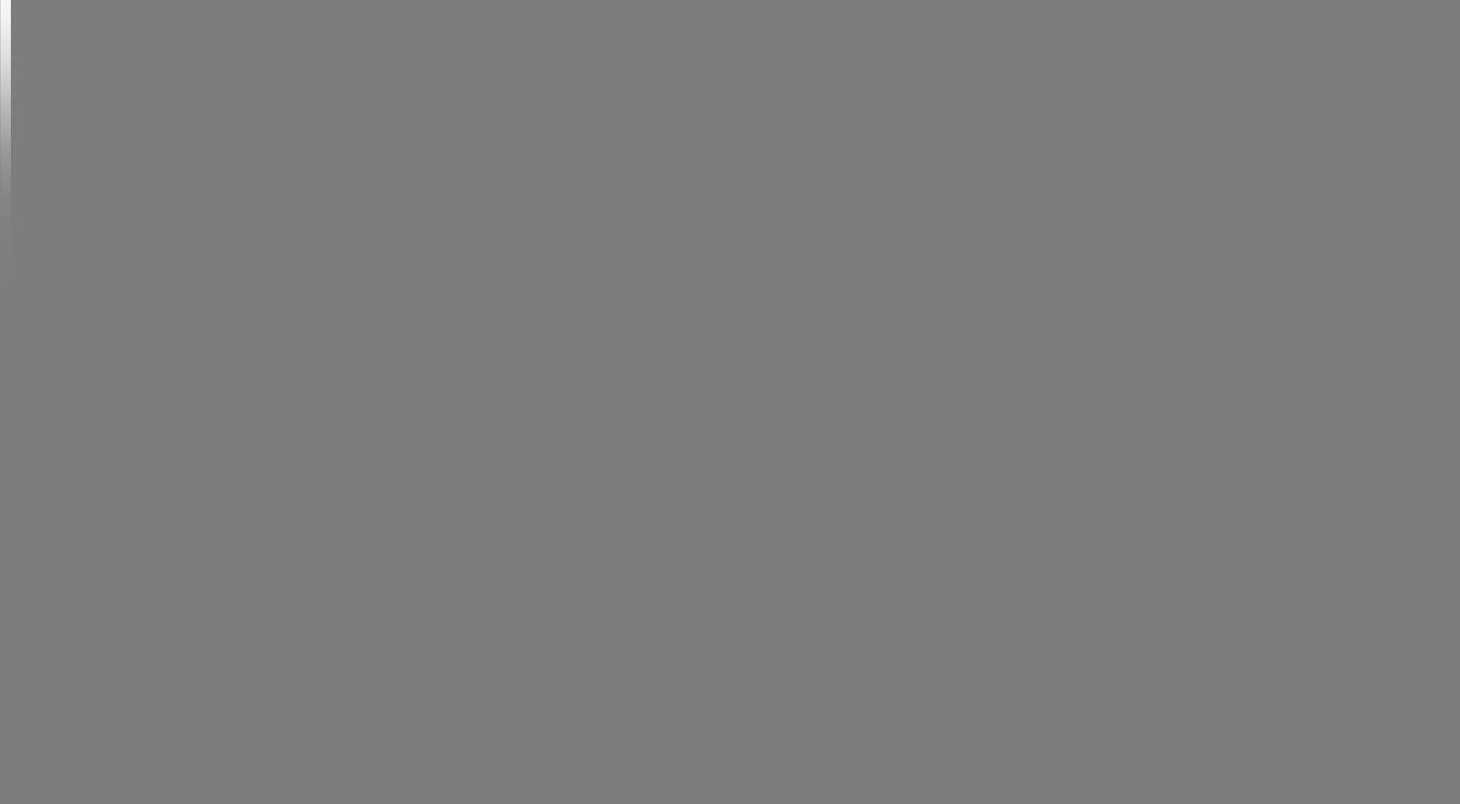

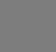

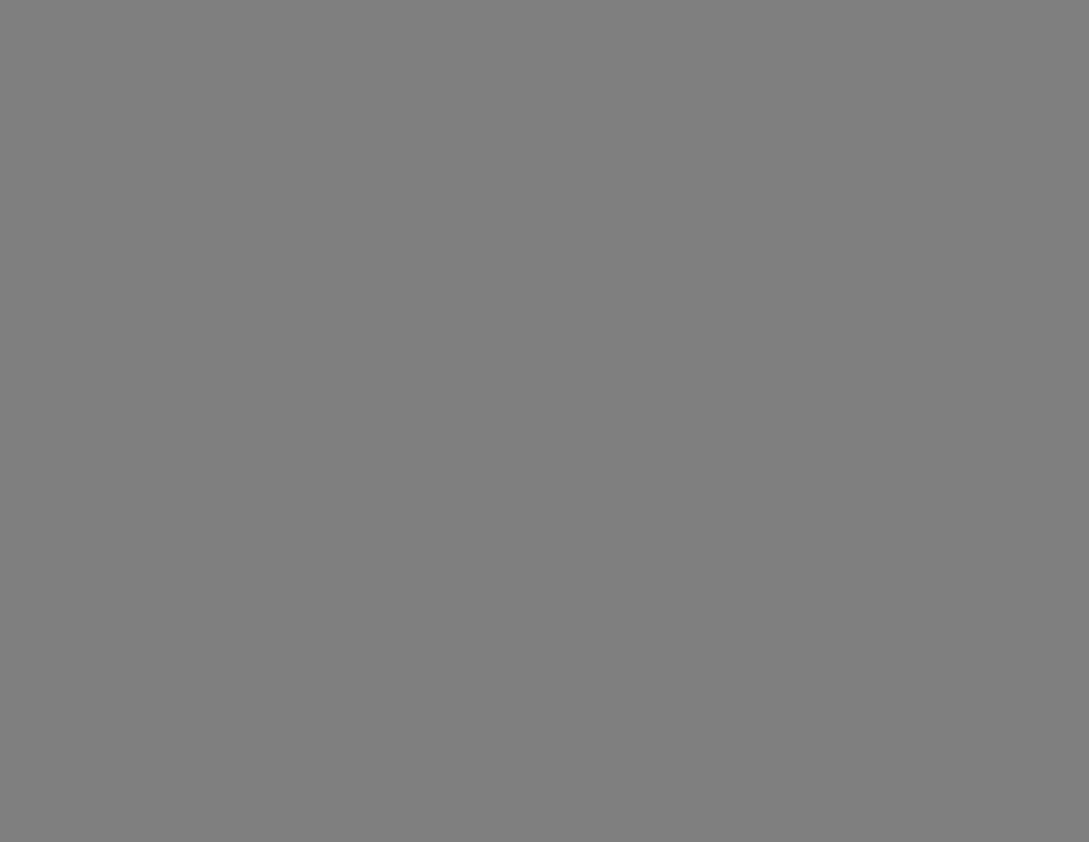




\section{MICRO-LIVING:}

learning to live large in small spaces

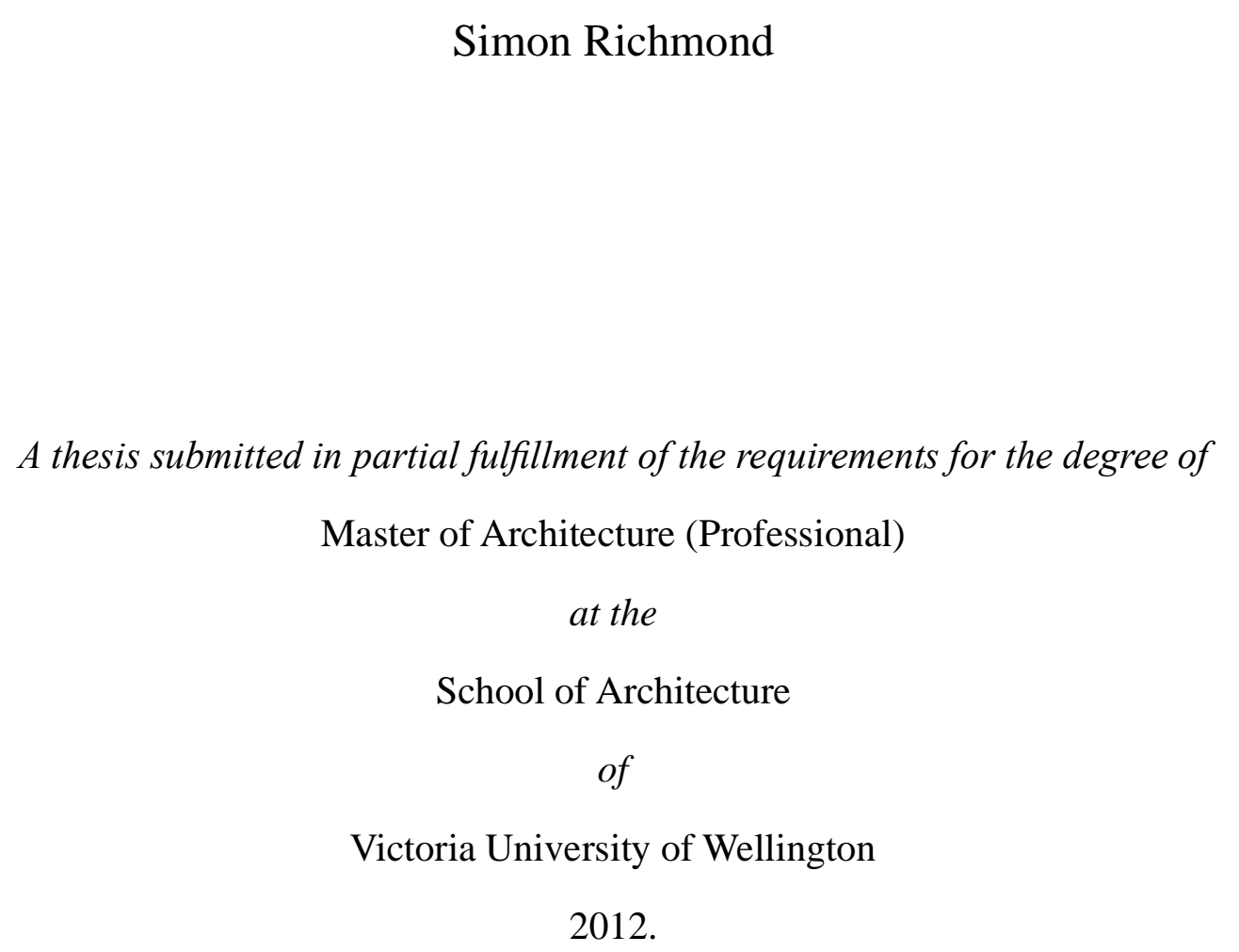

2012. 
High-density living has always been proclaimed as a way of the future, but the future is now here and we are plagued by inadequate, uninviting city-living environments. This design research paper aims to produce an alternate design method that can be applied to apartment living in New Zealand to produce positive, affordable apartment designs.

The late 20th and early 21st centuries has seen urban New Zealand become an increasingly popular place to live. Large numbers are drawn to the cities by the convenience of closer proximity to amenities and greater job prospects. This urbanisation overlaps with the constant growth of the country's overall population which, combined, puts pressure on cities as land becomes an increasingly rare commodity. In response, cities often expand outward. The negative effect of this has been heavily documented.

The introduction of high density living solutions has attempted to combat the ever increasing 'suburban sprawl.' Many apartment complexes have risen in response to this demand, especially in the cities of Auckland and Wellington. However, this is where the problem develops. A large proportion of smaller, more affordable apartments have been identified to be poorly designed, producing low quality spaces and unsatisfactory living environments. Moreover, the public perception of these 'shoebox' apartments is highly negative.

This research not only investigates the issues associated with the small apartments in New Zealand but seeks to improve upon them by learning from an international precedent. The Japanese architectural movement of Kyosho-Jutaku or Micro-living provides urban accommodation through space efficient stand-alone dwellings. These dwellings were developed in response to the harsh urban and economic conditions in the early 1990s and continue to be built throughout Japan's urban prefectures. The architects of Japanese micro-architecture approach small spaces with design strategies resulting in interiors which appear expansive beyond their physical limits and produce quality living environments. 
Through the analysis and diagrammatic formulation of these Japanese micro-architecture design strategies, this research aims to produce an applicable technique for 'micro' design in New Zealand. The contexts are removed allowing the singular strategies to be understood and manipulated, expanding the design possibilities for each technique. Ultimately, this thesis tests the applicability of planning and spatial design strategies, adapted from Japanese micro-architecture, to a New Zealand context in the development of small, high quality urban apartments. 
First and foremost I would like to thank my family. To my parents, Chris and Helen in particular, for not only the financial support to get me through, but the encouragement they provided, allowing me to pursue my goals. I greatly appreciate everything you have done for me.

Secondly, thanks to my supervisor Chris McDonald for your guidance and reminders that I am going in the right direction when I may have doubted it.

And to my class mates, it's been an honour studying with you. The good times and laughs, while largely responsible for low work output, made it easy and enjoyable to come into studio (nearly) everyday. Thanks everybody. 


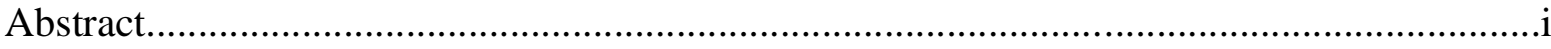

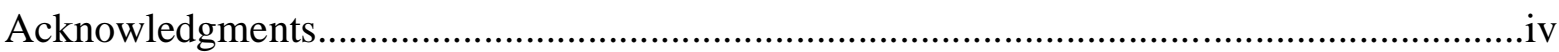

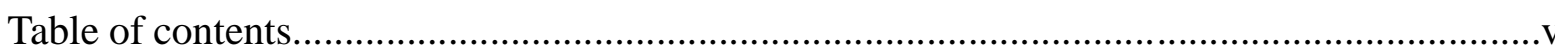

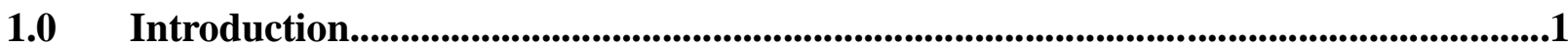

2.0 New Zealand Context...........................................................................................................

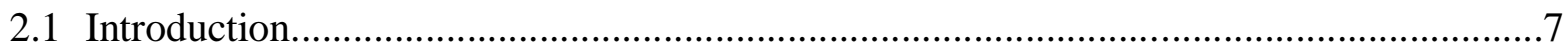

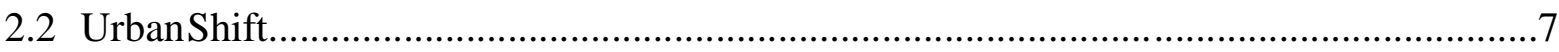

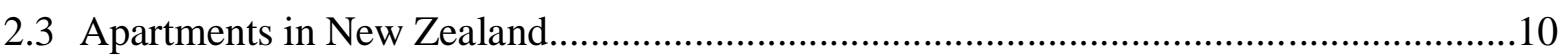

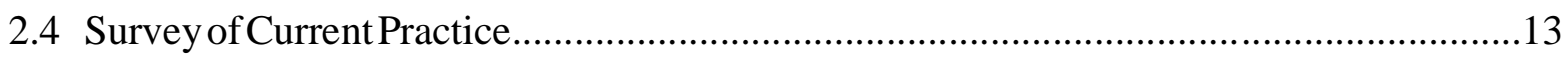

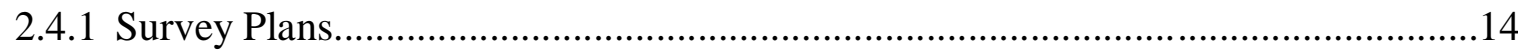

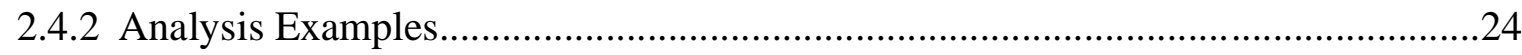

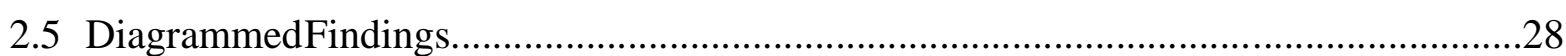

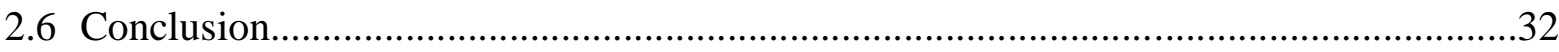

3.0 Japanese Context...........................................................................................................35

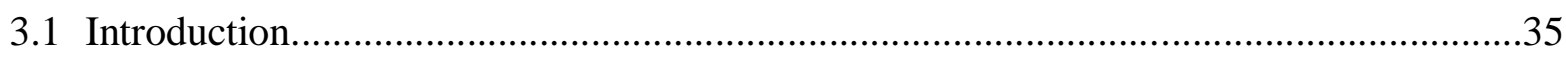

3.2 Japanese as Influential Precedent and Japonisme.............................................................36 
3.3.1 Post-war Period of Economic Growth and Urbanisation............... 39

3.3.2 Urban and Suburban Sprawl in Japan.....................................................................40

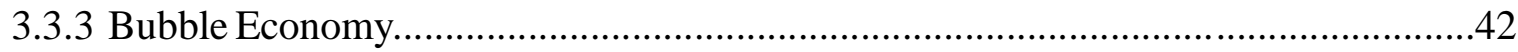

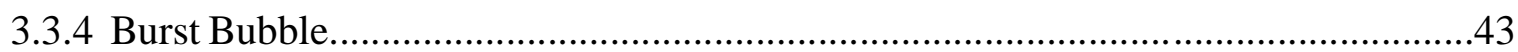

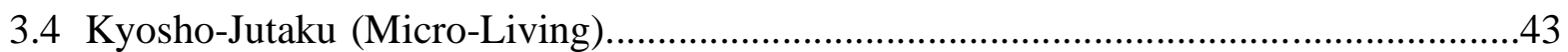

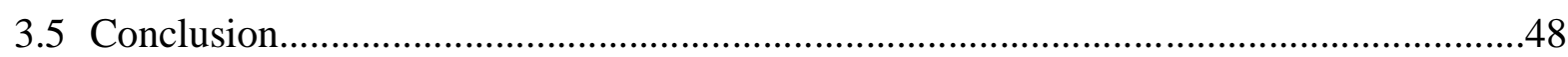

4.0 Analysis + abstraction $\ldots$

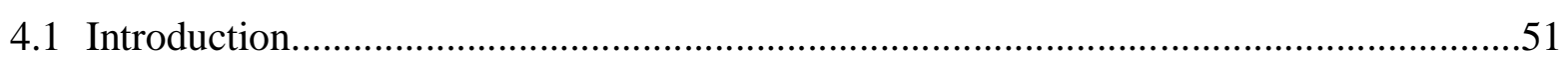

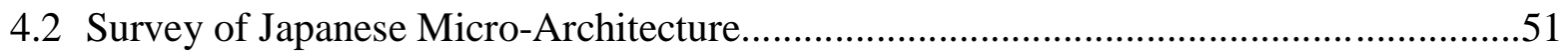

4.2.1 Analysis of Japanese Micro-Architecture...............................................................66

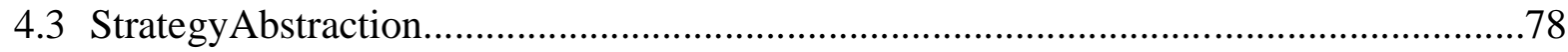

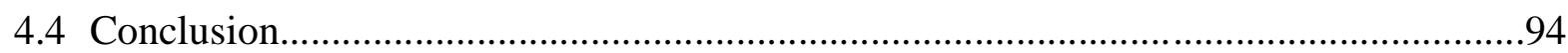

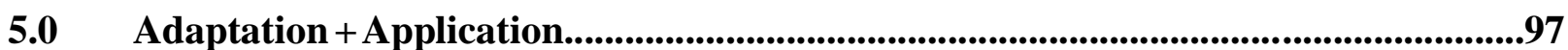

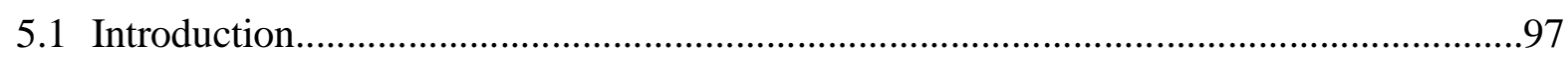

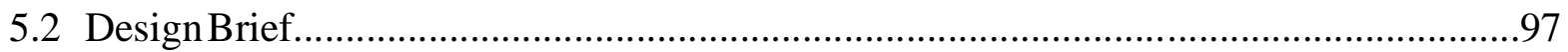

5.3 Site

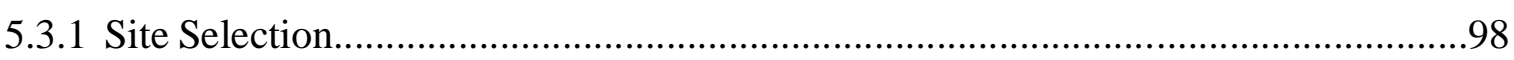

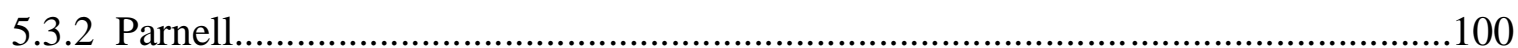


5.4 Building Design

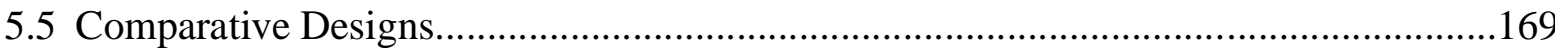

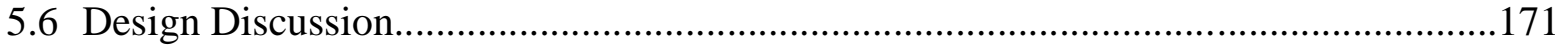

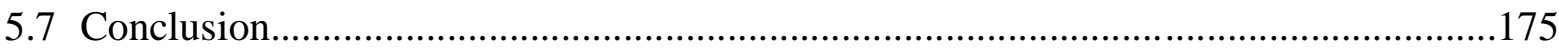

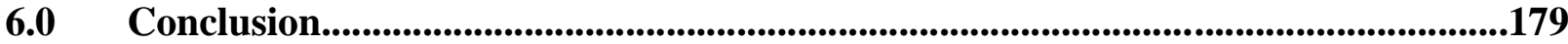

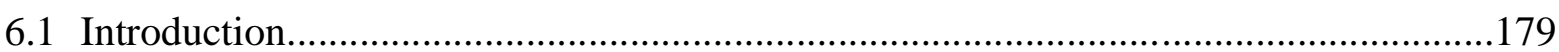

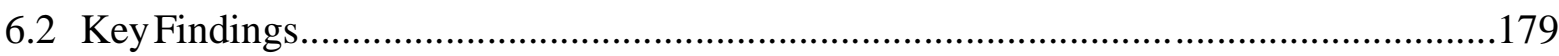

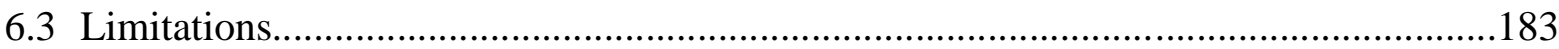

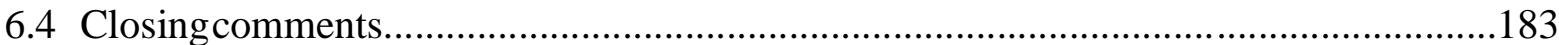

Bibliography...........................................................................................................................................185

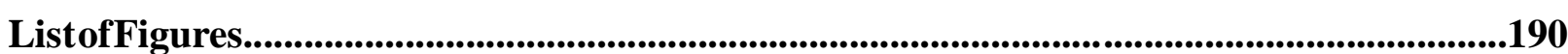



CHAPTER
ONE

INTRODUCTION

INTRODUCTION 更 
There is no reason why small apartments cannot be of a high quality and become a pleasant and appealing place to live. This research aims to improve the apartment stock of New Zealand by offering new design techniques to maximise the quality of compact living environments.

Throughout the late 20th and into the early 21st centuries, urban New Zealand has become an increasingly popular place to live with large migrations into the cities. At present $86 \%$ of New Zealand's total population live in urban areas, drawn by the convenience of proximity to amenities and commercial work opportunities. The urbanisation of the nation coincides with the continual growth of the overall population, estimated to have increased by $124 \%$ over a 60 year period. This continued growth and urbanisation is beginning to put pressure on cities as land becomes a scarce resource. In response, it is usual for the city to expand outward to the suburbs and beyond where land and rents are cheaper, but commuting distances are increased.

The introduction of higher density living solutions has attempted to combat the ever increasing 'suburban sprawl.' This thesis supports this response by looking to develop high quality urban apartments. Chapter Two will investigate New Zealand's changing urban environment and the evolution of economic, environmental and social climates that have instigated the growing demand for urban accommodation. There have been many apartment complexes that have risen in response to this demand, especially in the main centres of Auckland and Wellington. However, this is where the problem develops. A large proportion of smaller, more affordable apartments have been identified to be of a poor standard. Not just low quality of construction but also poor planning and design resulting in low quality spaces and negative experiences. Moreover, New Zealand's public perception of these 'shoebox' apartments is highly negative; it is unfair to expect inhabitants of small, affordable apartments to have to put up with such conditions. A survey of the current practice of these apartment complexes seeks to not only investigate the current perception, but also to identify further key issues and problems that occur in the planning and 
spatial design of these apartments. This research aims to upgrade the current method of design for these high-density apartments to produce an apartment that embodies the positive qualities missing from current apartment buildings and consequently create a apartment complex that offers a high quality experience for the occupants.

This research employs Japanese architecture as a precedent in the development of affordable urban dwellings in New Zealand's larger cities, continuing a long-standing relationship between Japanese and Western architecture. Chapter Three examines the rich history of Western culture looking to the East for inspiration across many aspects of society. Japan, particularly, has been of great influence to many architectural and artistic endeavours undertaken by Westerners. This chapter will touch on the economic, environmental and social climates in Japan that have spawned the urban conditions leading to the unregulated expansion of its cities. These expansions are seen as a cautionary tale for urban development in New Zealand, but more relevant to this research, we can understand how a particular architectural typology can become a means to remedy the problems we have to deal with on an increasing scale in New Zealand. This research closely examines the phenomenon of Kyosho-Jutaku (micro-living,) a movement that has explored the maximisation of space in very limited sites.

Chapter Four documents a large number of examples of Kyosho-Jutaku, examining their potential to serve as precedents for successful high density housing solutions in New Zealand. In-depth analyses of these precedents is undertaken with the intention of highlighting the recurring planning and spatial strategies that are employed in the designs. The focus is on techniques which contribute to high quality living environments in compact dwellings. From the data collected, a selection of models and strategies are chosen. Developed from these are design principles or criteria along with a 'menu' of architectural devices. Extracted from their contexts, these methods are expressed as diagrams which provide a design template for further examination in a New Zealand context.

The principles, criteria and devices, established through analysis in the previous chapters, will be tested in Chapter Five through the design of an apartment complex in Auckland. This design 
project is intended to be a precedent for future developments around New Zealand, enabling higher quality environments to be produced within the limitations and constraints typical of compact inner-city dwellings. An evaluation of the resulting design will be used to critique and refine these strategies, thereby testing the validity of more generic findings in the previous chapters. This chapter will also discuss the design outcome, evaluating both the successes and limitations of the chosen design solution.

This research process uses a combination of literature review and analytical drawing to identify positive design principles used in the phenomenon of Kyosho-Jutaku. Next, the design case study investigated how some of these principles can be used to combat the negative living environments prevalent in the current affordable apartment stock of New Zealand cities. The research shows that careful application of Kyosho-Jutaku principles can improve inner-city apartments and create high quality, affordable living environments. 

NEW ZEALAND CONTEXT 


\section{1 - Introduction:}

As populations grow urban areas must find an economical and environmental solution to accommodate the influx. In New Zealand, the intensification of cities is addressed in several ways: infill housing, outwardly expanding cities and apartment buildings (an increasingly common response). This chapter investigates the context of New Zealand's changing urban environment and how the economic, environmental and social climates have evolved in such a way to create a greater demand and necessity for urban accommodation. Furthermore, the current public opinion towards apartment living is examined in order to identify how New Zealanders perceive the lifestyle and quality of the dwellings. With an established understanding of the context in which they sit, a survey of the current practice of small, urban apartments in Auckland and Wellington is undertaken with the intention of bringing to light several of the key issues and problems that frequently occur in the designs. This analysis hopes to prove that there is a necessity for improvement in New Zealand apartment design.

\section{2 - Urban Shift:}

Beginning in the early 1990s, there has been a noticeable trend occurring in New Zealand urban areas. This mimics the international trend of urbanisation, where urban populations have rapidly increased and continue to swell. As of 2011, over 50 percent of the world's population live in urbanised areas with projected estimates suggesting that by 2050 the world's population will consist of 67 percent urban dwellers. ${ }^{1}$ More specific to New Zealand, at present, approximately $86 \%$ of the total population live in urban areas as defined by Statistics New Zealand. Simultaneously

\footnotetext{
1 United Nations, Department of Economic and Social Affairs, Population Division. (2012). World Urbanization Prospects: The 2011 Revision. New York: United Nations Department of Economic and Social Affairs. p. 3
} 
the decrease of the rural populations indicates a migratory shift of New Zealanders from rural to urban areas. ${ }^{2}$ The urbanisation of the nation coincides with the continual growth of the overall population, which was estimated in 2011 to be around 4.4 million as compared to the estimate in December of 1951, which saw the country's total population to be $1,970,500 .{ }^{3}$ That's an increase of around $124 \%$ over a 60 year period. Thus, the country's urban regions are expected to absorb all of the anticipated population growth over the ensuing years while at the same time drawing in some of the rural migrants.

One of the primary reasons for this shift is the change in lifestyle of New Zealanders over the past few decades. Most prolific in younger generations, there is change in the way in which people desire to live. Urban living provides the platform for people to balance their busy work lives with a more active and social way of life. The higher density urban dwellings offer the convenience of close proximity to amenities helping to promote economic and social interaction while reducing the movement of people and goods. Close proximity to workplaces and public transport not only minimises transit time, increasing time for leisure, but significantly reduces the reliance on private vehicles. It is also suggested that living in high-density communities offers occupants an increased sense of security, particularly for the elderly, single women and younger people. ${ }^{4}$ With the increased number of households either consisting of two working parents or a single parent, there is less opportunity for maintenance and caretaking of property. Therefore, the need for low maintenance dwellings increases. In the case of townhouses within a complex, an increasingly popular development strategy in today's urban areas, an overall body corporate often takes over the maintenance and upkeep of the properties, taking this responsibility away from the individual owners. In apartment buildings, while a similar system can be installed there is generally less maintenance in terms of gardens and exterior work of the shared spaces and building envelope than would be found in individual stand-alone dwellings.

2 The World Bank. World Development Report 2011: Conflict, Security, and Development. Washington: The International Bank for Reconstruction and Development / The World Bank. p. 345-353.

3 Statistics New Zealand. (2011). Long-term Data Series - Population Estimates in NZ. Retrieved February 20, 2012, from Infoshare - Statistics New Zealand: http://www.stats.govt.nz/infoshare/

4 Jacobs, J. (1993). The Death and Life of Great American Cities. New York: Modern Library.

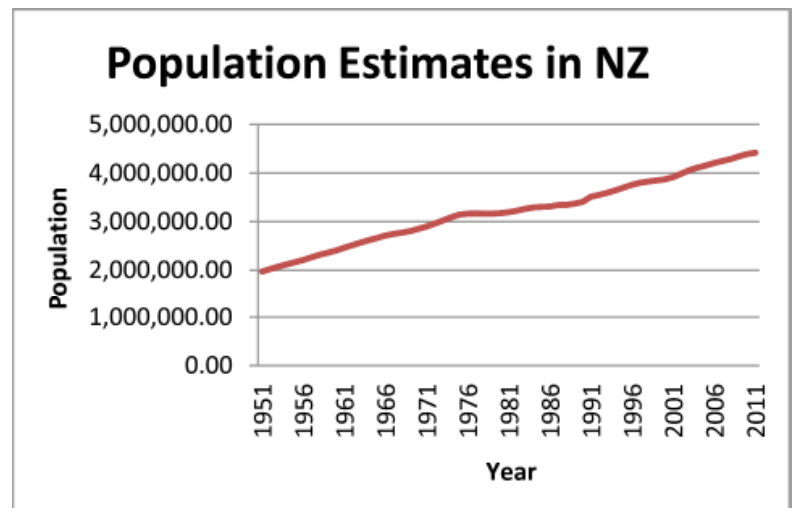

Fig. 2.0 New Zealand's increasing population over a 60 year period.

Data sourced from Statistics New Zealand. Longterm Data Series - Population Estimates in NZ. 2011. 20 February 2012. <http://www.stats.govt.nz/ infoshare/SelectVariables.aspx?pxID=85d52c37 a2cd-49e4-9fa9-bd42c39c1123>. 
Why do you Live in an Inner City Apartment?

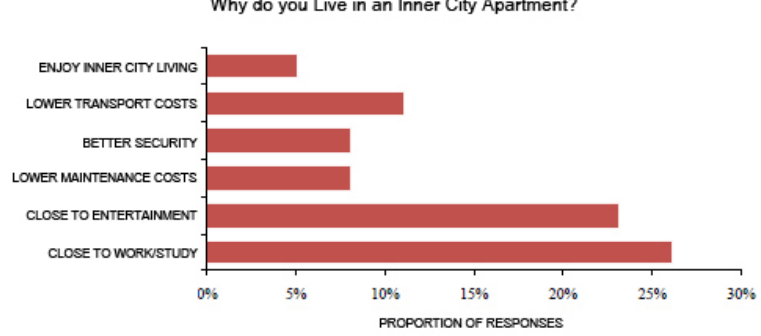

Fig. 2.1 Graph showing popular reasons for living in apartments.

Adapted from DTZ Research. "Executive Summary of the Auckland Inner City Living Survey." 20

November 2003. Auckland City Council. 3 June 2011. <http://www.aucklandcity.govt.nz/council/ projects/cbdproject/docs/executivesummary.pdf>.
It is also recognised that the property market has some influence on the increasing trend. The last two decades have shown the cost of inner-city apartments maintained at a reasonably consistent state, while suburban housing has fluctuated more significantly. ${ }^{5}$ Moreover, the small size typical of apartments lends itself to being a more affordable option. It is noteworthy however, that as inner-city land becomes more scarce, the high commodity of land may drive up prices. This builds on the argument for the need to develop more affordable alternatives of urban accommodation and make efficient use of available land in the future.

Along with increasing urbanisation, there are a number of other factors which are changing the urban environment and the way people live in New Zealand. Societal changes, such as the aging population and the increasing occurrence of families breaking up, alter the composition of households and indicate fewer people in each household. ${ }^{6}$ Parallel to this, is the shifting demand on land use. As more people seek to live in urban areas, scarcity of available land becomes an issue. Whether restricted by the geography, as in Wellington City, or the desire of Territorial Authorities to restrict urban sprawl, land is becoming a progressively more precious resource. ${ }^{7}$ What was formerly the North Shore City Council, for example, recognised the necessity to contain urban and suburban sprawl and grow in a sustainable way. ${ }^{8}$ Thus, intensification of the existing urban fabric through higher-density housing solutions is necessary to fulfil some of the demand as a result of the population influx and increased demand for more housing stock.

5 Crockers Property Group. (2006-2012). Crockers Market Research Archives. Retrieved March 2, 2012, from Crockers Property Group: http://www.crockers.co.nz/market-research/market-research-archive.aspx?c=1290.

6 Statistics New Zealand. (2011, June 05). Population: Demography Dwelling and Household Estimates. Wellington, New Zealand. (Accessed from Infoshare).

7 Wellington, has seen the city's population grow by nearly 16,000 and is expected to rapidly increase with demographic projections showing that Wellington will require over 20,000 new homes to house 37,000 more residents in the next 30 to 40 years. Wellington City Council. (2006). Urban Development Strategy: Directing Growth and Delivering Quality. Wellington: Wellington City Council.

$8 \quad$ North Shore City Council. (2007, March 20). Urban Design: Apartment Developments (Good Solutions Guide for Apartments). Retrieved August 1, 2011, from Auckland City Council: http://www.northshorecity.govt.nz/ YourCouncil/Planning/UrbanDesign/Pages/UrbanDesignApartmentDevelopments.aspx. 


\section{3-Apartment Building in NZ:}

As a response to the above demands, New Zealand cities saw a significant rise in construction of apartment buildings over the last two decades (although this trend has slowed in recent years). This is represented in the upward trend of building consents issued for apartment buildings throughout the 1990s and majority of the 2000s. ${ }^{9}$

Auckland, Wellington and Christchurch saw the largest growth as highlighted by the 2006 Census which revealed that, during the previous decade, "the number of people living in inner-city apartments almost quadrupled, from 4,974 to 19,020 ". ${ }^{10}$ Auckland had a 375 percent increase in inner-city apartment dwellers, while Wellington increased from 1,410 to 4,743 (236 percent). Both increases were greater than the growth rates of these cities - Auckland and Wellington's city populations growing by 17 and 14 percent respectively over the same time period..$^{11,12}$

A large proportion of the constructed apartment buildings containing small apartments raise several issues, particularly the perceptions of livability and quality. It can be argued that due to apartment living being a relatively recent phenomenon in New Zealand (compared to Asia and Europe), the New Zealand Building Code (NZBC) is incapable of providing the proper controls for this new building type. The current state of the NZBC does not sufficiently recognise the significant differences between apartment buildings and New Zealand's traditional detached dwellings, due to characteristics such as their unique spatial issues, location, increased density and reduced privacy. It is primarily aimed at the construction of detached dwellings, with few specific clauses dedicated to apartment buildings. As a result, the two different building types

\footnotetext{
$9 \quad$ Statistics New Zealand. (2012, April 05). Building Consents Statistics for New Apartment Buildings 1992 - 2012. Wellington, New Zealand. (Accessed from Infoshare).

10 Statistics New Zealand. (2010). Apartment Dwellers: 2006 Census. Wellington: Statistics New Zealand. p.

$11 \quad$ Ibid., p. 2

12 From information gained through the 2006 Census, it has been summarised that the largest proportion of apartment dwellers are between the ages of 20 and 29. However, in Christchurch this trend is refuted with older age groups primarily inhabiting apartments. Auckland, with the largest number of apartments, showed an emphasis on studying and tertiary educated occupants (only 5 percent of apartment occupants had no qualification, compared to 25 percent in New Zealand.) Additionally, the majority of occupants were of Asian ethnicity.
}

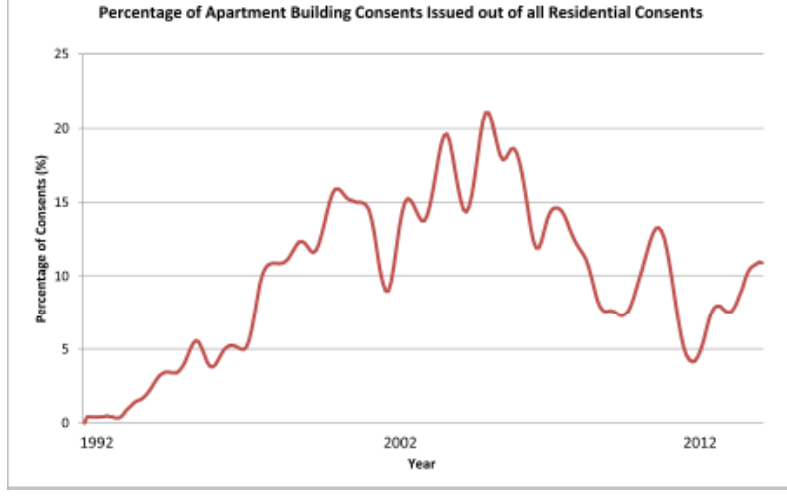

Fig. 2.2 Graph illustrating the percentage of apartment building consents issued out of all residential consents over the last two decades.

Data sourced from Statistics New Zealand. Building Consents Statistics for New Apartment Buildings 1992 - 2012. Wellington, 05 April 2012. 
share regulations, which when followed, may be considered suitable for stand-alone homes, yet may in some cases not be seen as appropriate for apartments. ${ }^{13}$ Although worth mentioning, this research will not focus on the regulatory side of the argument. Instead, this study aims to determine whether the widely held perception that small apartments are poor environments is accurate.

New Zealand is effectively in its first generation of apartment dwellers, so even while it is recognized there is a need to adopt the new form of high-density housing, for many, there is still an inherent reluctance and hesitation to do so. The "quarter-acre pavlova paradise," 14 which previous generations have grown up with and many New Zealanders aspire to, is becoming more unobtainable as the country would struggle "to support the transport and land conversion implications" 15 if this suburban lifestyle continued. Yet many people still desire this lifestyle. A recent study conducted by the United Nations, the Global Survey on Sustainable Lifestyles (GSSL), questioned eight thousand people aged 18 to 35 in 20 countries (132 New Zealand participants) about their hopes and fears. Interestingly, 34 percent of respondents said that they fear the concept of living in inner-city apartments, due to feelings that they are less connected with the outdoors. ${ }^{16}$

I would hate to live in a big city in an apartment, totally reliant on modern technologies with limited access to outdoor pursuits. - Female, 30-35 age bracket (United Nations Environment Programme, Task Force on Sustainable Lifestyles, 2011, p. 60)

13 An example of this is the NZBC Compliance Code (NZBC G7 - Natural Light requirement) for daylight in housing as highlighted in: Stewart, K. \&. (2008). New Zealand Daylight Code Compliance Tool: Development and Implementation. PLEA 2008 - 25th Conference on Passive and Low Energy Architecture (pp. 1-6). Dublin: Passive and Low Energy Architecture.

14 Mitchell, A. (1972). Quarter-acre Pavlova Paradise. Christchurch: Whitcombe and Tombs.

15 United Nations Environment Programme, Task Force on Sustainable Lifestyles. (2011). Visions For Change: Country Papers. Paris: UNEP Division of Technology, Industry \& Economics. p. 56.

16 Ibid., p. 60 
It is clear that some consider the traditional 'quarter acre' ${ }^{17}$ model more desirable than apartment living, however responses to the surveys suggest two main alternative conclusions:

1) It is suggested that the fear is not necessarily of living in an apartment but rather the fear of not having an alternative option or a choice of living preference.

2) Reactions propose that although certain fears pertaining to apartment living do exist, many people in this age bracket actually desire apartment living but it is the cost and quality of the available apartment stock that is of major concern.

Plenty of young people (18-30 something), would love to live in a nice city apartment. I guess the problem is that so many city apartments are either really expensive or really [bad], [young people]can't afford the expensive ones and don't want to live in a south-facing cupboard. - Kelly (Gates, 2011)

Despite the popularity of the life-style of apartment living the perception of the apartments themselves is largely negative. The small size of apartments, while providing higher-density, are perceived, at least by some, to be unpleasant living environments. Additional apartment living surveys (Wellington City Council, 2009) (DTZ Research, 2003) (Auckland UniServices Ltd,

\footnotetext{
17 With European colonisation came the surveying of new lots for residential use and the quarter-acre section was established early on by European settlers as a suitable size for a New Zealand home. The allocation of land use in this way was partly conceived due to conveniences in the process of surveying (as a typical quarter-acre section had a street frontage corresponding to the standard surveyor's measuring chain at a width of $20.1 \mathrm{~m}$ or (66 feet at the time), and a length of $50.3 \mathrm{~m}(165 \mathrm{ft})$ ), and partly attributed to the intentional design by the urban planners of the day to "help the new colony avoid the social ills of urban industrial England, such as over-crowding, prostitution, gambling, and other criminal or immoral behaviour, not to mention illness and disease". - Moore, K. P. (2005). The results of making a city more compact: neighbours' interpretation of urban infill. Environment and Planning B: Planning and Design, volume 32 , p. 718 .
} 
2004), books (Criscillo \& Tong, 1999) and articles (Bennett, 2010) reinforced these points and also helped identified the following recurring issues associated with apartment liveability and perception:

1) Inadequate natural light;

2) Inadequate ventilation;

3) Limited outdoor space;

4) Noise

The subsequent sections intend to highlight various design and planning issues in the current building stock which contribute to this public opinion.

\section{4-Survey of Current Practice:}

With a hypothesis suggesting that there are many deficiencies in the design of New Zealand's current stock of apartment buildings, this section of the study seeks to examine the current practice in order to both investigate recurring issues and identify possible reasons for negative perceptions. A selection of small apartments in Auckland and Wellington have been chosen to serve as a representation of the existing building stock. The plans and sections of these buildings are analysed to identify the problematic planning and spatial qualities. Apartments from Wellington and Auckland were chosen due to the large number of available examples and their housing the largest proportions of apartments in New Zealand. The process of analysis began with the re-drawing of each apartment's floor plans and sections (where necessary and available) into a consistent format and scale. The act of drawing offered a great insight into the common design decisions of the apartments, the functionality and the scale of spaces. The resulting set of drawings forms the foundational material for primarily observational analysis. 
The selection of the apartments to be analysed to is limited by the following criteria:

1) Located within the inner city areas of Auckland or Wellington City;

2) The construction of the apartment completed no earlier than the year 2000;

3) Apartments of three or more bedrooms with a floor area less than 110 square meters;

4) Apartments of two bedrooms with a floor area less than 90 square meters;

5) Studio apartments (shared living and sleeping space) and apartments with only one bedroom with a floor area less than 70 square meters.

\subsection{1 - Survey Plans:}

The following are the chosen examples which consist of 67 floor plans from 25 different apartment buildings. 
Micro-Living: learning to live large in small spaces

FORTE APARTMENTS

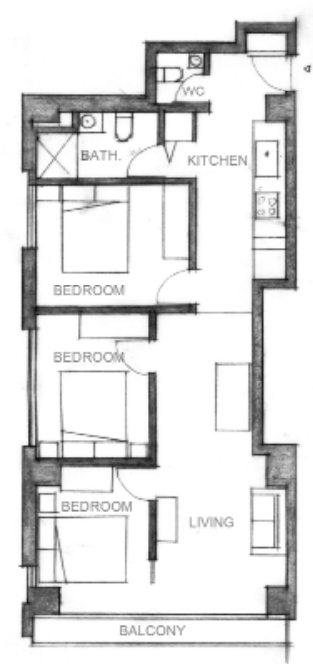

15

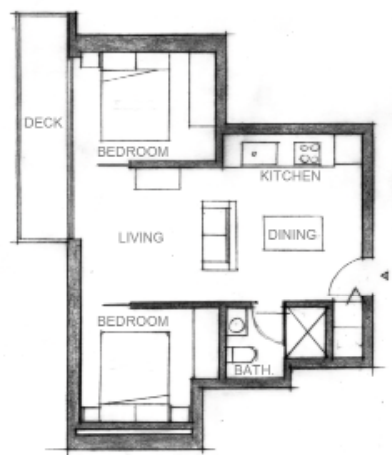

2 BEDROOM - 46 SQM

3 BEDROOM - 71 SQM

FORTE APARTMENTS
FORTE APARTMENTS

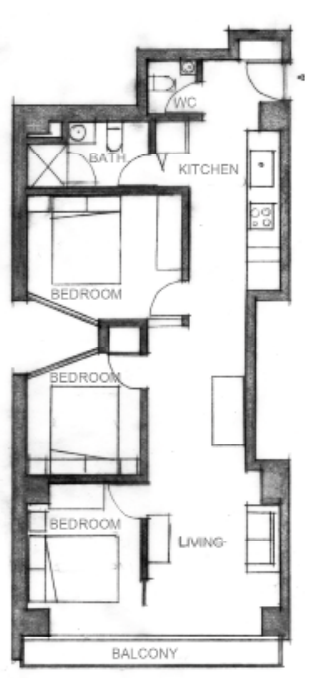

3 BEDROOM - 69 SQM

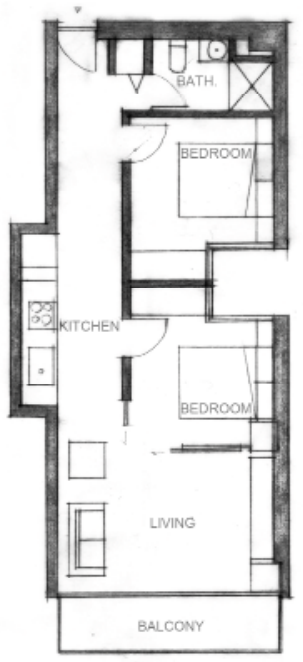

2 BEDROOM - 56 SQM FORTE APARTMENTS
TE ARO TOWERS

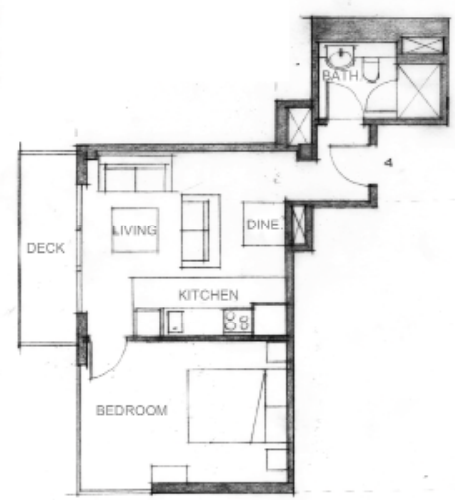

1 BEDROOM - 40 SQM
TE ARO TOWERS

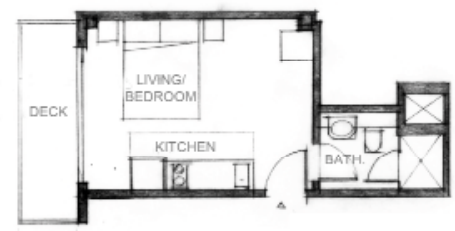

STUDIO - 23 SQM

TE ARO TOWERS

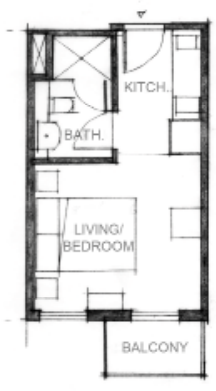

STUDIO - 21 SQM 


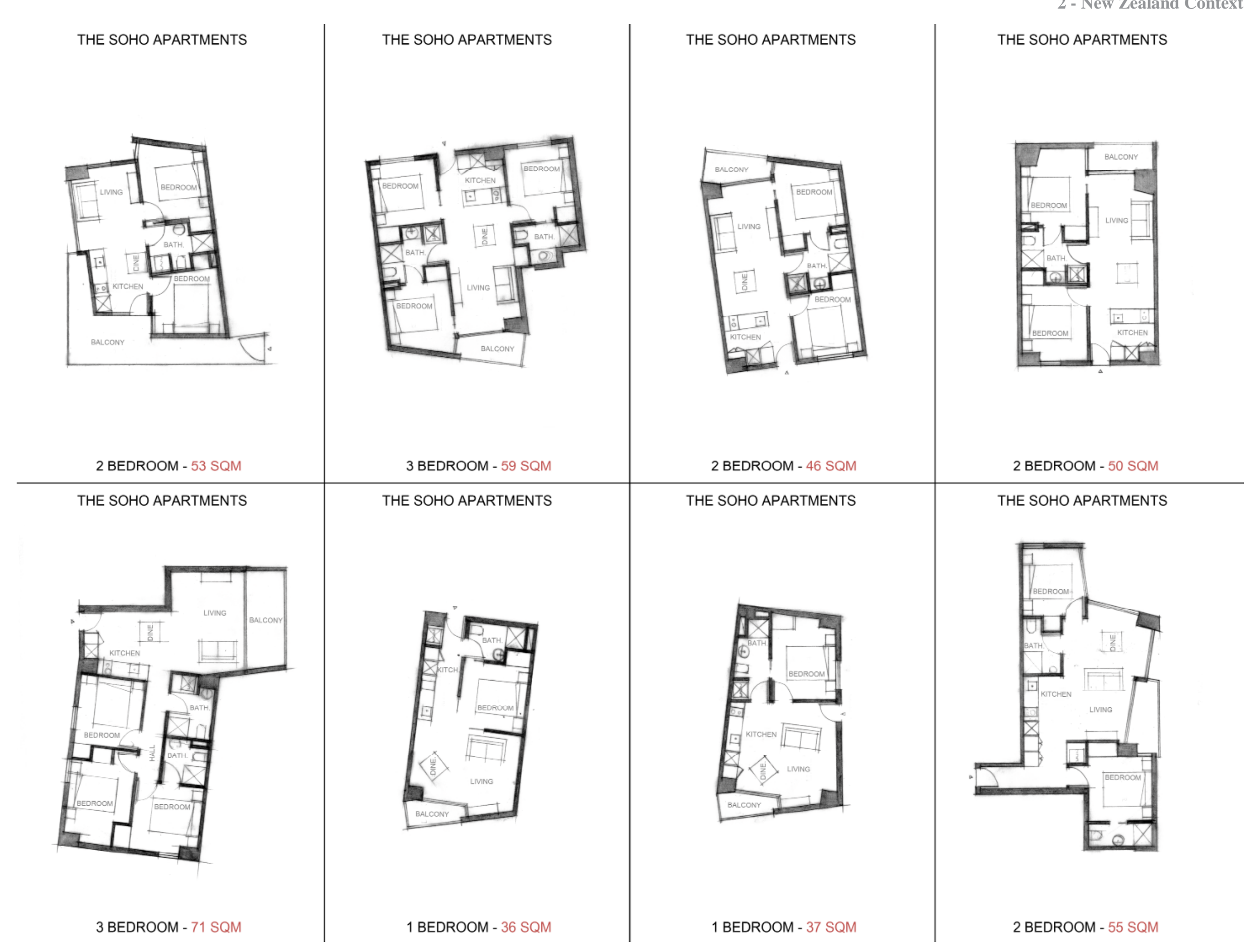




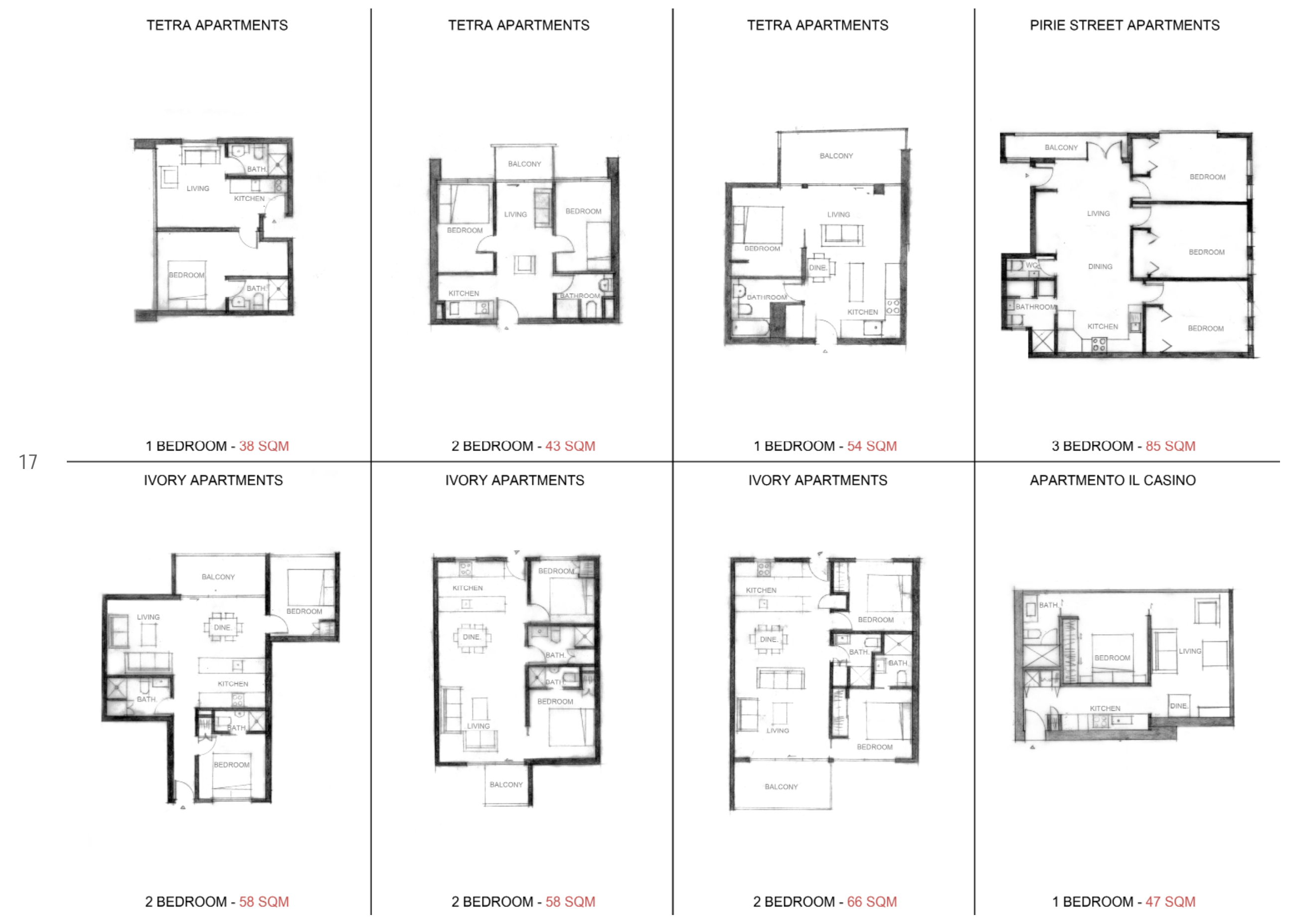




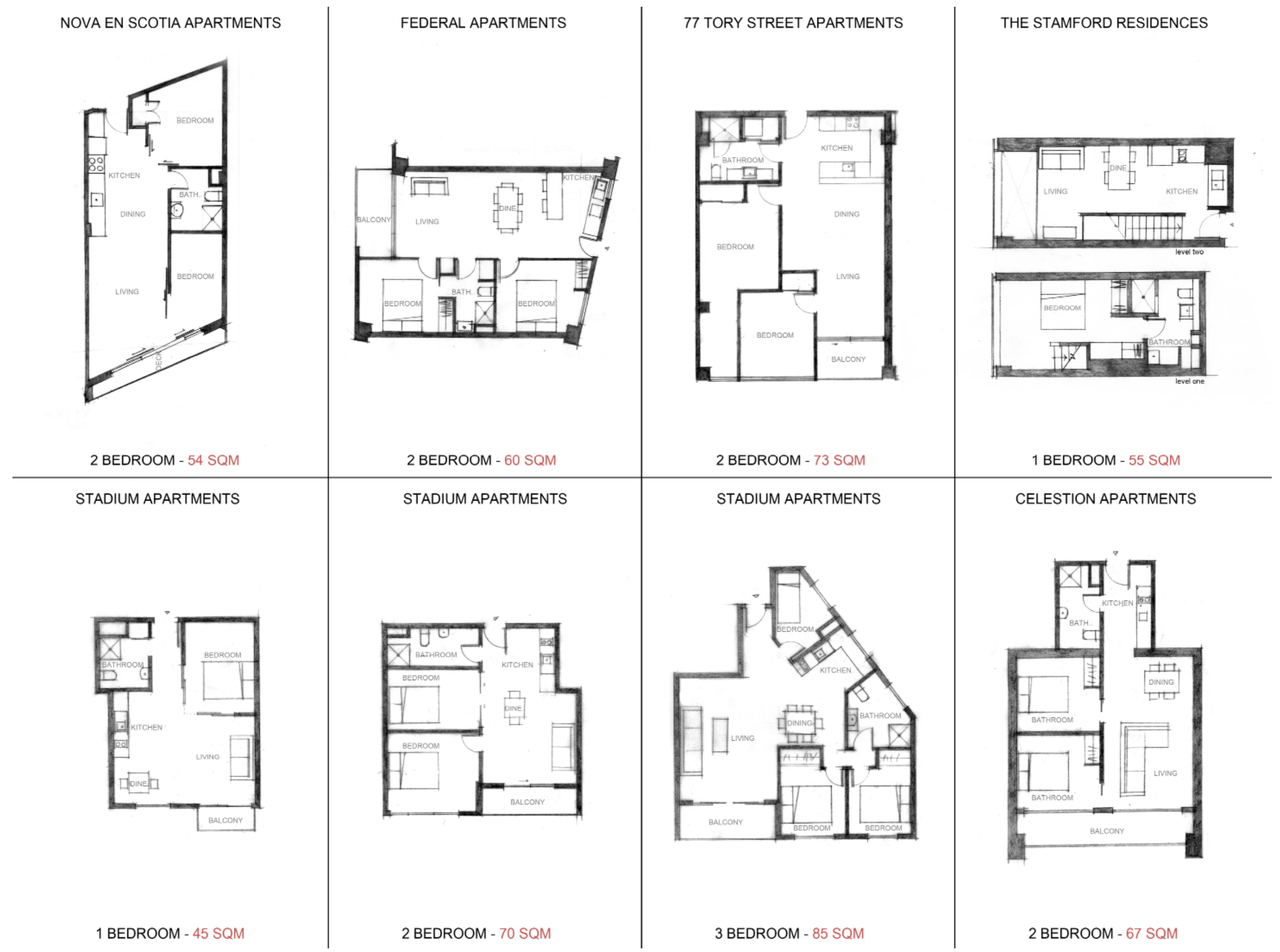


Micro-Living: learning to live large in small spaces

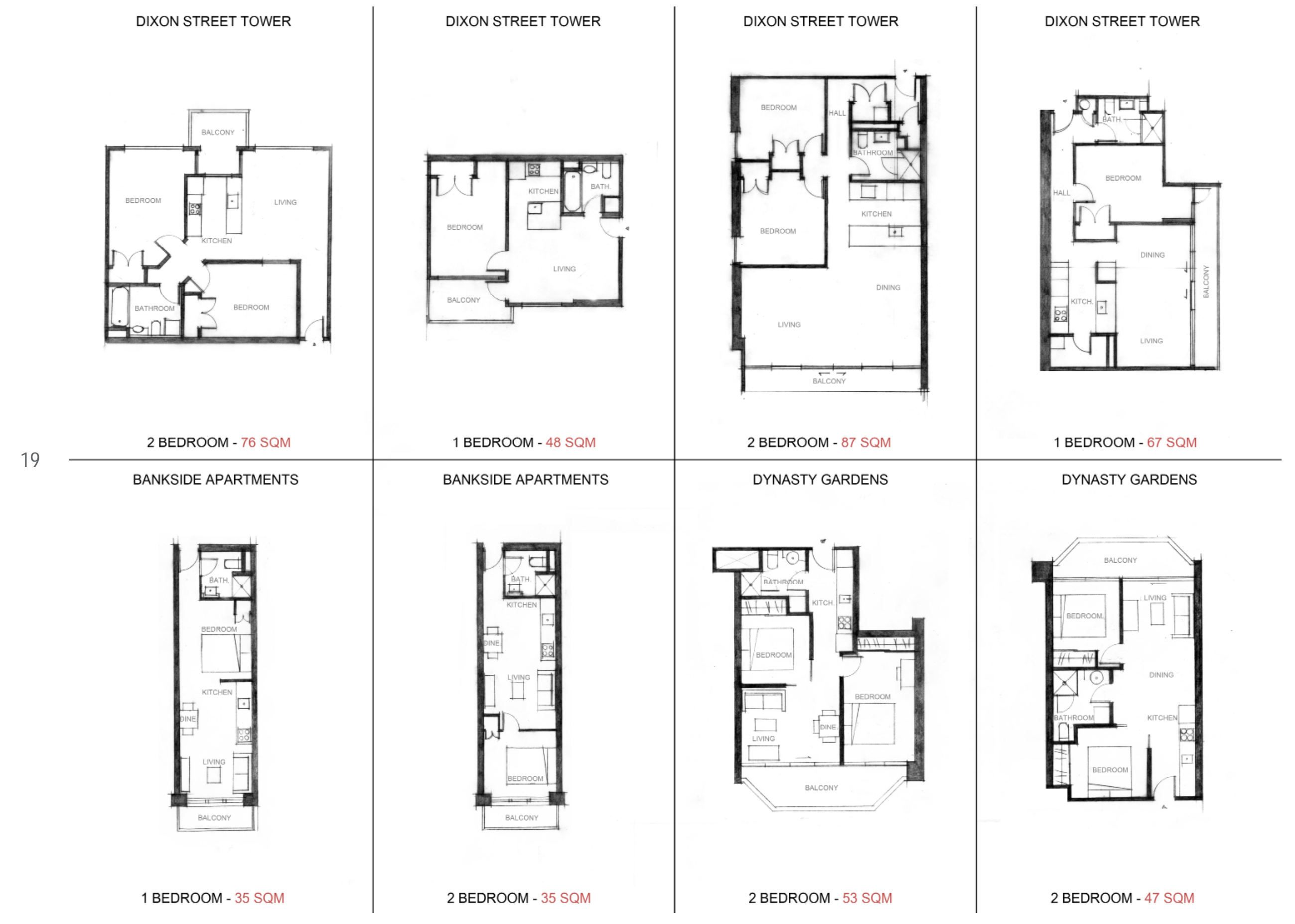




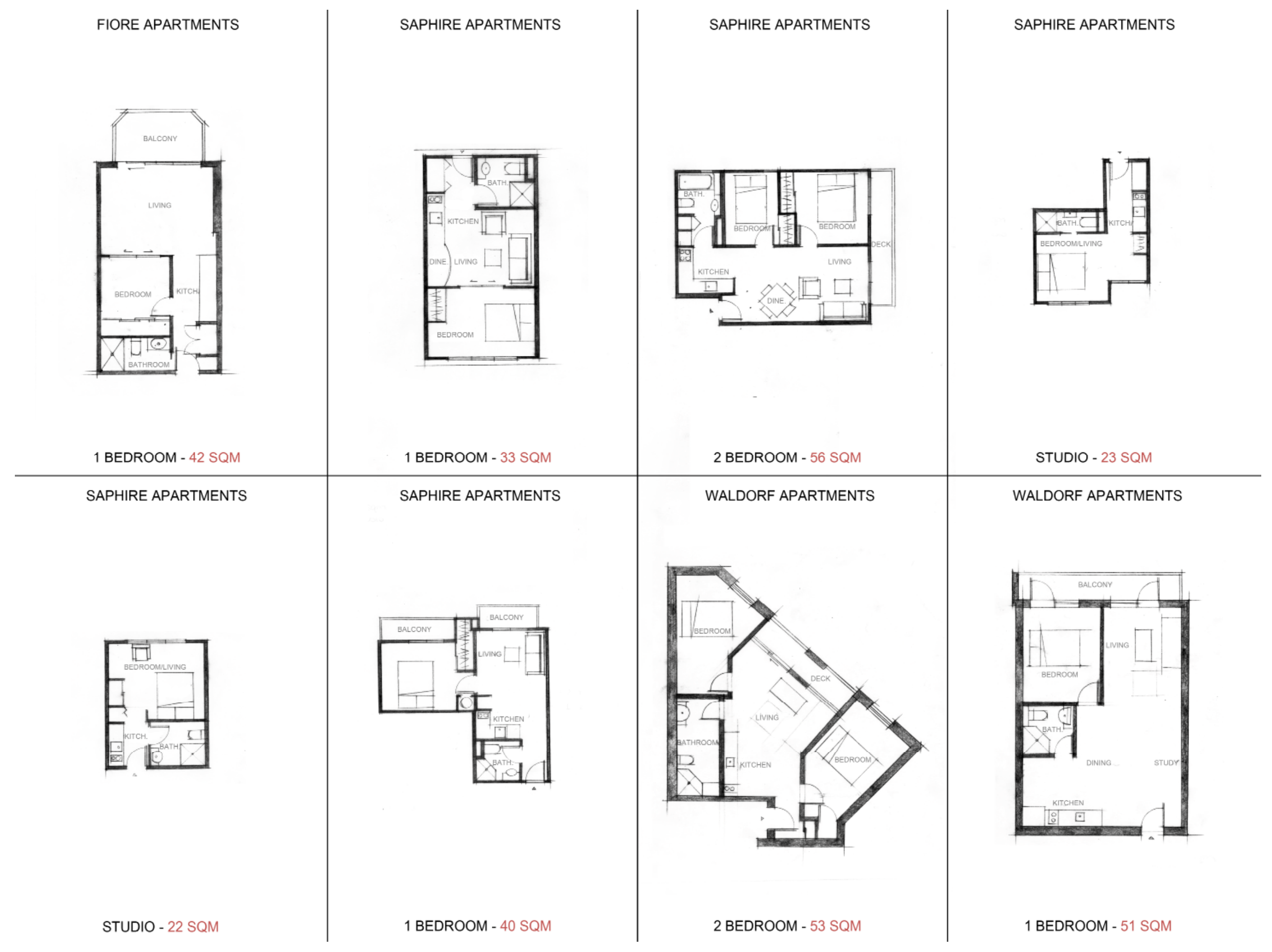


Micro-Living: learning to live large in small spaces

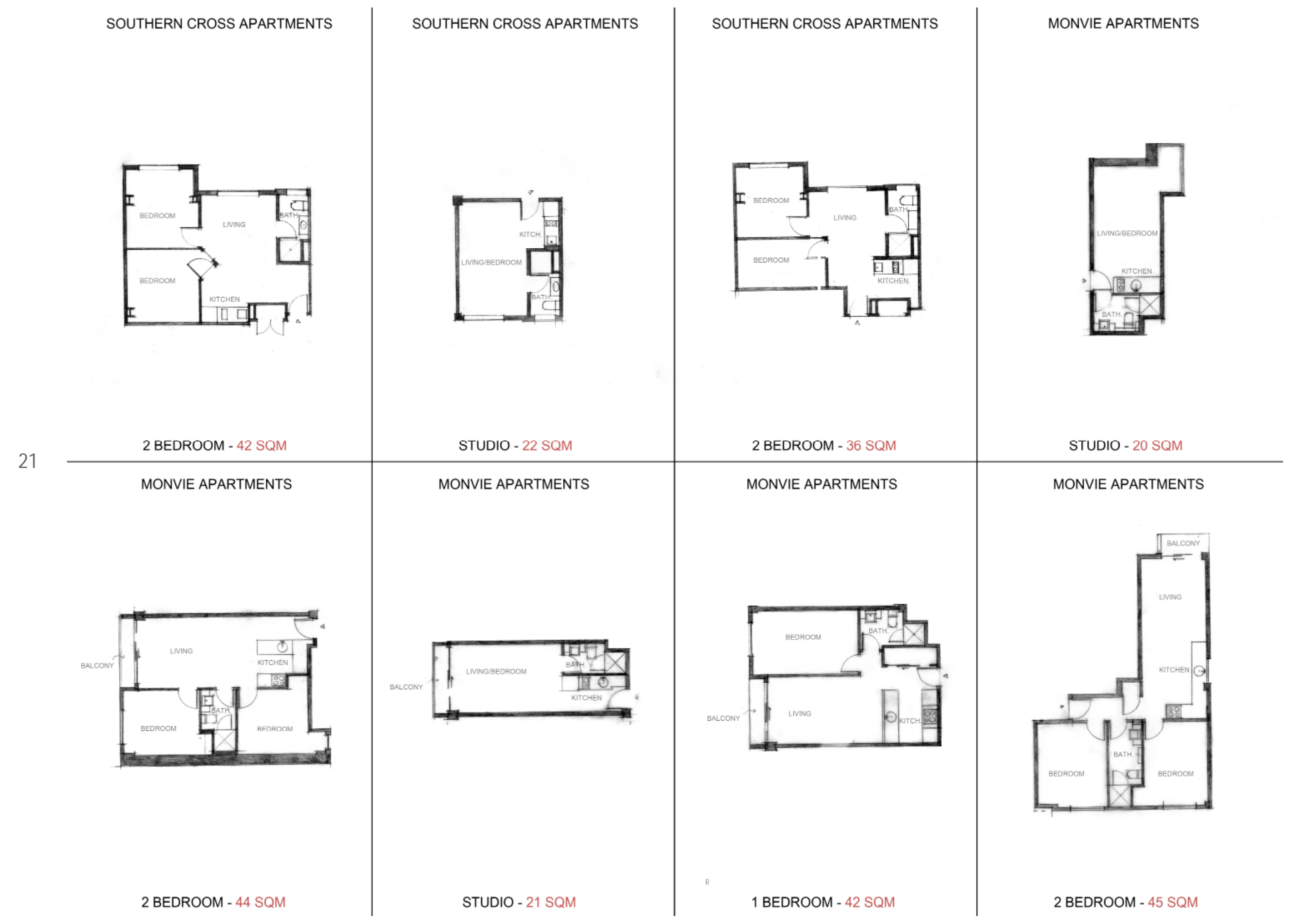




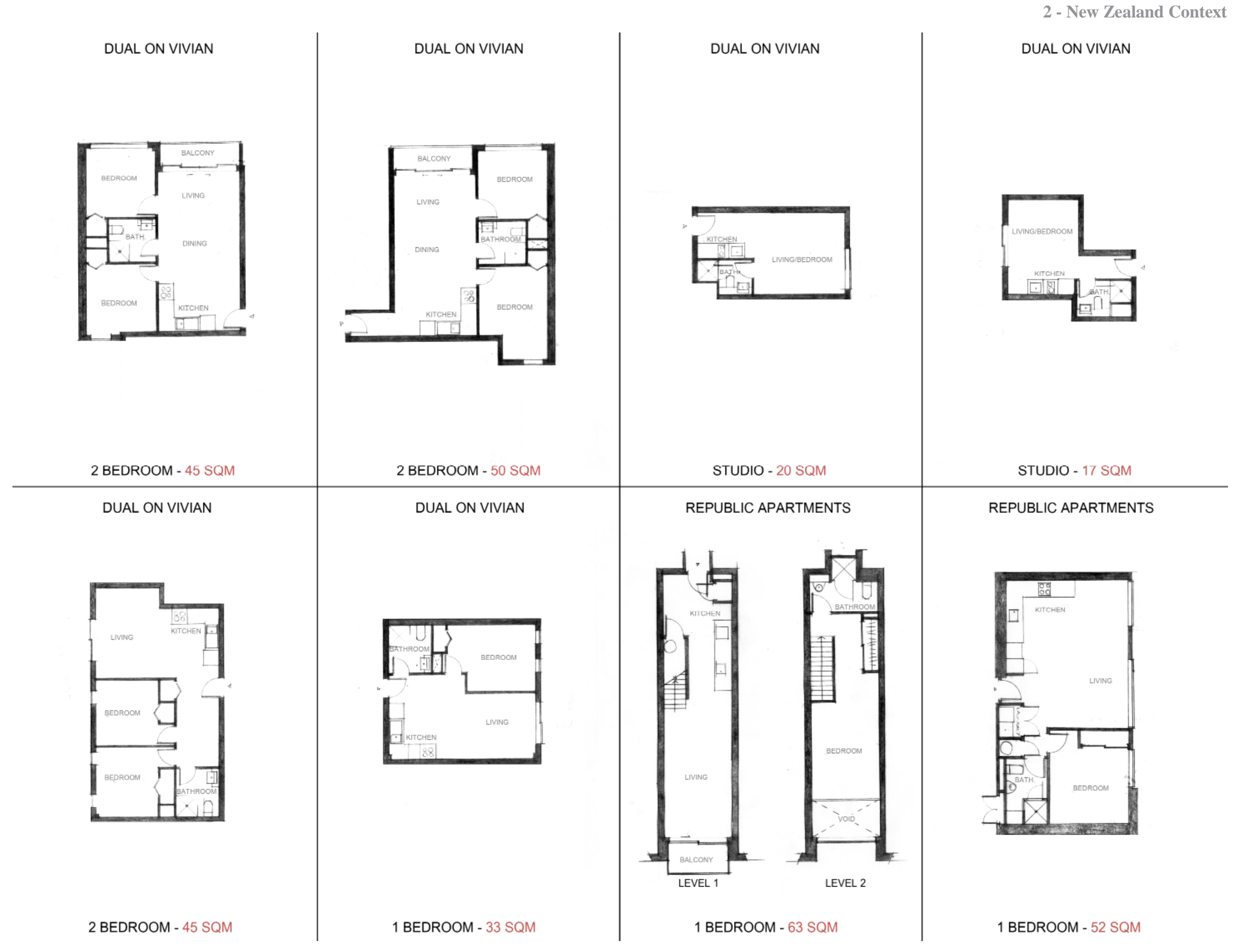


HALL APARTMENTS
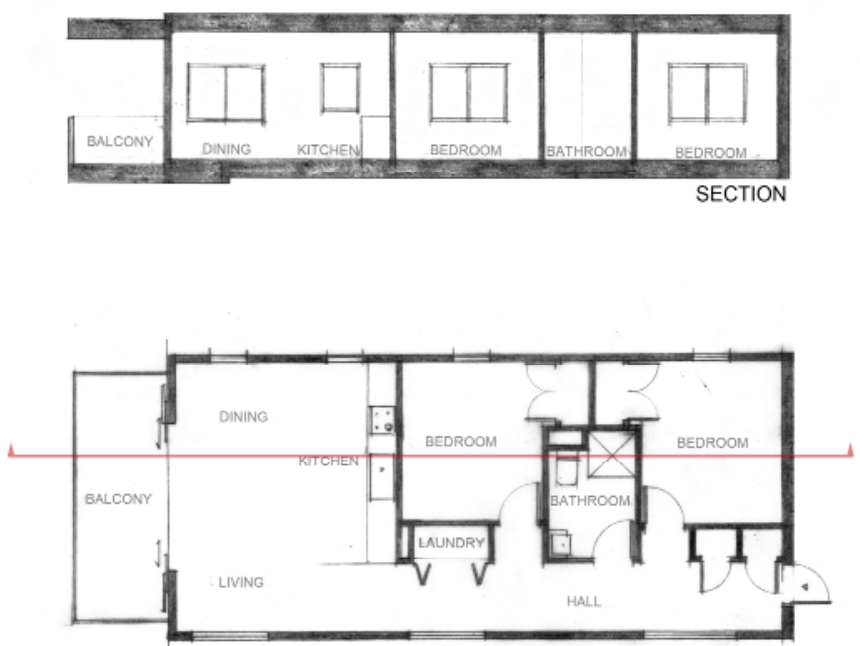

23

2 BEDROOM - 81 SQM

HALL APARTMENTS

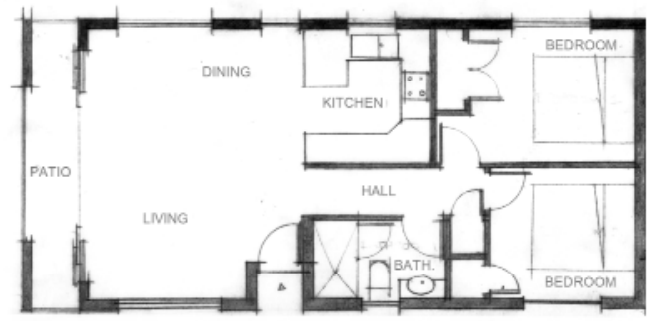

2 BEDROOM - 73 SQM
TATOO APARTMENTS
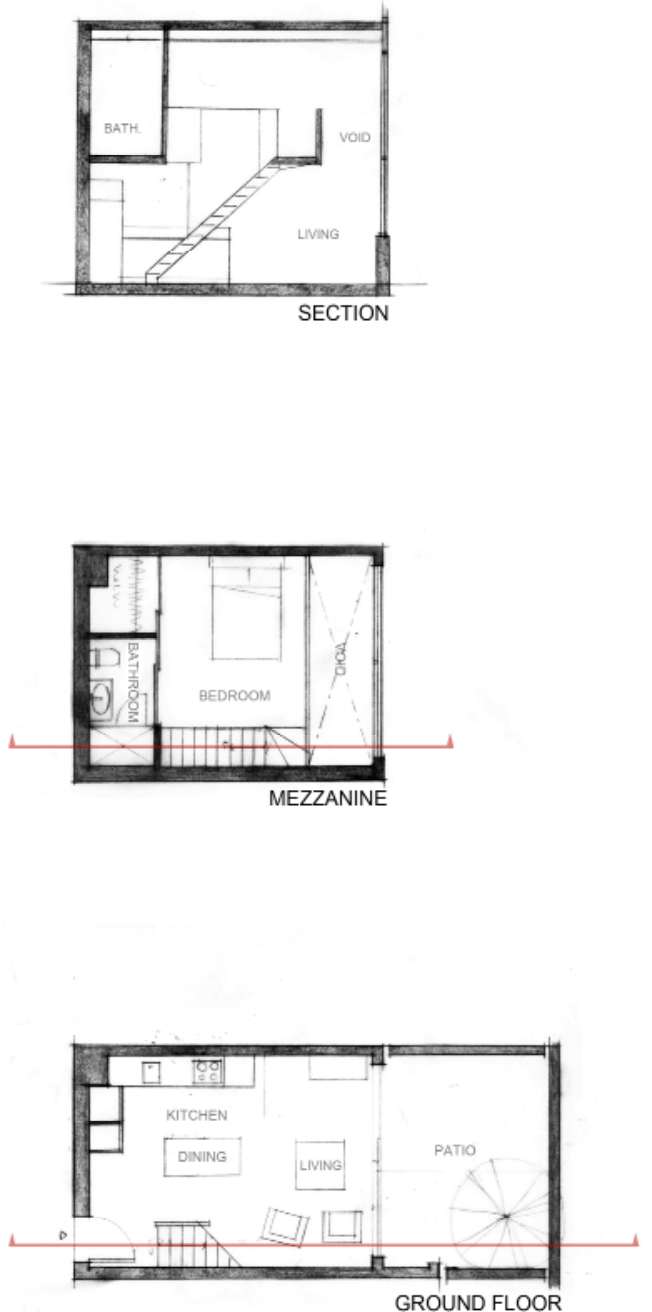

1 BEDROOM - 63 SQM 
Apartments with one bedroom only, including studio apartments had an average floor area of 38 square meters, ranging from 17 to $67 \mathrm{sqm}$. Two bedroom apartments had an average of 57 square meters $(36-87 \mathrm{sqm})$. and three bedroom apartments, 73 square meters (59 - 85sqm).

The method of analysis uses observation of the plans and sections to produce both quantitative and qualitative data. The intention is to find a series of trends occurring in the planning and design of the apartments which lead to poor environments. The qualitative nature of the analysis comes in the form of interpretation of observational data, for example, how the increased number of partitions or poorly lit spaces may contribute to an apartments' sense of quality or spaciousness.

\subsection{2 - Analysis Examples:}

The following are examples of observational analysis followed by key points of data: 


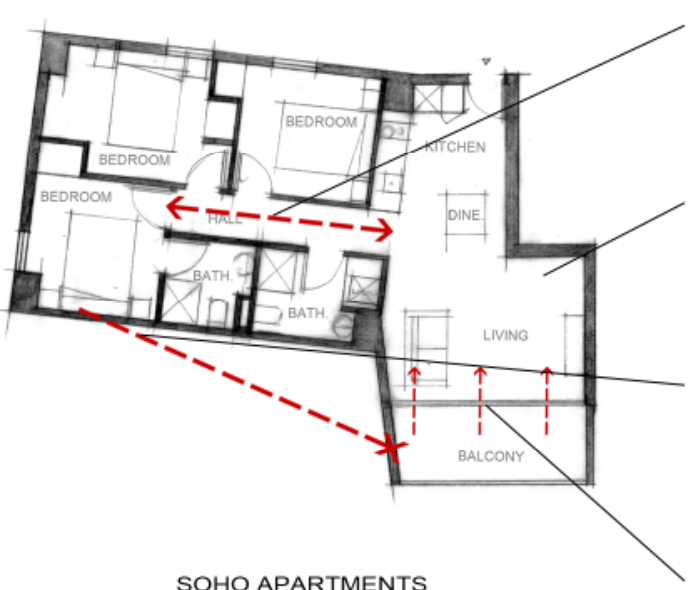

SOHO APARTMENTS
LONG CORRIDOR SERVING ONLY AS CIRCULATION SPACE

WITH ROOMS HAVING ONLY ONE WINDOW THERE IS NO OPPORTUNITY FOR CROSS VENTILATION

BEDROOMS HAVE NO VISUAL OR PHYSICAL ACCESS TO THE APARTMETN'S OUTDOOR SPACE

SINGULAR DAYLIGHT SOURCE FOR LIVING SPACE

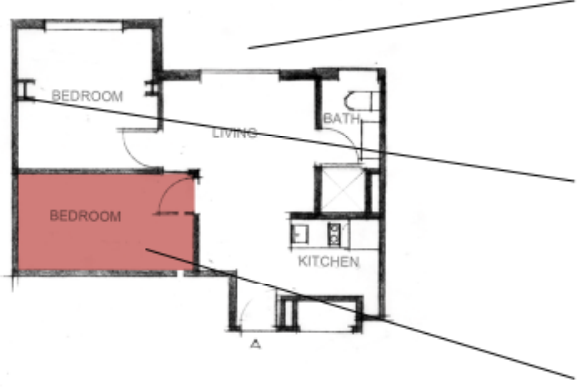

NO OUTDOOR AREA

STRUCTURE IMPOSES ON USEABLE SPACE

INTERNAL BEDROOM: NO WINDOWS FOR NATURAL LIGHT OR VENTILATION

A NARROW, ALMOST UNSUABLE CORRIDOR LEADS TO THE WINDOW FOR THIS BEDROOM, SUPPLYING LITTLE LIGHT TO THE MAIN SPACE OF THE ROOM. THIS IS A POOR USE OF SPACE AND AN AWKAWARD LAYOUT.

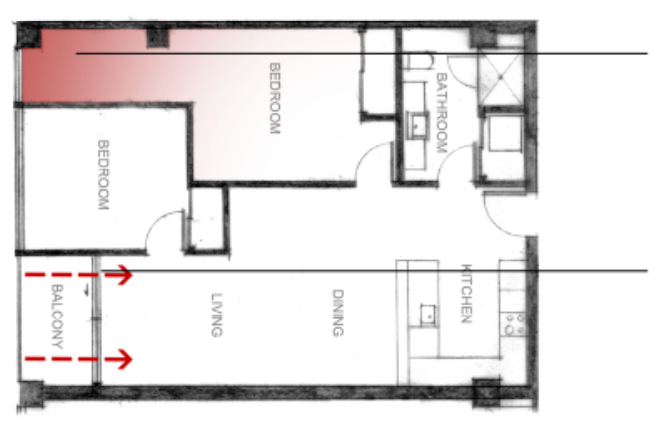

ONLY ONE SOURCE OF DAYLIGHT FOR THIS LONG LIVING SPACE

VISUAL AND PHYSICAL ACCESS TO AN OUTDOOR AREA IS LIMITED TO ONLY ONE SPACE. 
Fig. 2.13 Analysis examples.

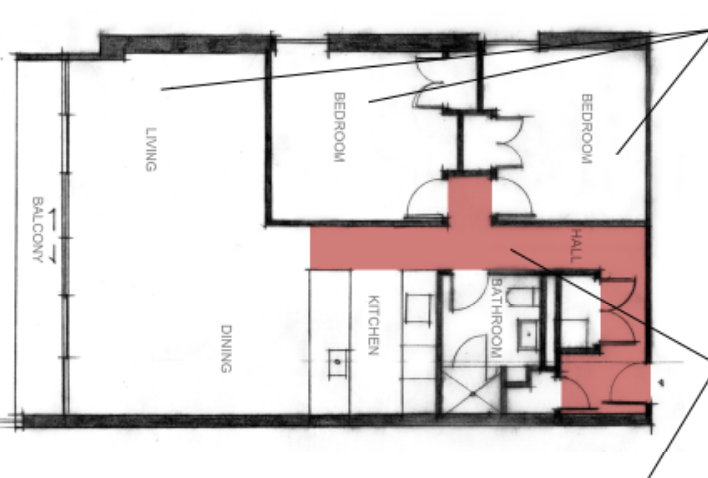

DIXON STREET TOWER

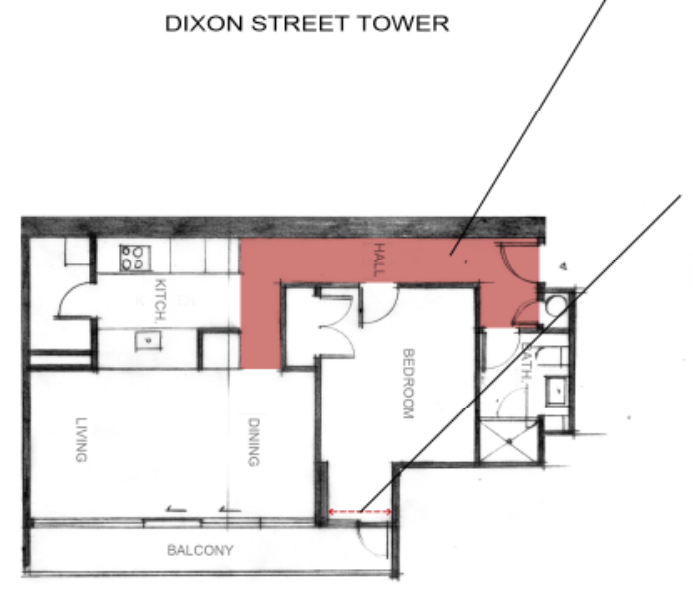

DIXON STREET TOWER

DAYLIT FROM ONLY ONE DIRECTION

EXAMPLE OF THE PREVALENCE OF CIRCULATION SPACE

NARROW FRONTAGE TO EXTERIOR

NO OUTDOOR AREA

ONLY SOURCEOF DAYLIGHT FOR ENTIRE APARTMENT

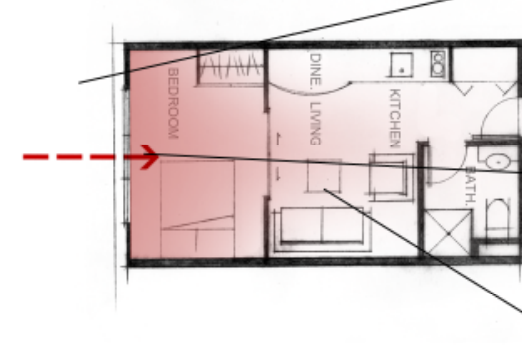

SAPHIRE APARTMENTS

LIVING ROOM IS LOCATED IN A CENTRAL POSITION WITH NO DIRECT ACCESS TO EXTERIOR 
- Only two floor plans are supplemented with a section. This is due to the fact that out of all of the apartments only three had significant variations in height or multi-level layouts. Typically, apartments are single story with a consistent stud height (usually between 2.4 to 3 meters) as exemplified by the section of the Hall Apartments Fig. 2.11 (top left). The three exceptions to this rule all occupy more than one level. An example of this varied sectional layout is shown in Fig. 2.11 (right) with the Tattoo Apartments.

- When ignoring bedroom count, and counting an open plan living space as one space, the average number of rooms which have visual and/or direct physical access to the apartments' outdoor area is 1.2 rooms per apartment. This was inclusive of apartments with no outdoor space.

- 13 apartments without access to their own outdoor space

- 20 apartments have designated circulation spaces (hallways, corridors or stairs) of more than two meters in length (nearly 30 percent of apartments). These are spaces which serve no purpose other than circulation.

- 17 instances of either a bedroom or living space being located in the plan where they have no windows to the outside of their own, dramatically limiting the direct access to external views, ventilation and day lighting. 12 bedrooms have no link to the outside whatsoever.

- Within a living space the average number of natural daylight sources, even when considering multiple windows on the same wall, is approximately 1.3 sources per living space.

This section introduced the examples of New Zealand apartments and the process of analysis. Following, the next section builds on this analysis through the formation of diagrams. The diagrams describe the key findings as observed in the examples of small apartments in New Zealand. 


\section{5 - Diagrammed Findings:}

Focussing particularly on the market of small apartments, a series of primary themes or characteristics have been identified which came to light through the analysis of existing apartment buildings in Auckland and Wellington. These characteristics highlight the recurring problematic planning and poor spatial qualities inherent in the vast majority of small apartments in New Zealand. Some apartments may only suffer from one of these problems whilst others have multiple issues contributing to their poor planning and spatial deficiencies. The key design problems are abstracted into diagram form to establish a series of design issues which need to be avoided or improved upon in the design phase.

\section{Sectional Arrangement:}

One of the most common traits of the surveyed apartments was the relationship between the plan and section. Early on in the research it became increasingly apparent that the apartments had a two-dimensional nature due to the simple sectional arrangement. All spaces and rooms are arranged horizontally with little or no variance in vertical placement or height. This simplicity in section is contrasted by the complexity of the floor plan where multiple rooms and partitions divide space across the horizontal plane.

Low ceilings compress the space in the vertical dimension, further adding to the restrictive feeling of small spaces. The monotonous levels of the horizontal planes - the ceilings and floors - offer no relief, a sensation that would be achieved were the space to open up vertically. This leads appropriately to the next attribute as explored in the following diagram.

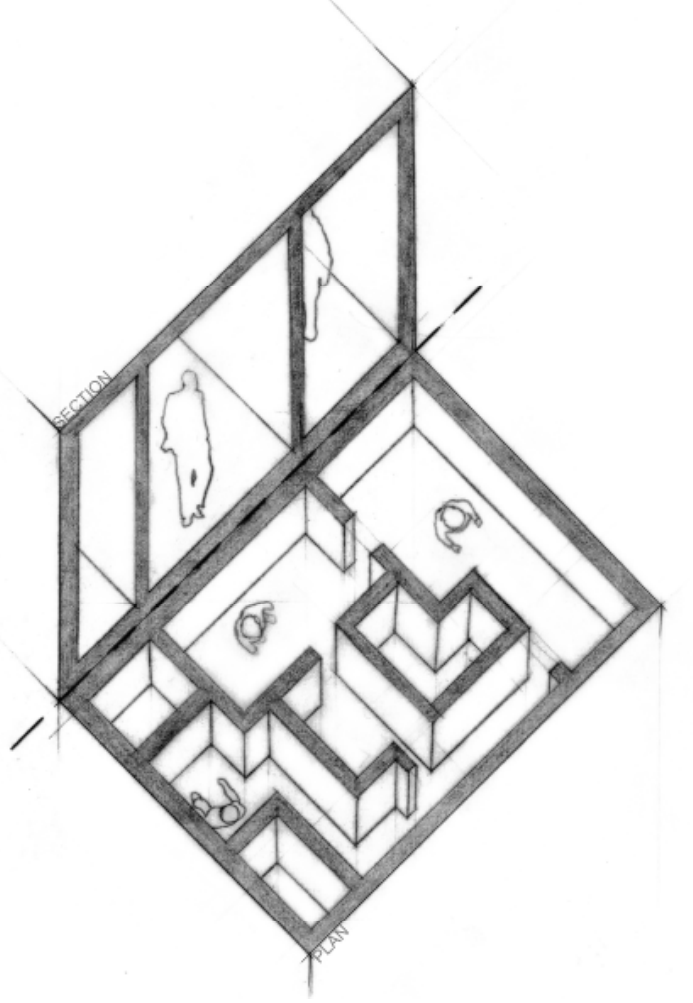

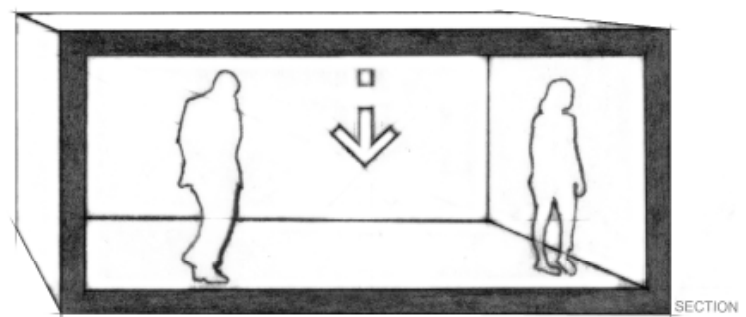

Fig. 2.15 Diagram illustrating low monotonous

Diagram illustrating apartments' complex

ceilings. plans and simple sectional layouts. 


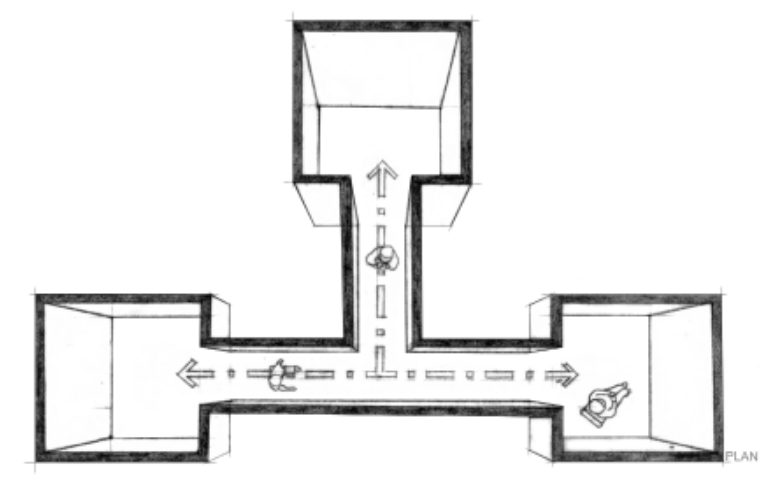

Fig. 2.16 Diagram illustrating dedicated circulation and cellular living.

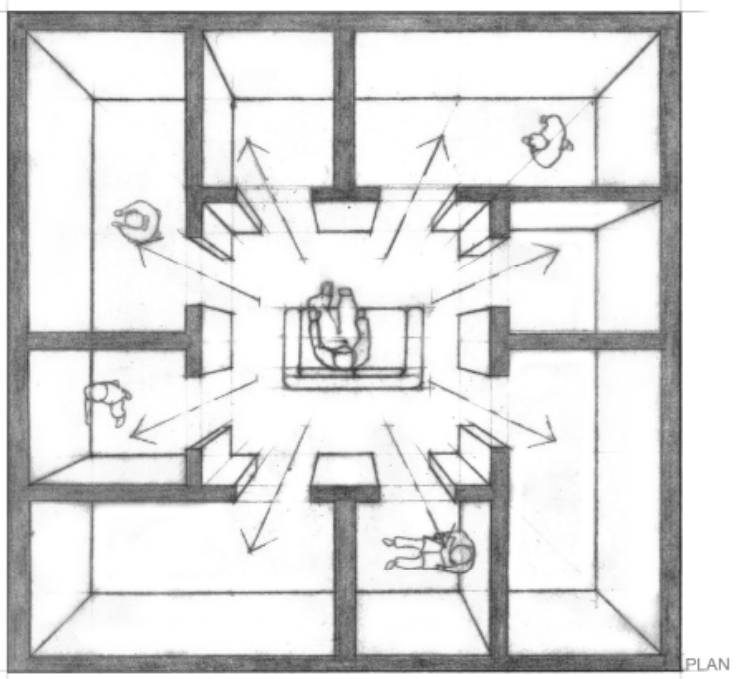

Fig. 2.17 Diagram illustrating living space serving as primary circulation/transition zone.

\section{Circulation:}

The horizontal arrangement typically results in corridors linking adjacent and separate spaces. Corridors offer little else to a space other than serving the purpose as a circulation route. One of the issues with this is, when not being utilised as a circulation route, the space serves little or no other purpose and becomes wasted, underutilised floor area. Consequently, fragmented interiors (separate rooms) are established, which tend to make the small volumes of apartments seem smaller still. In short, dedicated circulation areas and cellular living spaces increase the sense of confinement.

The next diagram calls attention to the planning relationship between the living room and the other spaces and functions. Here, the living space is acting as the main transition zone or circulation space. This arrangement was often seen to be the alternative to the corridor type discussed above. Although this creates a circulation space with a secondary function and increases space efficiency, in some cases too many doorways lead of the space resulting in problems with furniture placement and the definition of zones. Additionally, surrounding the living space can reduce its chance of having multiple exterior surfaces and may restrict the room from gaining natural light from different directions. 


\section{Natural Light:}

Having only a singular source of natural light in any given room was another prevalent characteristic established during the apartment analysis. Due to the typical 'shoe box' style of many of the apartments in New Zealand cities, often with the sole source of natural light being from one end window, there is an uneven lighting gradient throughout the space. Light from just one direction typically leads to poorer 'modelling' or rendition of shapes and also leads to dark, unpleasant zones further into the interior core of the apartment. The resulting lack of light has a damaging effect on the quality and perceptive size of a space. Christopher Alexander's A Pattern Language also suggests that acute contrast between light and dark promotes glare, therefore "every room where people feel more comfortable must have not merely one window, but two, on different sides". ${ }^{18}$

Similarly, bedrooms (and other inhabitable rooms) without windows suffer from the same perception of 'shrinking' of space, where the lack of light makes the room appear smaller. According to Flynn, lighting within an interior can affect perceptual clarity, evaluative impressions, and spaciousness. ${ }^{19}$ The survey revealed that there are fully internal rooms with no natural light, ventilation and no view or connection with the external environment. Daylight can have profoundly positive effects on psychological and physiological responses in inhabitants, and its absence can contribute to uncomfortable, unhealthy and depressing interior spaces.

18 Alexander, C. (1977). A Pattern Language: Towns, Buildings, Construction. Oxford: Oxford University Press. p. 526.

19 Flynn, J., \& Spencer, T. (1977). The Effect of Light Source Color on User Impression and Satisfaction. Journal of the Illuminating Engineering Society , 167-179.

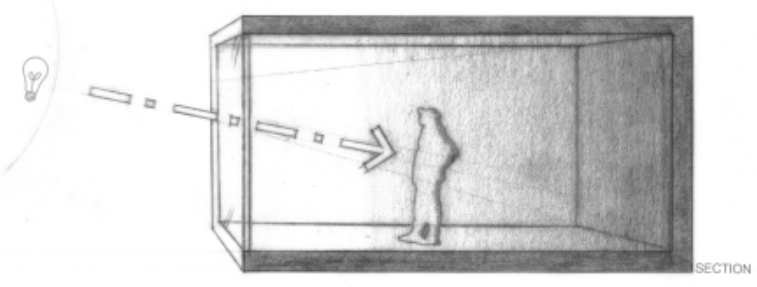

Fig. 2.18 Diagram illustrating apartments or rooms being lit by a single source of natural light.

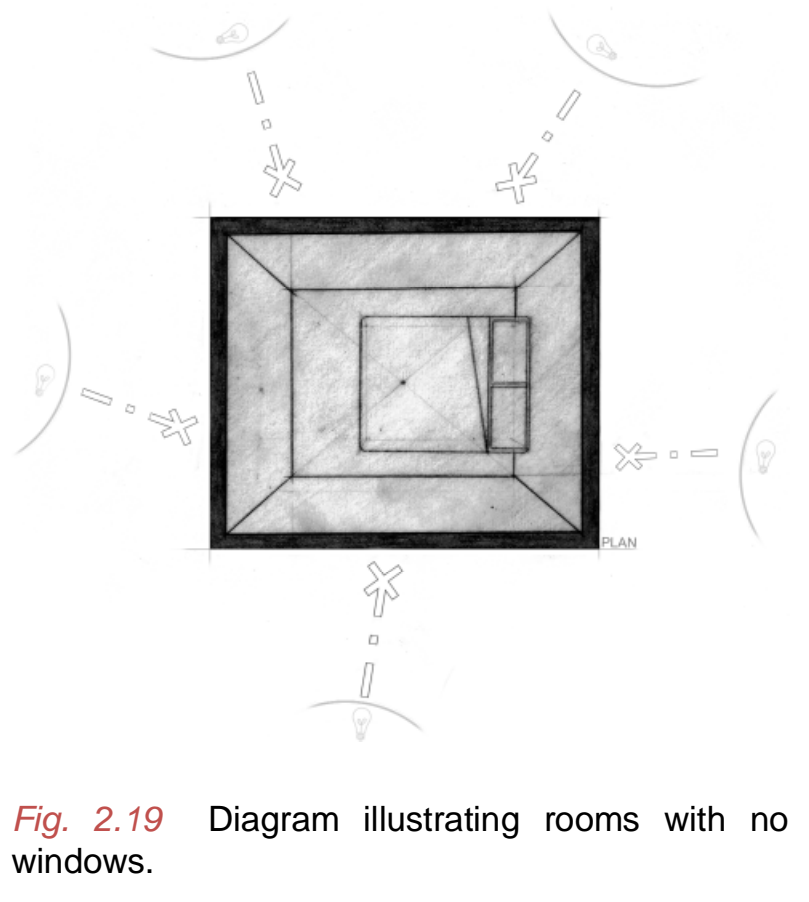




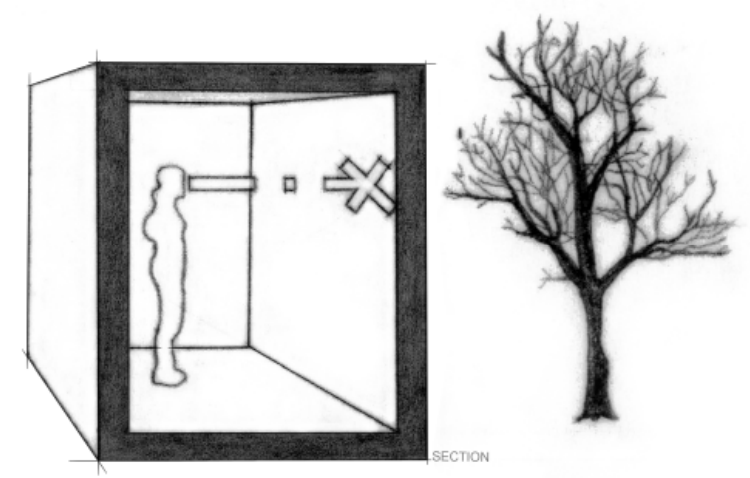

Fig. 2.20 Diagram illustrating poor connections with nature and external environments.

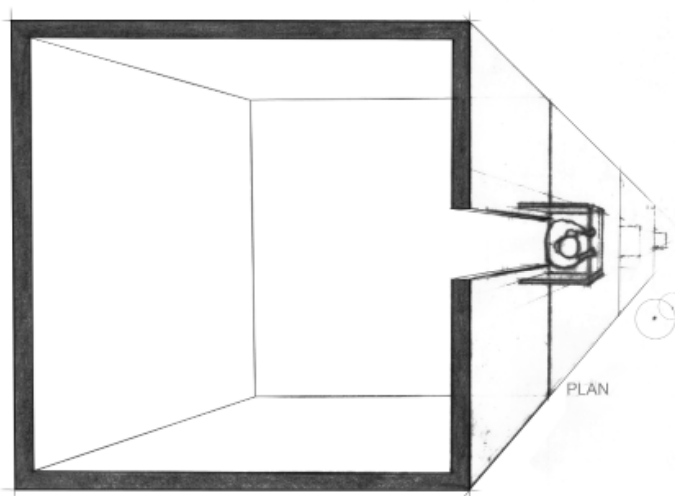

Fig. 2.21 Diagram illustrating the lack of dedicated outdoor space.

\section{Connection to Exterior:}

It can be argued that the poor connection with nature and external environment of these apartments is contradictory to the ethos of a nation like New Zealand, where residents value the relationship with outdoors. This notion is amplified by the fact that many occupants of such buildings are 'first generation' apartment dwellers. In many cases, particularly in affordable apartment complexes, the visual connection to nature and outdoor spaces appears to be undervalued, and as a result the apartments suffer from a constrictive atmosphere as they do not extend out beyond their physical envelope.

Typical to most of the apartments analysed is the small amount of dedicated outdoor space. This is inextricably linked with the previous diagram. These designs do not privilege the use of outdoor space usually only having one small balcony of about 5 square metres for the whole apartment. When balconies are included, they often provide little amenity, least of all in respect to privacy. Often, adjacent or opposite apartments offer little screening between their respective balconies. 


\section{6-Conclusion:}

This chapter has looked at the prevalent issue of inadequate apartment complexes available in New Zealand's cities. Statistics show the increasing percentage of the population are inhabiting the cities, with migratory patterns moving from rural to urban areas. In turn, survey's examine the public opinion on apartment living, proving the unappealing nature of the current apartment stock. Of particular note is the opinion that many people would be willing to live in apartments, due to the convenient, social lifestyle that often accompanies urban living. However, the poor quality of affordable apartments and the unattainable cost of good quality options is preventing them from doing so. A graphic examination of floor plans from examples of city apartments in both Auckland and Wellington has shown the spatial and functional layout of existing apartments, and subsequently revealed the issues with each. After denoting the prevalent issues within New Zealand apartments, as established through the examples chosen, diagrams were used to abstract these issues by removing them from specific contexts and expressing relationships in general terms. The main issues involved fall into three categories, each causing serious impacts on spatial quality and therefore the quality of living within these spaces. Firstly, the uniform height and uninteresting sections bring little diversity to the layout of the apartments, while low ceilings detract further from this environment. Secondly, circulation is addressed in very limited ways, with long corridors wasting limited space or living spaces by being used as transition zones. Thirdly, the lack of natural light and disconnection from the exterior minimizes the sense and quality of the spaces. In the following chapters, Japanese micro-architecture is analysed in relation to these issues. Later in the thesis, these design flaws are addressed within an experimental design. 



\section{1-Introduction:}

While it is recognised that countries and cities worldwide have dealt with the issue of affordable accommodation for urban dwellers in many ways with varying levels of success, this research aims to look solely to Japan as an influential precedent and source of inspiration to develop affordable, small-footprint urban apartments in New Zealand's urban prefectures.

This chapter establishes a background context focusing on the role of Japanese architecture. Firstly, it discusses the historical context of Japanese influence, where throughout history, Japanese visual arts have had a strong influence on the visual arts of Western societies. Secondly, this chapter will touch on architectural traditions, which have been translated into the designs of contemporary micro-architecture. This leads into a brief overview of the phenomenon of KyoshoJutaku (small house living) in Japan.

Japan was chosen as a precedent for analysis because it epitomises the typologies focused on in this thesis. The development of affordable apartments deals with the issues of limited floor area, small footprint size, space-efficiency and quality of space. These are issues and concepts with which Japanese architects have had a history of successful outcomes. Many examples of these ideals are manifested in the form of a particular architectural phenomenon, Kyoshu-Jutaku.

As a result of rapid unregulated urbanisation and unregulated expansion, large areas of Japan's natural environment experienced extreme degradation and its cities became associated with reduced quality of living and soaring land prices. The extreme conditions of this environment have spawned creative and original architectural responses. Not only can lessons be learnt from Japan's mistakes in urban development, but more relevant to this paper, we can understand the capability of this architectural typology as a means to remedy the problems manifesting more recently in New Zealand. 


\section{2 - Japan as Influential Precedent and Japonisme:}

Western culture has historically looked to the East for inspiration across many aspects of society. This relationship is emulated through the research method used in this thesis. Japan in particular has been of great influence to many architectural and artistic endeavours undertaken by Westerners as typified in the era where Japonisme became a significantly popular trend. This brief overview outlines the events leading to the phenomenon of Japonisme, spanning a number of named periods in Japan's history. The Sengoku Period (1467 to 1573) saw the arrival of the first Westerners, followed by a succession of Jesuit, Dominican and Franciscan missionaries. From this early stage in the relationship between Japan and 'The West', Westerners showed their interest and fascination with all things Japanese; the Western world "became the object of extreme Orientalist fantasies". 20

During the Edo Period (1603-1868) a threat was posed by the increasing numbers of Christian converts and the propaganda of the Protestant English and Dutch traders. The Shogunate feared an alleged plan to culturally colonise and dominate countries of the orient and therefore imposed and enforced the Sakoku policy in 1638. ${ }^{21}$ This removed the religious influence, but also prevented trade in and out of the country. The country was effectively closed between 1638 and 1853 , no foreigners able to enter or Japanese citizens to leave. ${ }^{22}$ This isolation acted as an early catalyst for Japonisme. Two centuries of national seclusion only increased the allure of Japan to Westerners, leading to repeated, unsuccessful attempts from the maritime nations of Europe to breach Japan's coastal defences. This period was particularly influential in the development of Japanese society and culture due to the self-imposed isolation. Development of the arts, devoid of external influence, led to visual representation unique to Japan. One of the most significant artistic productions in this era came in the form of the ukiyo-e, a form of wood-block print, which

\footnotetext{
20 Smith, Patrick. Japan: A Reinterpretation. New York: Pantheon Books, 1997. p. 2.

22 Tashiro, Kazui. "Foreign Relations During the Edo Period: Sakoku Reexamined." Journal of Japanese Studies. Vol. 8, No. 2 (1982): p. 289.

22 Laver, Michael S. The Sakoku Edicts and the Politics of Tokugawa Hegemony. New York: Cambria Press,
}

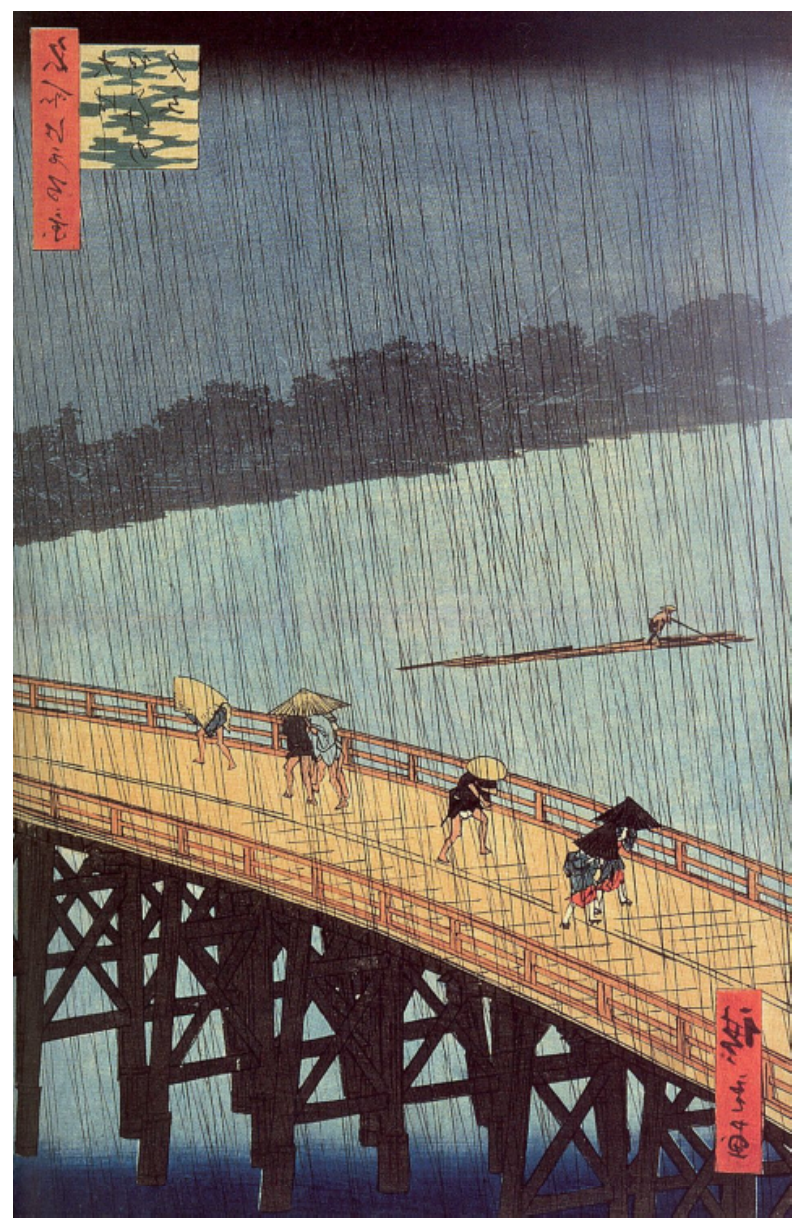

Fig. 3.0 Ukiyo-e print; "Great Bridge, Sudden Shower at Atake" by Hiroshige. (Source: http:// commons.wikimedia.org/wiki/File\%3AHiroshige_-_ Evening_Shower_at_Atake_and_the_Great_ Bridge.jpg) 
was soon to be highly influential to the Western art world. ${ }^{23}$

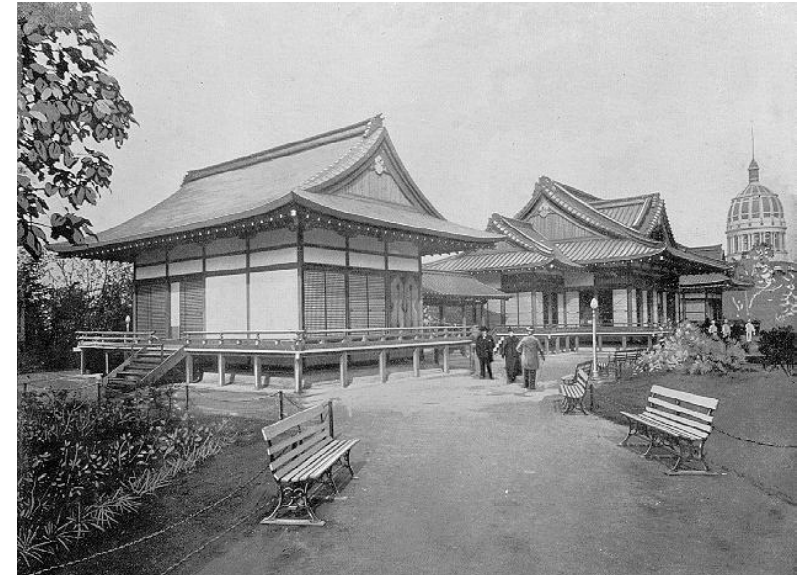

Fig. 3.1 The Ho-oden Hall at the Chicago 1893 World Fair (Source: http://www.discovernikkei.org/ en/journal/2012/4/5/meeting-of-the-twain/)
This isolation period was finally concluded with the signing of a treaty between Japan and the United States of America, who demanded the opening of Japan's borders under the threatening presence of Navy Commodore Perry's war ships. This treaty became the mechanism which, with the fall of the Shogunate and start of the Meiji Restoration era, led to the dispersal of Japanese culture into the Western world. Japanese art and architectural styles quickly gained recognition and appraisal, becoming a significant influence on many notable Western artists and architects including the works of Whistler, Monet and Van Gogh. French author, Philippe Burty coined the term Japonsime in 1872, encompassing the idea of the 'borrowing' of, or the influence of Japanese art. $^{24}$

Japonisme had an exemplary effect on renowned American architect Frank Lloyd Wright. Throughout his life, Wright was heavily inspired by Japanese art and architecture. As an avid collector and dealer of Japanese prints, he was exposed to fundamental design principles that he applied to his own creative work. Wright translated the prints' asymmetry, simplicity and connection with nature into his presentation drawings, many of which resembled the compositional arrangement of one of his favourite artists, Ando Hiroshige, even going to the extent of mimicking Hiroshige's representation techniques, such as striated skies. ${ }^{25}$

I have never confided to you the extent to which the Japanese print has such inspired me. I never got over my first experience with it and I shall never, probably, recover. (Wright, 1992, p. 116)

\footnotetext{
23 Lambourne, Lionel. Japonisme : cultural crossings between Japan and the West. London: Phaidon, 2005.

p. 7.

$24 \quad$ Ibid., p. 6,32.

25 Meech-Pekarik, Julia. "Frank Lloyd Wright and Japanese Prints." The Metropolitan Museum of Art Bulletin, Vol. 40, No. 2 (1982): p. 47
} 
In the same way, while not implicitly Japanese in their appearance, Wright's architectural works were directly shaped a great deal by Japanese art and architecture. His style and principles stem from his understanding and affection for the rational design of Japan's indigenous architecture. ${ }^{26}$

The World's Columbian Exposition, Chicago, 1893, exposed Wright to the horizontal lines and large overhangs of a Japanese pavilion, characteristics which influenced his later designs of Falling-Water and the Praire Homes. For Wright, Japanese architecture has "been a catalytic agent in the development of a new vision of form". ${ }^{27}$ It is evident that the inherent connection between nature and Japanese design led to his concept of organic architecture, in which he suggests a building should be in sympathy with nature and be part of its surroundings. ${ }^{28}$ While Frank Lloyd Wrights' works will not be used within this thesis as analytical case studies, it is interesting to see the domineering influence of Japanese architectural concepts on renowned designs.

\section{3 - Evolving Urban Conditions:}

For a number of reasons, both geographical and social, Japan provides some of the most interesting solutions to living spaces that are more than usually restricted. (Freeman, 2004, p. 6)

The Japanese cities of today are the setting for an interesting typological phenomenon which has developed as an answer to many of the negative qualities that are plaguing these urban centres. This section will look more specifically at the environmental, economic, political and social

26 McNeil, Peter. "Myths of Modernism: Japanese Architecture, Interior Design and the West, c. 1920-1940." Journal of Design History, Vol. 5, No. 4 (1992): p. 281.

27 Thiel, Philip. "Review: Japanese Influences on Western Architecture." The Journal of Asian Studies, Vol. 16, No. 2 (1957): p. 271.

28 Nute, Kevin. Frank Lloyd Wright and Japan: The Role of Traditional Japanese Art and Architecture in the Work of Frank Lloyd Wright. London: Routledge, 2000. p. 81. 
climates which have attributed to the existence of the small housing typology or Kyosho Jutaku (micro-living) in Japan. Understanding the Japanese situation will help provide an insight into some of the urban problems faced by cities internationally. This understanding will also provide a context for the unique design approach of micro-living as a means for optimising urban living conditions.

The main causes which have led to the formation of the specific residential typologies of microhouses are inextricably interrelated and include: mass urbanisation, the changing Japanese economy, population influx, migratory patterns and environmental degradation. All of these factors have either influenced, or are the results of, Japanese urban planning.

\subsection{1 - Post-war Period of Economic Growth and Urbanisation:}

Japan's involvement in World War II can be seen as a major catalyst for events which shaped the urban form of Japanese cities. The American bombing raids of 1944 consumed the urban areas of Japan in a devastating fashion, which, at the time consisted of densely packed buildings of wood and paper. The city populations dropped drastically over the war period due to the destruction of housing stock and mass civilian evacuations. ${ }^{29}$ The near complete obliteration of Nagasaki and Hiroshima by atomic bombs in August, 1945 marked the defeat of the Japanese war machine, and ushered in a new era of American occupation and reconstruction process.

The war had proven exceedingly costly for Japan with the task of rebuilding damaged cities and a weakened economy. Policy aimed at regaining the economy and rebuilding the lost industry, primarily promoting the economic growth of heavy and chemical industry. This rapid economic growth became the "defining characteristic of the early post-war decades" ${ }^{30}$ The economic expansion transformed Japan into a primarily urban and industrial nation, stepping away from

29 Sorensen, A. The Making of Urban Japan - Cities and Planning from Edo to the Twenty-first Century. New York: Routledge, 2002. p. 150.

30 Allinson, G. D. Japan's Postwar History. Cornell University Press, 2004. p. 83. 
its more traditional, rural-based agricultural roots. Although the pre-war era had seen a shift to urbanisation, it was dwarfed by the scale of the post-war shift. ${ }^{31}$ Large scale migration stemmed from the shift to industrial and service-based employment concentrated in the three main metropolitan regions of Nagoya, Osaka and Tokyo. Industry was concentrated along the Pacific Belt Region, spanning from Tokyo to northern Kyushu, an area known to Japanese as the 'Tokaido Megalopolis.' This concentration resulted in two-thirds of the population living on 23 percent of the country's land. "Of the large developed countries, urbanisation was fastest, and its resulting urban areas biggest". 32

While the economy was flourishing, unfortunately the environmental and urban issues shaped by industrialisation also developed. The planning style adopted had an attitude of neglect towards sustainable long-term growth and quality of life with spending on social capital, infrastructure and residential areas opposed by central government. ${ }^{33}$ Japan's urban and environmental problems, while attributed to the focus on expansion of the economy and the nation's resulting rapid urbanisation and industrialisation, the general exclusion of other priorities are also to blame. This has led to the necessity to find more sustainable strategies for growth including forms of future development which have a less severe impact on the environment.

\subsection{2 - Urban and Suburban Sprawl in Japan:}

Parallel to economic and industrial expansion was the expansion of urban and suburban areas in a typically ad hoc, sprawling fashion. The 1960s saw a metropolitan-to-suburban trend in migration, particularly in Tokyo. Although Tokyo continued to grow it experienced an unprecedented loss of migrants from the central ward area with great numbers leaving the central cities and moving to adjacent suburbs. It should be noted that steady migration from rural to metropolitan prefectures,

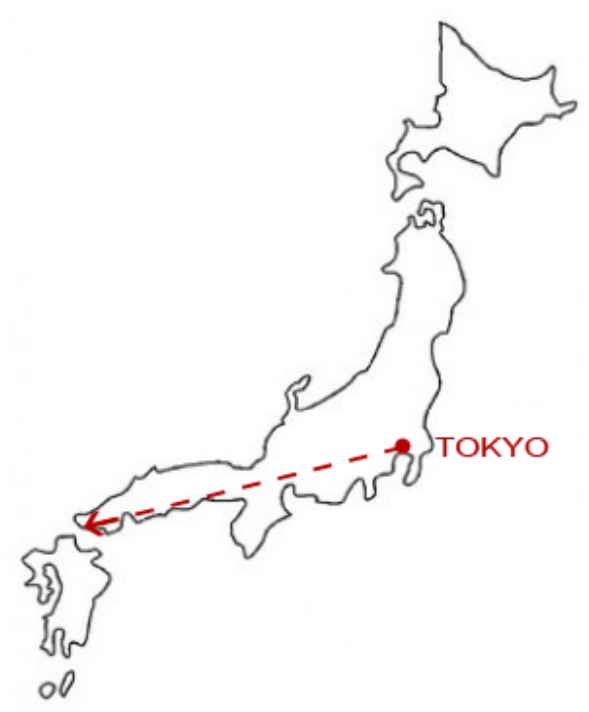

Fig. 3.2. The 'Tokaido Megalopolis': Industry was concentrated along the Pacific Belt Region, spanning from Tokyo to northern Kyushu. 
seen in the previous decade, continued to occur.

Japan does not have a strong tradition in urban planning and at this time the planning systems in place were unable to prevent the scattered, haphazard suburban development. With no subdivision controls, land development for residential use within commuting distance of major employment centres tended to be encouraged, with problematic results. ${ }^{34}$ In an attempt to cater for the migrant influx and compensate for the post-war housing shortage, local governments established large scale public housing construction with the primary objective of supporting a new generation of industrial workers. A Japanese Housing Commission (JHC) policy justified the construction of high-rise housing estates on green-field sites located far from existing settlements as the land was cheaper, and therefore, the cost per housing unit less. These estates acted as dormitory suburbs with very little in the way of local amenities; they contributed greatly to sprawl in Japan. ${ }^{35}$ For Japan the main problems produced by urban sprawl were the creation of large areas of haphazard development that would become a hindrance to future urbanisation and contributed greatly to environmental decay.

The spread of factories and housing was responsible for a highly visible loss of environmental amenities, as beaches and coastal areas disappeared beneath landfills for industrial complexes, hills and forests were razed and paddies filled in for new housing. (Sorensen, 2002, p. 207)

It was not until the late 1960s that overwhelming political pressure forced the government to introduce measures to address these problems. A rethinking of how 'Urban Japan' was to operate began.

$34 \quad$ Sorensen, A. (2002). p. 206

35 Miyakawa, Y. "The Location of Modern Industry in Japan.” Gakkai, Nihon Chiri. Geography of Japan Teikoku-Shoin, 1980. p. 275 


\subsubsection{Bubble Economy:}

A further shift in economic growth towards electronics, automobile manufacture, precision machinery and finance in the late 1970s and early 1980s. Tokyo rapidly became the epicenter of the economic growth; this phenomenon became known as the Unipolar Concentration of Tokyo, ${ }^{36}$ and its dominance as one of the world financial capitals caused the continued movement of large numbers of migrants into the region throughout the 1980s. ${ }^{37}$

As the economy ballooned, Japanese land prices increased dramatically - particularly in Tokyo - owing to: greater demand due to population increase, the lowering of interest rates intended to counteract the ascending Yen, and land deregulation. High capital gains taxes were imposed on land to discourage speculation. Therefore, land rarely changed ownership unless unreasonably high prices were offered. Consequently, land owners needed to quickly invest in profitable construction to generate revenue for the payment of high taxes, in turn inflating the value of real estate in the area. So "despite the government intentions, land speculation was the order of the day" 38 and the lenient bank lending regulatory system, using land as collateral, allowed businesses to make speculative land purchases with borrowed money.

During this period, land prices, affected by the variables discussed above, were so high that construction costs in urban areas were on average only 10 percent of the value of the land on which they were erected. ${ }^{39}$ The high cost of land in Japan's metropolitan areas is one of the contributing causes that has seen innovative approaches to the housing market including the advent of micro-dwellings.

$36 \quad$ Hatta, Tatsuo and Takatoshi Tabuchi. "Unipolar Concentration in Tokyo: Causes and Measures.” Japanese Economic Studies, Vol. 23, Issue 3 (1995): p. 74.

37 Mera, Koichi. "An Economic Policy Hypothesis of Metropolitan Growth Cycles: A Reflection on the Recent Rejuvenation of Tokyo.” Review of Urban \& Regional Development Studies, Vol. 1, Issue 1 (1989): 37-46.

38 Bognár, Botond. Beyond the Bubble: The New Japanese Architecture. London: Phaidon Press, 2008. p. 9

39 Bognar, B. (2008). p. 9 


\subsubsection{Burst Bubble:}

The 'post-bubble' period is arguably the most significant era with regard to small residential projects. It was not until the collapse of the Japanese economy in the early 1990s that saw the emergence of micro-dwellings on a larger scale. The audacity of the bubble era proved to be the undoing of the economy. Triggered by the raising of interest rates in December of 1989, a succession of events occurred that saw the devastating crash of the Japanese stock market followed by the expected drop in land value.

With the near collapse of the financial sector in the decade following the stock-market crash "land prices began to drop rapidly, financial institutions, including many banks, overloaded with huge non-performing property portfolios or un-repayable property loans [and] went bankrupt". ${ }^{40}$ Japan's economy was in ruins with an almost negligible economic growth in the ensuing years; the 1990s came to be branded as Japan's 'Lost Decade'.

The bursting of the bubble slowed building activity considerably in Japan with the large scale, flamboyant projects seen during the bubble period drying up almost completely. The majority of large projects that were carried over from the period of excess typically struggled to stay afloat financially. At the same time, provided there were no legal restrictions, many landowners began to divide up their real estate assets into smaller residential plots because all commercial development had stopped. Small sections of land scattered throughout the urban environment now became viable sites for construction.

\subsection{Kyosho-Jutaku (Micro-Living):}

In the wake of the economic crisis came architectural commissions in the form of small scale residential projects. Adapting to the new urban and economic context was a necessity. There was still a shortage of space for construction, a shortage of housing in urban prefectures and a need 
for a more cost effective solution to urban living. A new generation of prospective home owners, wanting to reduce the long commutes to outlying areas, looked for affordable urban alternatives. Living in more central areas provides inhabitants with more proximity to amenities such as schools, jobs and shops. Architects learned to make use of the constraints provided by the urban conditions; the small sites and left over spaces became sites where designers "discovered value in the given, less-than-perfect conditions of the city...and benefit from them". ${ }^{41}$ These circumstances spawned the 'Bow-Wow Generation' a term referencing the architecture firm Atelier Bow-Wow, a husband and wife team founded early on in 'the lost decade'. The founders, Yoshiharu Tsukamoto and Momoyo Kaijima, embarked on research into the small and awkward architecture that makes up Tokyo's urban vernacular, which they have coined 'Pet Architecture,' and went on to publish a small guidebook in 2001, 'The Pet Architecture Guidebook,' that examined the ways in which these small structures approached creative spatial configuration. ${ }^{42}$ The firm began to specialise in small residences which possess unique spatial qualities and were interested in how these small innovative dwellings worked in their urban context. Atelier Bow-Wow are well known as a leader in this specific typology which spawned a generation of predominantly younger, up and coming architecture firms which also specialised in this type of architecture, hence the 'BowWow Generation'.

Among other things, the Bow-Wow Generation shifted the emphasis of Japanese architectural discourse from an interest in kaleidoscopic urban intensity to a more programmatic and humble examination of urban and suburban settlement patterns, not to mention the practices of everyday life. (Daniell, 2008, p. 14)

\footnotetext{
41 Bognar, B. (2008). p. 56 2008. p. 14 
In Japan the small residential projects are part of the Kyosho-Jutaku (micro-homes) movement. While there are no specific sizes or constraints which define what makes a micro-home, they occupy sites rarely larger than 50 square metres. At the same time, total floor areas can sometimes seem generous, but may be spread over many floors on a small plot. Two of the most common building types are reflective of the shape of their sites; the 'eel's bend' (Unagino Nedoko) is a long, narrow site or building sandwiched between adjacent structures, where the width may only be three of four metres, yet the length can be more than five times that. Conversely, the 'corner' (Kado) is a small triangular site. ${ }^{43}$ This research recognises contemporary Japanese dwellings which have one or a combination of the following attributes: total floor area less than 130 square metres, site area or building footprint less than 100 square metres, building frontage less than four metres. Within these attributes, the dwellings may contain between one and four bedrooms, and can be spread across as many as six floors. Their designs typically share the common themes of space efficiency and the creation of spaces which appear larger than their footprint would suggest. The masterful use of space allows the architects to accommodate building programmes larger than one would typically conceive as feasible on the chosen sites.

This introduction to Kyosho-Jutaku establishes the foundations of the movement and helps define the building type. The following chapter will elaborate more on the characteristics and architectural strategies of Japanese micro-dwellings. 

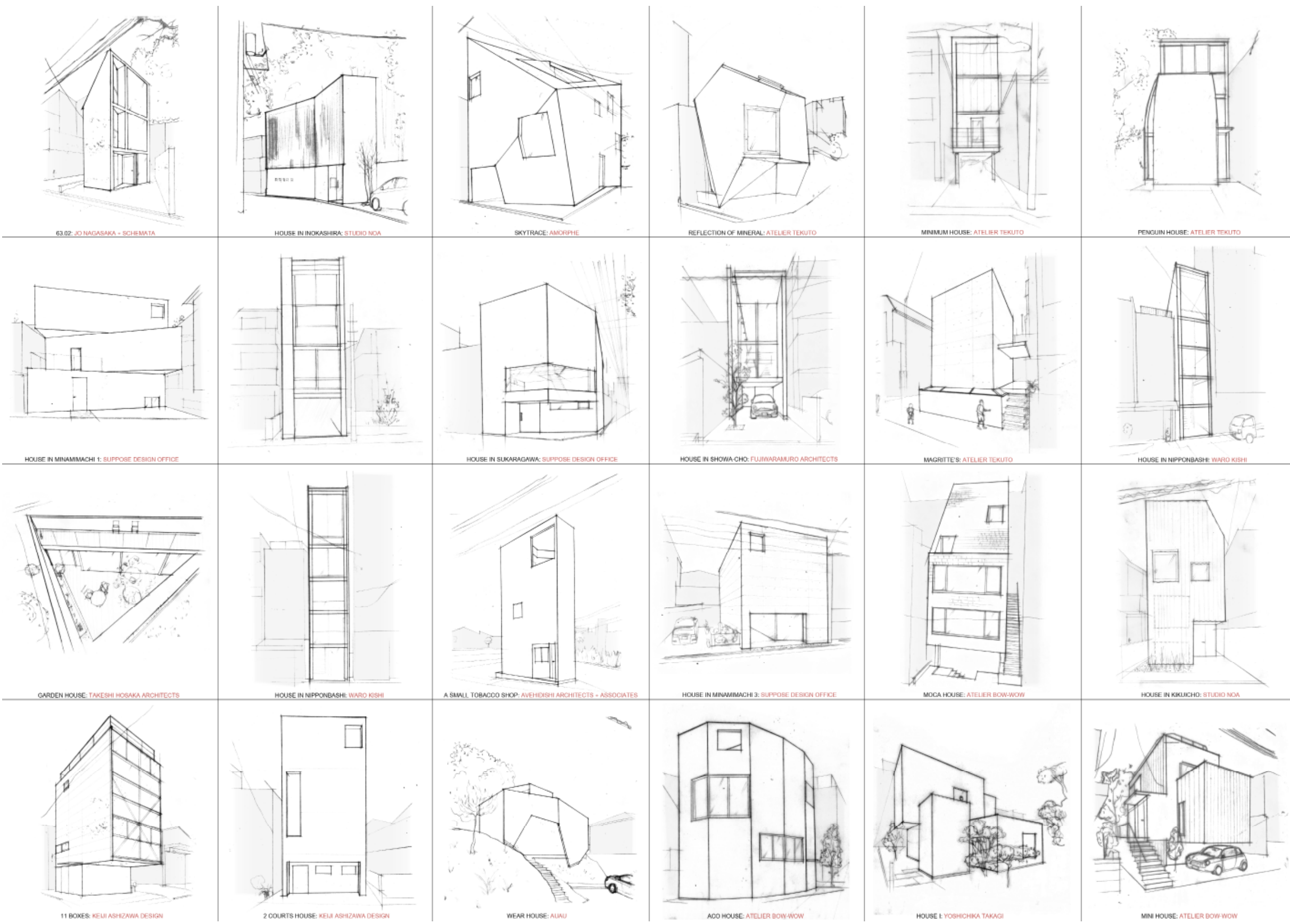

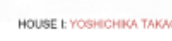

MIN HOUSE: ATELER BOWW WOW 

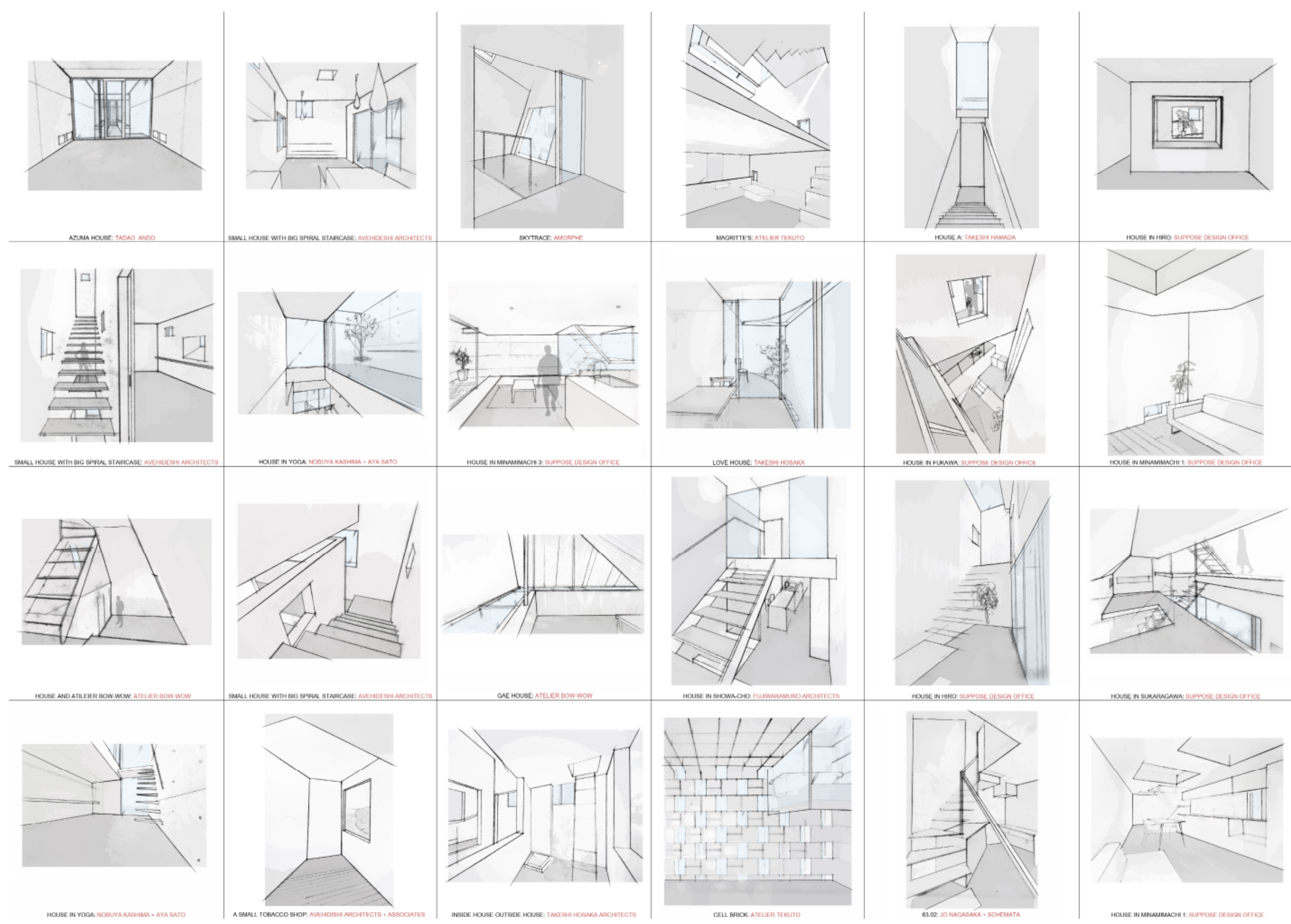


\section{5-Conclusion:}

This chapter has provided a history of Japanese architectural and urban development, with several phenomena being outlined that involve the continuing influence of Japanese culture on the West. More specifically, the research follows the principle of Japonsime, where inspiration is drawn from principles of Japanese arts and in-turn is interpreted in a different context. The social history and urban environment of Japan leading to the phenomenon of Kyosho-Jutaku, provides obvious reasoning for the choice of Japan as a precedent. Government policies and their outcomes have lead to intriguing and original architectural responses. Finally, the introduction to Kyosho-Jutaku, or micro-living, establishes the key concepts of the typology to be explored further in the following chapter. Chapter Four provides analyses of forty examples of Japanese micro-dwellings in order to gain a better understanding of the architectural strategies employed by the architects to achieve the high quality of space within such constrained dimensions. 



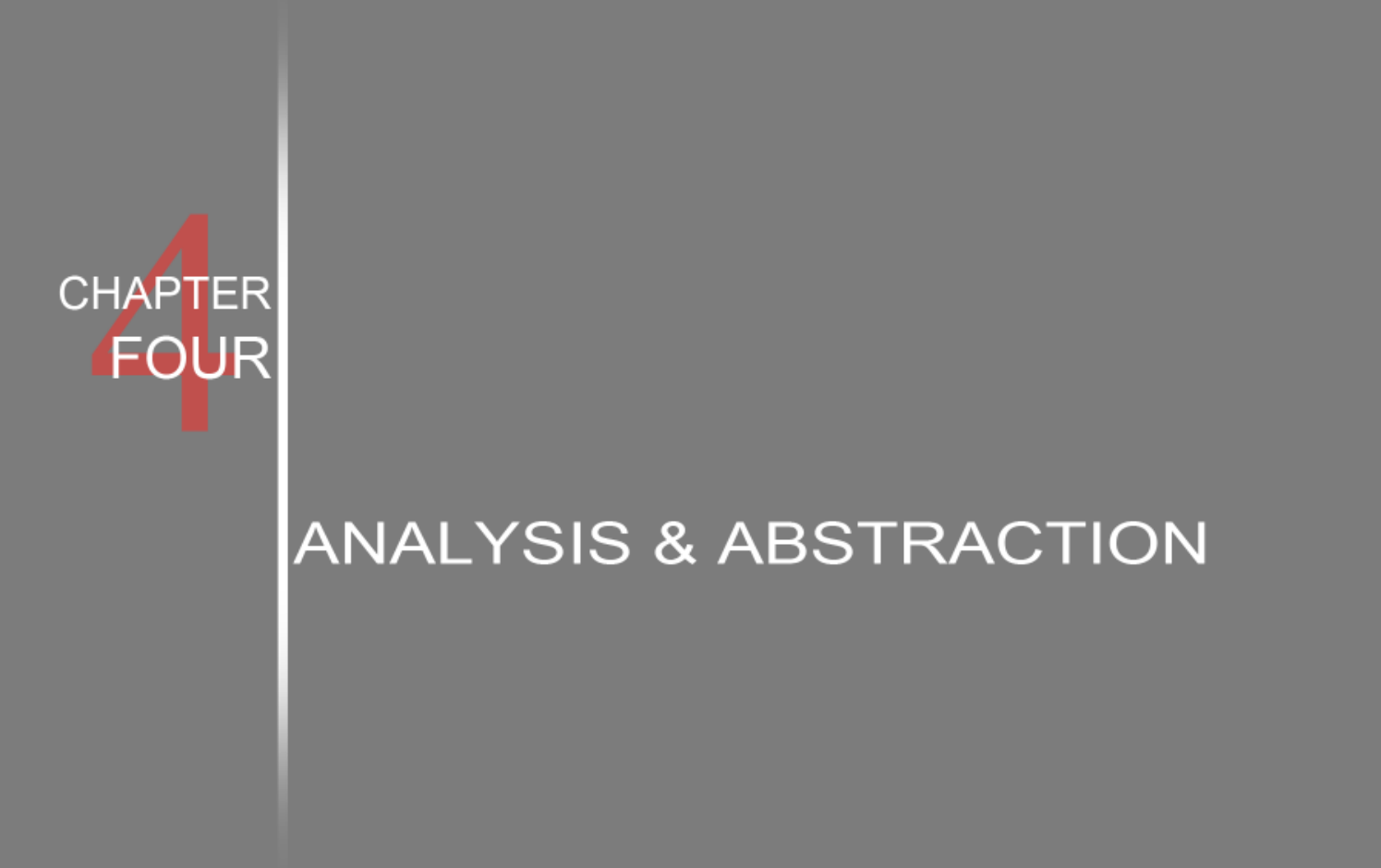




\section{1 - Introduction:}

Japanese architects' masterful design of small architecture has stemmed not only from the rich history of small design, but the more recent movement to micro-dwellings as a result of the urban conditions in Japan. With this in mind, the aim of this chapter is to gain an awareness of what 'tools' and strategies are used to create such quality architecture within tight size constraints so they can be adapted for the New Zealand context. In this chapter, an array of Japanese microdwellings operate as precedents to be analysed for this purpose. The opening section will initially familiarise the reader with the precedents used in the analysis process, outlining the conceptual and size characteristics of these buildings. Following this, the analysis of the examples is described and undertaken with particular reference to design moves understood to be implemented due to the reduced sizes of the dwellings. Finally, these planning and architectural strategies observed in the analysis of the precedents are abstracted into a diagrammatic format for later application in the design phase. Each strategy explores the merits and methods in which it can be introduced into a design with several strategies enabled through multiple techniques. This final stage allows the strategies to be de-contextualized, enabling them to be viewed abstractly and applied to other diverse contexts.

\section{2 -Survev of Japanese Micro-Architecture:}

While there are many examples of Japanese micro-architecture, this research looks primarily at forty separate dwellings which serve as precedents. These examples provide a wide range of the types of dwellings which fit under the general umbrella of the term Kyosho-Jutaku, as outlined in the previous chapter. It is these examples which form the main 'literature' for this study. In a similar method to the analysis of the New Zealand examples, the process of analysis 
began with the re-drawing of each building's floor plans and sections (where possible) into a consistent format and scale. This act alone offered a great insight into the design of the dwellings, as through drawing, a greater understanding of the nuances' and strategies of the architecture is achieved. The result of this is a set of drawings which, when coupled with supplementary photographs, forms the foundational material for primarily observational analysis. Below are the aforementioned precedents: 

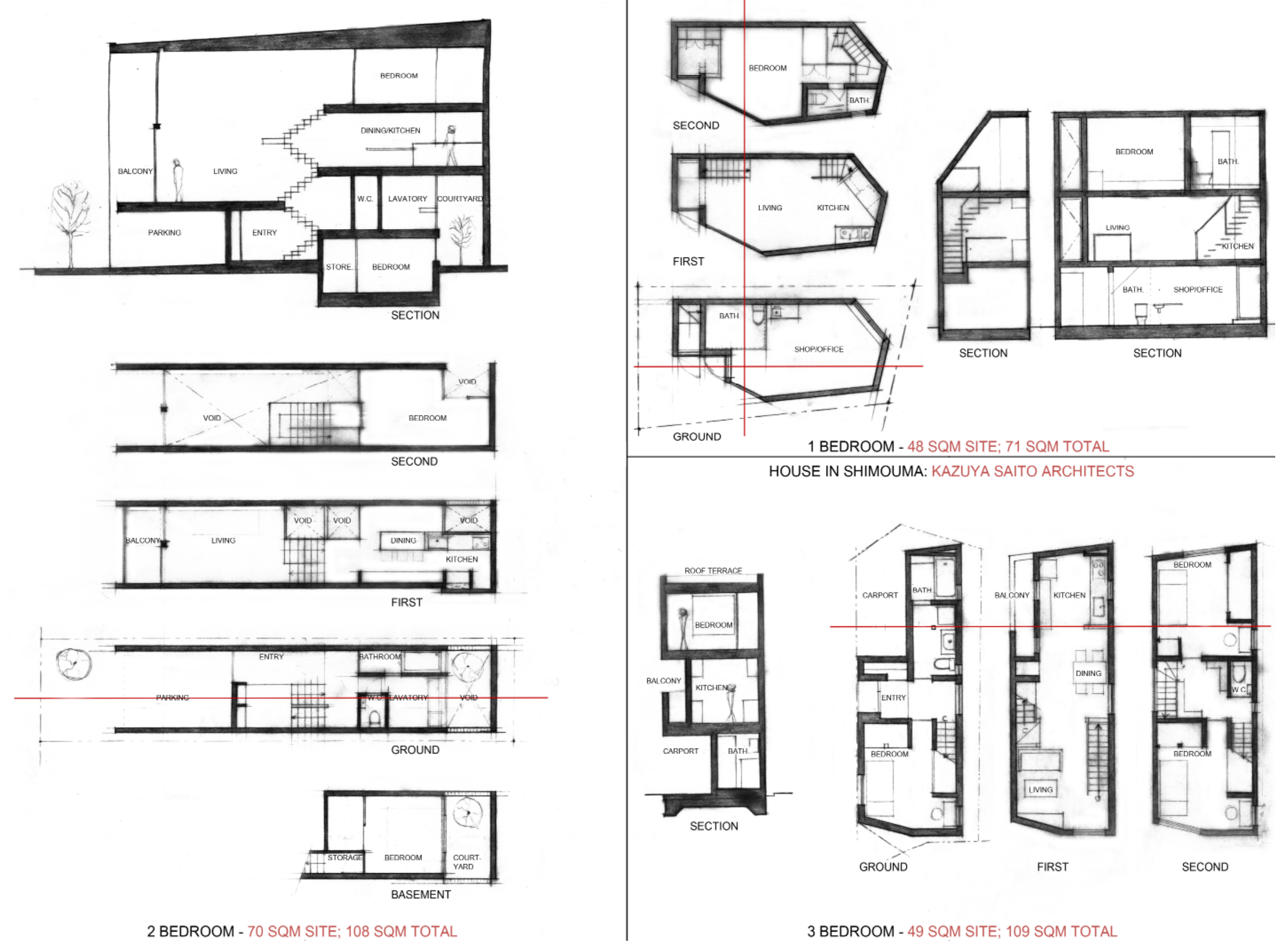

2 BEDROOM - 70 SQM SITE; 108 SQM TOTAL 


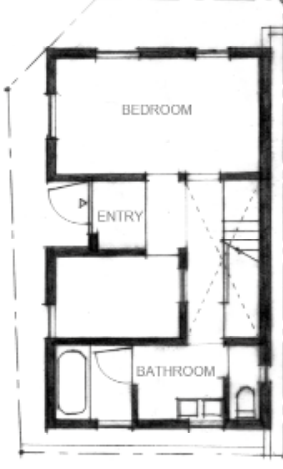

GROUND

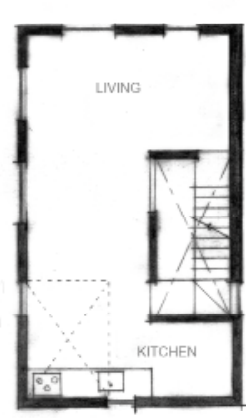

FIRST

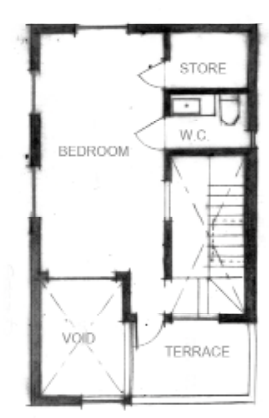

SECOND

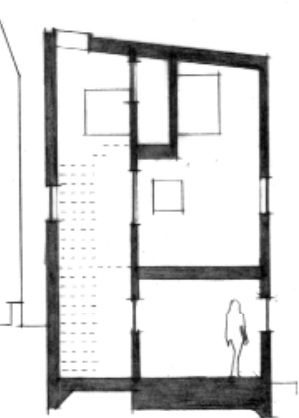

SECTION

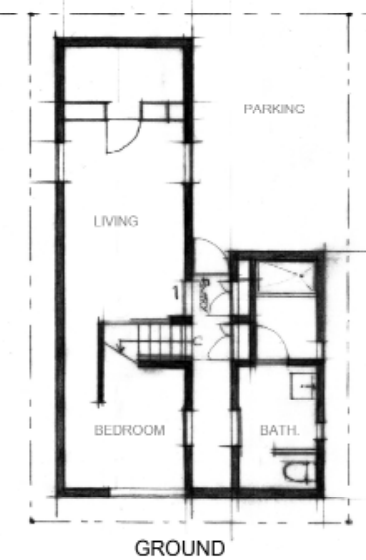

2 BEDROOM - 70 SQM SITE; 80 SQM TOTAL

HOUSE IN HIRO: SUPPOSE DESIGN OFFICE
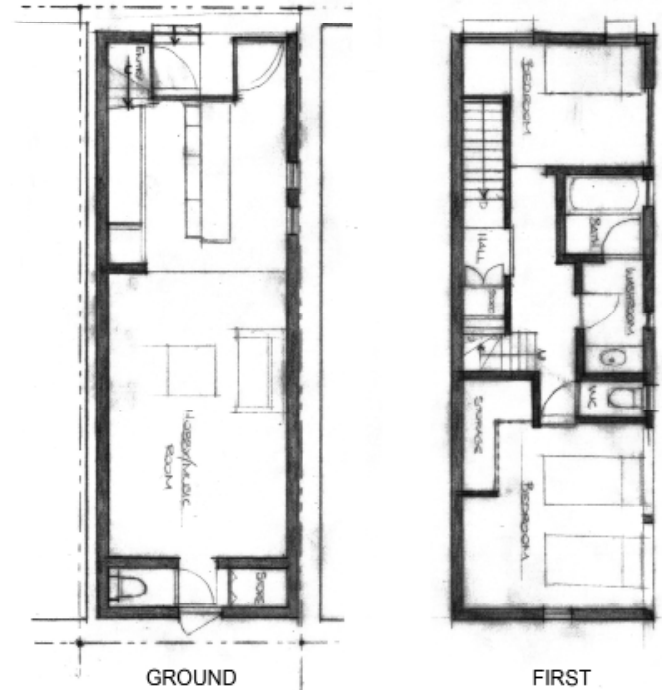

FIRST

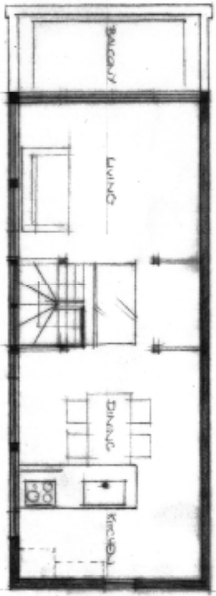

SECOND
SECTION

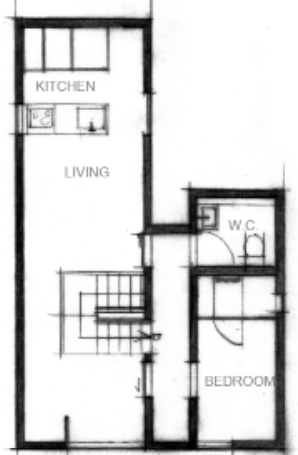

FIRST
2 BEDROOM - 38 SQM FOOTPRINT; 97 SQM TOTAL

2 BEDROOM - 58 SQM SITE; 47 SQM SITE; 128 SQM TOTAL

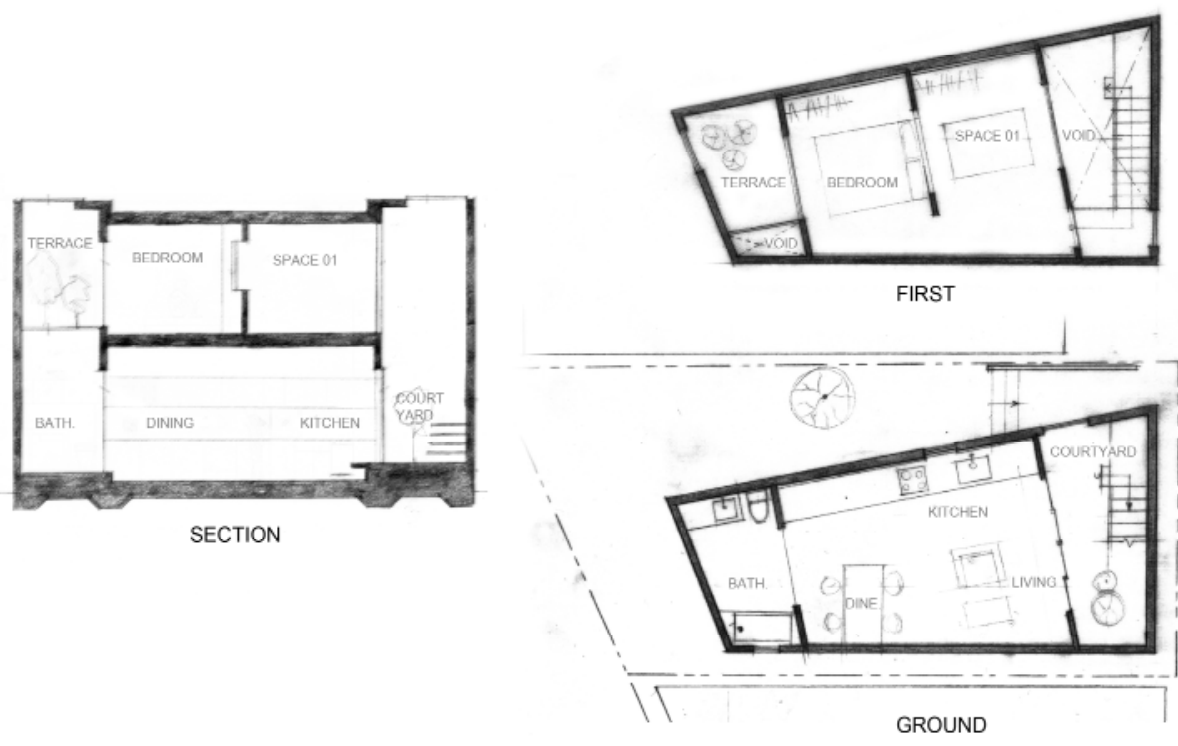

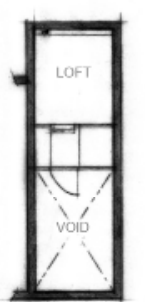

LOFT

1 (2) BEDROOM - 78 SQM SITE; 66 SQM TOTAL 


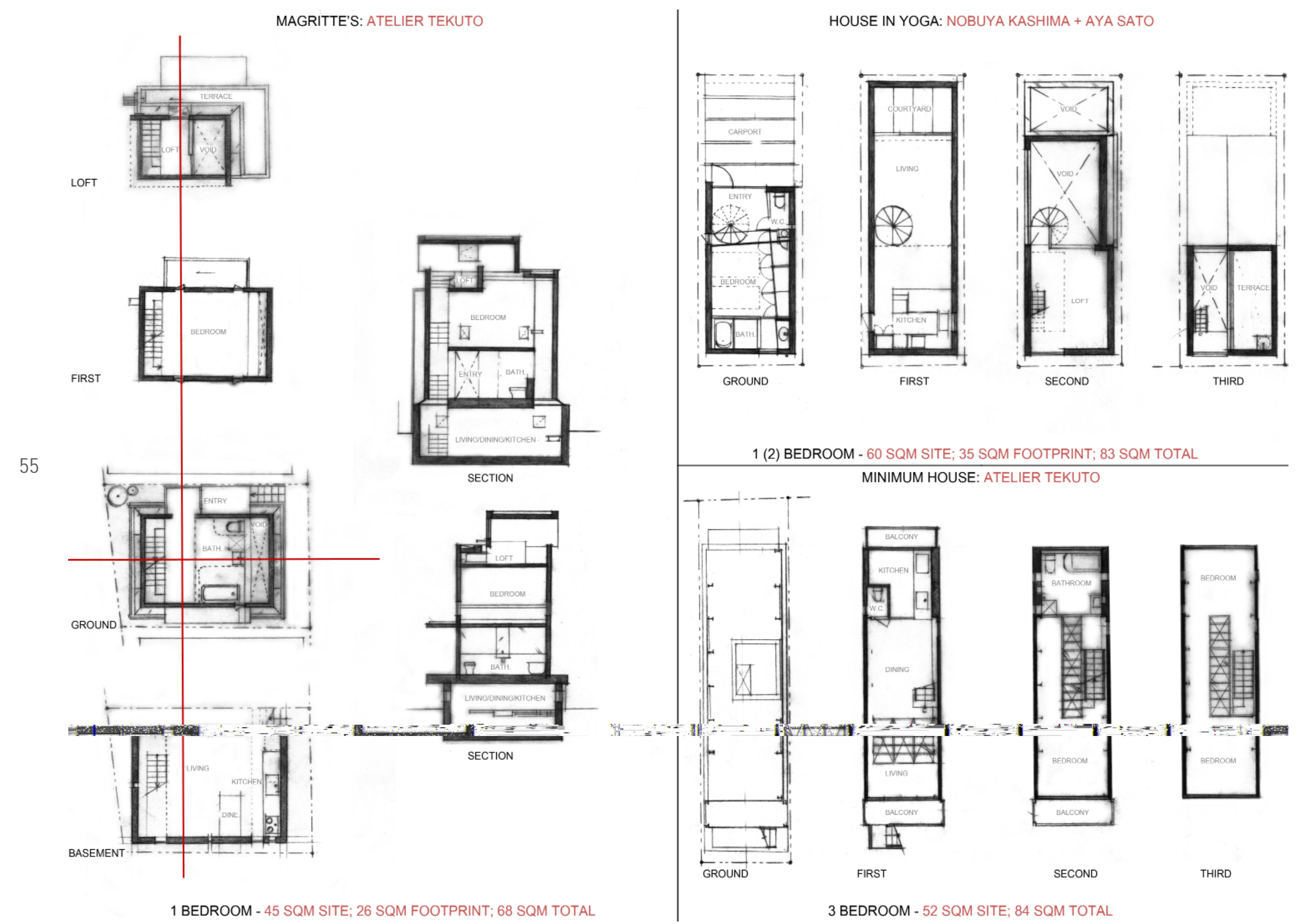



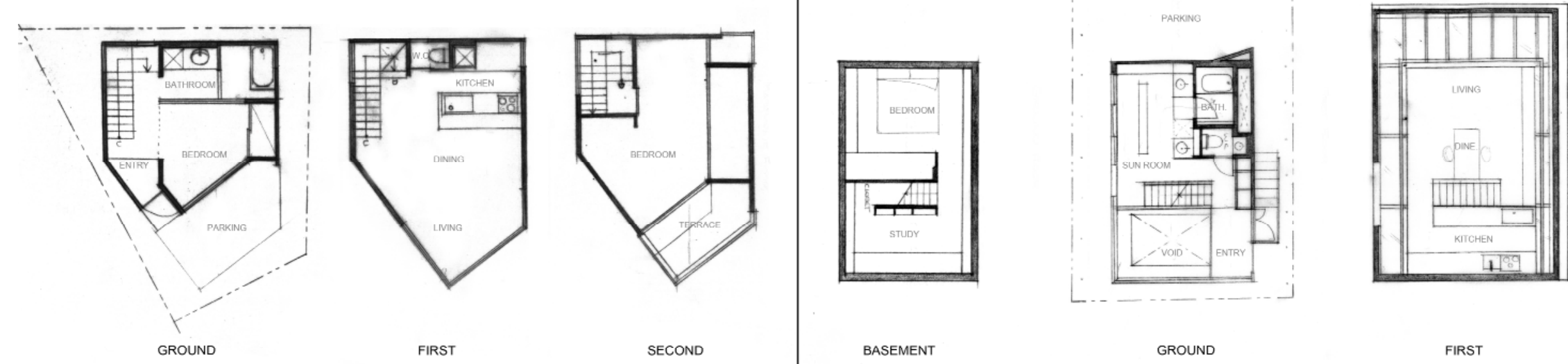

2 BEDROOM - 57 SQM SITE; 83 SQM TOTAL

BASEMENT

GROUND

FIRST

1 BEDROOM - 71 SQM SITE; 37 SQM FOOTPRINT; 89 SQM TOTAL HOUSE AND ATILEIER BOW-WOW: ATELIER BOW-WOW

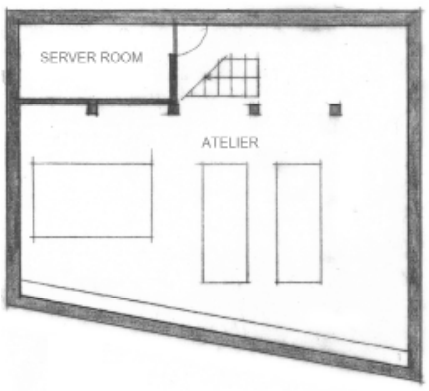

BASEMENT

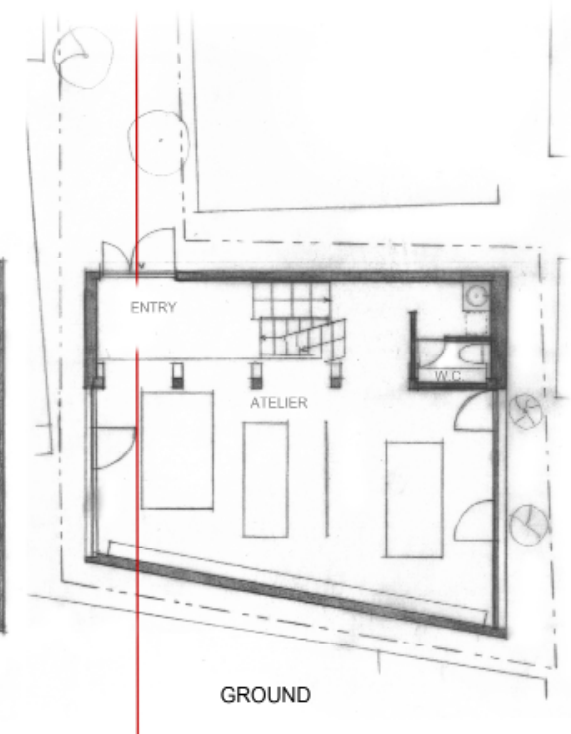

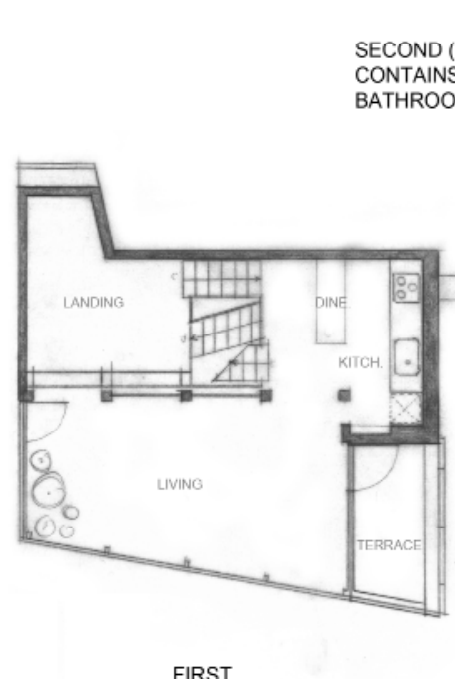

FIRST
ECOND (PLAN MISSING -

COTHROOM

1 BEDROOM - 109 SQM SITE; 61 SQM FOOTPRINT: 211 SQM TOTAL

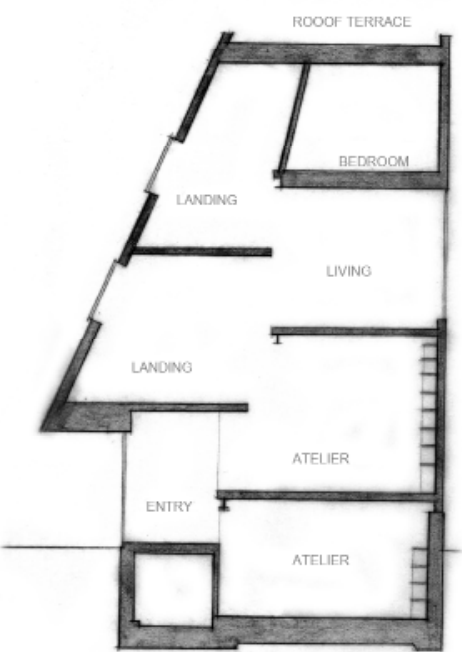

SECTION 


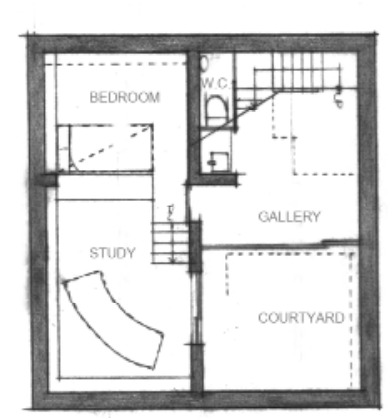

BASEMENT

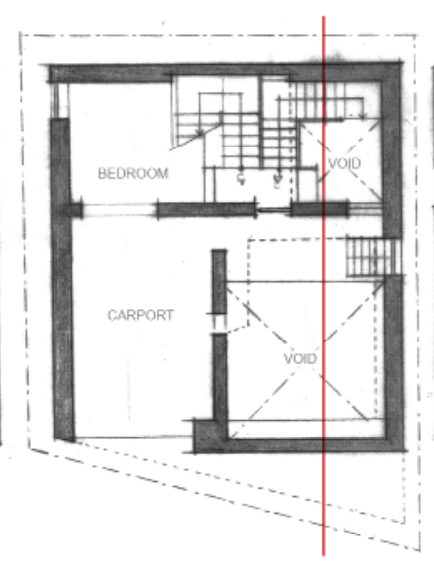

GROUND

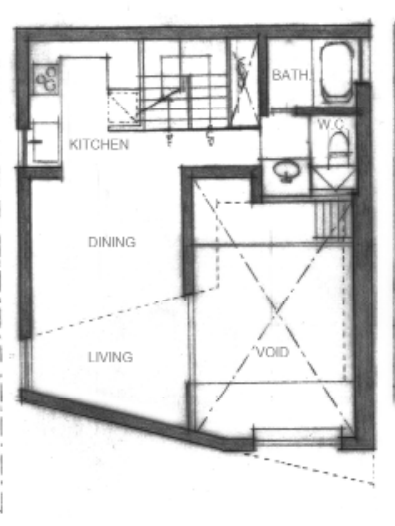

FIRST

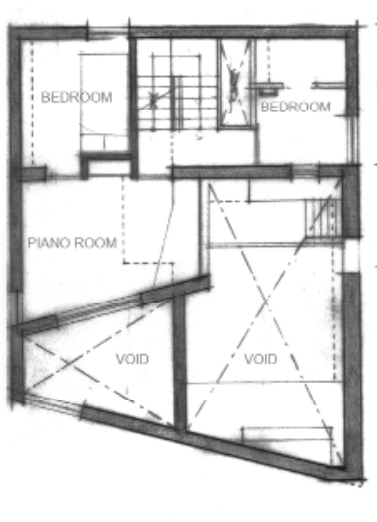

SECOND

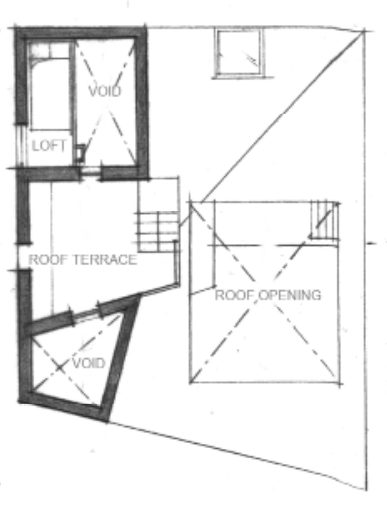

THIRD

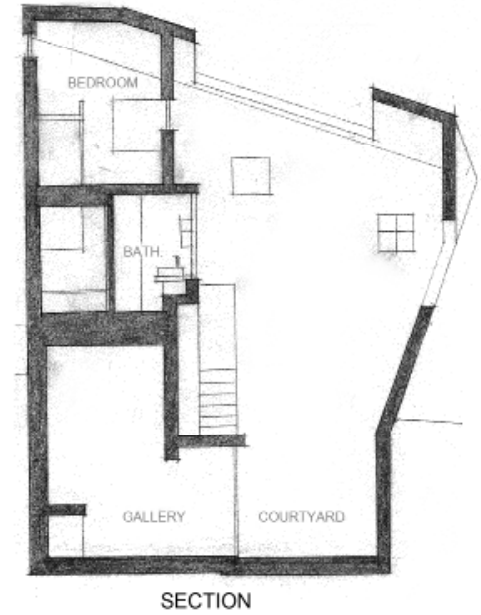

SECTION
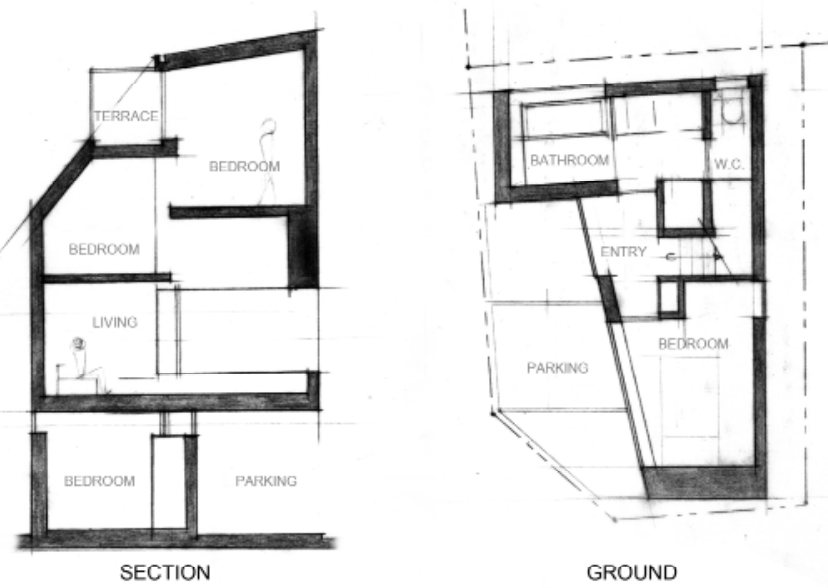

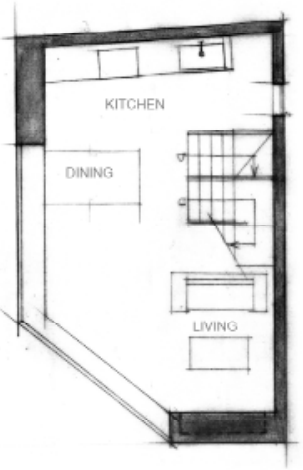

FIRST

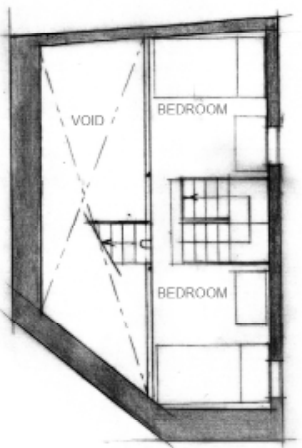

SECOND

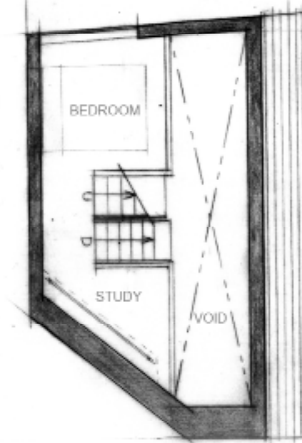

THIRD

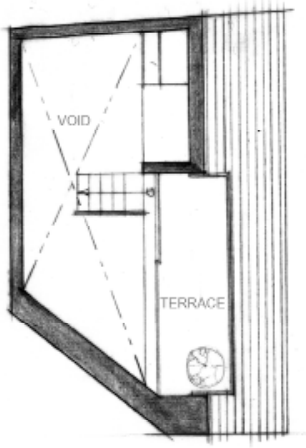

ROOF TERRACE 


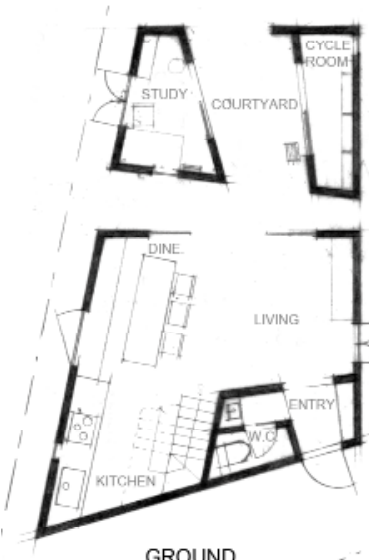

GROUND

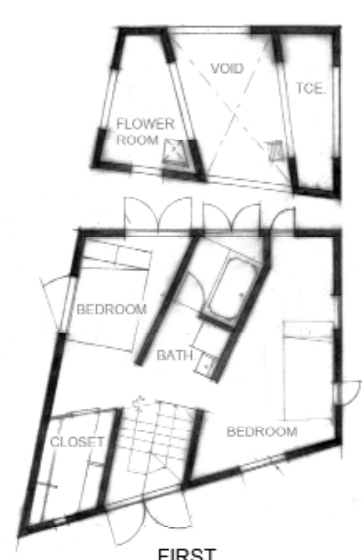

FIRST
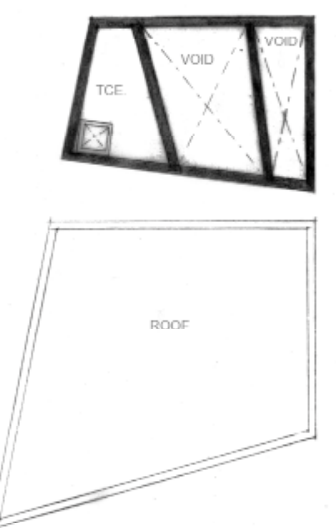

SECOND

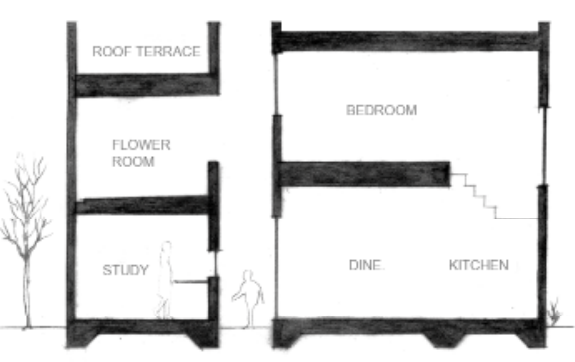

SECTION

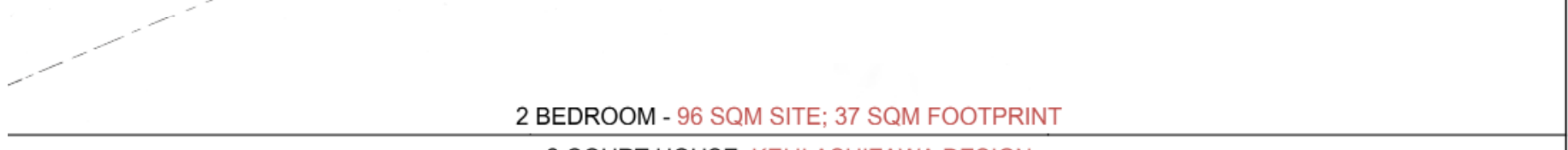
2 COURT HOUSE: KEIJIASHIZAWA DESIGN
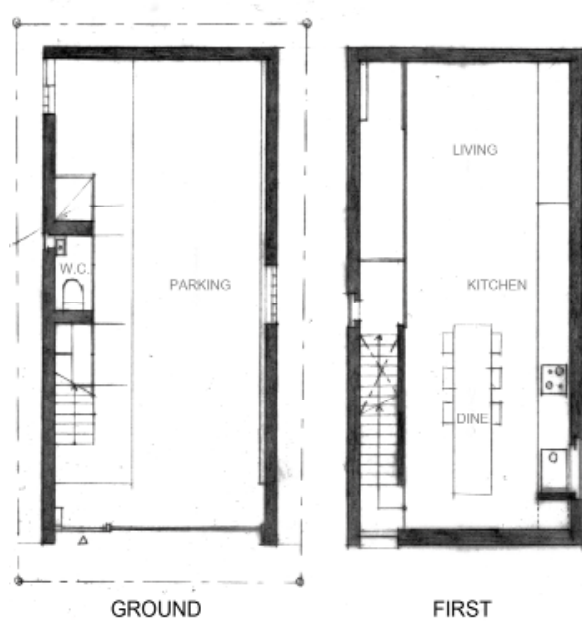

FIRST
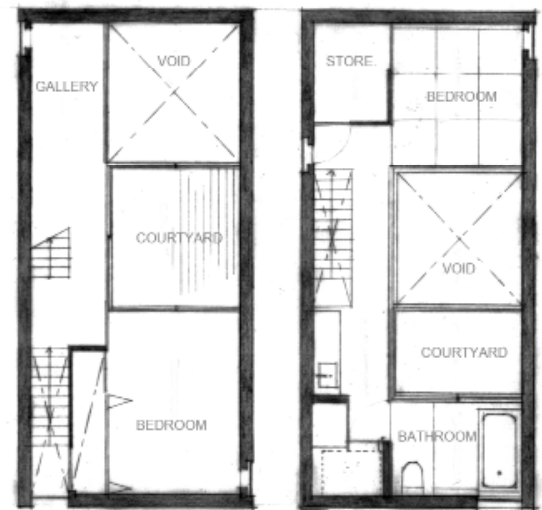

SECOND

THIRD

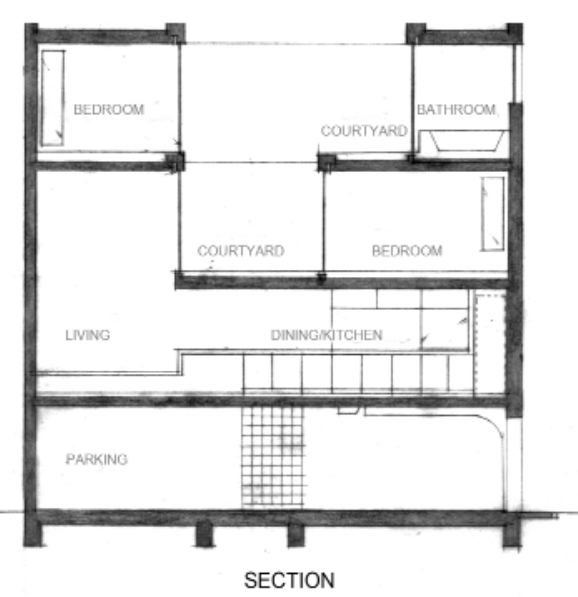

2 BEDROOM - 87 SQM SITE; 85 SQM TOTAL
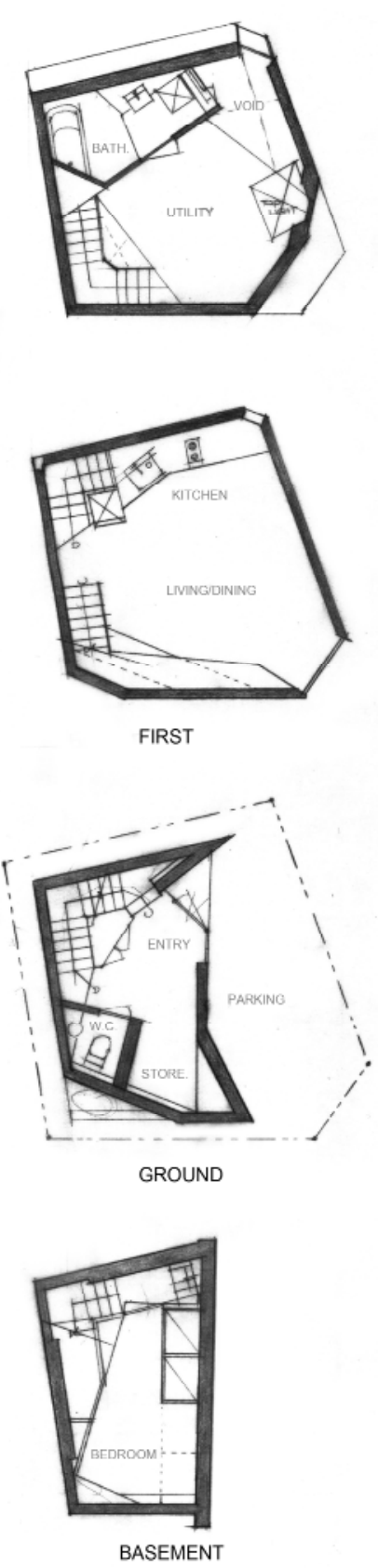

1 BEDROOM - 44 SQM SITE; 86 SQM TOTAL 


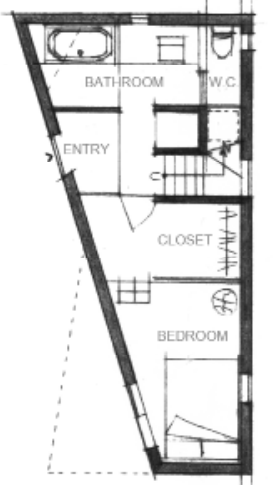

GROUND

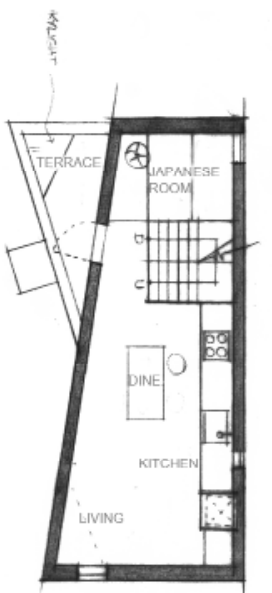

FIRST

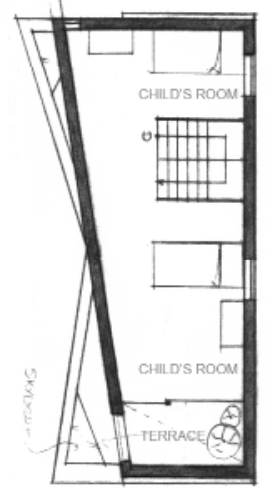

SECOND
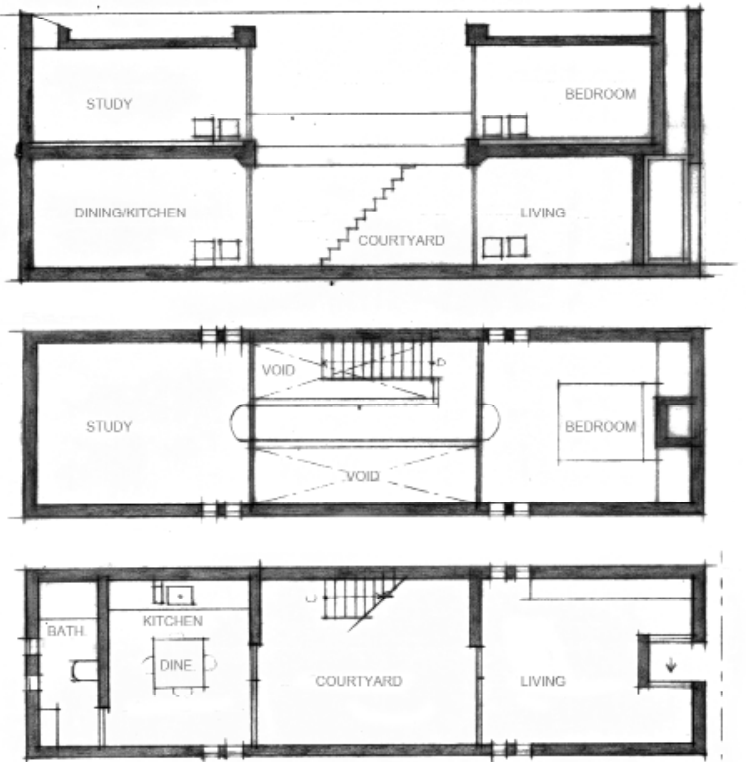

1 BEDROOM - 57 SQM SITE; 34 SQM FOOTPRINT; 65 SQM TOTAL NEAR HOUSE: MOUNT FUJI ARCHITECT STUDIO
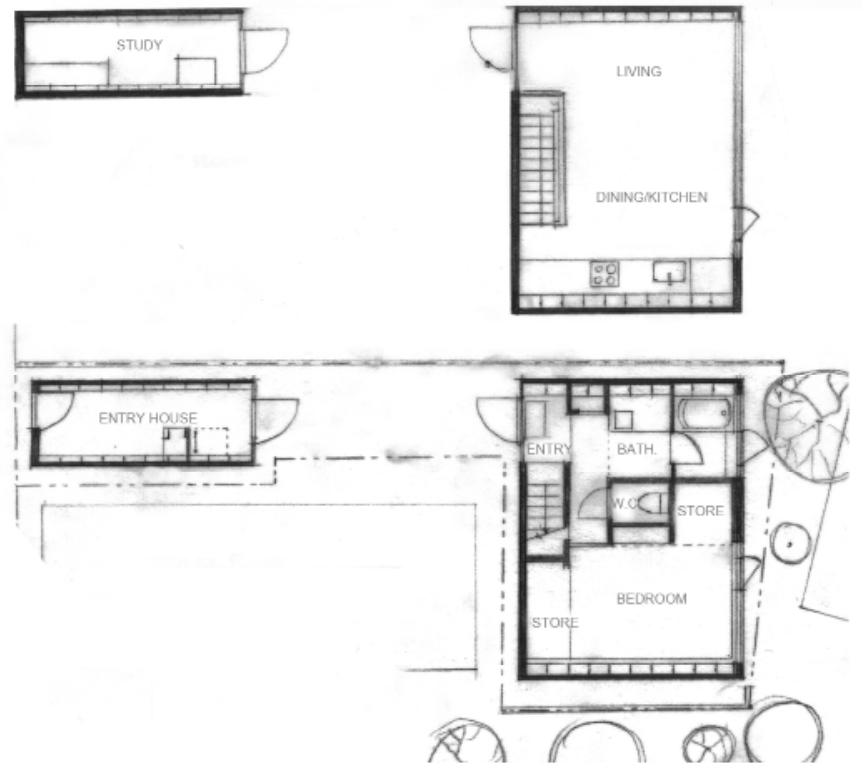

1 BEDROOM - 66 SQM SITE; 75 SQM TOTAL

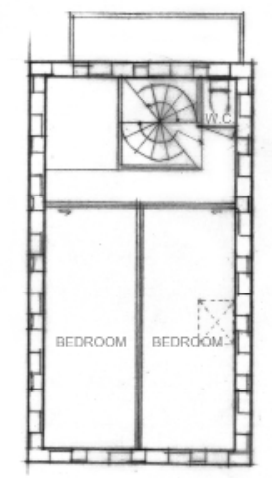




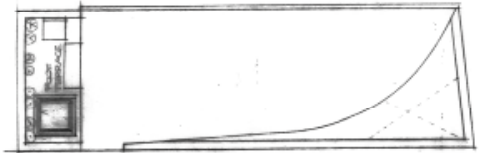

ROOF

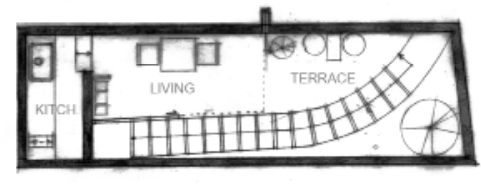

FIRST

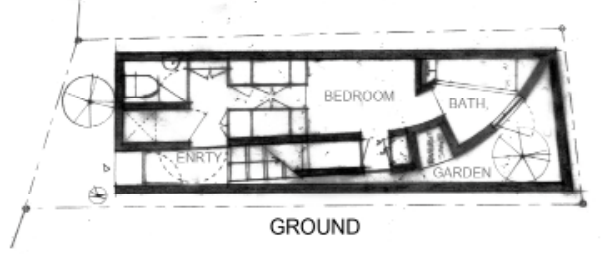

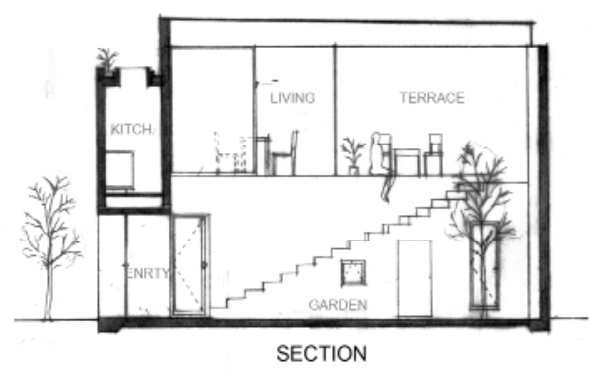

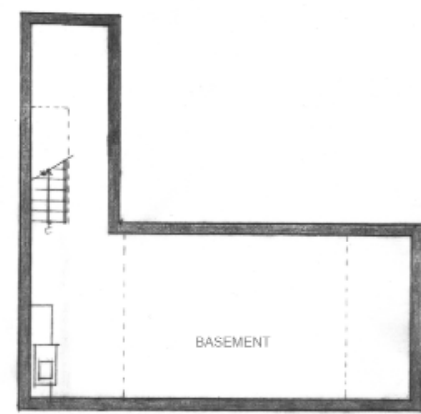

BASEMENT

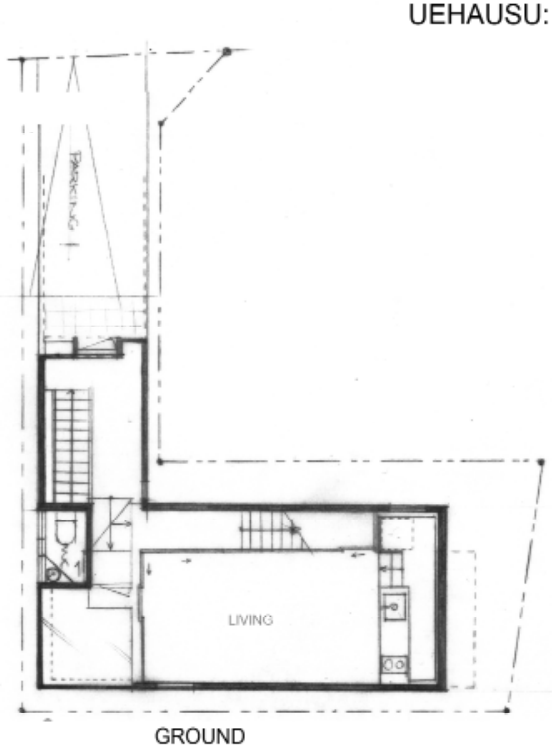

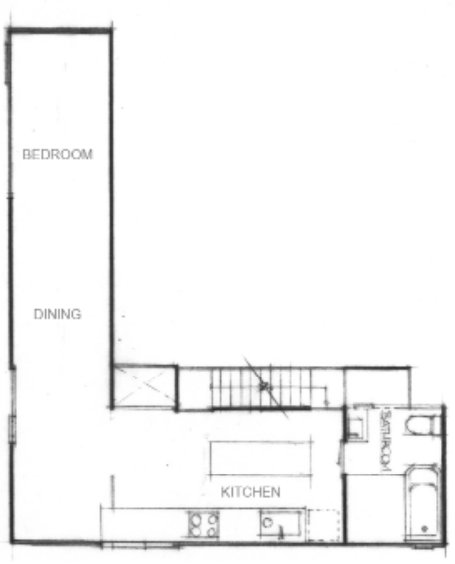

FIRST

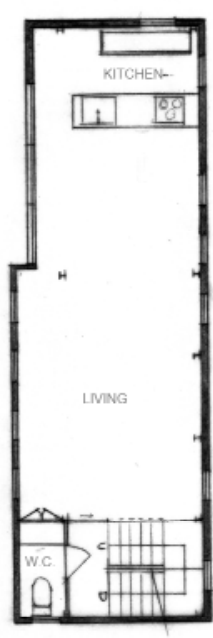

FIRST

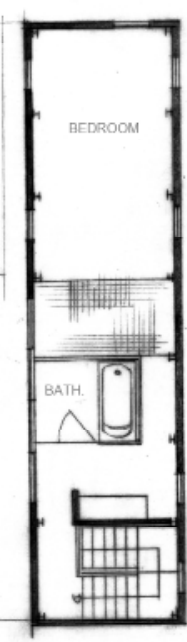

SECOND

1 BEDROOM - 62 SQM SITE; 102 SQM TOTAL

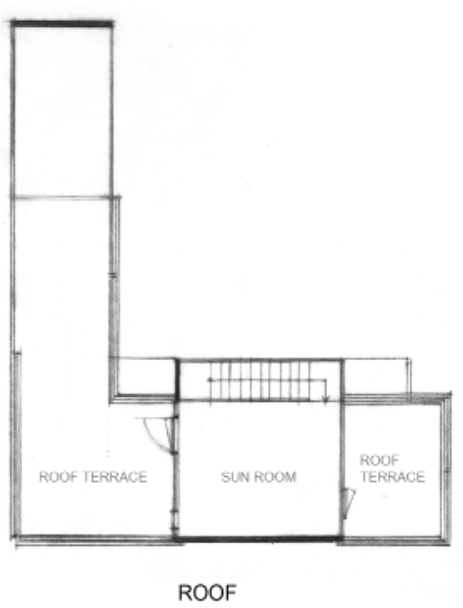


LUCKY DROPS: ATELIER TEKUTO

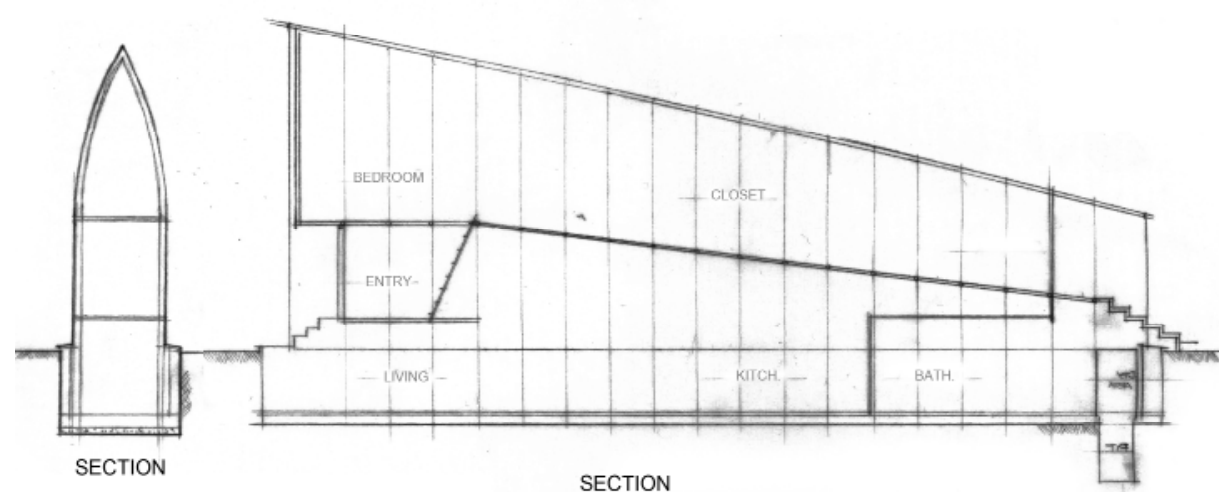

61

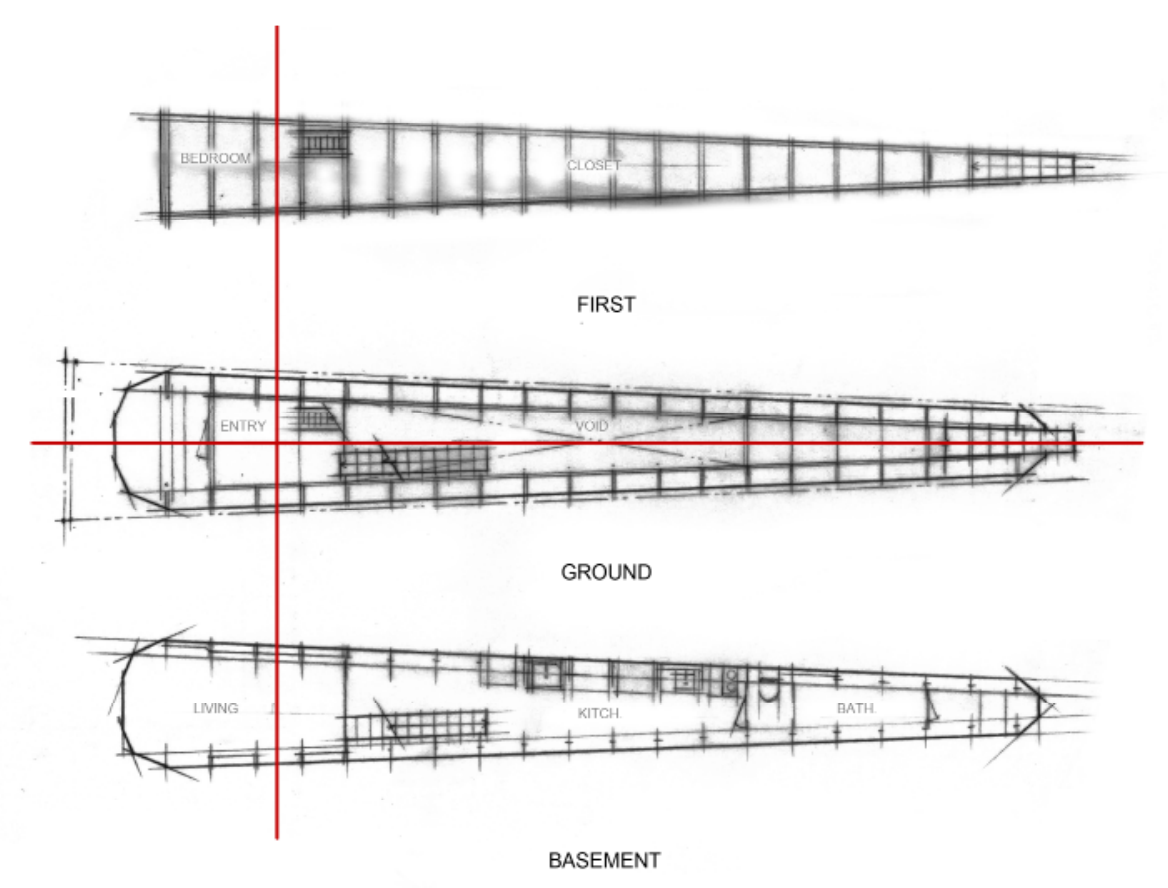

1 BEDROOM - 58 SQM SITE; 61 SQM TOTAL

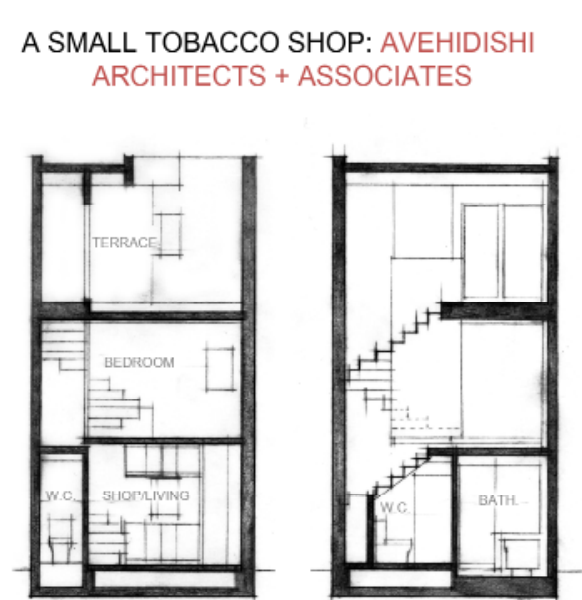

SECTION
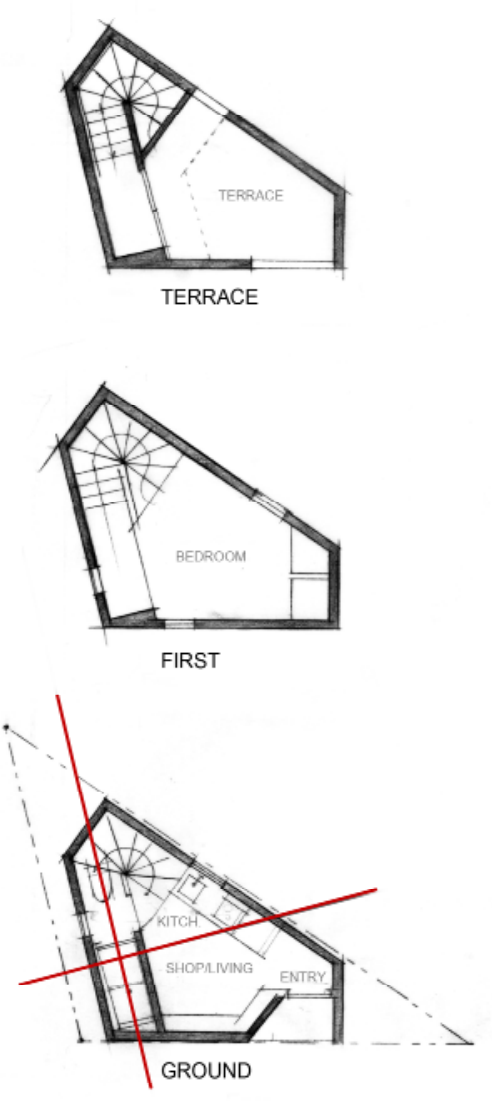

1 BEDROOM - 24 SQM SITE; 37 SQM TOTAL 1 (2) BEDROOM - 77 SQM SITE; 90 SQM TOTAL

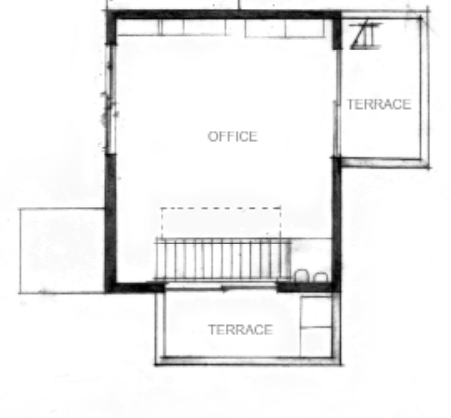

SECOND

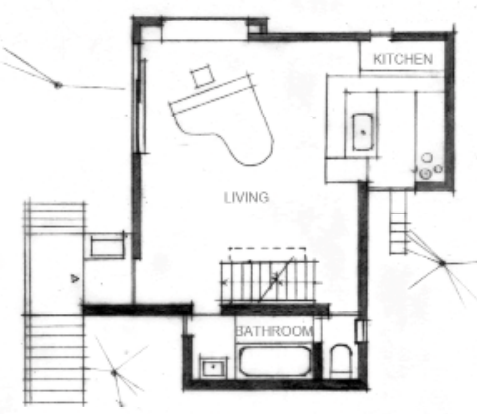

FIRST

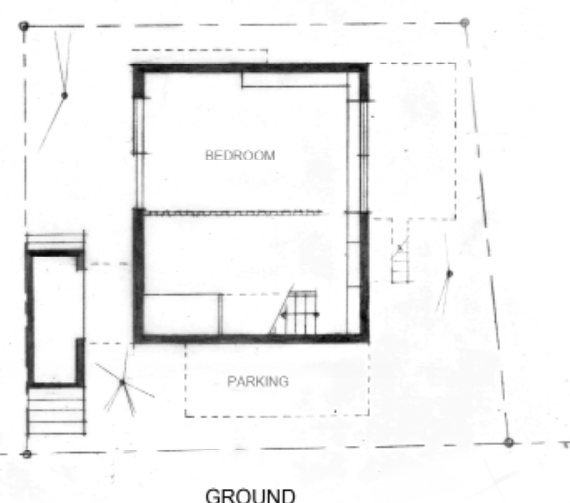

GROUND 

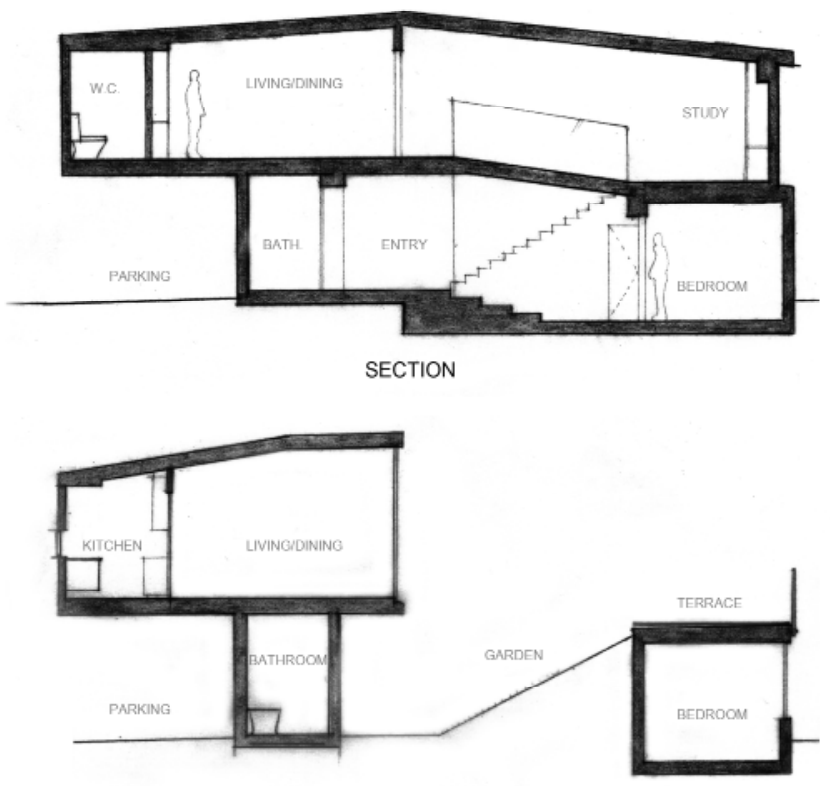

SECTION
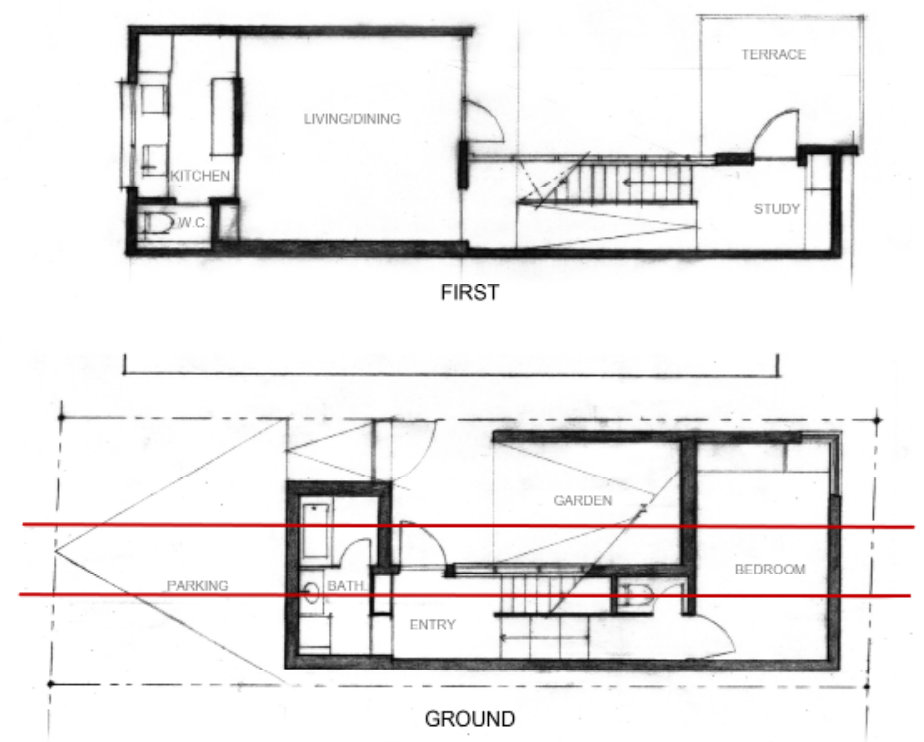

1 BEDROOM - 94 SQM SITE; 80 SQM TOTAL

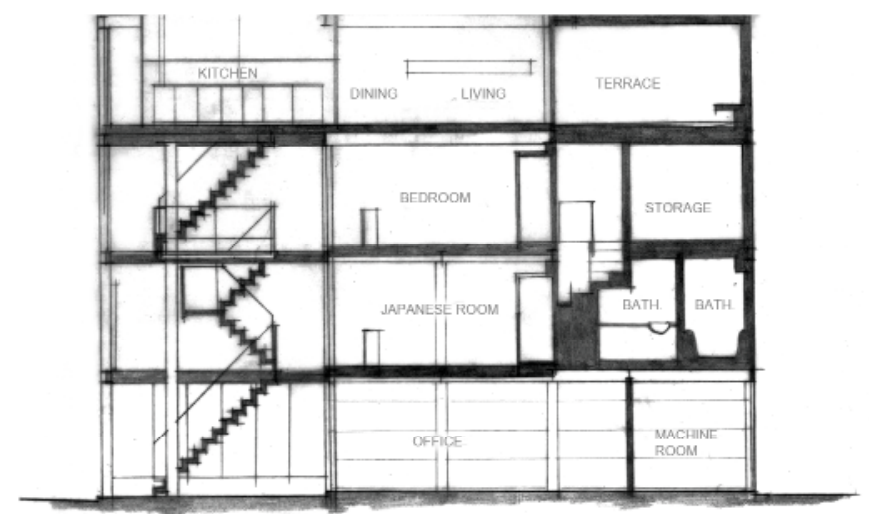

SECTION
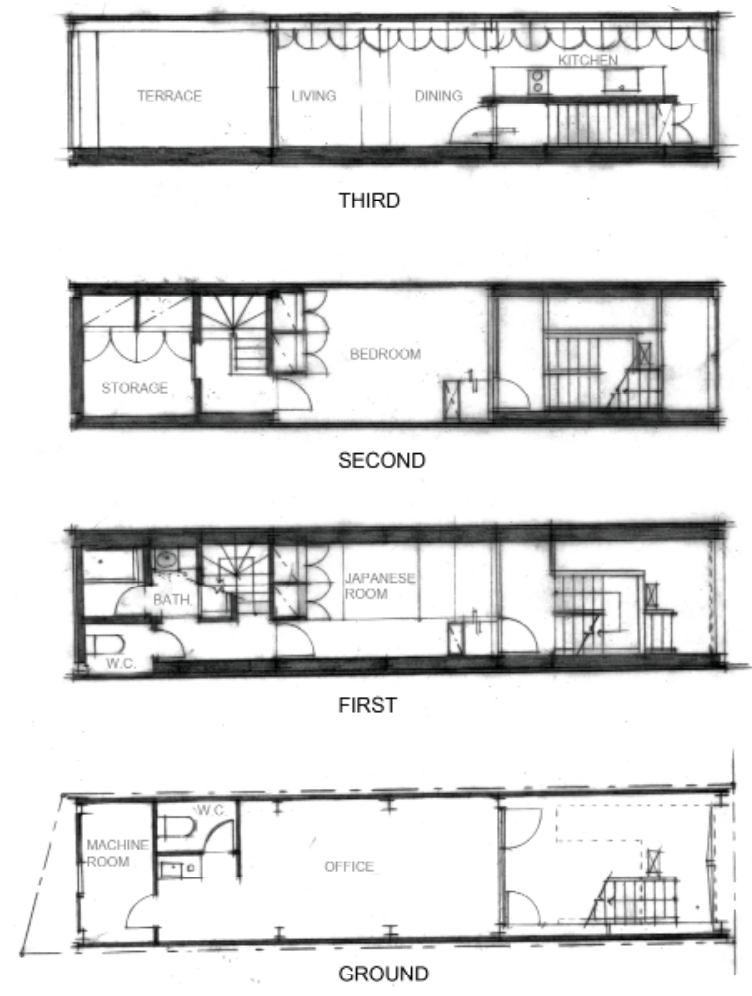

1 BEDROOM - 43 SQM SITE; 113 SQM TOTAL 

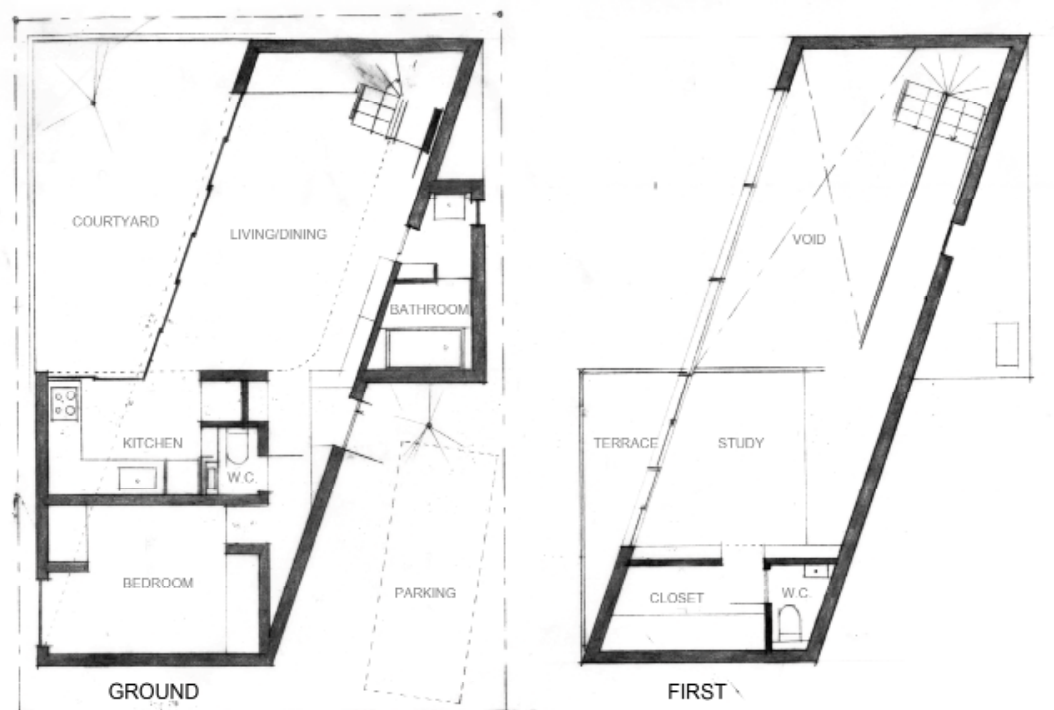

1 BEDROOM - 53 SQM FOOTPRINT; 80 SQM TOTAL

63 SMALL HOUSE WITH BIG SPIRAL STAIRCASE: AVEHIDESHI ARCHITECTS
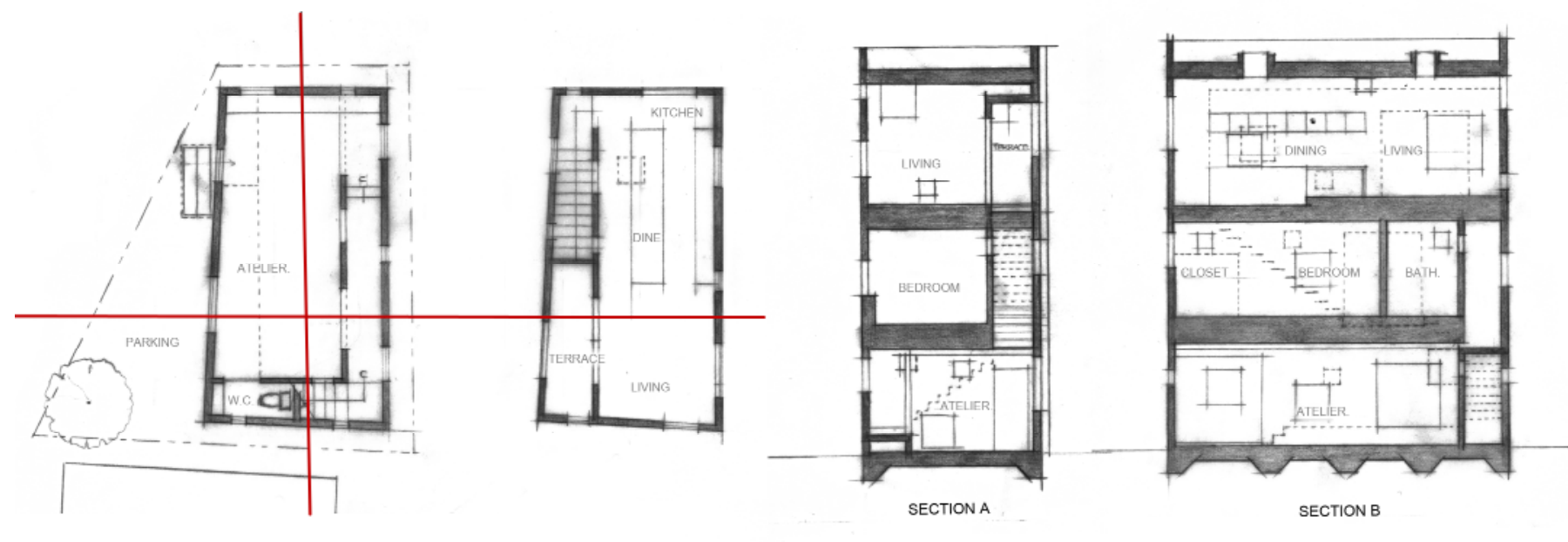

GROUND

FIRST (PLAN MISSING) SECOND

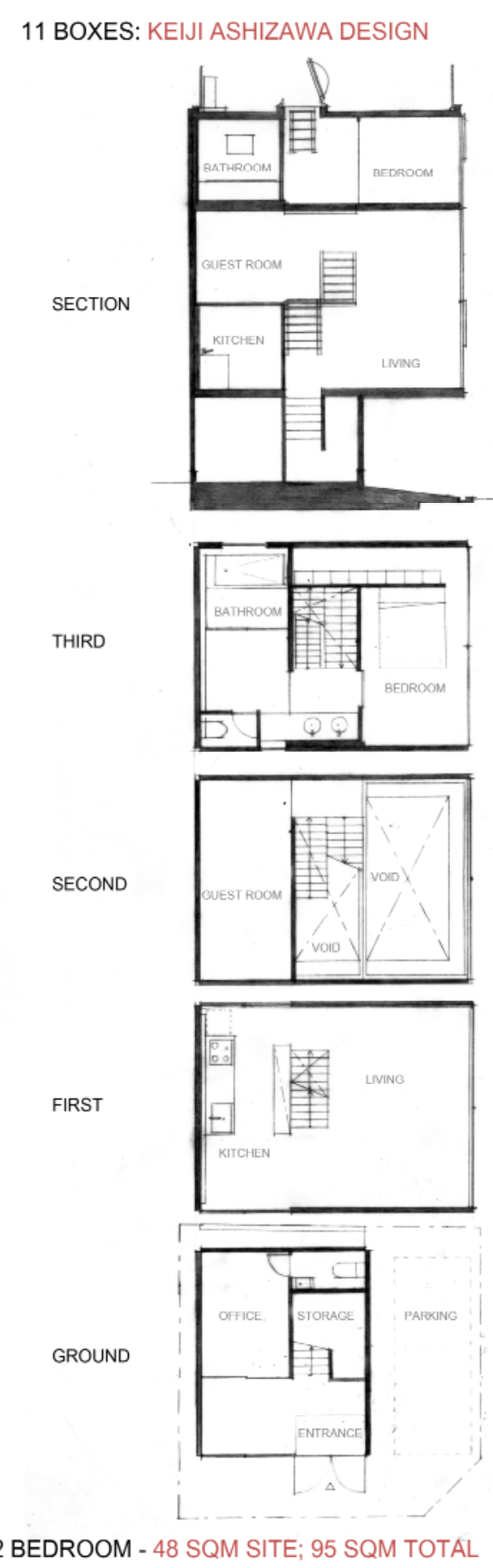




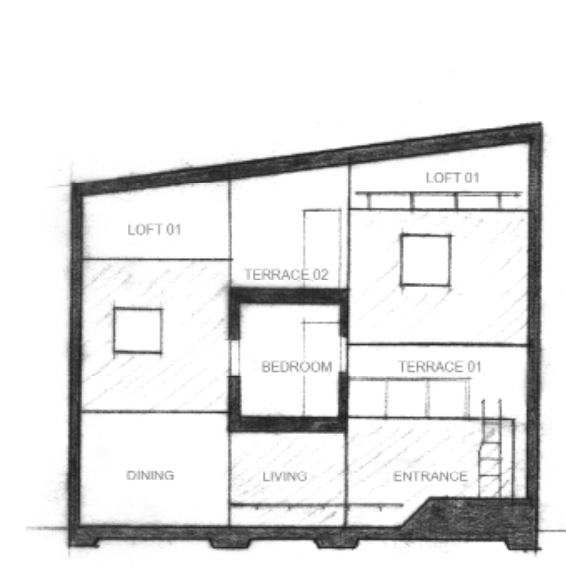

SECTION

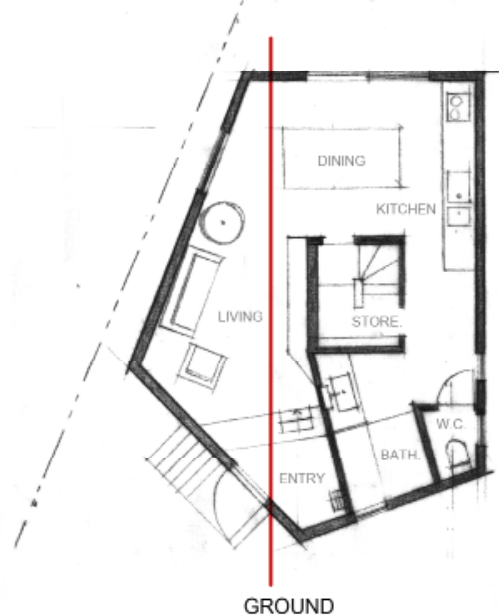

GROUND

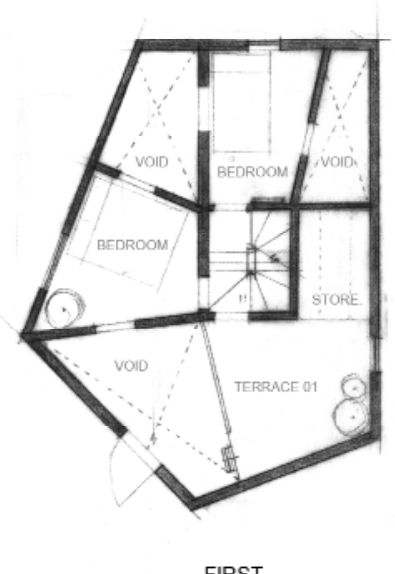

FIRST

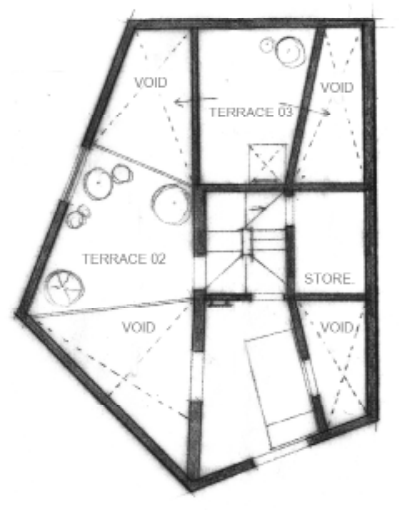

SECOND

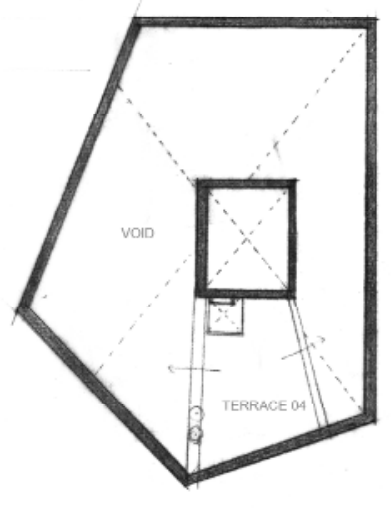

LOFT

3 BEDROOM - 50 SQM FOOTPRINT; 114 SQM TOTAL
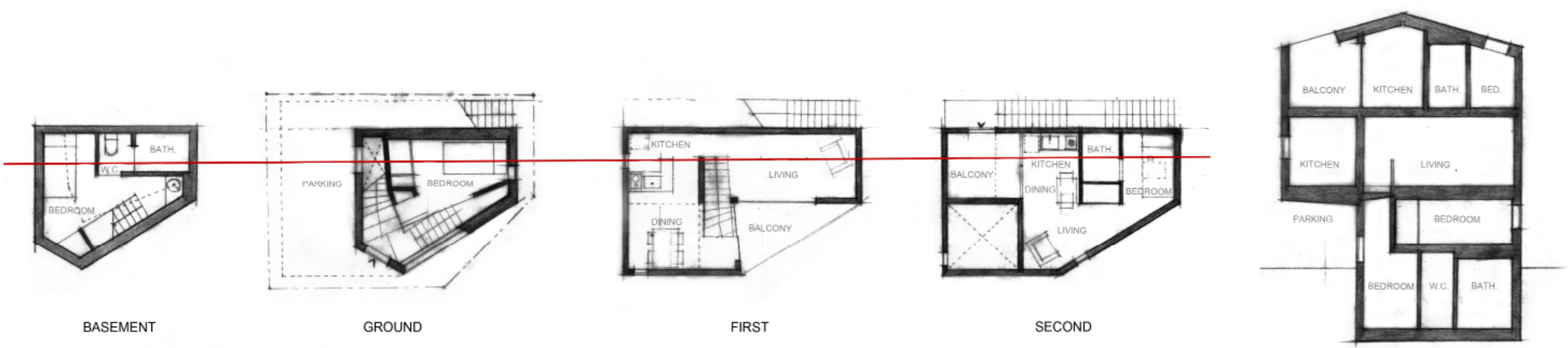

SECTION 
Micro-Living: learning to live large in small spaces

HA HOUSE: YOKOHAMA ARCHITECTS
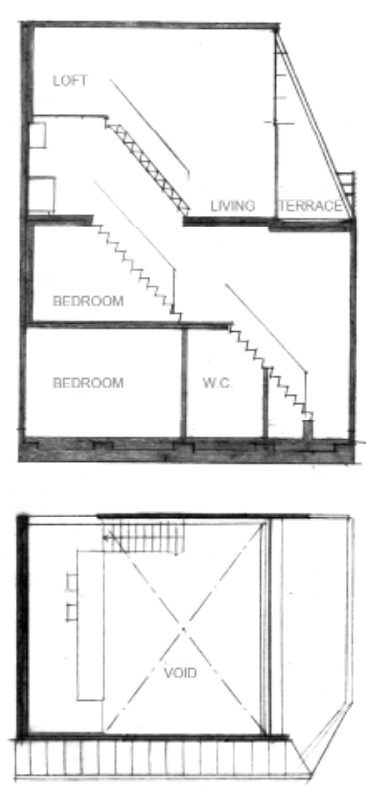

65
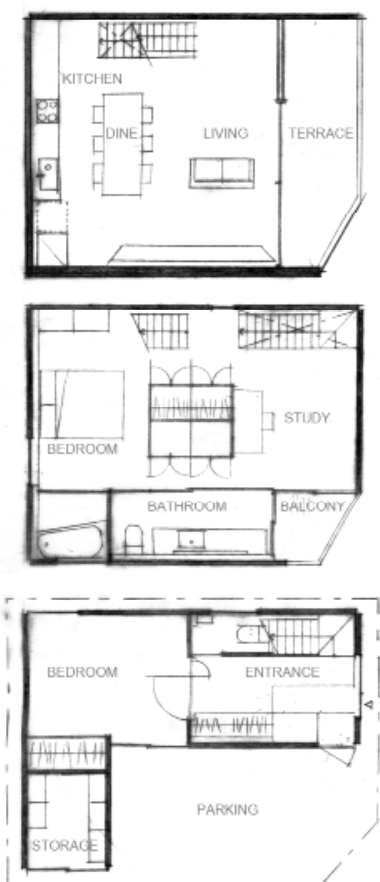

GROUND

2 BEDROOM - 90 SQM TOTAL
WEAR HOUSE: AUAU
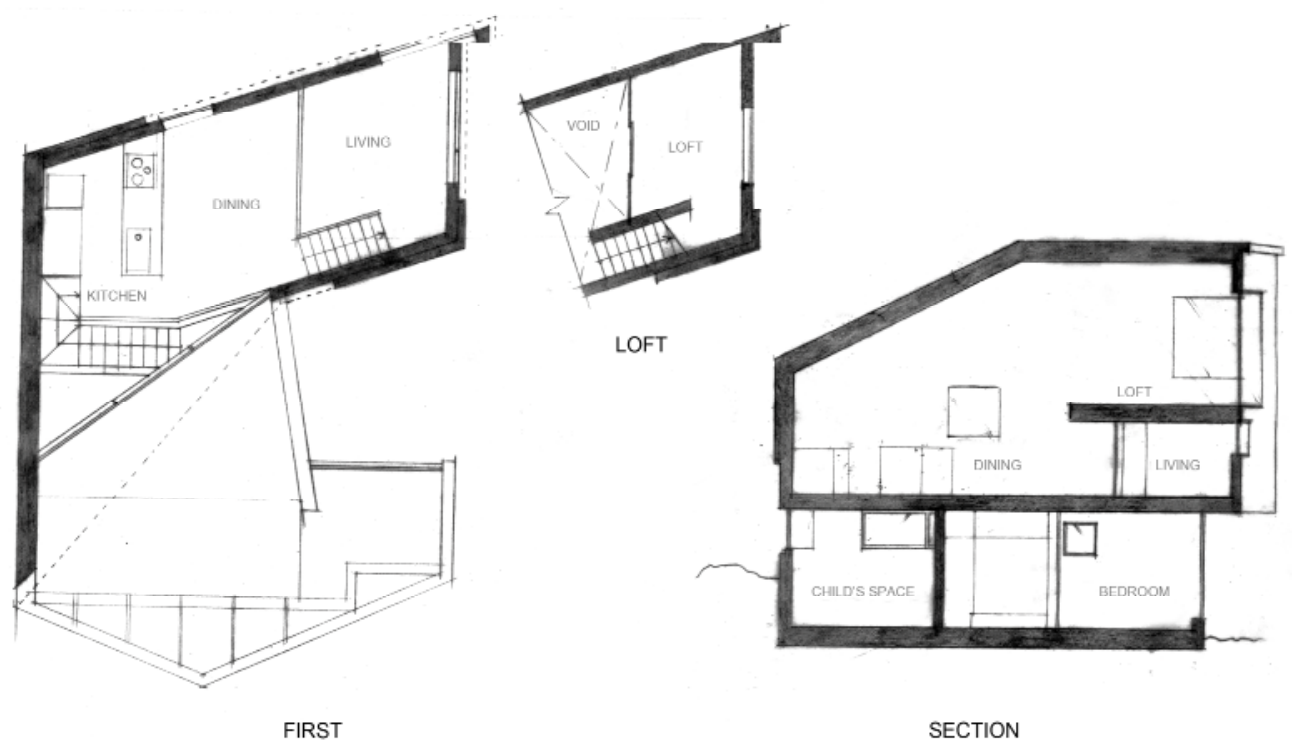

SECTION

2 BEDROOM - 67 SQM FOOTPRINT; 92 SQM TOTAL

GARDEN HOUSE: TAKESHI HOSAKA ARCHITECTS
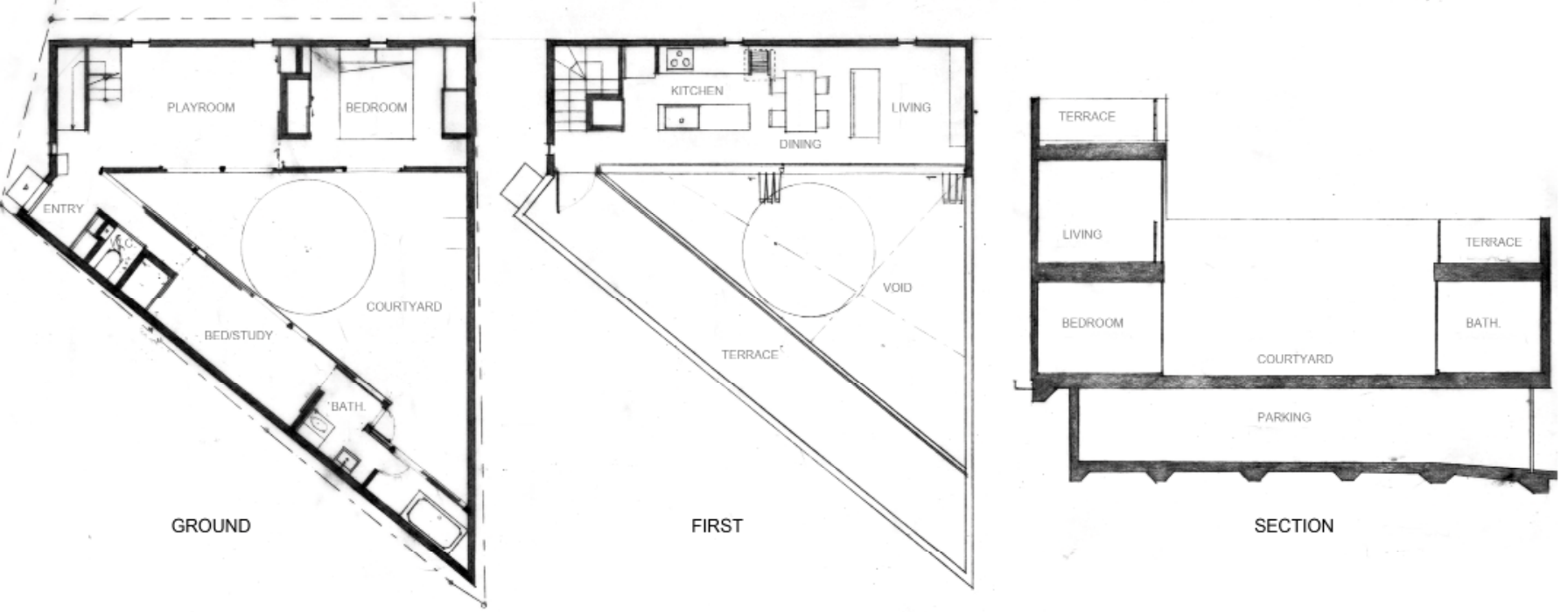

2 BEDROOM - 98 SQM SITE; 114 SQM TOTAL 
From this material, recurring themes, relationships and strategies within the architecture were singled out. Some of the key relationships involved are, for instance, the ratio between total floor area and void space, site area, allocated outdoor space and circulation space, and the relationships between different spaces within a dwelling.

\subsection{1 - Analysis of Japanese Micro-Architecture:}

This section will highlight some of the areas of analysis, but due to the large number of buildings analysed, only a small sample of examples are represented in detail.

Noteworthy are some of the key square metre figures, they give insight into the compactness of the buildings and their sites. The average total floor area of the precedents is 90 square meters with a range from 37 to 211 sqm; this includes dwellings with one to four bedrooms. The footprints of these dwellings has an average of $36 \mathrm{sqm}$, ranging from 15 to $67 \mathrm{sqm}$. An average site area of the precedents is approximately $67 \mathrm{sqm}$ ranging from 24 to $186 \mathrm{sqm}$. Despite these small areas, outdoor space is still given a high priority, out of the forty examples, 67 percent had at least one dedicated outdoor area whether it be a balcony, roof terrace, garden, courtyard or a combination of these (though it must be noted that some are of a more significant size than others). The average number of allocated outdoor spaces per analyzed dwelling is 1.5 , quite an achievement considering the obvious constraints. 


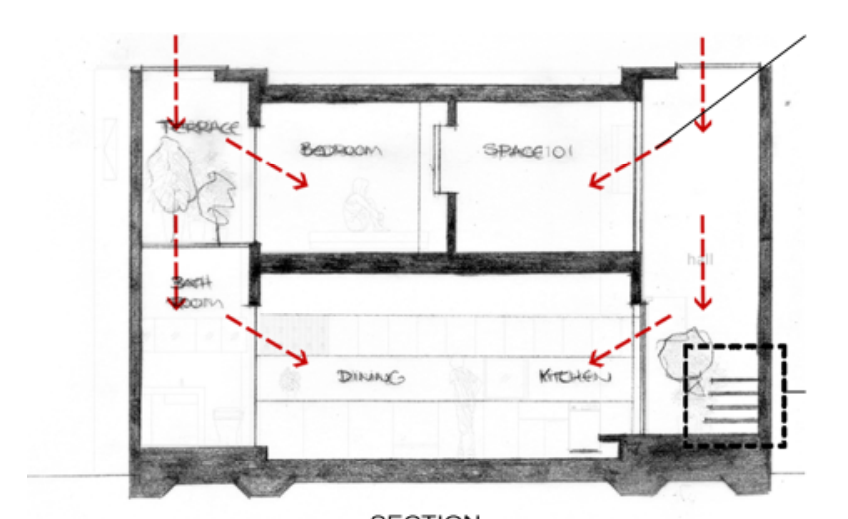

SECTION

67

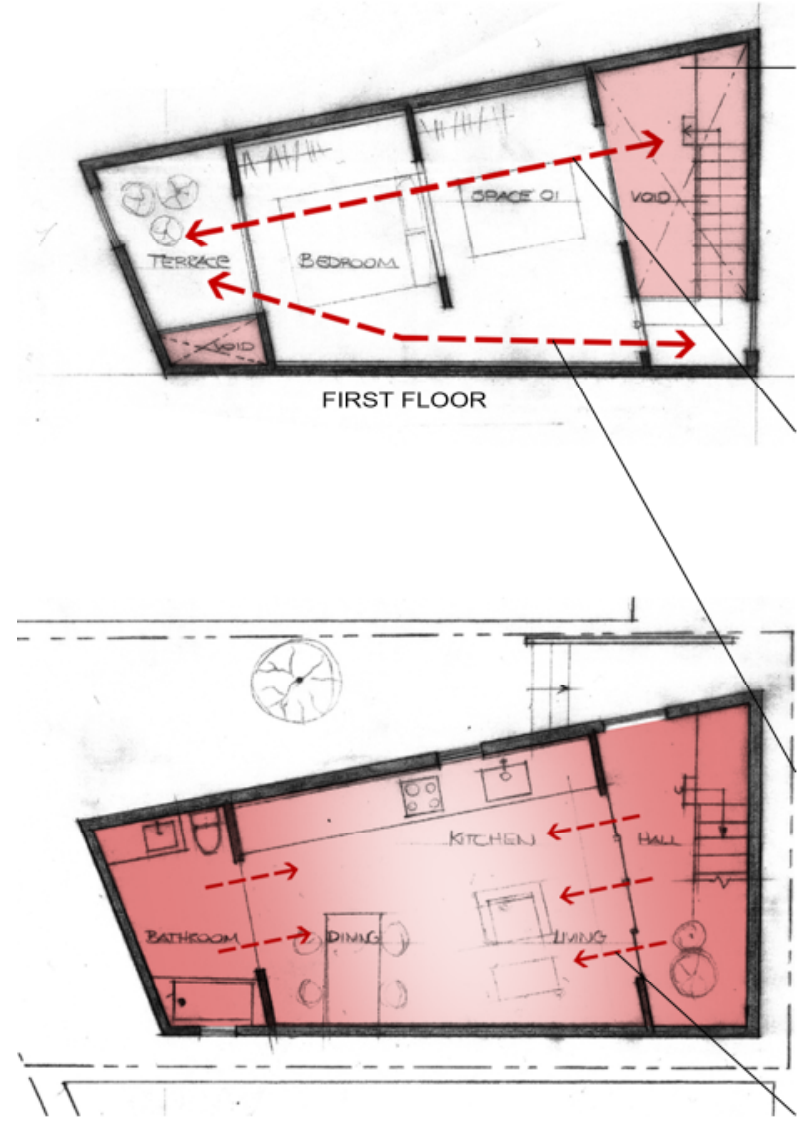

GROUND FLOOR
TOP LIT SPACES, DESIGNED TO FEEL LIKE OUTDOOR ROOMS SUPPLY THE ADJACENT INTERIOR ROOMS WITH DAYLIGHT.

OPEN RISERS AND SLIM PROFILE TREADS MINIMISES THE STAIRCASE'S VISUAL IMPACT ON THE SPACE

VOID SPACE CREATES EXPANSIVE ATMOSPHHERE AND ALLOWS UIGHT TO PENETRATE TO LEVEL BELOW

SIGHTLINES MAINTAINED THROUGHOUT INTERIOR FROM 'EXTERNAL SPACE' AT ONE END TO THE ONE AT OPPOSING END.

INTEGRATED CIRCULATION THROUGH PRECEDING SPACES.

SINGULAR, OPEN INTERIOR SPACE ALLOWS NATURAL LIGHT FROM END SPACES TO PERMEATE FURTHER INTO THE INTERIOR.

\section{House in Hiro: Suppose Design Office}

Site size: $78 \mathrm{sqm}$

Floor size: $66 \mathrm{sqm}$

No. of Bedrooms: 1 (space 1 can also be used as 2 nd temporary bedroom)

This introverted home, located on a busy commercial street, creates privacy by internalising its outlook. At each end of the dwelling are top lit spaces that are designed to create the effect of an outdoor area. Raw, natural material treatments enhance this idea. The double height spaces pull light in from above to supply the adjacent interior rooms with daylight. Because the interior is only two rooms deep, each space is successfully lit through this method. On the first floor, efficient use of space is created through the virtual elimination of dedicated horizontal circulation. Entry to the western-most spaces is through the progression of spaces to the east.

Fig. 4.13 Analytical observations of House in Hiro by Suppose Design Office. Not to scale. 


\section{Magritte's: Atelier Tekuto}

\section{Site size: $45 \mathrm{sqm}$}

Floor size: $68 \mathrm{sqm}$

No. of Bedrooms: 1

Top-lighting features heavily in this precast concrete dwelling. Split into two main volumes, one sunken into the ground, the other seemingly floating above. The latter is set back from the basement level to allow for skylights around the perimeter of the basement. This strategy adds privacy to living spaces below while introducing natural daylight and views to the sky. This is supplemented by 'borrowed' light form the floors above where the voids filter light through the levels. Fitting each function of the building program into the tight constraints of the $45 \mathrm{sqm}$ site has led to the architect allocating a specific function for each floor. The basement floor contains the living spaces (living, dining and kitchen), the raised ground floor has the bathroom and the first floor features the sleeping quarters. Above the bedroom is the loft area which gives access to the compact outdoor space. All of these levels are connected via an efficiently designed stairwell pressed up against the boundary wall.

Fig. 4.14 Analytical observations of Magritte's by Atelier Tekuto. Not to scale.

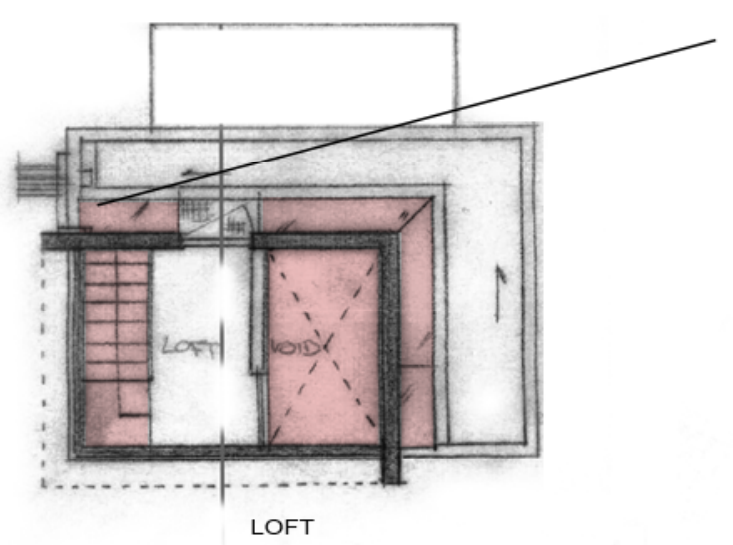

SKYLIGHTS, VOIDS AND STAIRWEEL HELP LIGHT FROM ABOVE FILTER DOWN TO THE LOWER LEVELS.
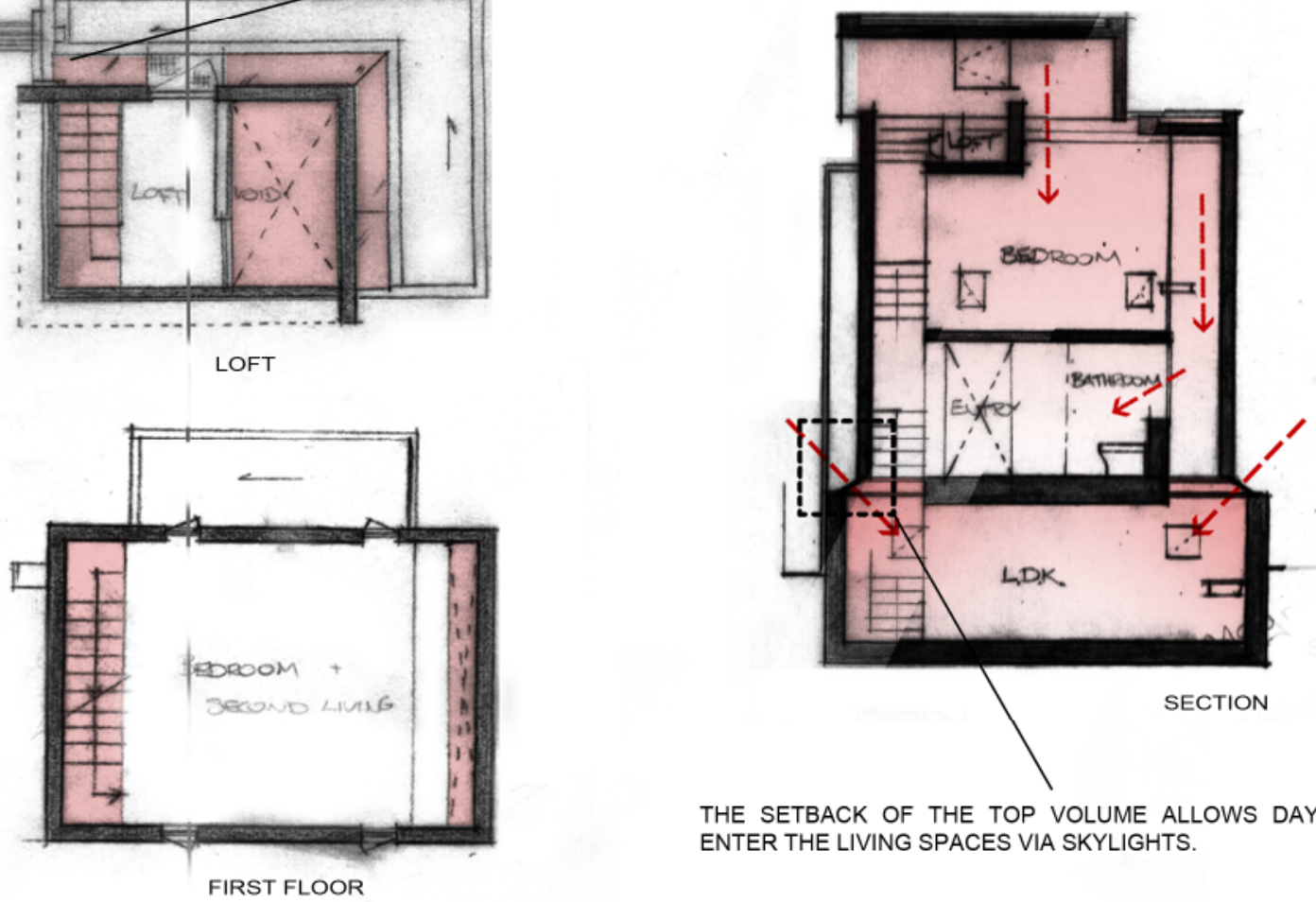

THE SETBACK OF THE TOP VOLUME ALLOWS DAYLIGHT TO ENTER THE LIVING SPACES VIA SKYLIGHTS.

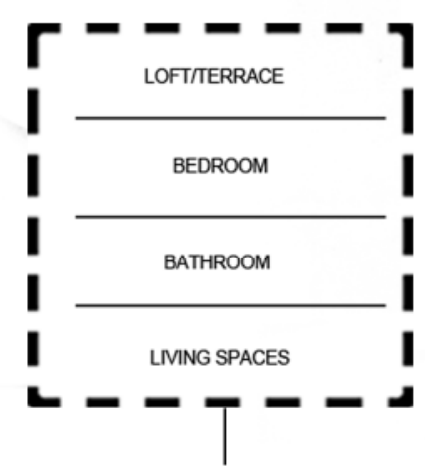

EACH FLOOR CONTAINS A DIFFERENT FUNCTION. THE PROGRAMME IS REQUIRED TO BE STACKED IN THIS WAY DUE TO THE CONSTRAINTS OF THE SMALL SITE.

THE BATHROOM 'BORROWS' DIFFUSE LIGHT FROM THE LIGHTWELL VIA THE GLAZED PARTION GROUND FLOOR (BASEMENT NOT SHOWN)

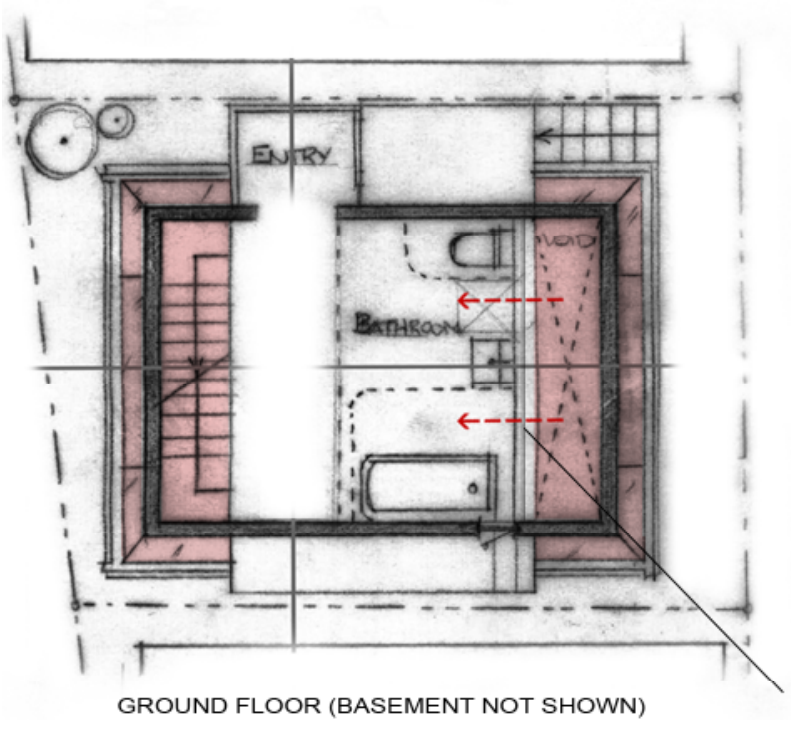




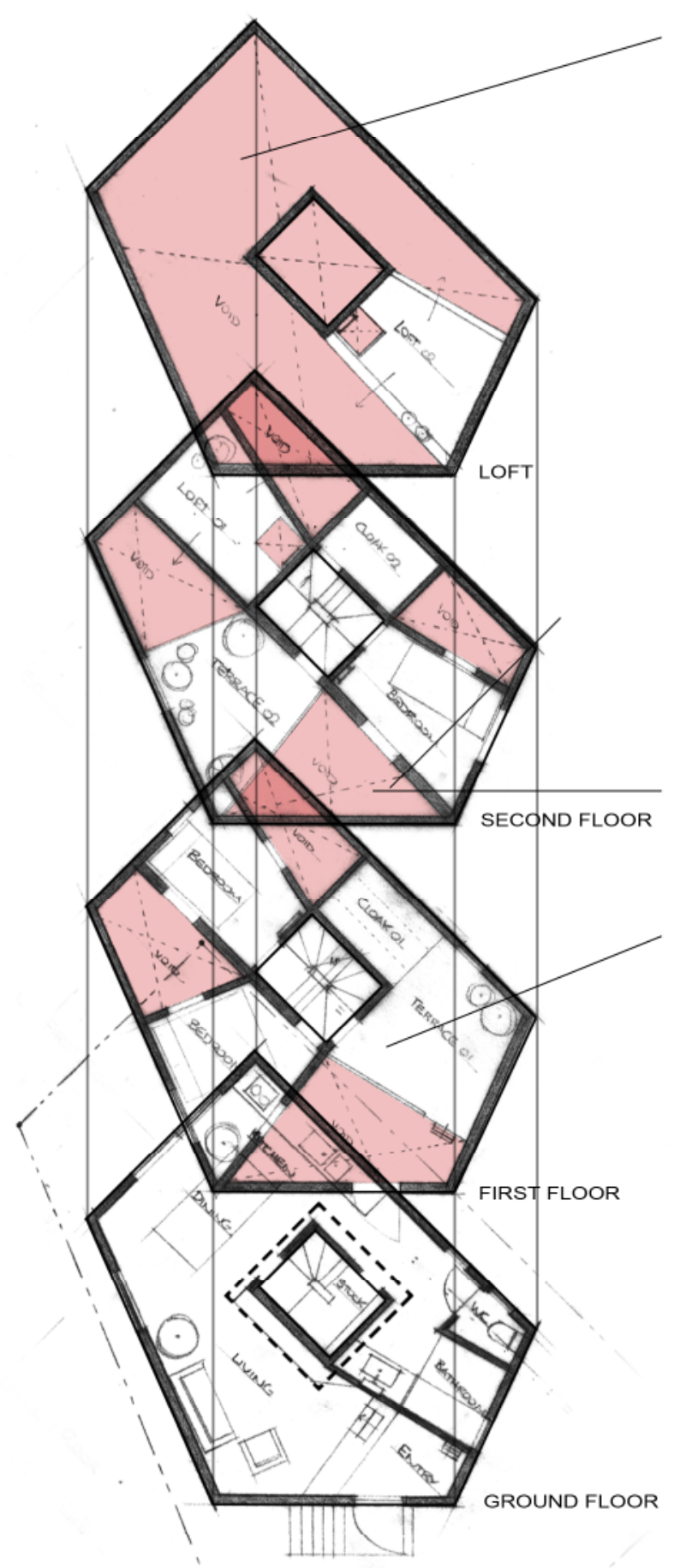

VOID SPACE PLAYS WITH THE SENSE OF SCALE AND CREATES AN INTERIOR WHICH FEELS EXPANSAIVE BEYOND ITS DIMENSIONS

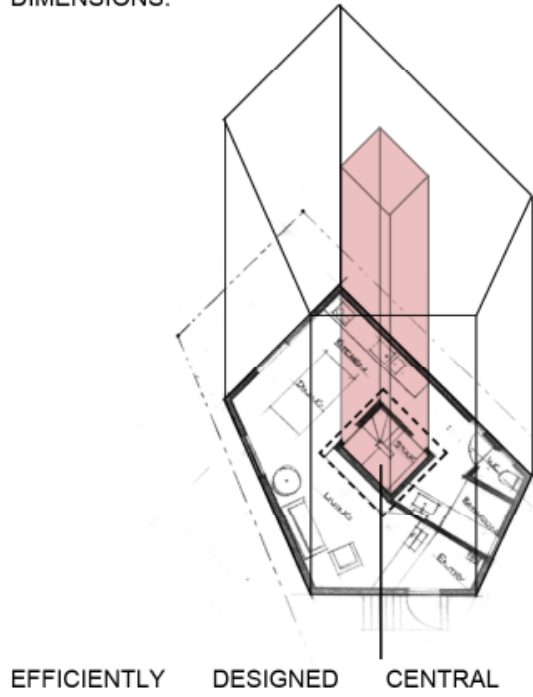

CIRCULATION AND STORAGE SPACE.

A CONTIUOUS SPIRAL OF VOID SPACE MAKES ITS WAY UP THE BUILDING, COUNTERACTING THE VOLUMES.

INTERIOR TERRACES ARE FORMED ON TOP OF SPACES, ACTING AS INFORMAL LIVING SPACES WHICH HAVE AN EXTERIOR QUALITY TO THEM.

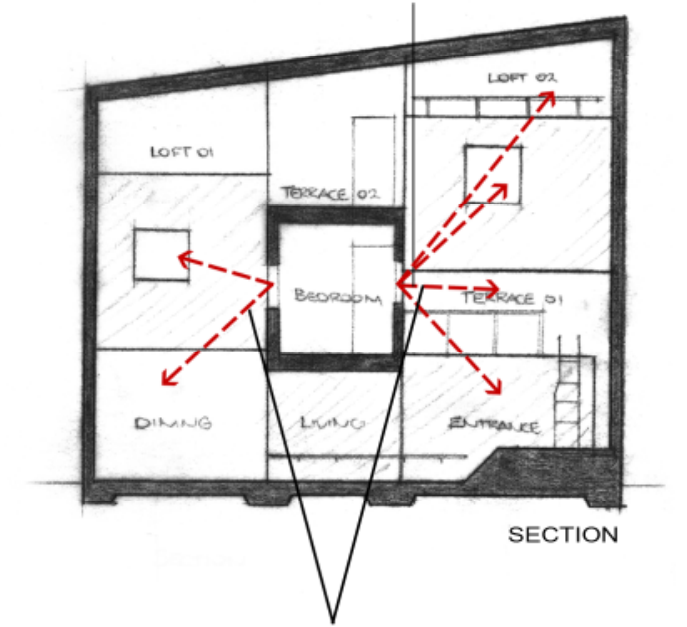

FROM EVERY SPACE, MULTIPLE VIEWS ARE CREATED TO OTHER SPACES WITHIN THE GREATER ENVELOPE OF THE BUIDLING.

\section{House in Fukawa: Suppose Design Office}

\section{Footprint size: $50 \mathrm{sqm}$ \\ Floor size: 114 sqm \\ No. of Bedrooms: 3}

Suppose Design Office has produced another home which seeks to create internalised views. A central core containing the vertical circulation suspends a series of bedrooms, each orientated at a different angle and each located at a different height. This spatial arrangement creates a lot of void space with the intention of playing on the sense of scale of the space. The inhabitants are unable to obtain a sense of scale of the building, suggesting the interior is continuous. On top of the suspended spaces, the architects have created terraces. The effect of this is a sense of both interiority and exteriority all within the buildings' envelope, where inhabitants have views to multiple spaces.

Fig. 4.15 Analytical observations of House in Fukawa by Suppose Design Office. Not to scale. 


\section{Skytrace: Amorphe}

\section{Site size: $75 \mathrm{sqm}$}

Floor size: $135 \mathrm{sqm}$

No. of Bedrooms: 3

Site and regulatory constraints required the architects of Amorphe to think creatively to make the most of the small site. Here, underground spaces are permitted to add roughly an additional 50 percent to the allowed total floor area. In this case, the subterranean spaces are necessary to fit in all of the demanding program. These basement levels are lit and ventilated by one of the several roof top apertures. The large void cuts through each level of the plan, where the rooms face inwards into this void space and upward to the controlled view of the sky. Further voids within the interior help the light permeate throughout.

Fig. 4.16 Analytical observations of Skytrace by Amorphe. Not to scale.

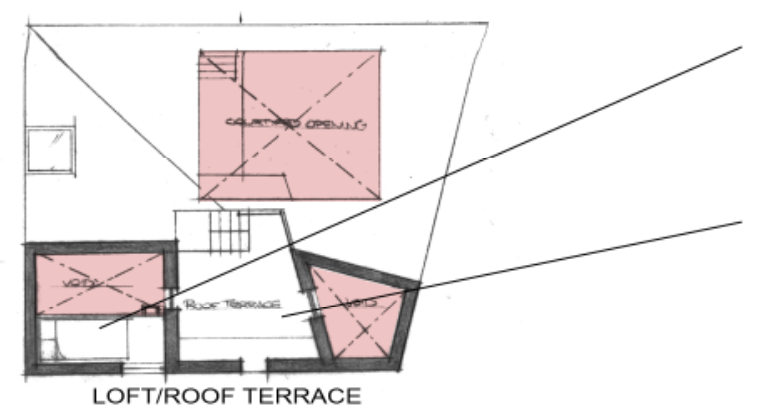

WITH LITTLE FREEDOM TO EXPAND OUTWARDS, THE BED IN THIS ROOM IS STACKED ABOVE FREEING UP THE SPACE BELOW.

DESPITE THE SMALL SITE, A SECONDARY OUTDOOR SPACE IS FOUND IN THE PLAN THROUGH THE INCLUSION OF A ROOF TERRACE
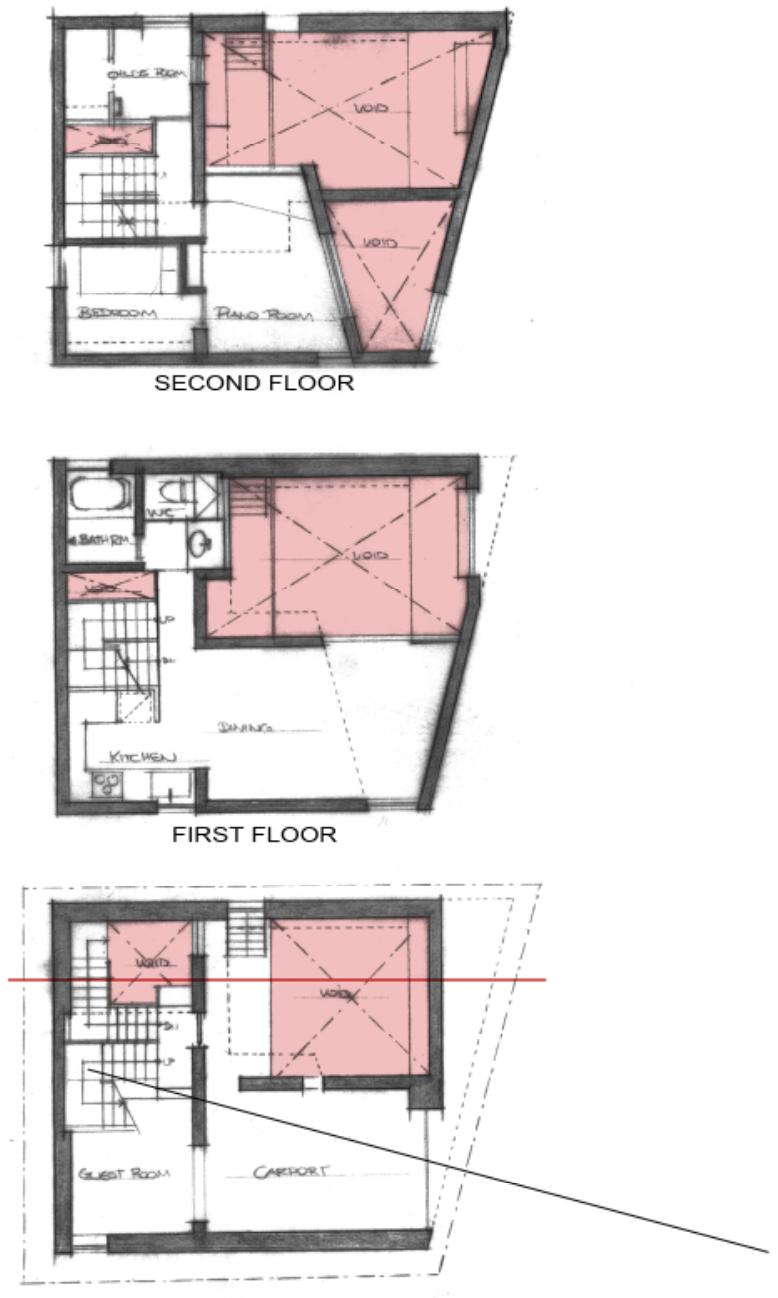

GROUND FLOOR

(BASEMENT SHOWN IN
THE LARGE LIGHT WELL PROVIDES DAYLIGHT AND VENTILATION TO THE LEVELS BELOW, WHILE ALLOWING A PRIVATE OUTLOOK FOR INHABITANTS OF THE INTERIOR SPACES TO THIS TOP-LIT AREA AND CREATING A VISUAL LINK TO THE SKY ABOVE.

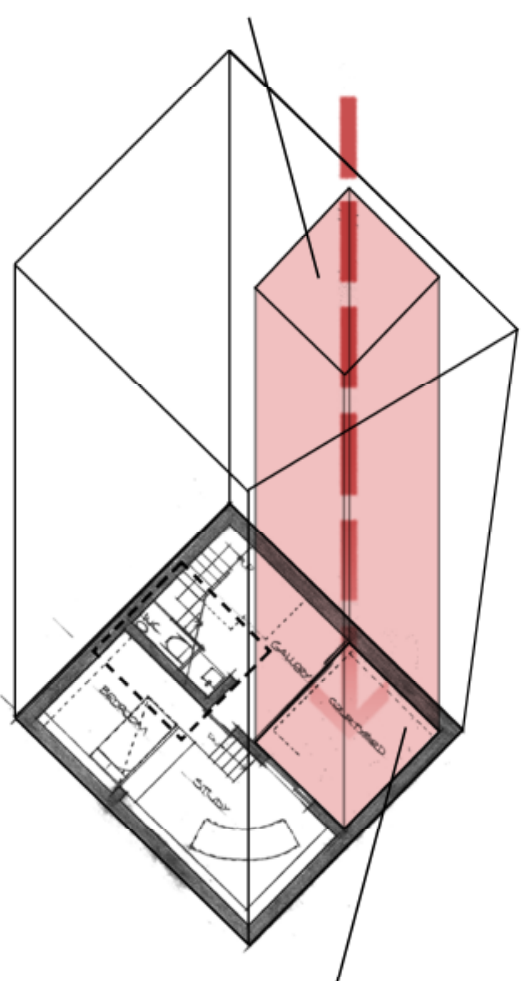

THE COURTYARD BECOMES A SIGNIFICANT FOCAL POINT IN THIS HOME, ITS SIZE RELATIVE TO THE BUILDING'S FOOTPRINT SIGNIFIES THE IMPORTANCE OF THE OUTDOOR AREA.

CIRCULATION IS TREATED IN TWO WAYS: THE STAIRCASE LINKS EACH LEVEL AND ACCESS INTO PRECEDING ROOM E.G. ACCESS TO THIS BEDROOM IS THROUGH THE PIANO ROOM 


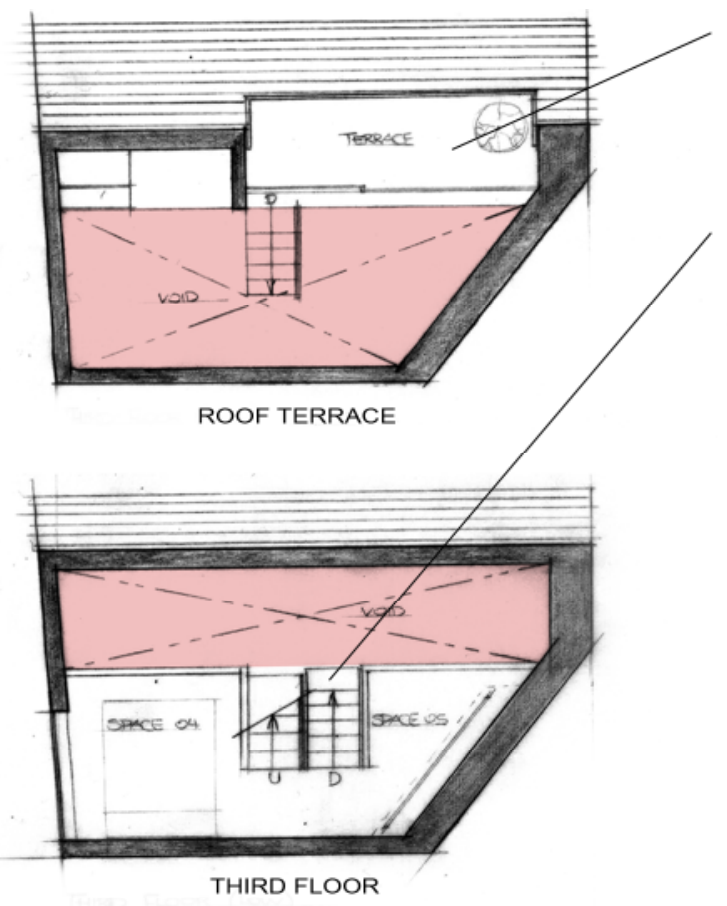

71

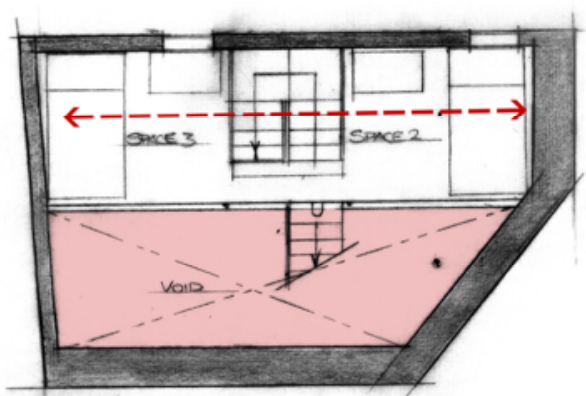

SECOND FLOOR

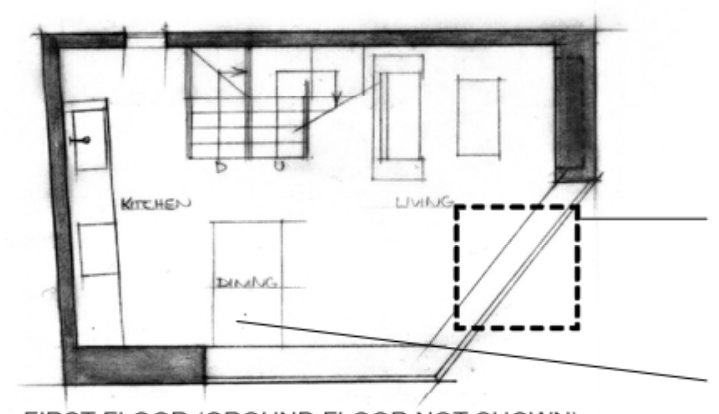

FIRST FLOOR (GROUND FLOOR NOT SHOWN)
ROOF TERRACE PROVIDES OUTDOOR SPACE AND CREATES A PLANTED OUTLOOK FROM THE INTERIOR SPACE.

THE STAIRWELL ALSO HELPS INTRODUCE LIGHT DOWN TO THE LOWER LEVELS. ITS UNOBTRUSIVE DESIGN ALLOWS SIGHTLINES TO BE MAINTAINED ACROSS THE INTERIOR SPACES.

THE TERRACE INTRODUCES LIGHT INTO THE PLAN FROM ABOVE. THE SPLIT-LEVEL DESIGN ALLOWS LIGHT TO BE SHARED BETWEEN LEVELS AND CREATES EXTENDED LINES OF SIGHT.

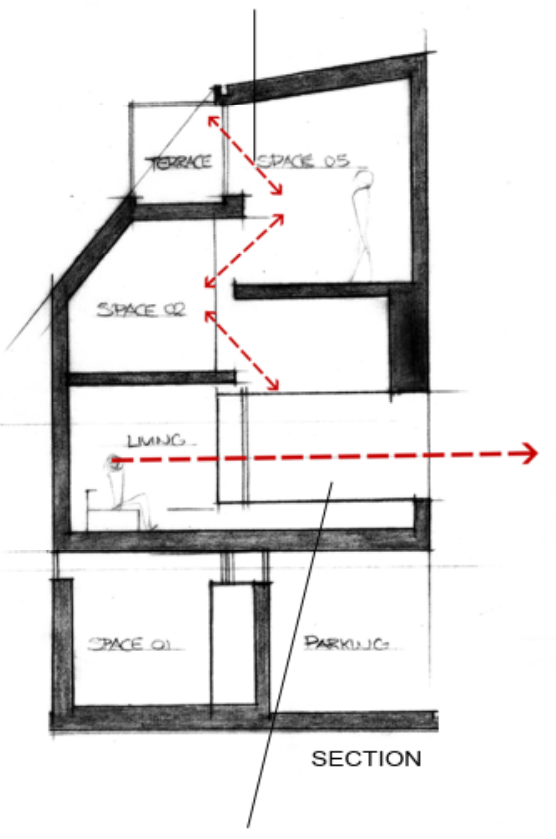

THE LARGE BAY WINDOW DISSOLVES THE BARRIER BETWEEN THE INTERIOR AND EXTERIOR. VIEWS OF THE ADJACENT PARK ARE BORROWED CREATING A SENSE OF OWNERSHIP OF THE PARK BY INTRODUCING IT INTO THE INTERIOR THROUGH THE CONTROLLED VIEW.

THE BAYWINDOW INCORORATES A LEDGE TO BE USED FOR STORAGE OR CASUAL SEATING. WHILE THE KITCHEN IS COMPACT, THE DINING TABLE'S CLOSE
PROXIMITY ALLOWS IT TO BE USED AS ANOTHER BENCH SURFACE.

\section{House in Sakuragawa: Suppose Design Office}

\section{Site size: $50 \mathrm{sqm}$ \\ Floor size: $91 \mathrm{sqm}$ \\ No. of Bedrooms: 4}

The design of the large bay window that wraps around the living area helps dissolve the barrier between the interior and exterior. On the small site, little space for outdoor areas or planting is available so the architect attempts to 'borrow' the view of the adjacent park. This connection with the park helps experientially expand the size of the dwelling by creating a sense of ownership of the park by introducing it into the interior through the controlled view. Elsewhere in the home, the almost wall-less interior of the split-level design can be conceived somewhat as one unified space, thus, creating a greater sense of space than the dimensions suggest. The split levels allow for an ease of communication between the inhabitants and maintains connections within every space of the house whilst still defining separate zones of activity. Each level is physically connected by the discreetly designed staircase. This compact stairwell also acts as a void piercing through the centre of the plan, introducing light down into lower levels. 


\section{Love House: Takeshi Hosaka Architects}

Site size: $33 \mathrm{sqm}$

Floor size: $38 \mathrm{sqm}$

No. of Bedrooms: 1

It may appear to be an inefficient response to introduce a full-height void and large sweeping curve into an already small dwelling. But in the case of Love House the sacrifice of floor area for the small courtyard space, which traces an arc from the entry to the back of the site, brings light into the glazed interior of the first floor. The interior is now able to open up out to the outdoor area and allow the inhabitants to connect with nature. While still maintaining privacy, the living spaces are extended into the outdoor room, making the space feel larger as the distinction between inside and outside is blurred. Under the curving stairs, the architect has efficiently incorporated storage space and a bathroom which also receives light and enjoys a private view of the garden area.

Fig. 4.17 (Opposite) Analytical observations of House in Sakuragawa by Suppose Design Office. Not to scale.

Fig. 4.18 Analytical observations of Love House by Takeshi Hosaka Architects. Not to scale.

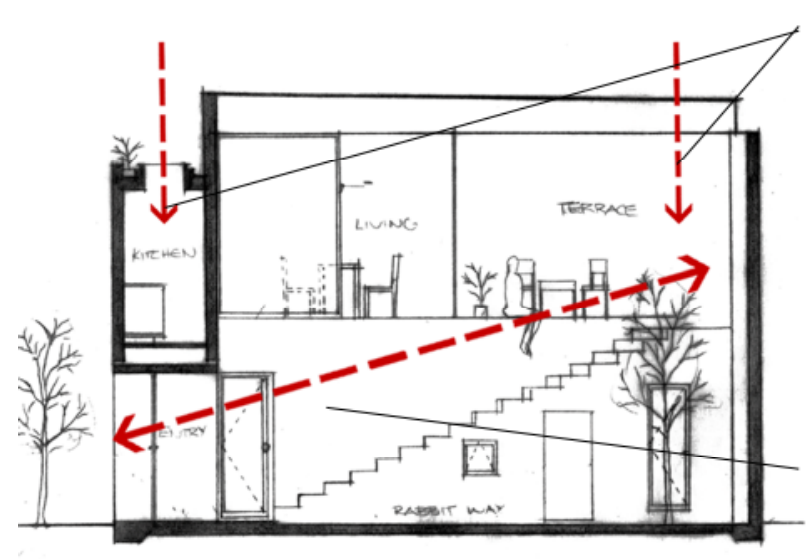

SECTION

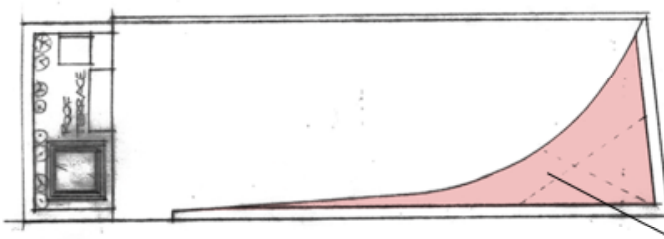

ROOF

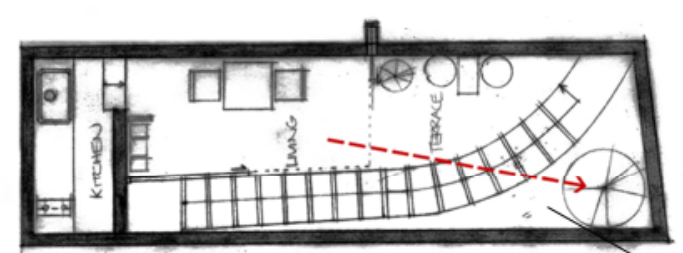

FIRST FLOOR

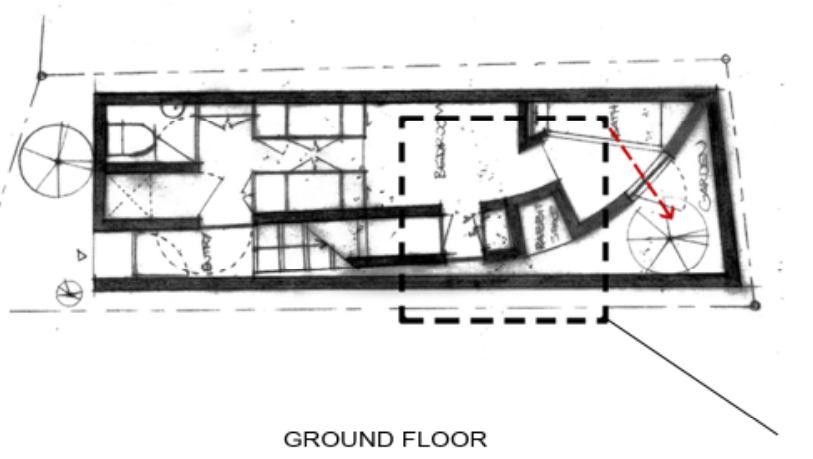

IIGHT IS INTRODUCED PRIMARILY THROUGH OPENINGS IN THE ROOF, MAINTAINING PRIVACY.
UPON ENTRY, A LINE OF SIGHT IS CREATED ALL THE WAY TO THE REAR OF THE SITE, THE GARDEN AND TO THE VIEW OF THE SKY ABOVE.

AN OPENING TRACES AN ARC FROM THE FORNT TO THE REAR OF THE SITE
THE SACRIFICE OF FLOOR SPACE FOR THE GARDEN AND LIGHT WELL PROVIDES AN OUTLOOK FOR THE LIVING SPACES AND BATHROOM BELOW, WHILE BRINGING A SENSE OF NATURE INTO THE HOME. 

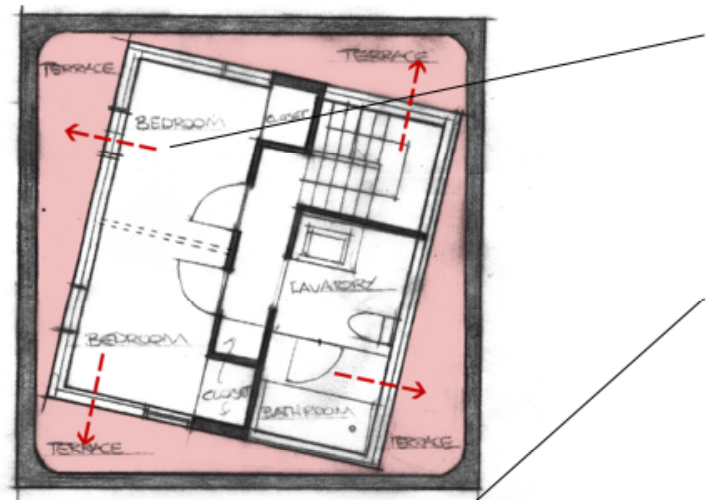

SECOND FLOOR

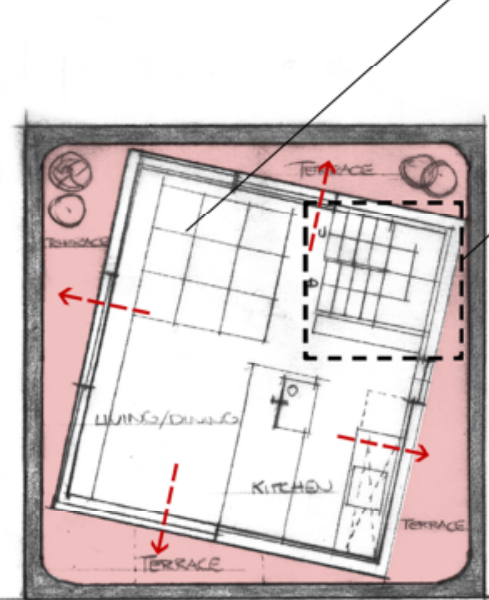

FIRST FLOOR

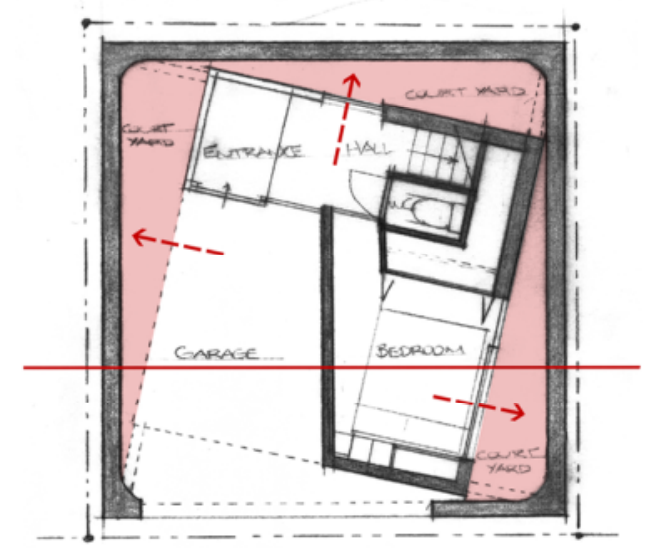

GROUND FLOOR
EACH SPACE HAS A PRIVATE OUTLOOK TO A SMALL COURTYARD OR TERRACE FORMED BETWEEN THE TRANSPARENT INNER SKIN AND THE OUTER CONCRETE ENVELOPE.

THE OPEN LIVING SPACES WITH LITTLE IN THE WAY OF PARTITONS CREATES A SPACIOUS ATMOSPHERE

THE STAIR NOT ONLY PROVIDES CIRCULATION BUT ACTS SIMILAR TO A VOID IN THAT IT ALLOWS LIGHT TO PENETRATE THE LOWER LEVELS

TOP-LIT CAVITIES AND THE PERFORATEDSTEEL TERRACES ALLOW LIGHT TO FILTER DOWN INTO THE COURTYARDS BELOW.

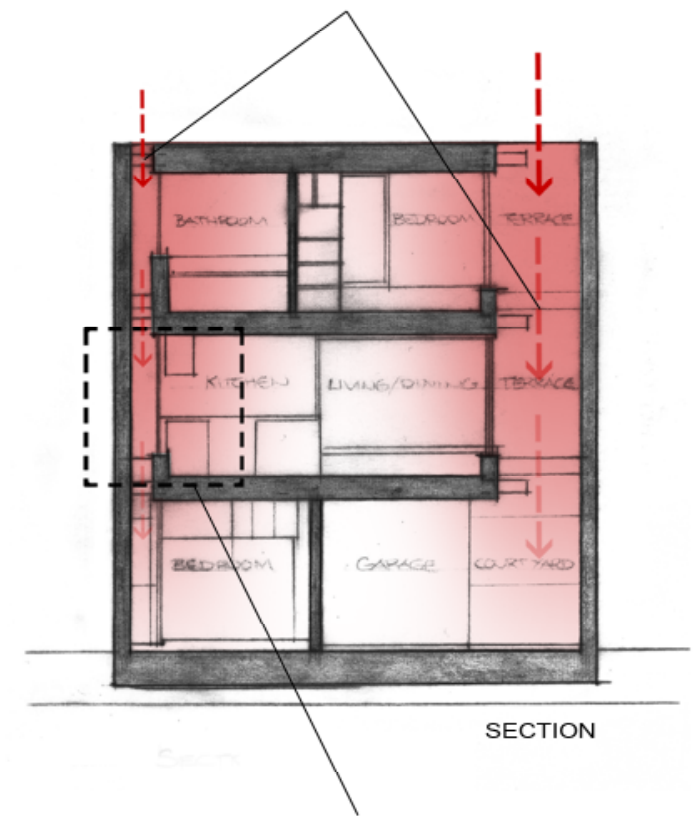

THE KITCHEN CUPBOARDS AND BENCH SURFACE ARE SEPARATED BY GLAZING SO VIEWS TO THE TERRACE BEYOND ARE MAINTAINED AND LIGHT FROM THE LIGHT WELL CAN BE 'BORROWED' BY THE INTERIOR SPACE.
House in Minamimachi 3: Suppose Design Office

\section{Site size: $54 \mathrm{sqm}$}

Floor size: $79 \mathrm{sqm}$

No. of Bedrooms: 3

Situated in a densely packed residential neighborhood, this home's enclosed envelope seeks to maintain privacy. The building is essentially two offset skins. The outer concrete shell is at an angle to the interior structure which forms a series of triangular terraces between the inner and outer walls. The interior skin is glazed and opens out onto the small terraces, the large windows gather light from the top-lit cavities on each level thanks to the perforations of the steel terraces that allow light into the courtyards below. Each room has its own private outlook to the day-lit exterior spaces connecting the occupant with the exterior conditions. There is almost no horizontal movement between spaces as the small site has made a stacking of spaces a requirement. The compact staircase serves as the vertical circulation linking each level while its open design aids in the filtering of light between levels.

Fig. 4.19 Analytical observations of House in Minamimachi 3 by Suppose Design Office. Not to scale. 


\section{Garden House: Takeshi Hosaka Architects}

Site size: $98 \mathrm{sqm}$

Floor size: $114 \mathrm{sqm}$

No. of Bedrooms: 2

The amalgamation of inside and out dominates this house. Outdoor space is given a high priority, through the small interior spaces opening out seamlessly to the courtyard as the doors slide back. Therefore, this design brings the private garden into the living spaces. In addition to the courtyard, a roof terrace above the rooms offers more outdoor living areas for the inhabitants. With a limited site, the rooftops are utilised to their full extent to provide a useable space. There are no defined circulation paths, rather access is either progressive through one room to another or through the courtyard acting as a transition space. The omission of designated circulation space, maximizes the total living area, instead of wasting space on unnecessary zones.

Fig. 4.20 Analytical observations of Garden House by Takeshi Hosaka Architects. Not to scale.

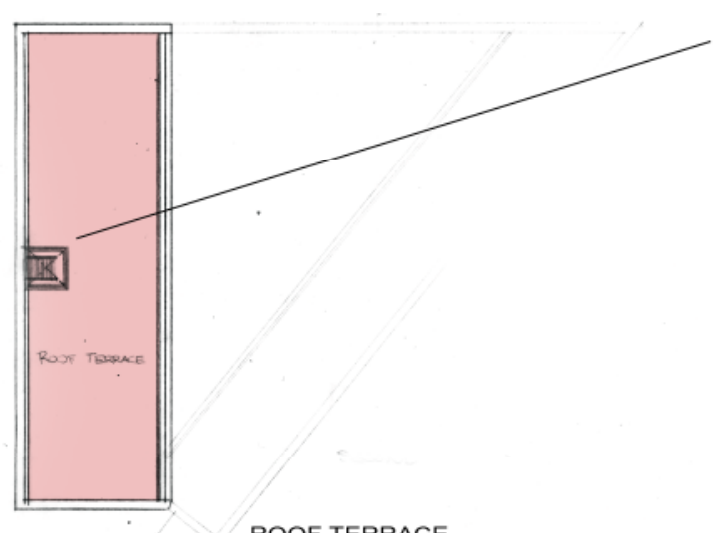

ROOF TERRACE
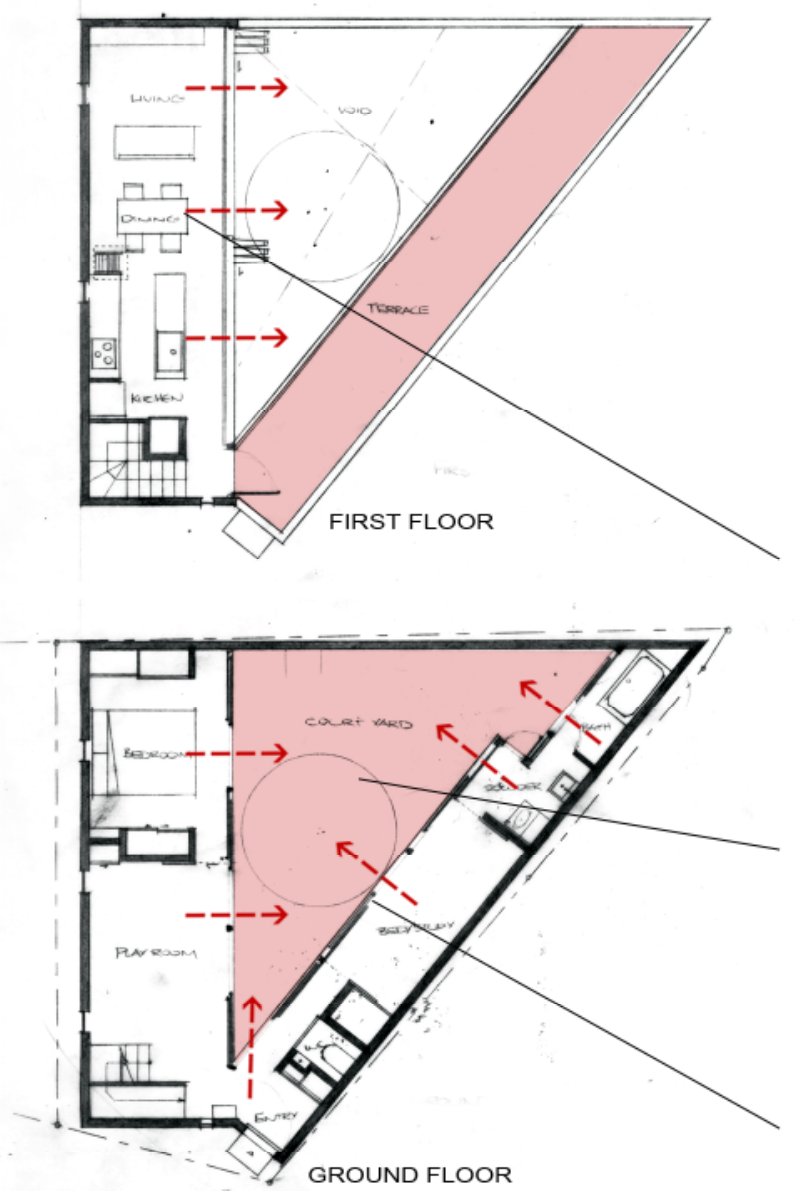

ARRANGING THE SPACES AROUND THE PERIMETER OF THE SITE, ALLOWS EACH SPACE TO FACE INWARDS TO THE PRIVATE COURTYARD
THE SMALL INTERNAL SPACES APPEAR LARGER, ESPECIALLY WITH THE DOORS FOLDED OUT OF THE WAY, THROUGH THE INCLUSION OF THE EXTERIOR SPACES.

ALLADD UP, THE THREE OUTDOOR SPACES NEARLY EQUAL THE TOTAL FOOTPRINT OF THE BUIDING THIS HIGHLIGHS THE HIERARCHICAL IMPORTANCE AND RECOGNITION OF THE VALUE OF OUTDOOR SPACE, EVEN IN A SMALL DWELLING

DAYLIGHT IS ABLE TO PENETRATE DEEP INTO THE PLAN THANKS TO THE LARGE FENESTRATIONS AND SHALLOW WIDTH OF THE SPACES ARRANGED ONE ROOM DEEP.

THIS GARDEN COURTYARD ALSO SERVES AS A TRANSITIONS SPACE BETWEEN THE TWO WINGS 
THE OPEN STAIRCASE DIVIDES THE LIVING SPACE AND THE OTHER ROOMS, DELINEATING THE PUBLIC AND PRIVATE ZONES WITHOUT USING SOLID PARTITIONS

\section{$\underline{\text { House }}$}

in

Architects

Site size: $70 \mathrm{sqm}$

Floor size: $108 \mathrm{sqm}$

No. of Bedrooms: 2

This long and narrow home's spatial configuration is based around the alternating staircase. The open staircase divides the double-height living space and the other rooms, delineating the public and private zones without using solid partitions. This allows sight-lines to be maintained from the front to the back of the home with the intention of creating a focus on the views of the exterior offered at each end. Drawing the inhabitants' focus to the natural setting outside extends their perception of the space's boundary beyond its physical envelope. The planting in the front courtyard acts as a privacy screen while also providing a focus for rooms throughout the house due to the uninterrupted interior and large glazed facade. The deep void at the rear of the site permits light to penetrate down to the courtyard below and filters light into each floor of the split level home. When combined with the void in the centre of the plan, and the limited use of opaque partitions, a quality spatial atmosphere is achieved. Another strategy employed by the architect is the multifunctional bench top in
DOUBLE HEIGHT SPACE, INCREASES THE EXPERIENTIAL FEELING OF THE NARROW SPACE AND ALLOWS THE ROOMS AT FULL-HEIGHT GLAZED FACADE. 
the kitchen which doubles as the dining table, saving space and also creating a streamlined, uncluttered environment.

THE DEEP VOID AT THE REAR OF THE SITE FILTERS LIGHT INTO EACH FLOOR OF THE SPLIT LEVEL HOME.

SLOT IN ROOF ABOVE ALLOWS A WASH OF LIGHT TO HELP DISSOLVE THE BUILDING'S ENVELOPE

MULTIFUNCTIONAL BENCH TOP IN THE KITCHEN DOUBLES AS THE DINING TABLE.

END TO END SIGHTLINES, VIEWS ARE ACCESSBILE FROM NEARLY EVERY POINT IN THIS HOUSE.

EVEN THE BEDROOM, LOW DOWN IN THE BUILDING'S SECTION AND LOCATED DEEP IN THE SITE HAS AN OUTLOOK TO A PRIVATE COURTYARD DAYLIT FROM THE LIGHT WELL ABOVE.

Fig. 4.21 (Opposite) and Fig. 4.22 (Right) Analytical observations of House in Showa-Cho by FujiwaraMuro Architects. Not to scale.

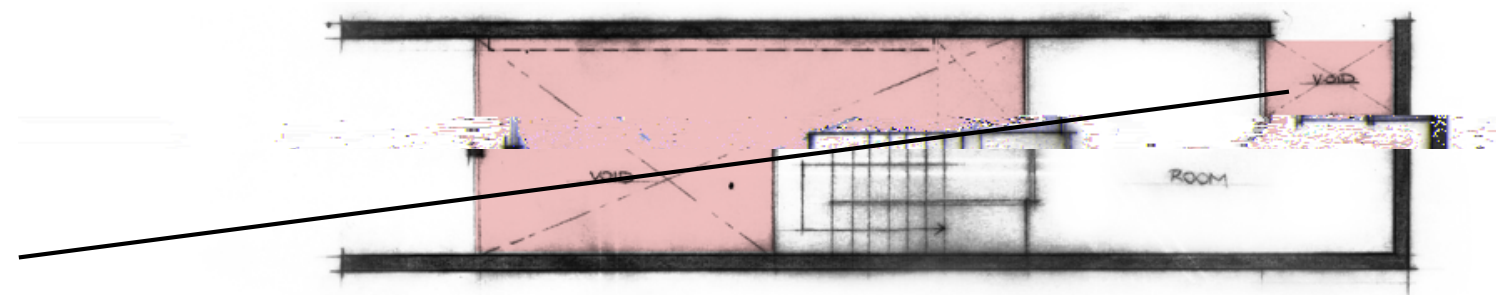

SECOND FLOOR
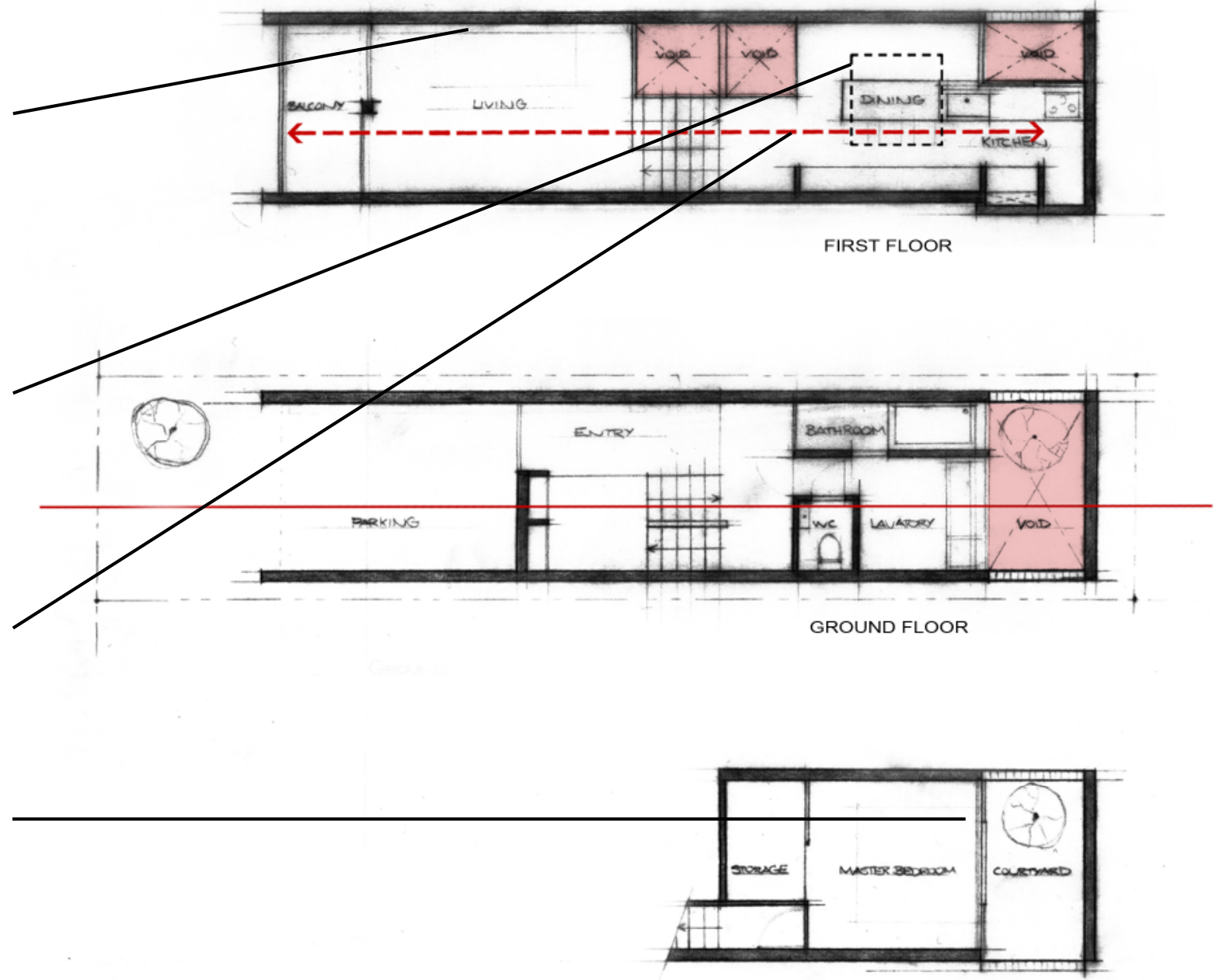

BASEMENT 
The above examples of analysis illustrate the types of observations made throughout the analysis process. The following section further highlights the recurring strategies, forming a series of diagrammatic design principles. 


\section{3 - Strategy Abstraction:}

The analysis of the Japanese precedents provided a deeper insight into techniques and strategies that were found repeatedly in their designs. The following diagrams are stripped back, abstracted concepts, extracted and decontextualised from the precedents to generate a 'toolkit' of strategies which can be applied in the design of small residences. These architectural strategies rethink typical planning elements in a way in which they "instill a sense both of order and of expansiveness", ${ }^{44}$ manipulating space, light, views, planning and integrating furniture to create architecturally unified surroundings. 


\section{Internal Sight-lines and Views:}

Extending view points and sight-lines within a building is a powerful tool in creating environments which are perceived to be larger. Other spaces and rooms in the dwelling, whether located adjacent, on other levels or in the distance, provide the occupant with an internal view greater than that of the space which they occupy. By allowing sight-lines to connect one space to another, both legibility and ease of communication between occupants are increased. The same principle can also be applied on a smaller scale. For example, partitions and stairs can be constructed so that sight lines can penetrate deeper through the interior to space beyond. Small gestures such as partial height walls, interior windows between rooms or open riser staircases can also be used to break down barriers within the buildings and consequently increase the sense of space.

Fig. 4.23 (Left) Internal sight-line diagram. 

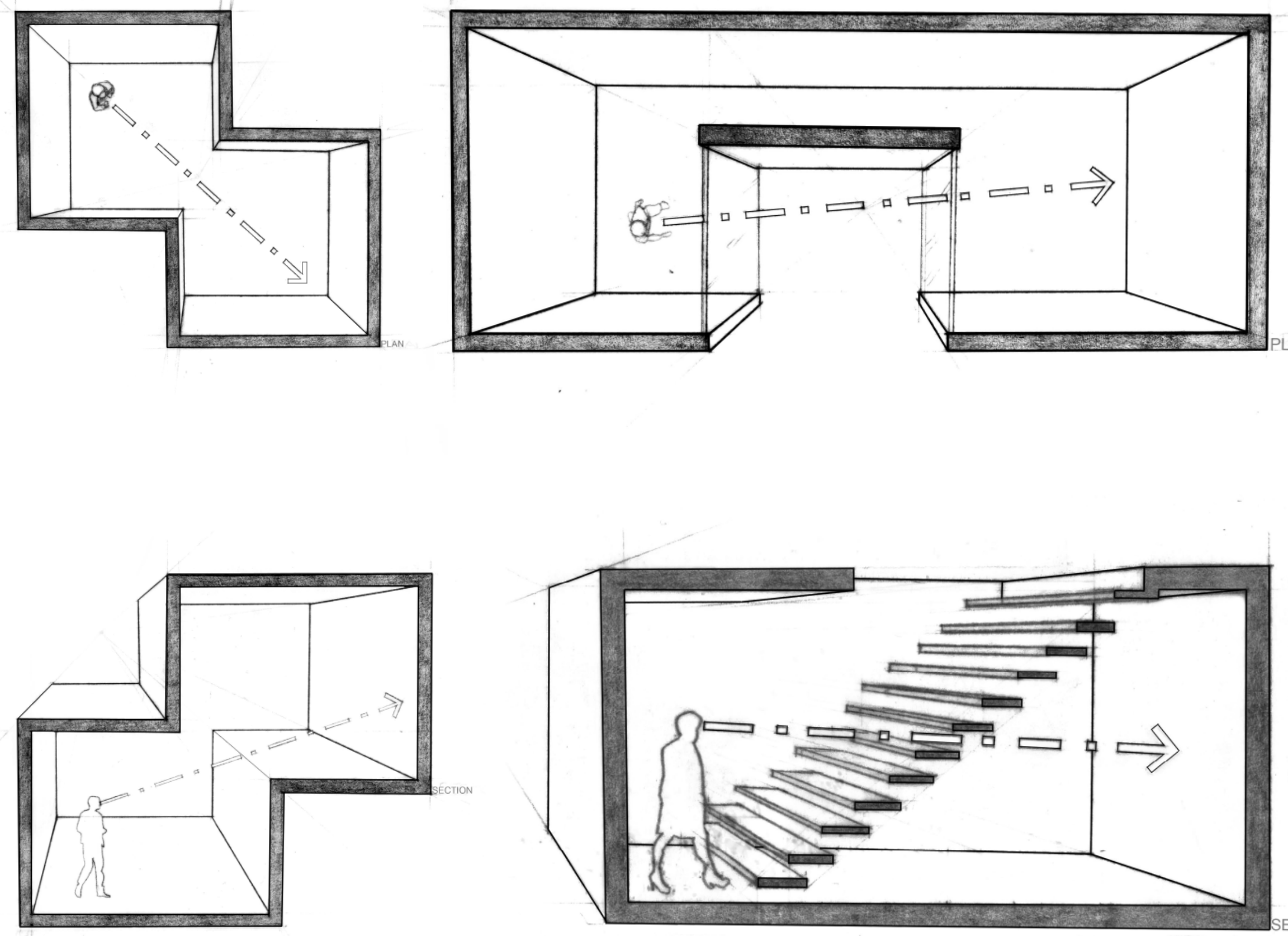


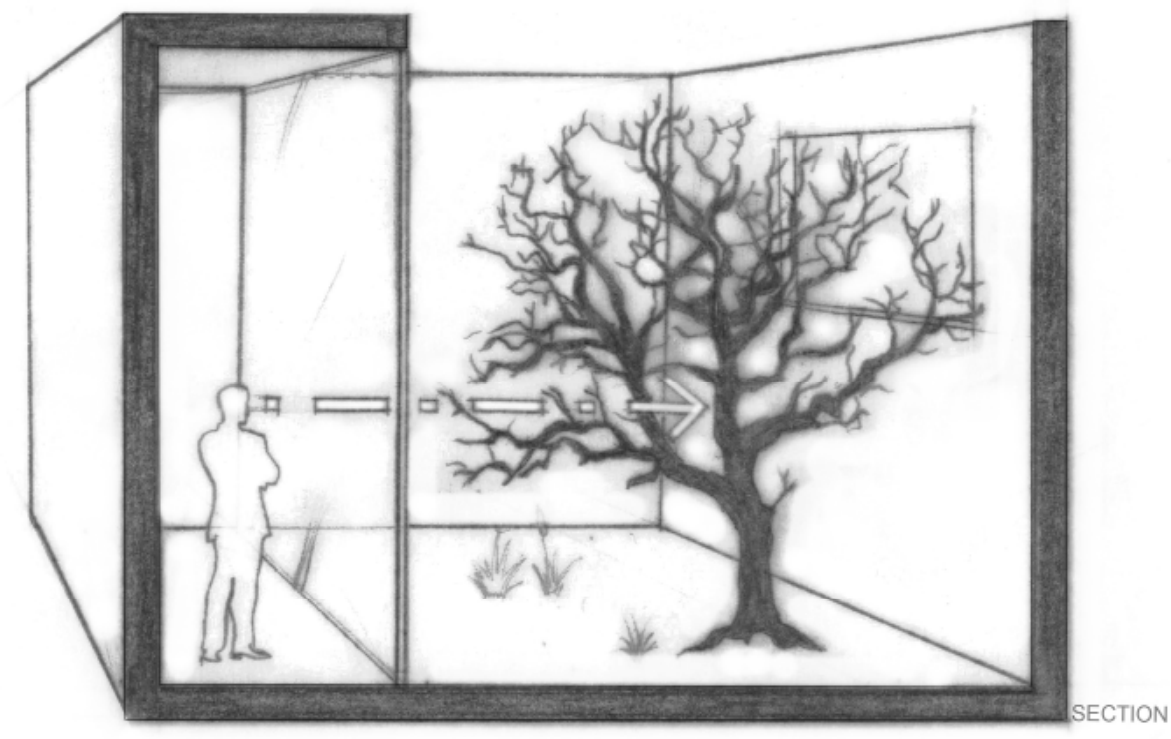

81

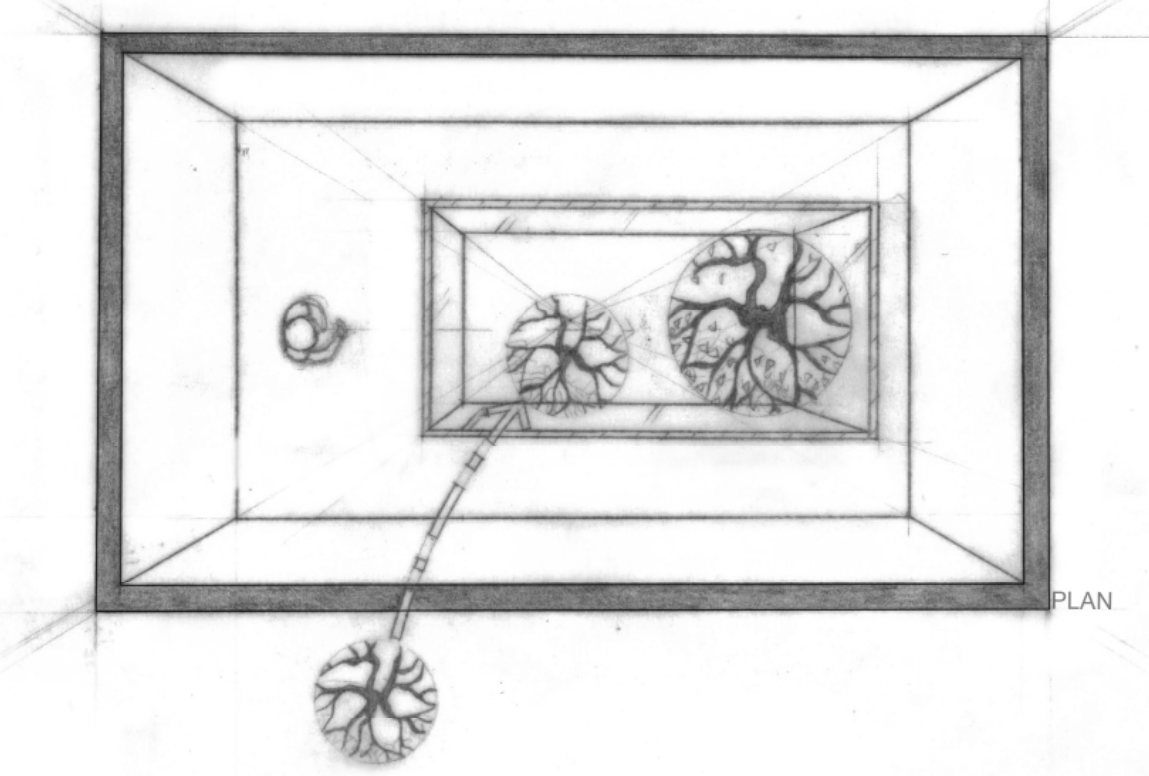

Similar to the above diagrams, this series explores the notion of extending sight-lines, though in this instance, in order to make use of views created on the exterior. Shakkei is the traditional Japanese principle of borrowing from the landscape, and is prevalent throughout the examined case studies. With little "room for spatial elaboration, visual complexity and interest must often be borrowed from outside". ${ }^{45}$ By connecting the occupant of a building with its wider context, the visual envelope is extended beyond the interiors' physical limits and extends the experiential sense of the space through inclusion. With the barrier between the external environment and the building's inhabitant blurred, the connection between inside and out is heightened to a point where they appear to be the same space, in turn increasing the perceived space. For the Japanese precedents, due to the tight site constraints of their urban setting and necessity to maintain privacy, the designers typically do not rely on conventional fenestration. Instead, in response to their surroundings they create their own exterior vistas by opening out to courtyards, internal gardens and terraces.

45 Daniell, T. (2008). p. 30 
Susanne Tamborini suggests that "the size of the garden is of no importance. It could be tiny, e.g., only an adjacent corner courtyard. What is important is that it be perfectly arranged from the perspective from which it will be seen from within the house". ${ }^{46}$ The majority of the examples offered some form of outdoor space, regardless of the size of buildings, highlighting how such spaces are valued and prioritised. Alternatively, the buildings open upwards to the sky. The designers' take advantage of the endless, often uninterrupted view of the sky as an ever-changing window to the external conditions. To a lesser extent, though still successful, the architects' attempt to connect to the outdoor environment in a more abstract sense by capturing temporal and ephemeral daylight or celestial qualities, creating an awareness of the external conditions. Such contextual relationships are preserved through the use of devices such as translucent skins, skylights and interstitial slots. ${ }^{47}$

Fig. 4.28, (Opposite Top) Fig. 4.29 (Opposite Bottom), Fig. 4.30 (Top) and Fig. 4.31 (Bottom) External sight-line diagrams.

46 Tamborini, S. (1999). Living in a Small Space: Experimental Projects From Four Continents. Stuttgart: Edition Axel Menges. p. 12

47 Daniell, T. (2008). p. 29-30

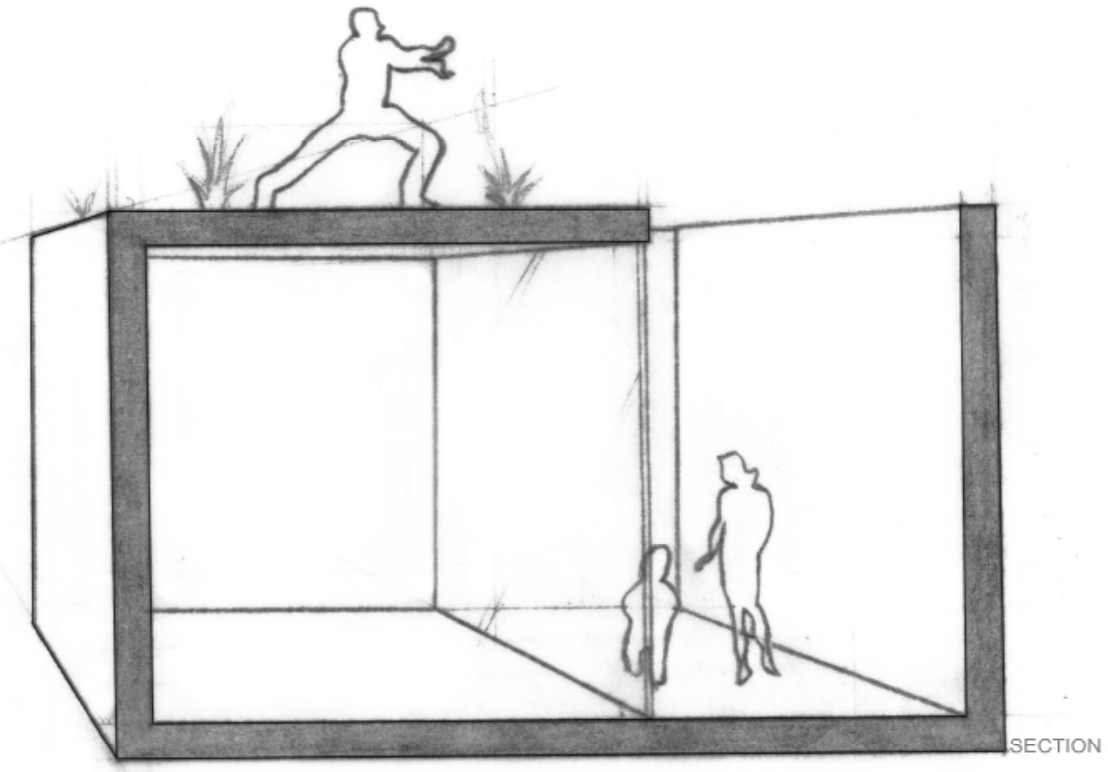

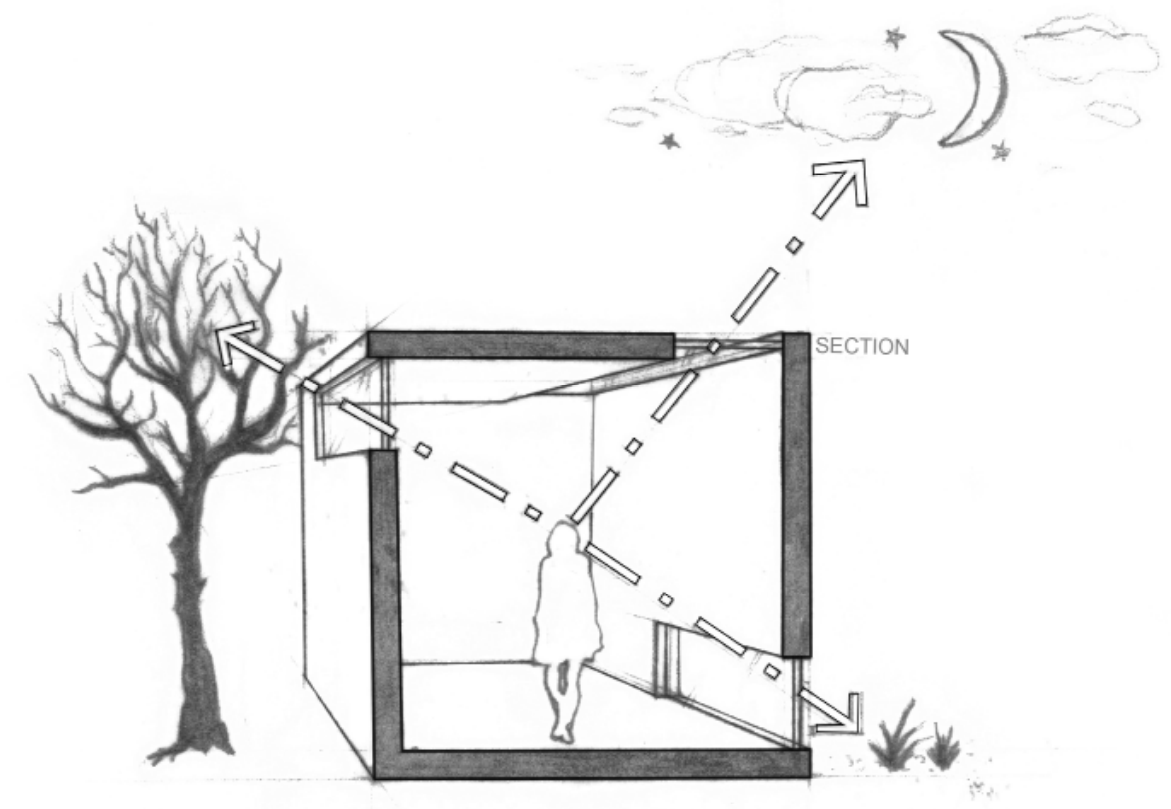




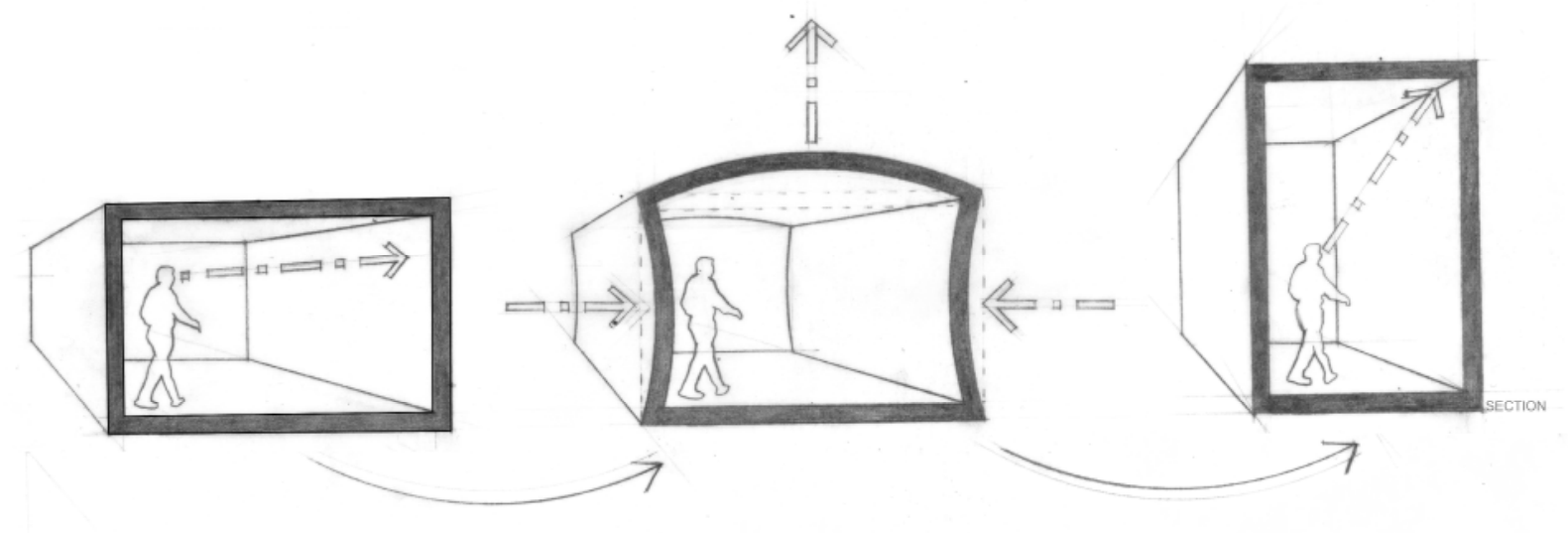

footprint shrinks:

While extending sight-lines is one available technique to improve space limitations, this diagram demonstrates that with the expected foreshortening of space in the horizontal axis, due to the obvious site restrictions, some of the spatial size experienced by the inhabitant can be compensated by enlarging the volume in the vertical axis. 
Rooms and spaces arranged in a vertical stacking configuration as opposed to horizontal layout:

Given the unorthodox small plots of land the analysed dwellings are constructed on, the designers have little option but to stack the various functions of the programme in a vertical configuration in order to accommodate them. As a result, there are usually fewer partitions because functions are frequently divided by the floor planes. By reducing (sometimes eliminating altogether) the horizontal configuration of spaces, space consuming horizontal circulation is lessened and replaced with vertical circulation. The benefits of this are discussed below.

Fig. 4.33 Vertical stacking configuration diagram.

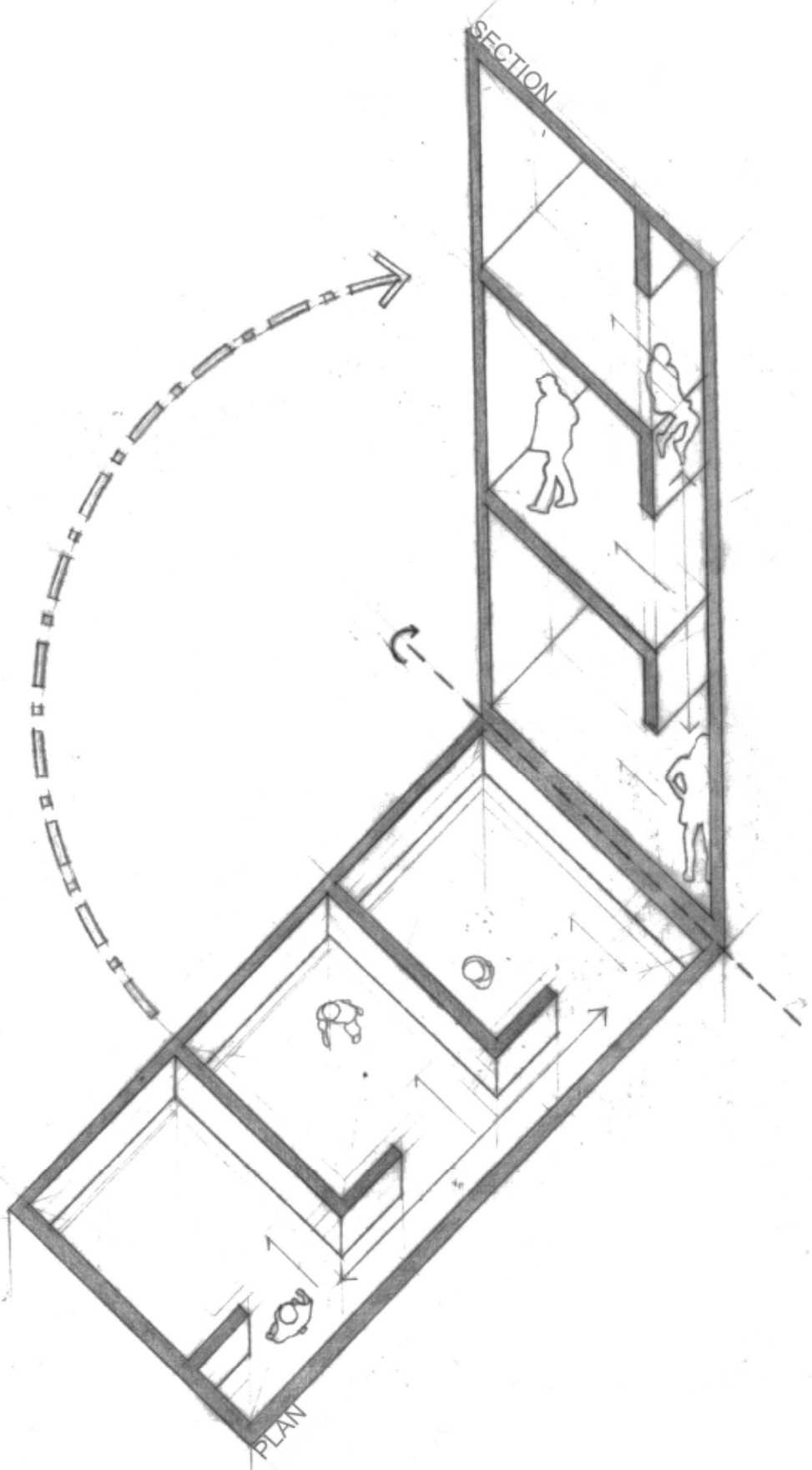




\title{
Vertical Circulation:
}

Following on from the previous design strategy, this diagram looks at how incorporating vertical circulation can provide a variety of secondary functions to a dwelling's circulation route.

\begin{abstract}
Vertical circulation links spaces both physically and conceptually, creating a cohesive structure throughout. If one rule of small houses is that long corridors are to be avoided, then stairs must be considered as more than a diagonal corridor. (Tamborini, 1999, p. 63)
\end{abstract}

When considering the stair as more than a functional element for transporting people between levels, the stairwell becomes an architectural element with the ability to disperse light by simultaneously acting as a void space. The stair improves legibility by providing a strong compositional element and by establishing a clear zone for vertical circulation. This control of movement can help orientate and direct the inhabitant to specific view shafts. The stairwell can alternatively be 
designed to incorporate storage or utility rooms like a laundry or toilet underneath, making use of what is often unusable space. However, there is a trade-off, as this design solution limits the stair's use as a light-well if incorporated on floors above ground level.

\section{Split Level:}

A prominent design concept becomes particularly evident when analysing the Japanese precedents in section. Many dwellings utilised split levels, where floors are offset, usually by half a level. In terms of planning, this permits shorter stair runs between the different levels and program functions, while still achieving the stacking affect and vertical ascent desired on small sites. Split level design allows for visual connections between spaces, communication between levels and light to be 'shared' between multiple spaces, yet still offers distinction between different areas.

Fig. 4.34 (Opposite) Vertical circulation diagram.

Fig. 4.35 Split-level diagram.

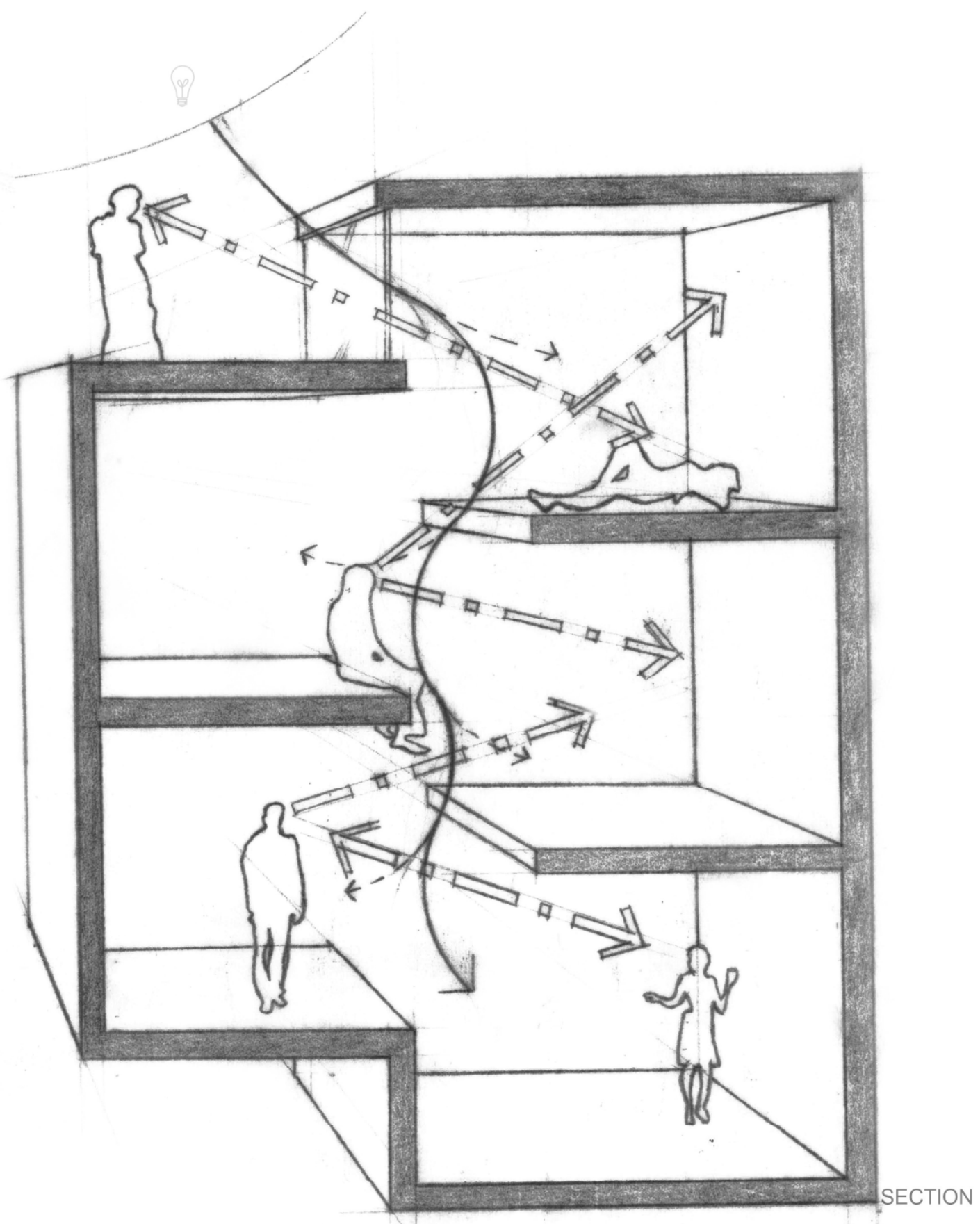




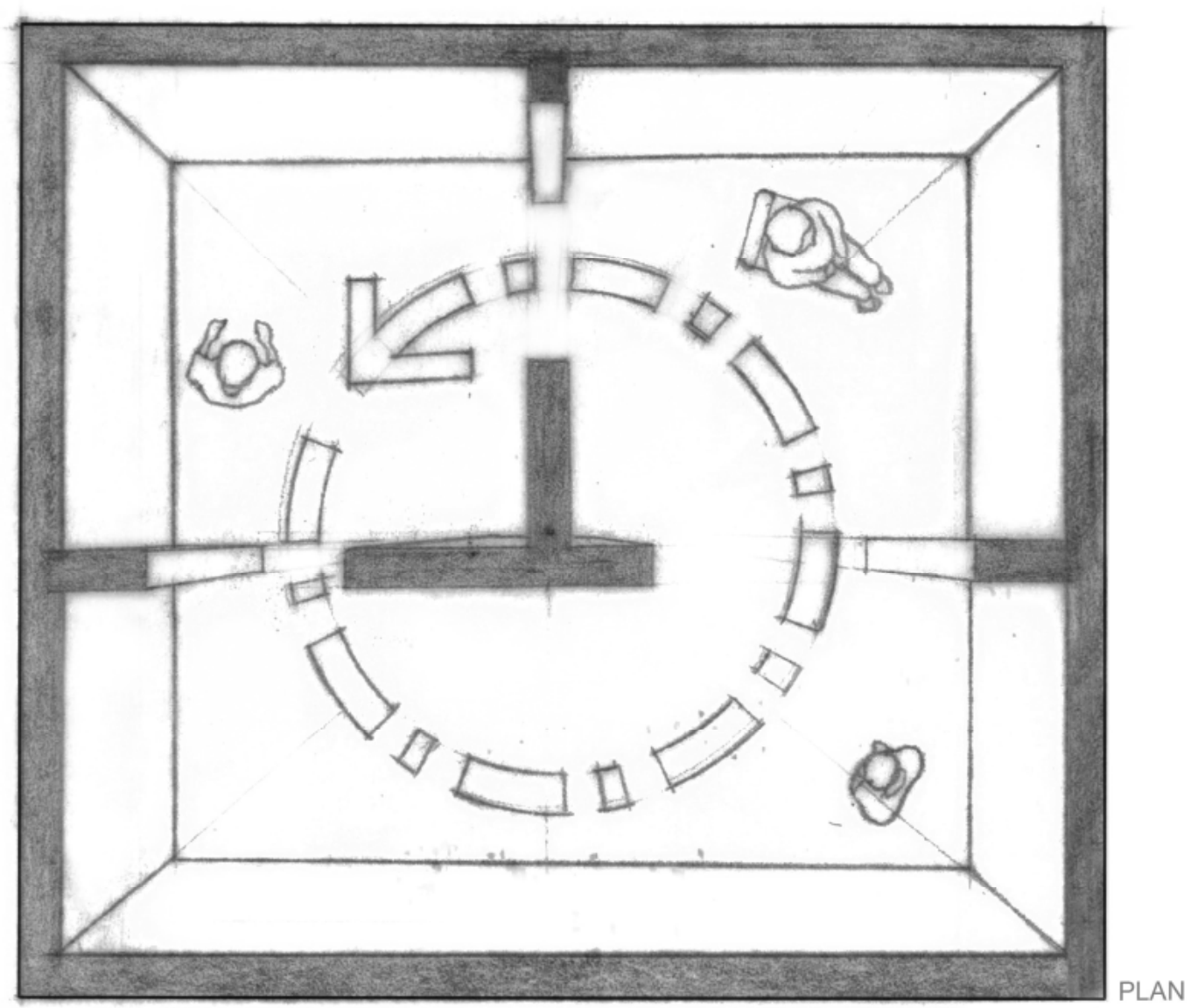

When working with such small sites, it is desirable to allocate as little dedicated circulation space between rooms. The Japanese designers have several solutions for this, including; one room being given a secondary function as a circulation space. An example of this in an extreme circumstance is the access to a child's bedroom being through the parents' room. What the architect was trying to achieve clearly links to the values of traditional Japanese family life, but equally illustrates how a room can double as a circulation space. Due to inherent cultural differences between Japan and Western society, this example would be considered unusual in a New Zealand context. However, on a more basic and familiar level, the open plan living space can accomplish a similar result in culturally acceptable ways. 


\section{$\underline{\text { Voids: }}$}

It may seem counter-intuitive to remove usable floor area in a situation where it is a scarcity. However, the architects of the Japanese precedents reveal the powerful potential of void space in micro-architecture. One can consider it a sacrifice of floor area for the greater good of the space. While floor area may be reduced, the quality of the space increases. The architects carve out of the building's volume to allow for light to be spread around the space and penetrate deeper into the volume. Voids create a greater sense of space and are utilised in the analysed examples on the exterior to create courtyards and light wells or on the interior to create more generous double-height spaces.

Fig. 4.37 (Top) Internal void diagram.

Fig. 4.38 (Bottom) External void diagram
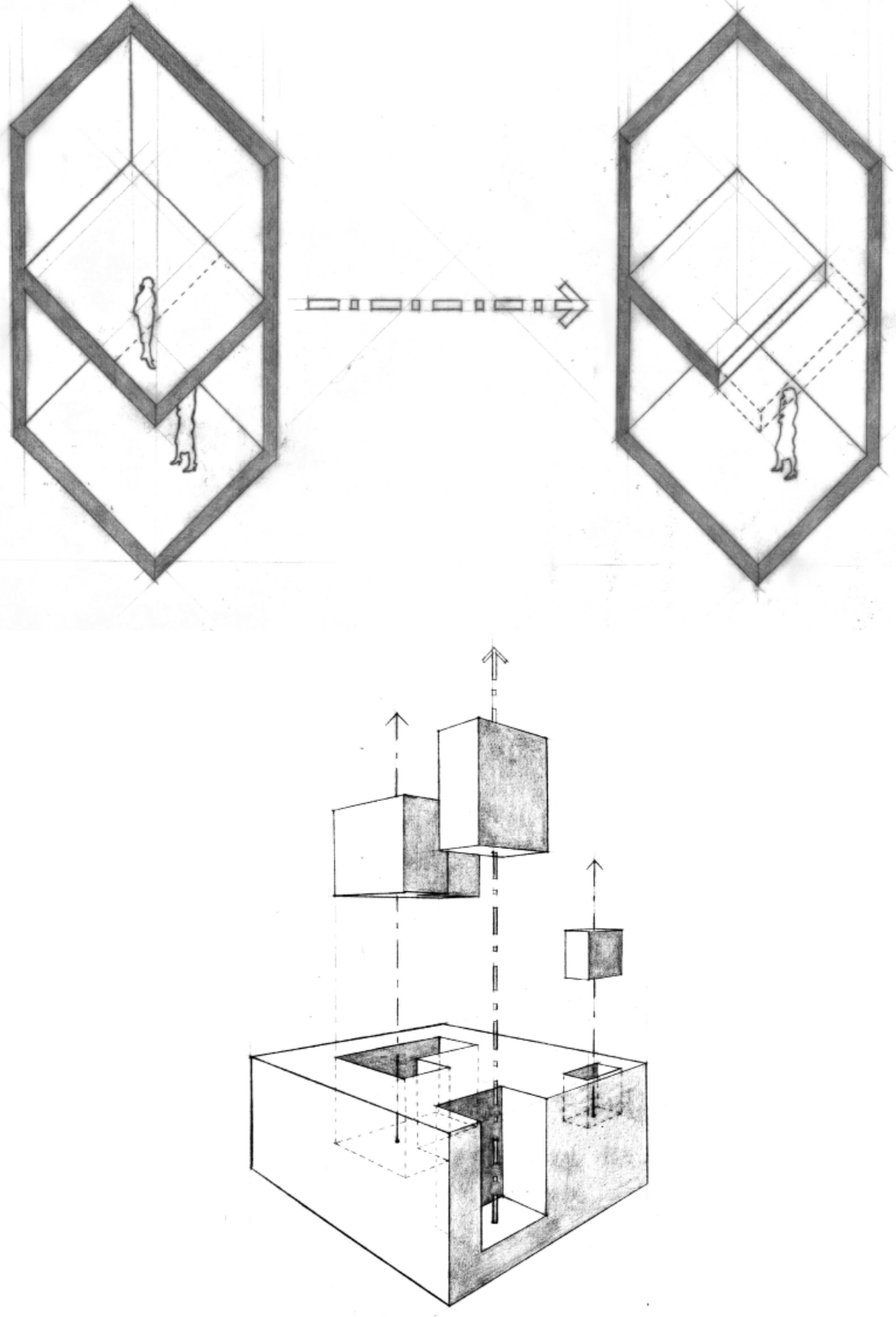


\section{Natural Lighting:}

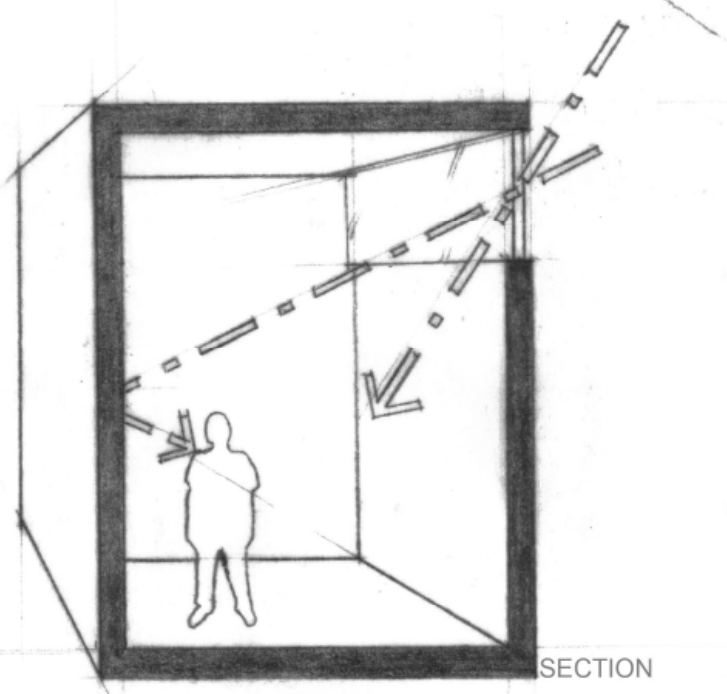

89
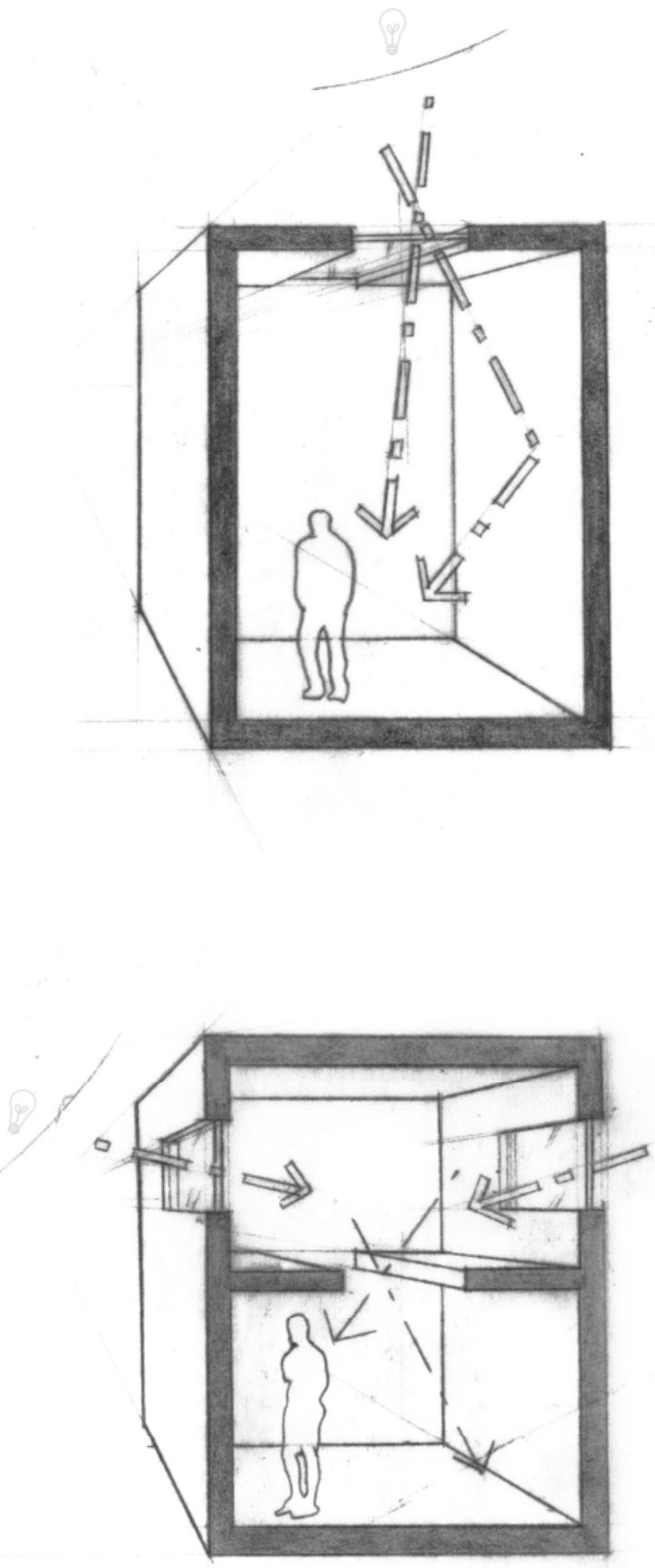

Light has an immense power to influence the perception of space. Therefore, the placement and planning of day-lighting becomes increasingly more important with small dwellings. This is especially true when the site is in a densely packed urban area where privacy becomes an issue. A careful mediation between light and privacy is required and some of the common techniques used in Japanese-microarchitecture "for considering light as a medium in the home" 48 are revealed below. The concept of borrowing light refers to introducing daylight from adjacent spaces being utilised to light what may be otherwise under-lit spaces via voids or cut-outs in the internal partitions. A light-well is often used to disperse diffuse light into multiple rooms of a dwelling. This strategy becomes particularly beneficial when rooms are unable to have windows for privacy reasons or their placement within the building. A basement level can be lit by a void; 'borrowing' light from the lit space above. Top lighting is a useful device for architects to introduce light into the building while omitting views for situations where privacy may be a concern. As light filters down from fenestrations either in

$\overline{48 \quad \text { Chan, Y. }}$ (2007). p. 14 
the ceiling or above eye line, it has the potential to dissolve the architectural form especially if openings are created by subtracting corners. Diffuse light also softens the edges and lines of the interior space, subsequently increasing the perceived size of the space. In a similar way, translucent or perforated materials and screens allow light to penetrate into spaces while maintaining privacy and an awareness of external conditions.

Fig. 4.39 (Opposite Top) Top lighting diagram.

Fig. 4.40 (Opposite Bottom) 'Borrowed light diagram.

Fig. 4.41 (Top) Light from multiple directions diagram.

Fig. 4.42 (Bottom) Translucent and perforated screening diagram.
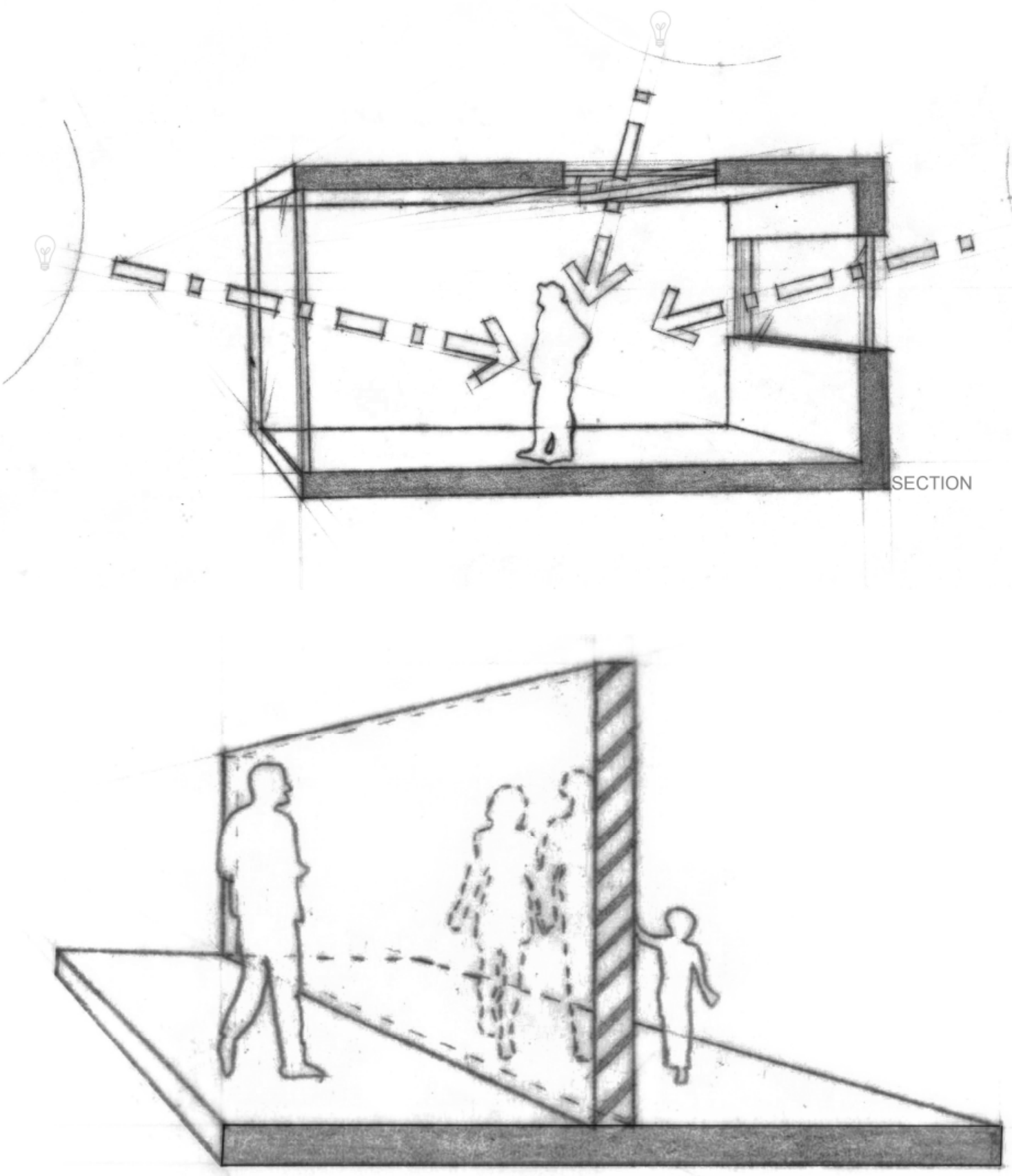

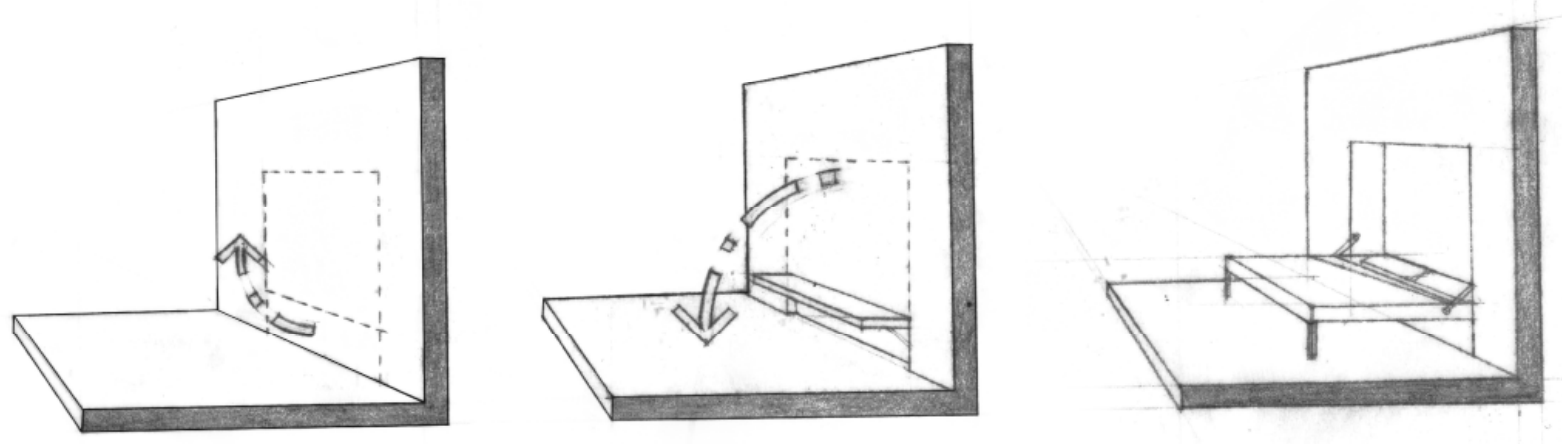

Due to limitations of floor area, architects of micro-architecture employ strategies to maximise space by programming a single volume or element to take on multiple functions. Rooms adapt and transform with a fluidity that emulates the lives of the inhabitants. Depending on the activity, a partition may slide over changing the room from public to private. Seating may be hidden away to be replaced by a fold-down bed. More simply, a kitchen work bench becomes a dining table. These convertible spaces are a clever way of accommodating all of the required functions of a small residential program. They are also a convenient way to simplify the furniture items required by the occupants, thereby reducing clutter, which can reduce the perceived size of small spaces. 


\section{$\underline{\text { Custom Furniture and Built-ins: }}$}

When approaching small house design, furniture plays an important role. Lessons can be learnt from the Japanese precedents, many of which incorporate custom made built-in furniture; the furniture becomes part of the architecture. Built-ins are generally conceived as smaller pieces and are treated as part of the building envelope. Examples include simple shelving, cabinetry or seating with incorporated storage. Not only can carefully designed furniture use space efficiently, but the visually restful effect that clutter-free, complimentary built-ins have on the environment can be very powerful.

Designers often employ built in pieces of furniture to maintain and reinforce their aesthetic intent. In a small space, this aesthetic control is important but furniture design and placement can, quite

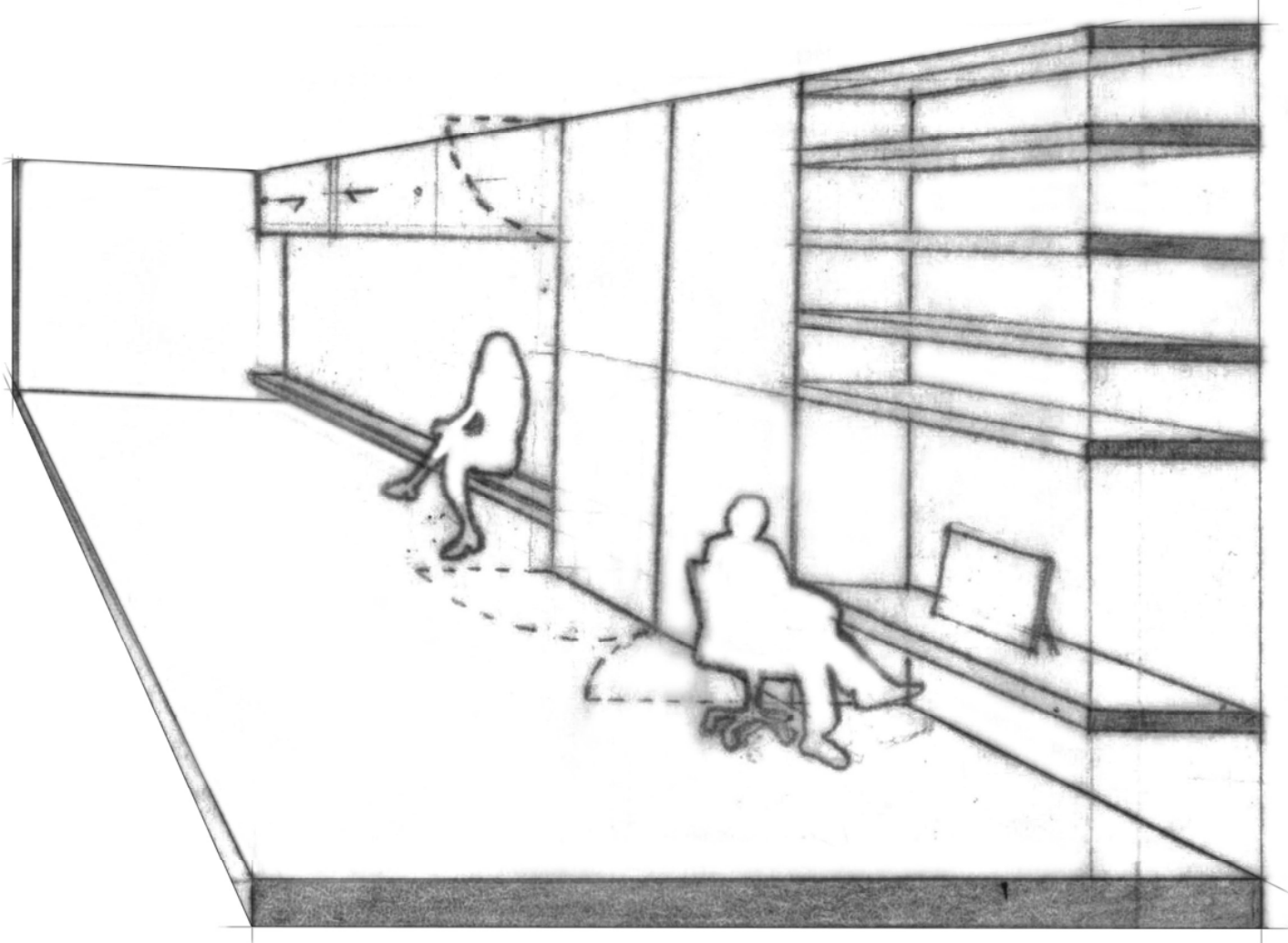
simply, save space - or at least use the space more efficiently. (Smith, 1995, p. 63) 
organisational simplification of the interior functions, in the form of built-in and custom fit furniture, the architect can preserve the ostensible continuity and openness of an interior space. ${ }^{49}$

49 This strategy is recommended to be used with caution. Limiting the amount of the inhabitants individual pieces of furniture, the sense of ownership through personalisation may be affected. With a high turnover of occupants in apartments, it is necessary to instill ways in which people can personalise space. While the built-in furniture is beneficial, it is suggested to be used in combination with loose pieces which are more individualised. 


\section{3-Conclusion:}

Japanese architecture was chosen to be analysed for this work due to its extensive development in the region of micro-architecture - a result of the increasing urbanisation and population of Japan. This chapter has looked at many examples through the technique of tracing floor and section plans to gain understanding of the functional programming and space constraints within these buildings. While extracting nine specific examples to be further analysed it is seen that several techniques are utilised to increase the perceptions of size and maximise the quality of spaces which would otherwise suffer from their constraints. Removing these techniques from their origin - eliminating context and culture - they can be studied as independent strategies. These strategies are abstracted and explored through diagrams that discuss the positive implications and offer several design options, expanding the method in which the strategy can be explored in different situations. It is established that space can appear bigger through the use of external sight-lines (linking the interior to the extended space of the surroundings), the infiltration of natural light and the extension of interior heights. The tight constraints of a space can be maximised through built-in and custom designed furniture, reducing the number of additional elements, therefore minimising clutter. Finally, the design of circulation is key in micro-architecture with circulation explored beyond the horizontal into the use of stacking vertical spaces, the introduction of mezzanine and split levels and the secondary use of rooms as circulation space. The following chapter will implement these strategies in a New Zealand context, introducing the concept of Japanese microarchitecture to the urban areas of New Zealand's cities. Furthermore, the strategies will be used to combat the issues and problems identified in the small apartment survey in Chapter Two. 

ADAPTATION \& APPLICATION

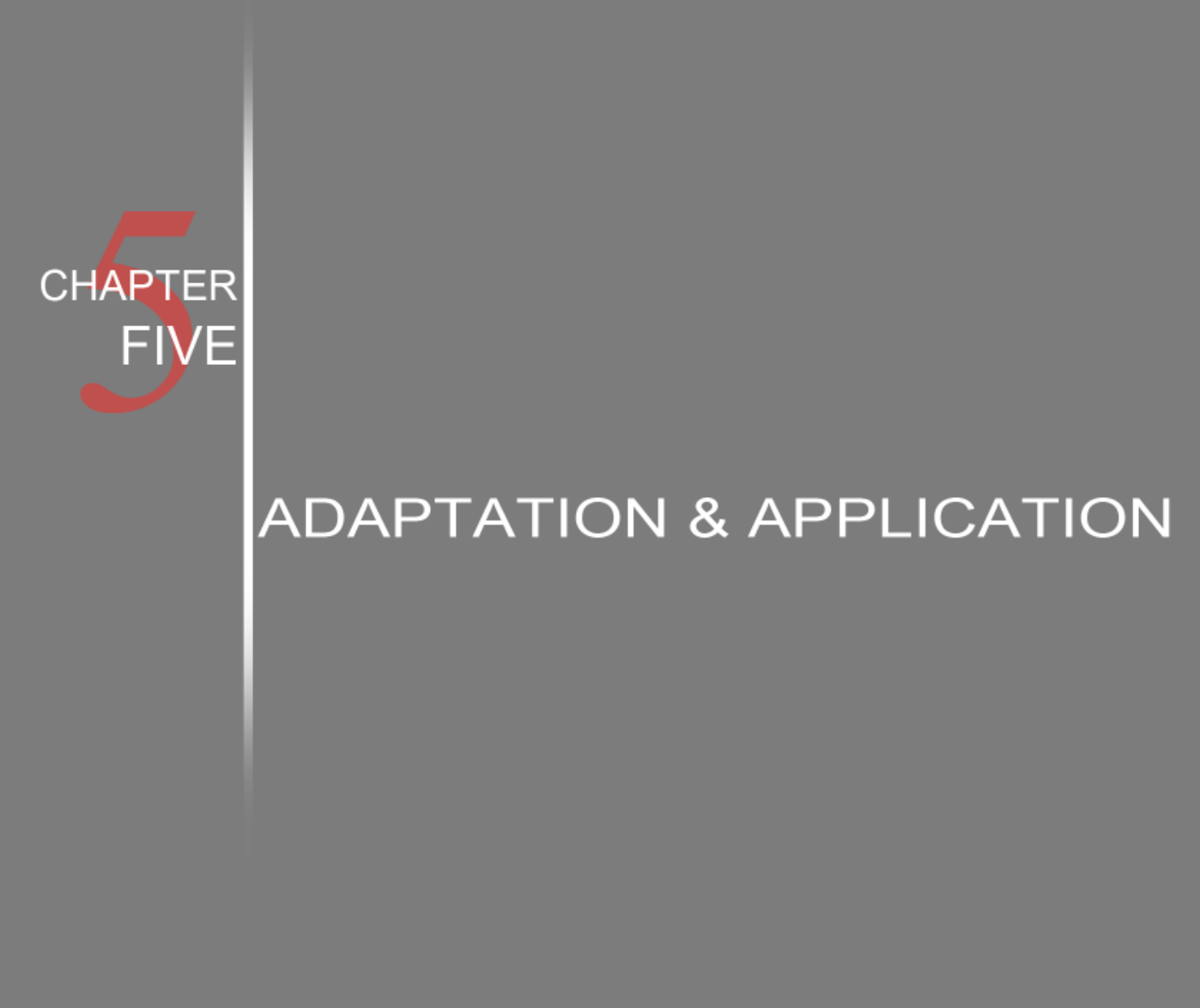

N




\section{1 - Introduction:}

From the previous chapters it was recognised foremost that, with the trends of urbanisation, there is an increasing need for urban accommodation. However, it was revealed that the majority of current urban apartments which seek to address this need feature many flawed design and planning characteristics. Secondly, several key architectural strategies were identified as a result of Japanese precedent analysis. These strategies are intended to be applied in a New Zealand context to develop small apartments of a higher quality. This chapter seeks to test these strategies through their application in the design of an apartment building in Auckland. The first sections (5.2 and 5.3) introduce the design brief, programme and site. The following section (5.4) progressively explains the building's design including floor plans, sections and perspectives. Within this section the application of the strategies is also examined. Finally, the last section (5.5) discusses and reflects on the design and the application of the design and planning strategies.

\section{2 - Design Brief and Programme:}

- An urban apartment complex which contains a variety of small apartments.

- A range of bedroom numbers including studio, one, two and three bedroom apartments.

- Small urban site to demand space efficient design and a creative response to tight constraints.

- Requirement to conform as close as possible to the main points of the district plan.

- Create a design that makes high-density use of the site.

- Include communal spaces. 
- Employ the Japanese design strategies within the design of not only the apartments but the communal areas where applicable.

\section{3-Site:}

This section outlines the selection and consequent analysis of the site.

\section{$\underline{\text { 5.3.1 - Site Selection: }}$}

The search for an appropriate site was limited to Auckland City which was the location of many of the analysed examples of New Zealand apartments. It was also identified earlier that urbanisation and the number of apartment dwellers is greatest in Auckland. A small or awkward shape was an important site attribute to demonstrate how even small sites can be utilised in a way to successfully increase residential density. At the same time it imposes more physical restrictions on the site, in turn demanding a more creative design approach, and will test the capabilities of the adapted design strategies. Other important considerations when selecting a site are the amenities, in particular the proximity to transport nodes and shopping centers. With this criteria in mind, a site was selected at number 15 Cheshire Street in the inner-city suburb of Parnell, just to the east 


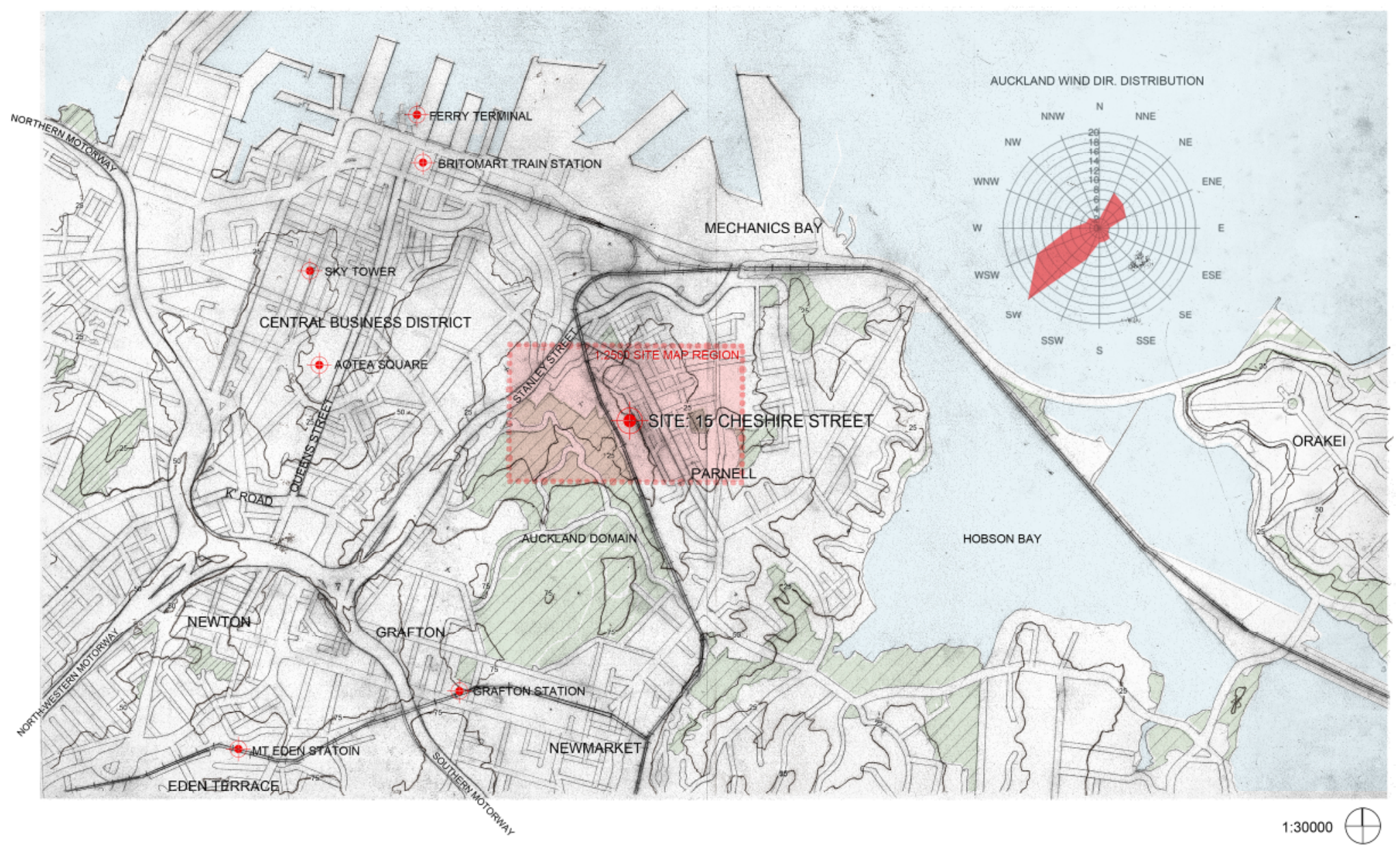

Fig. 5.1 Site location within Auckland. 


\subsection{2 - Parnell:}

Parnell, while being the oldest suburb in Auckland, is a lively place. 'Parnell Village' and the peripheral areas are host to a range of residential, retail and commercial activities centered around the retail strip of Parnell Road, which remains a prime example of "traditional suburban commercial/retail strip development that evolved along the primary thoroughfares in Auckland's early days". ${ }^{50}$

As a result of Parnell's age it has gone through many eras of change. Many remnants of these various eras remain as heritage or historically significant buildings, providing a certain quality which contributes to the suburb's character and identity. The eclectic character of Parnell can be attributed to the great diversity of buildings and lot sizes which are a reflection of the various eras of development. Modern, utilitarian structures provide an appropriate contrast to the character buildings.

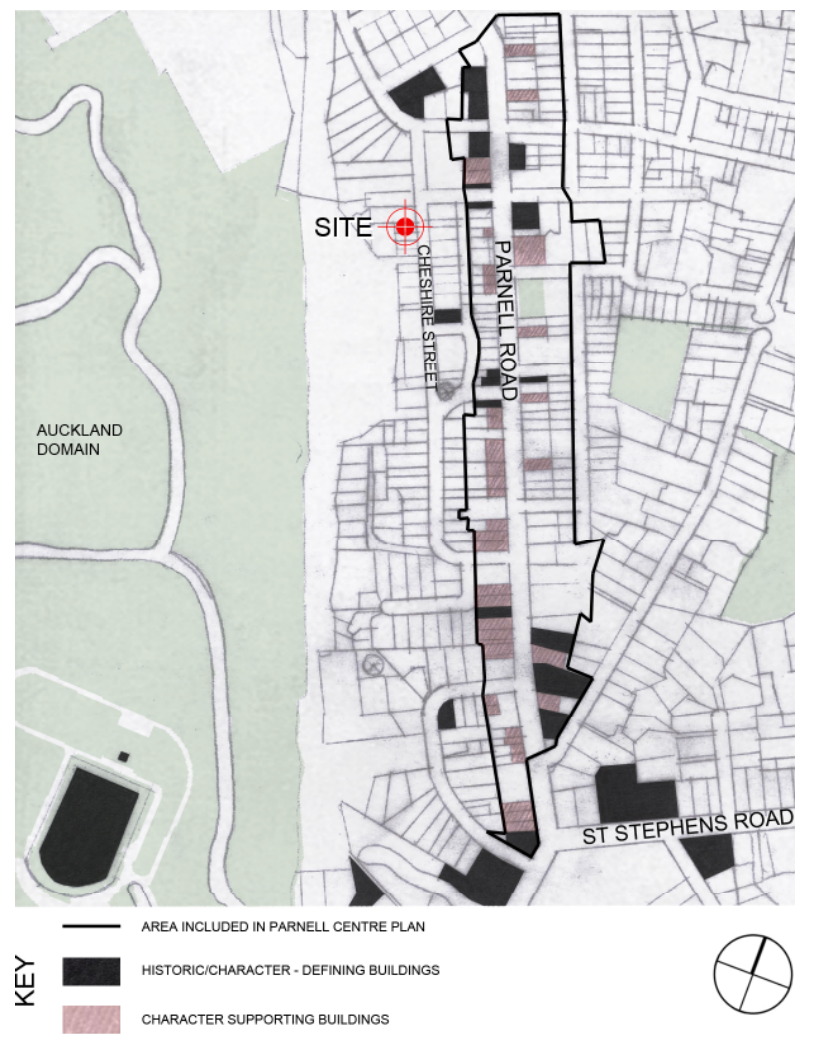

Fig. 5.2 Parnell heritage and character buildings. 


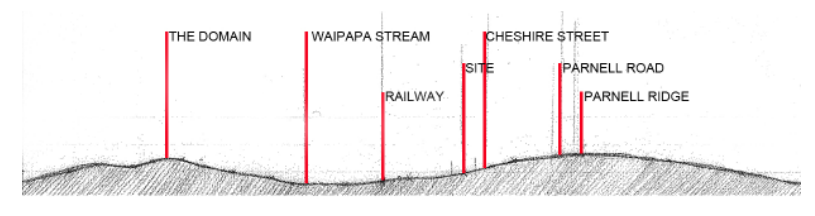

101

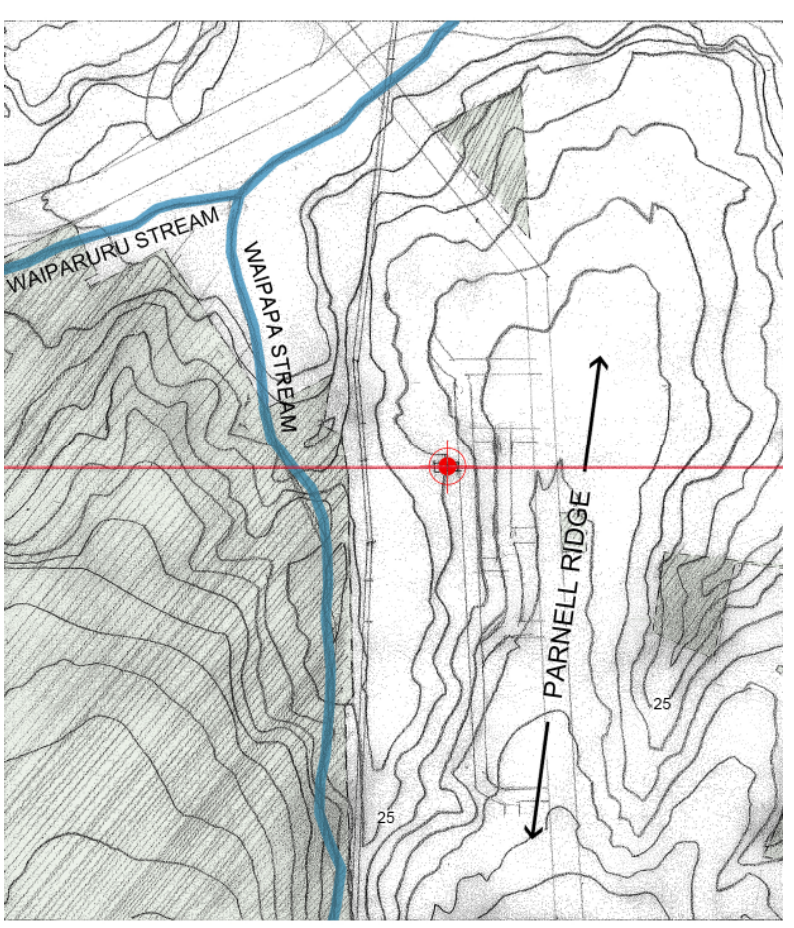

Q
Parnell's topography has had a significant influence on the suburb's development patterns. Parnell Road, the main street, follows the naturally formed ridge-line which offers views towards the harbour, Auckland Domain, the Museum and the traditional neighbourhoods spreading outwards from this center point.

This rise has determined the street layout; a comparatively fine grid structure where the streets running in the north-south direction tend to span longer, running parallel to the ridge-line. Smaller streets link these roads. The narrow streets and sites are also a reflection of the topography's control on development, producing a relatively dense building fabric lining the street frontages. The aforementioned density has lent itself to Parnell's pedestrian friendly quality. Similarly, the wide mixture of uses, activities and amenities further enhances the strong pedestrian orientation of Parnell.

The commercial core supports high levels of pedestrian activity throughout the day, with arriving office workers and employees early in the morning, commuters travelling from Parnell to the city centre and Newmarket, shoppers and the cafe scene during the day, followed by the evening bar and restaurant patrons. The area also attracts a significant tourism market by virtue of its proximity to other attractions, such as the Parnell Rose Garden and the Auckland Museum, and its inherent character. (Auckland City Council, 2004, p. 3)

Fig. 5.3 Parnell topography map. 

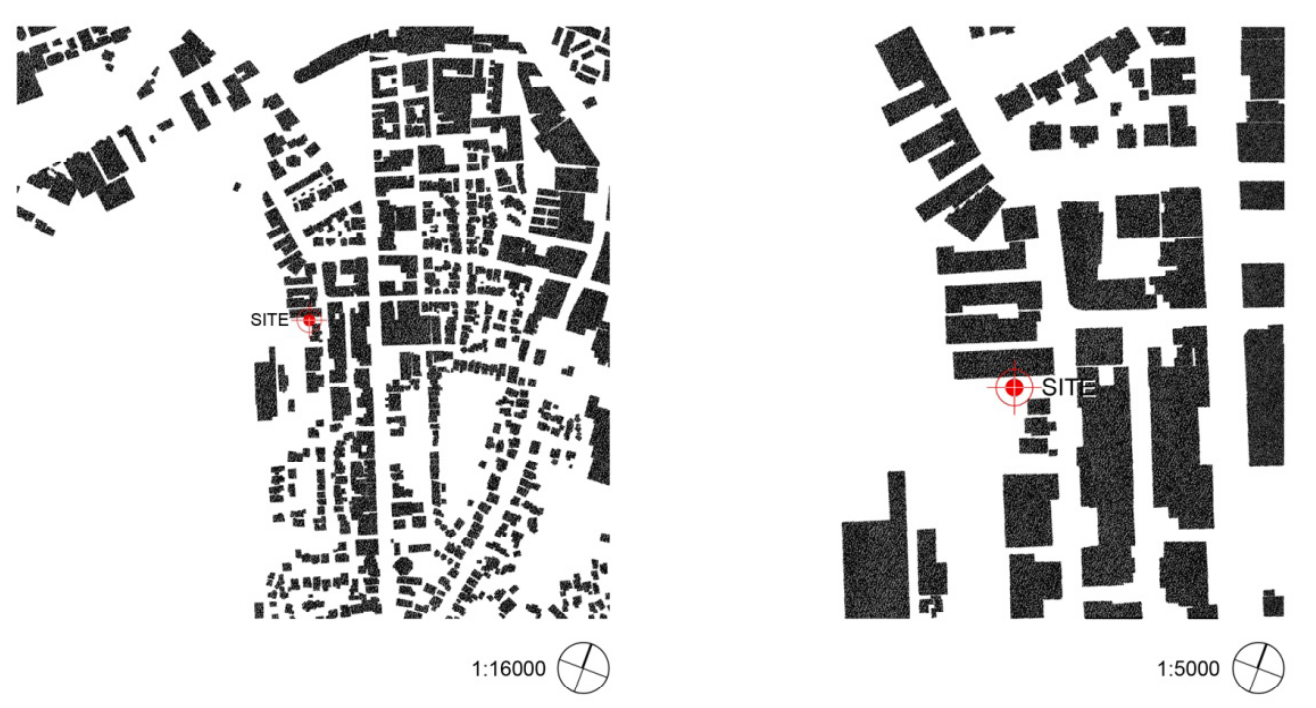

Fig. 5.4 Figure-ground maps.
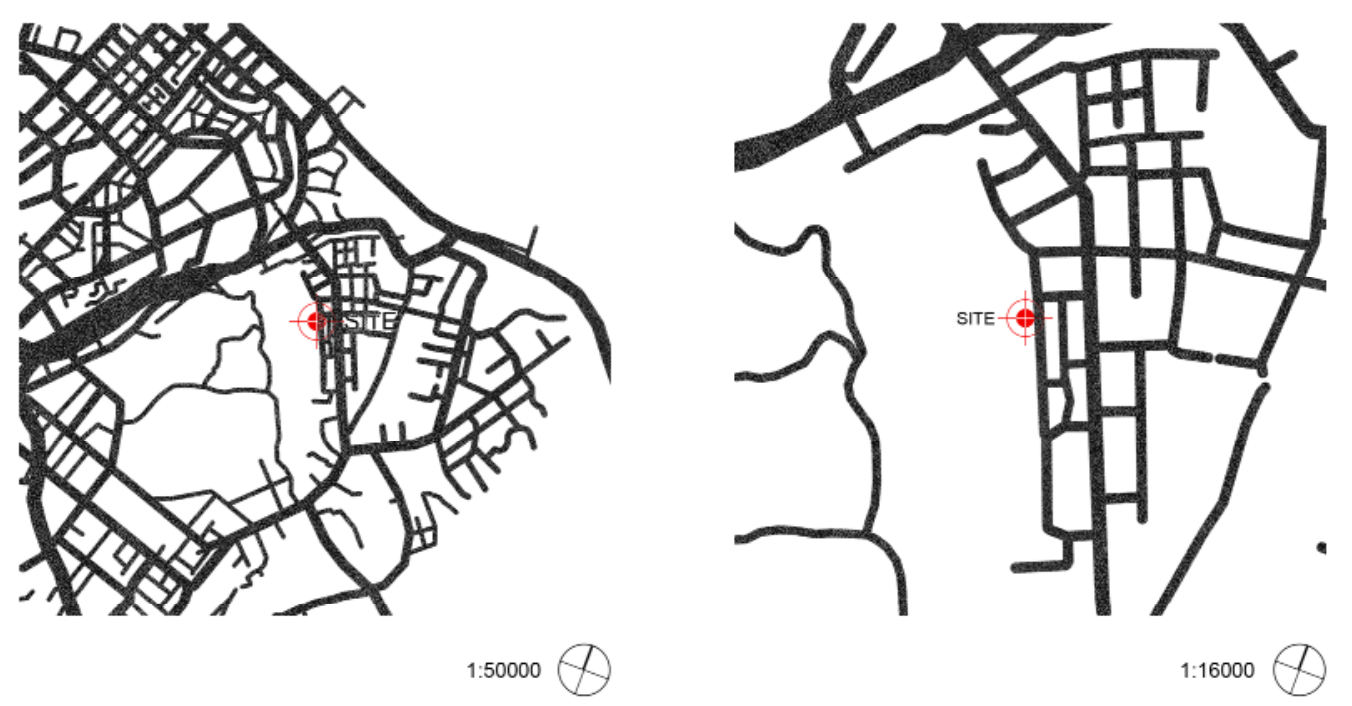

Fig. 5.5 Street grid maps. 


\subsection{3 - The Site:}

Prior to being cleared, the site contained a small detached dwelling, somewhat typical of more traditional New Zealand housing. The three detached dwellings to the south of the site represent the leftovers of what was a traditional residential neighbourhood. Now however, the other buildings in the surrounding vicinity result in the development of a mixed use zone, where higher-density residential buildings are mixed with commercial activity.

Cheshire Street is located along the east boundary. It is a narrow street with a low volume of vehicular and pedestrian traffic, which may change with the future development of the proposed train station around 100 meters to the west. This train station would strengthen the connection of Parnell to surrounding areas and specifically looks to promote the pedestrian link and neighbourhood cohesion between lower Parnell and the Domain, Carlaw Park across the rail corridor and the University district beyond. ${ }^{51}$

The adjacent site to the west is currently an open car park, yet it is still recognised that any surrounding site has equal potential to be developed, and consequently is likely to affect the site's view shafts, privacy and day-lighting. In its present state, the site affords views across the railway corridor to the rising slopes of Auckland Domain opposite. Running along the northern boundary is a three story commercial building.

$51 \quad$ Auckland Transport. (2011, November 15). Parnell Station Public Information. Retrieved November 2011, from Auckland Transport: http://www.aucklandtransport.govt.nz/improving-transport/current-projects/Rail/ Documents/parnell_station_intial_meeting.pdf. 


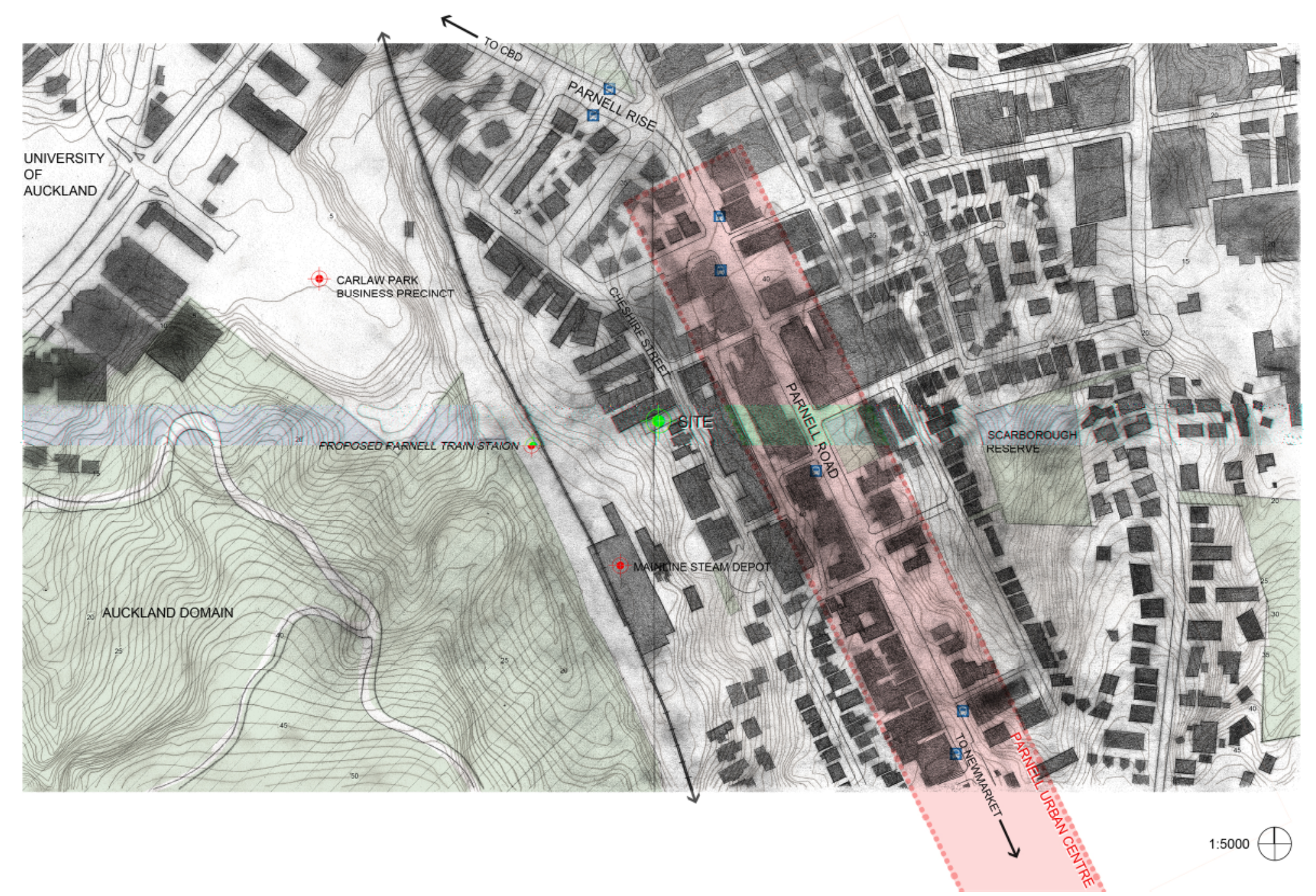



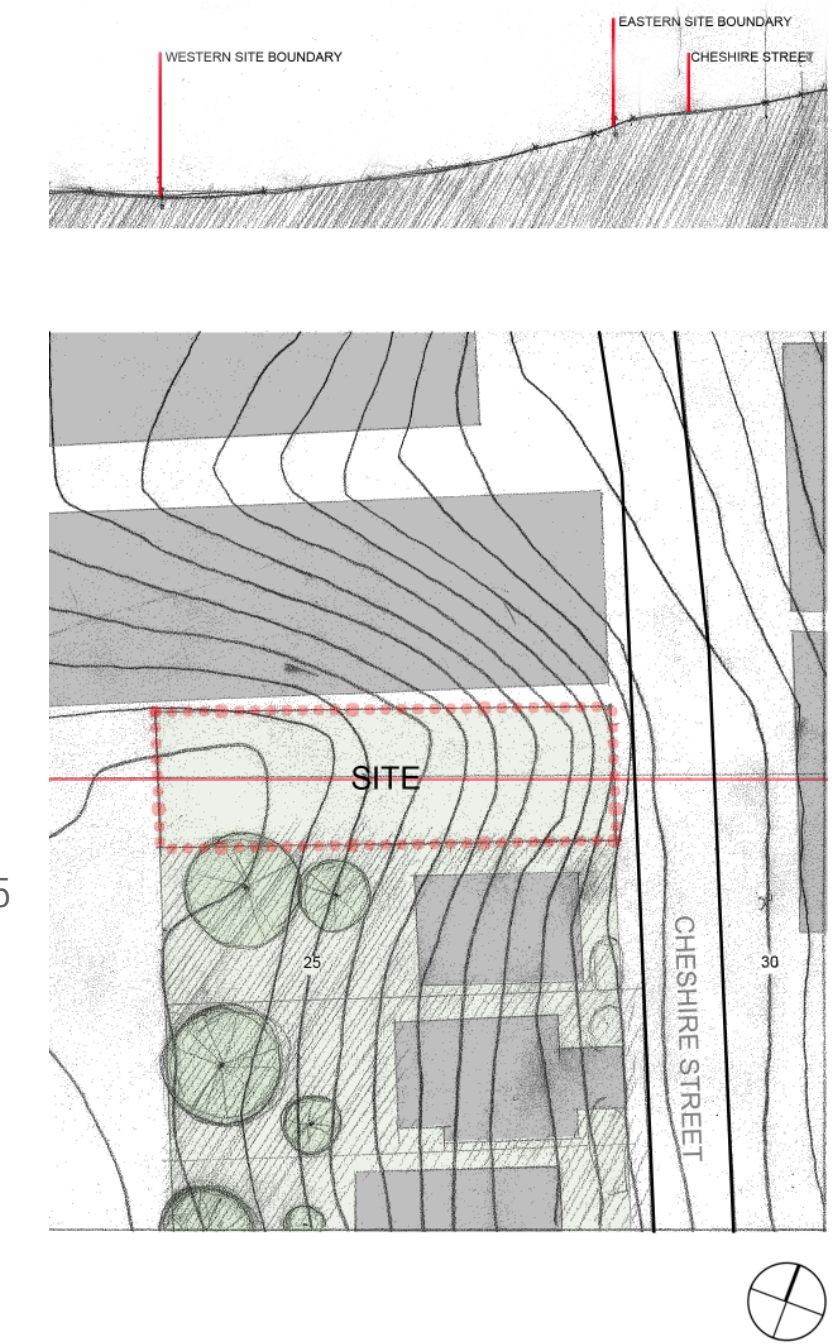

The site itself is rectangular aligned from east to west, its length perpendicular to Cheshire Street. From the street, the site slopes down to the rear, with the rear boundary displaced vertically by approximately four meters from the street. At just under 300 square meters (30m by $10 \mathrm{~m}$ ), the site may be considered small for a multi-unit residential complex and therefore produces a development which must creatively respond to this constraint.

This study attempts to recognise the key regulations and guidelines from Auckland's District Plan in order to apply some further controls and parameters for the design. However, not all controls are followed and some creative license has been used in the interpretation and application of the regulations. The main points from the District Plan which pertain to this site and building type while be highlighted when addressed in the following design section (5.4).

Fig. 5.7 Site plan. 


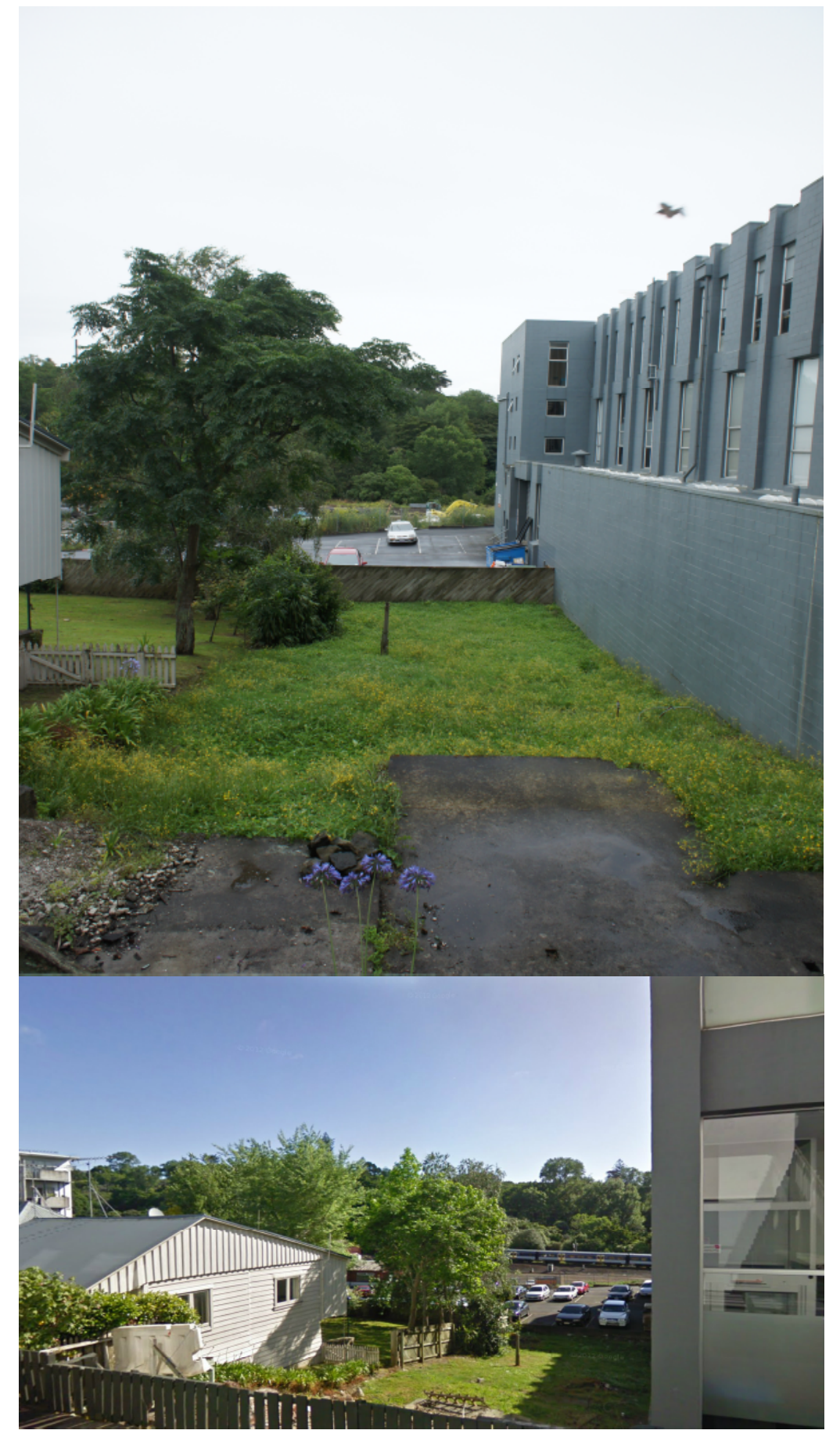




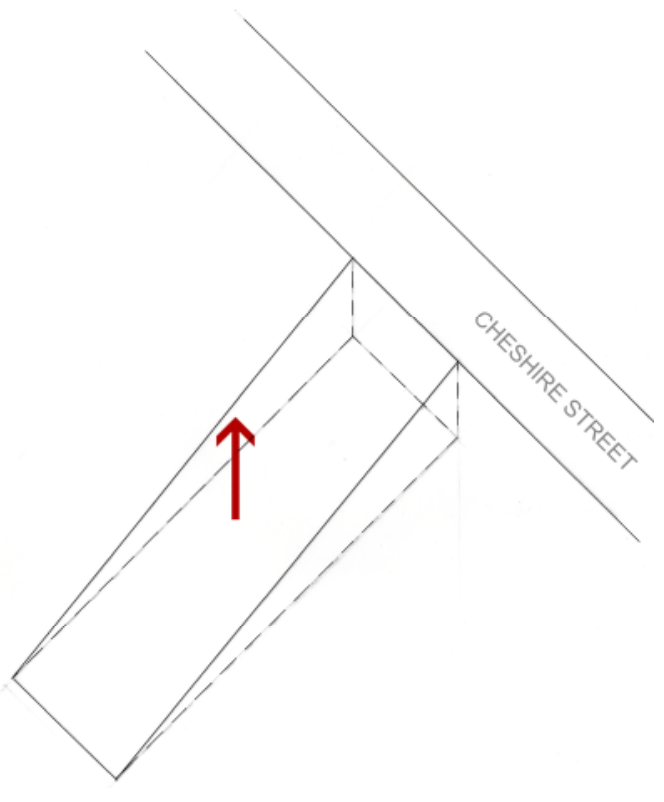

Fig. 5.9 Stage one diagram: Site extrusion 107

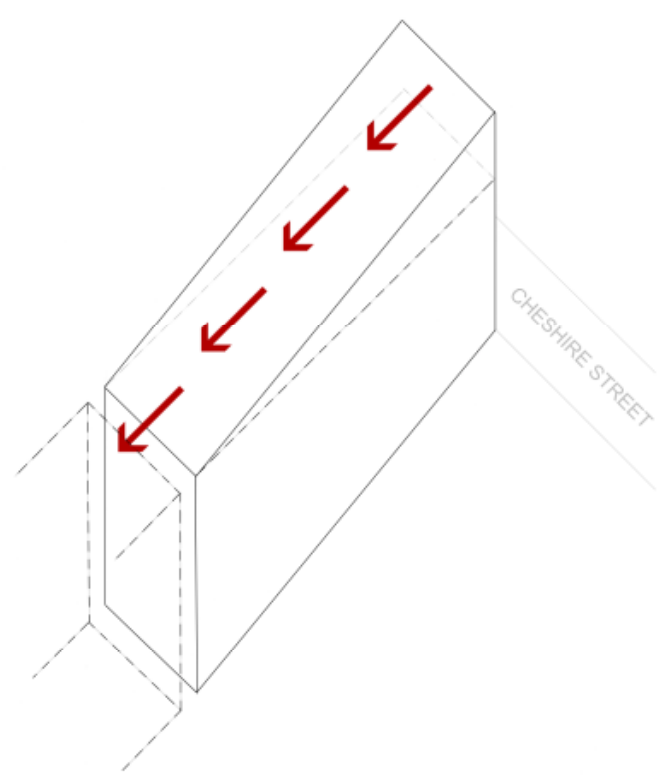

\section{4 - Building Design:}

This section describes the design of the apartment building, initially outlining the general design before expanding with further detail of each apartment and the application of the Japanese strategies.

\subsection{1 - Building Design Process and Development:}

First, an overview of the design is undertaken with a focus on key design decisions relating to the overall tectonics of the building. The following diagrams illustrate these main points.

1. A simple vertical extrusion of the site's footprint to the maximum building height creates a large volume to manipulate. According to the District Plan there are two options for determining the maximum height plane:

a. The vertical distance between the highest part of the building and the average ground level, being the average level of the ground at the external foundations of the building or

b. The vertical distance between ground level at any point and the highest part of the building immediately above that point.

By using the sloping site method for determining the maximum height plane there are opportunities to create views over potential developments on the adjacent site to the west in the direction of the Domain. 
2. The District Plan requires car parking to be included with residential developments; one park per residential unit is required. The number of car parks that can be squeezed into the small site will restrict the number of apartments. The guidelines also suggest that car parking should not be at the front of the site but instead located towards the rear. With these points in mind several iterations of car parking layouts within the site were designed. The small, narrow site prevented most traditional forms of parking to be incorporated. Ultimately this lead to the adoption of a multi-car stacker, in this case it provides nine full sized parks. Its location within the building's volume is towards the rear, inset from the building's boundary, and at the maximum distance for the access ramp to remain within the allowable slope ratio. Additionally, it is sunken down to prevent it occupying a valuable position on the site.

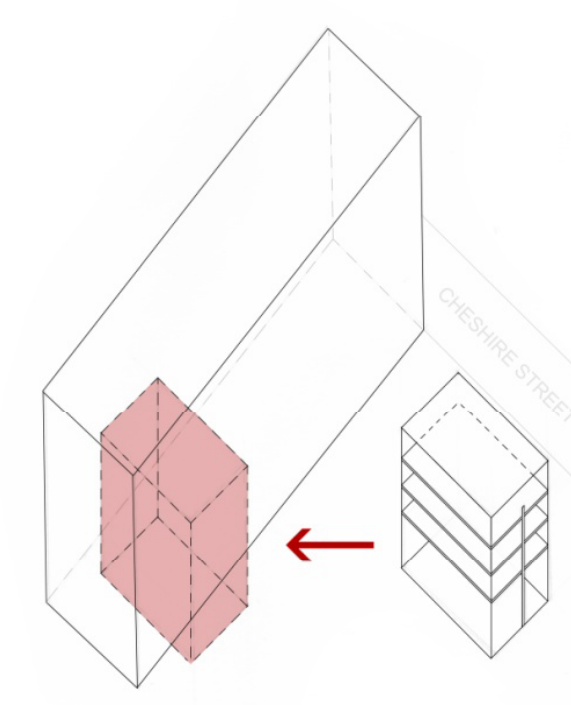

Fig. 5.11 Stage two diagram: Insertion of car stacker. 


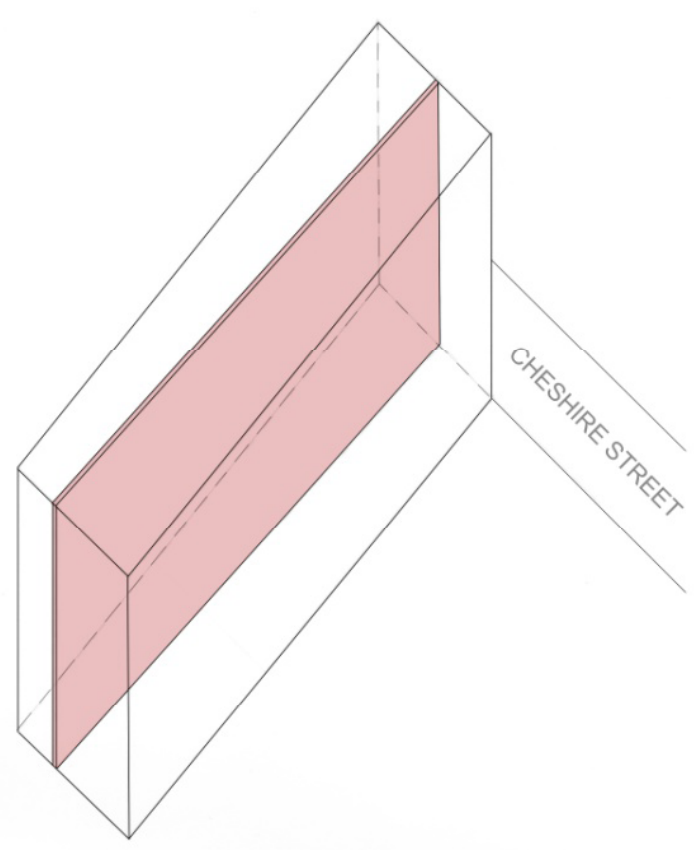

Fig. 5.12 Stage three diagram: Diagonal division.

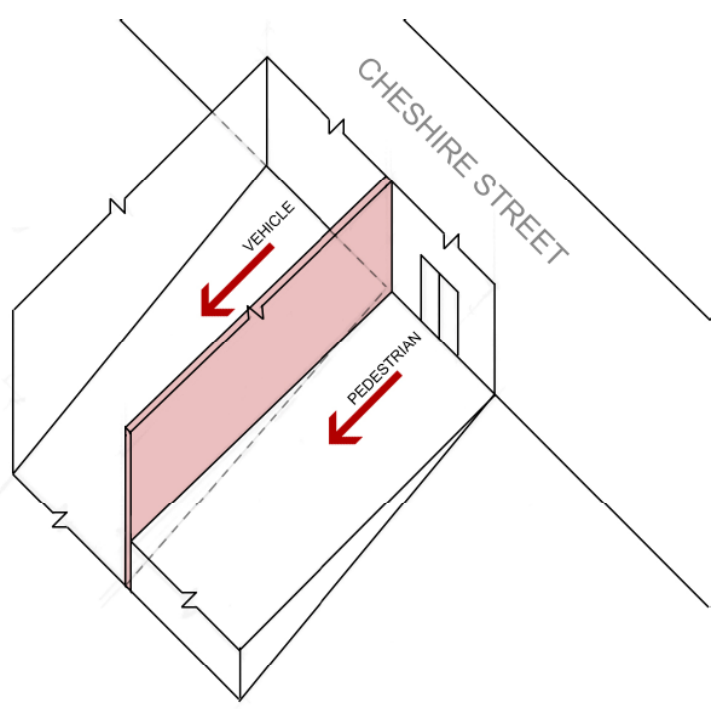

Fig. 5.13 Dividing wall separating pedestrian and vehicular access.
3. A diagonal partition is introduced dividing the volume lengthwise. First of all, this partition separates the vehicle access ramp and pedestrian access via the lobby. The angle allows for space at the road boundary of the vehicle access ramp wide enough to incorporate a passing bay. This bay's dimensions also allows it to be used as a loading zone for a large van, when on-street loading bays are unavailable. Through the addition of a passing bay, and given the short length of the access-way, the width of the ramp can be reduced, allowing its tapering to a narrower width, freeing up more space for other functions. The longitudinal division is continued through the height of the building and is intended to divide the building in a way that promotes a variety of apartment types, shapes and sizes in order to test the design strategies under different conditions. 
4. With the main vehicular and pedestrian entry points established, the building's primary circulation routes are developed. The intention here is to limit horizontal circulation to the lower levels, thereby privileging the higher levels to apartments. Two vertical cores are linked at the ground and basement parking levels by horizontal routes. From here, access to each apartment is via the vertical cores. Amongst these public circulation spaces, voids are introduced to create a more spacious environment and reduce the total floor area of the building (within the allowable ratio as determined by the District Plan/Council regulations).

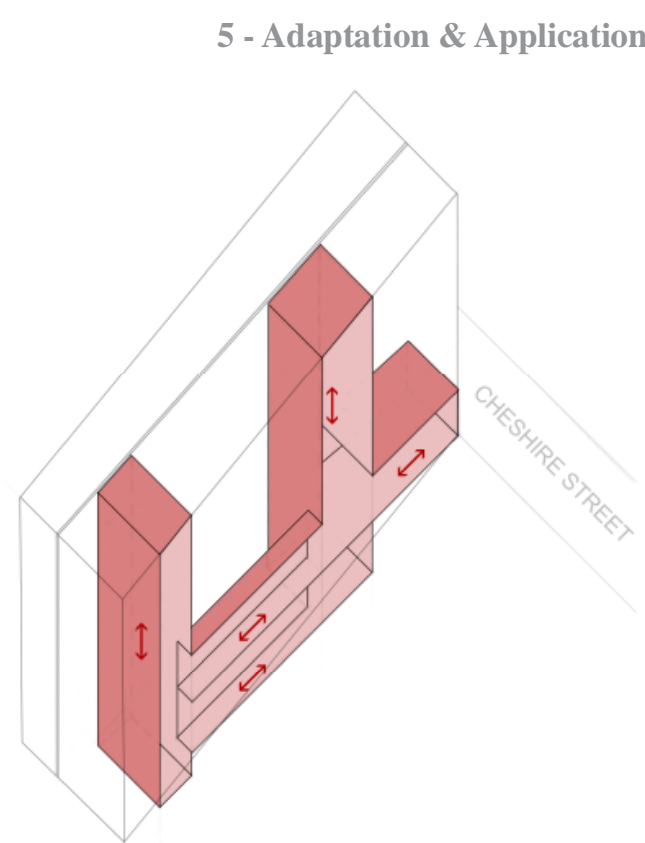

Fig. 5.14 Stage four diagram: Circulation routes established.

5. At the rear (west) of the site the north-west corner is removed to establish a communal garden area, and provide an open space for the adjacent apartments to view. Also, the void created enables more daylight to be provided to the adjacent and lower apartments.

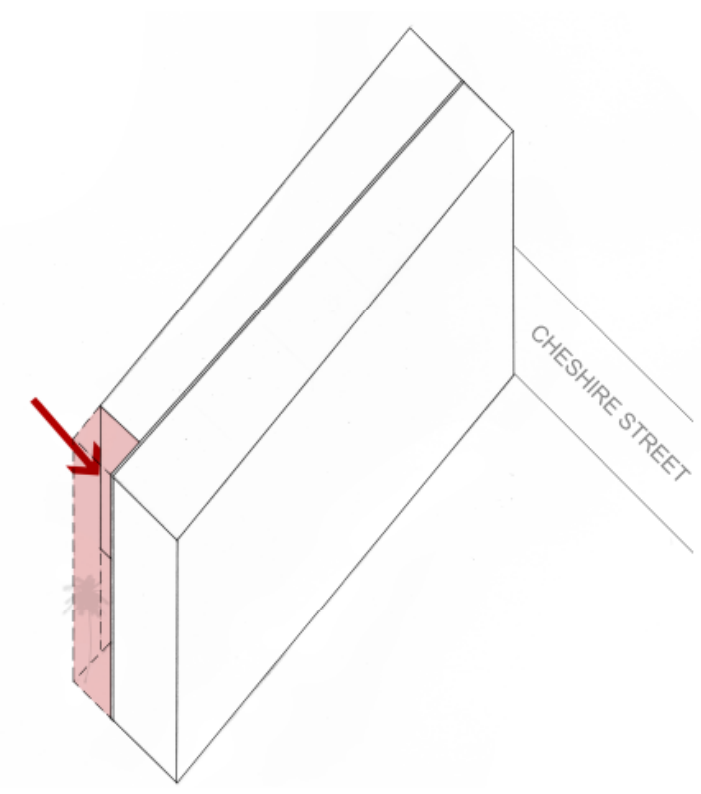

Fig. 5.15 Stage five diagram. Garden void created. 


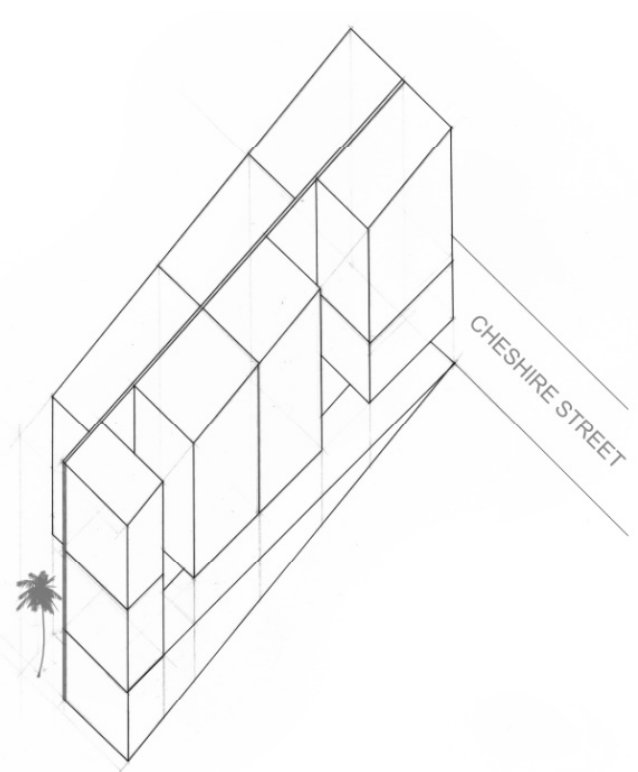

Fig. 5.16 Stage six diagram: Division of volume 111

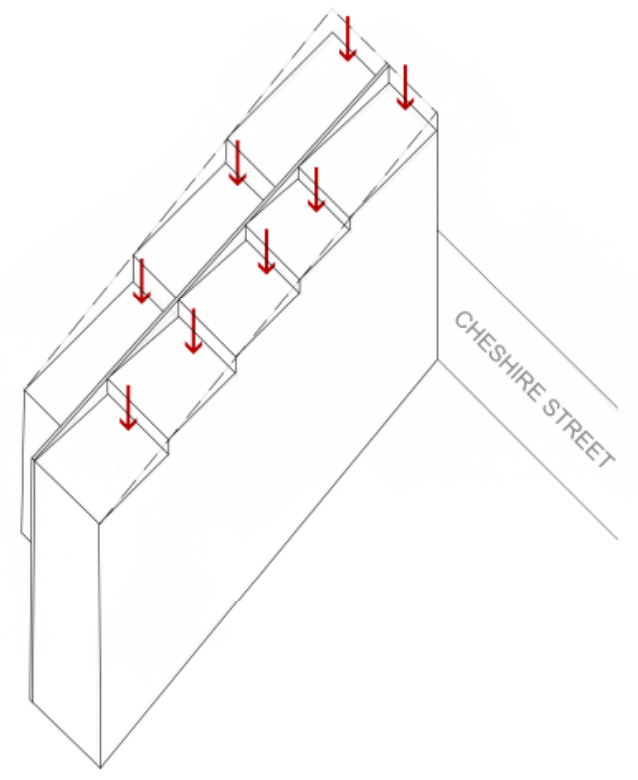

Fig. 5.17 Stage seven diagram: Sloped roofs formed into terraces.
6. The volume is then divided into nine apartments including: two studio apartments, a single one bedroom, five two-bedrooms and one three bedroom apartment.

7. Finally, the sloped roof is terraced to provide rooftop sanctuaries for the apartments. As the rooftop rises towards the front of the site, a sight-line to Auckland domain is gained over the apartment in front. The inclusion of rooftop gardens and terraces also provides a bonus floor area allowance, increasing the allowable limit of total floor area. 


\subsection{2 - Plans, Sections and Perspectives:}

This section will explore the functional layout of the apartment building design, presenting the design through the floor plans, sections and perspective images. While this section will provide a layout of the building in its totality, due to the complexity of the apartment design with vertical orientation and split levels the individual apartments will be detailed further in section 5.4.3.

\section{Basement 2:}

This level contains the residents' garden at the rear of the site, accessed through the western stairwell. This gives the residents a shared space to socialise and interact. The spa area, is a semi enclosed space where the inhabitants feel connected with the landscaped exterior while being protected from the elements. The tree within this outdoor garden becomes the focal point, creating a greater relationship to the natural environment and acting as a soft buffer between the residents and the harsher built environment surrounding the site.

\section{Basement 1:}

The car park is the prominent feature of the programme on this floor. The vehicle access ramp slopes down to the turning bay and on to the car-stacker (nine car capacity). Access to the apartments from this level is through two circulation cores; four apartments and the residents' garden are accessed via the west core and five apartments and the lobby via the east core. Also located on this floor is a storage space and rubbish collection area.

\section{Ground Floor:}

The main access to the building is located along the eastern boundary on Cheshire Street (18). Entry to the car park is through the tapering vehicle ramp. Separated by the angled wall is the pedestrian access into the lobby area and main vertical core. From this point, residents descend to the basement level. Conversely, the stairwell and lift accesses the apartments. Continuing towards the western core, inhabitants pass a small internal garden backed by a glazed wall allowing a view down to the space below. Further along, where the passage narrows, visual relief is created by an 
increased height of the space and windows on both sides. While this allows more light into the space, it also gives views outside and into other spaces thereby increasing the length of the sightline. Studio apartment ' $\mathrm{H}$ ' is accessed on this floor, and a lower level of apartment 'B' can be seen along the northern boundary (accessed from the first floor).

\section{First Floor:}

On this floor, apartments ' $\mathrm{A}$ ', 'B', ' $\mathrm{D}$ ' and ' $\mathrm{F}$ ' are accessed off the eastern circulation core. The void adjacent to this stairwell helps bring light down to the lobby below and creates a more spacious feel for what is dimensionally a compact circulation space.

\section{Second Floor:}

Entry into apartment ' $\mathrm{E}$ ' is via the eastern circulation core and apartments 'C', 'G' and 'I' through the western core.

\section{Third Floor:}

Located above the western core is a roof garden (12) which increases the allowable floor area of the building and provides a planted outlook from the roof terrace of apartment ' $G$ ' (10). Also seen on this floor plan are the two secondary access points to apartments ' $F$ ' and ' $E$ '. 

1. living
2. bedroom
3. kitchen
4. bathroom
5. closet/storage
6. study
7. dining
8. courtyard
9. terrace
10. internal void
11. external void
12. roof garden
13. elevator
14. car stacker
15. turning bay
16. vehicle access ramp
17. plant/machine room
18. lobby
19. cycle/storage area
20. rubbish
21. spa
22. residents garden

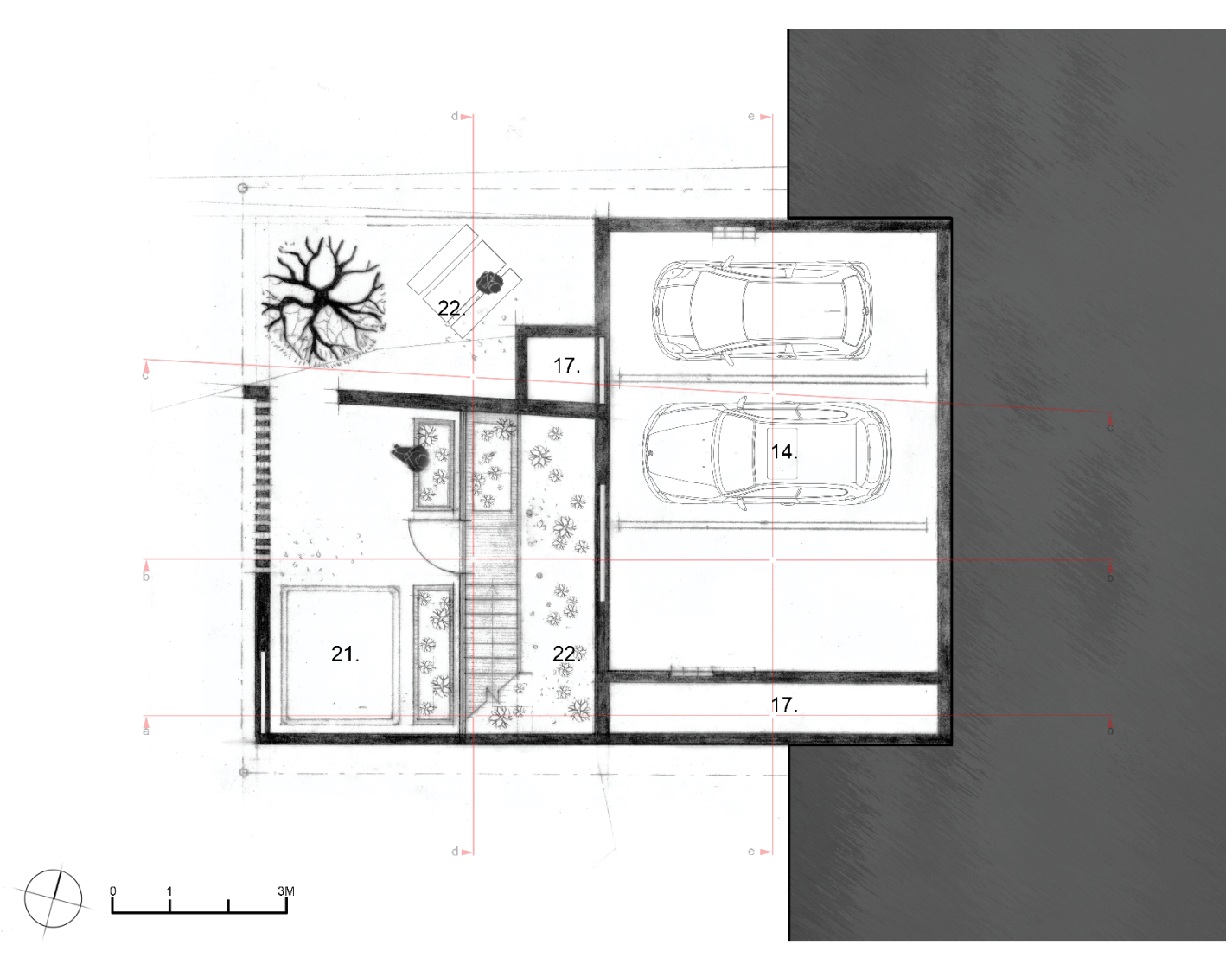

Fig. 5.18 Basement 2 plan. 


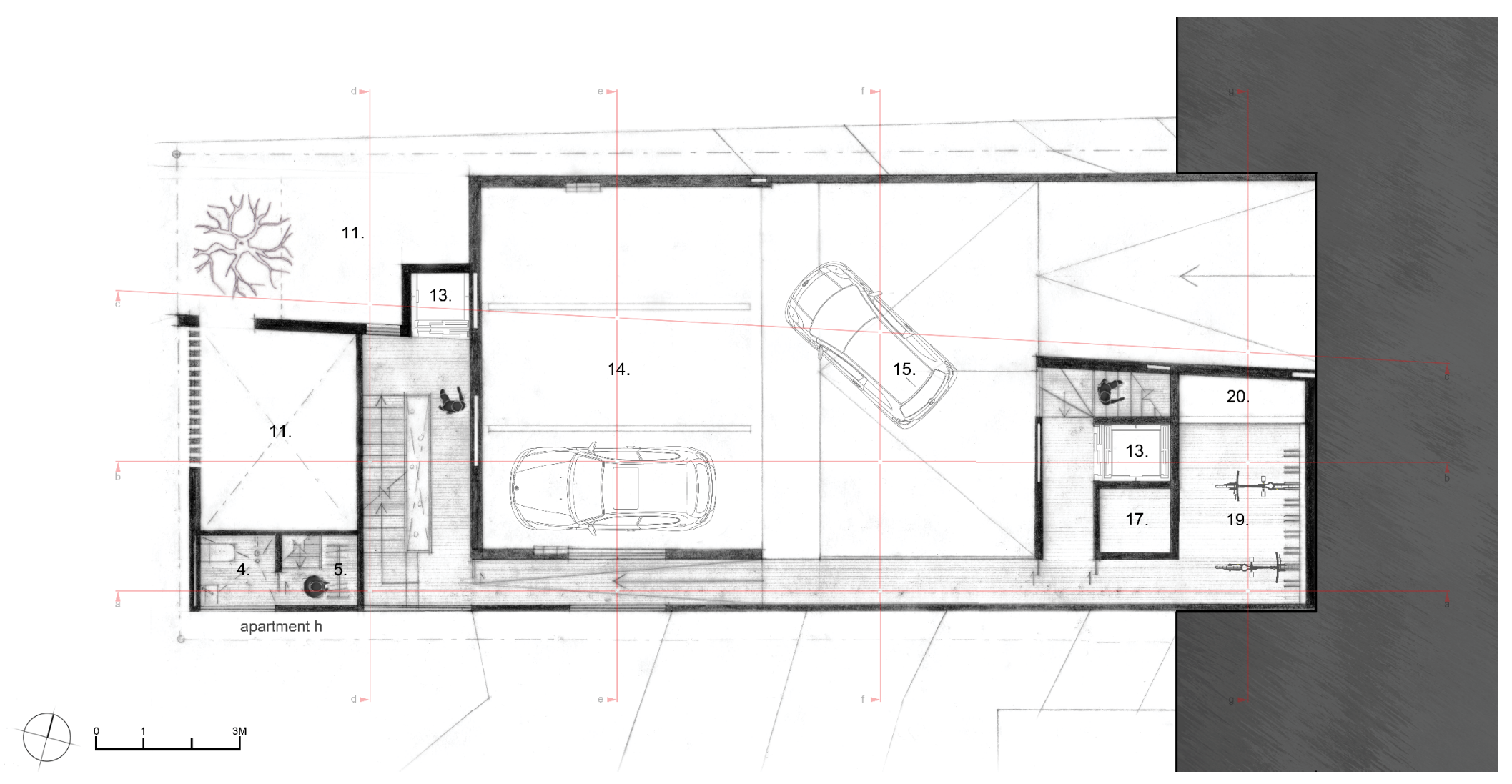


117

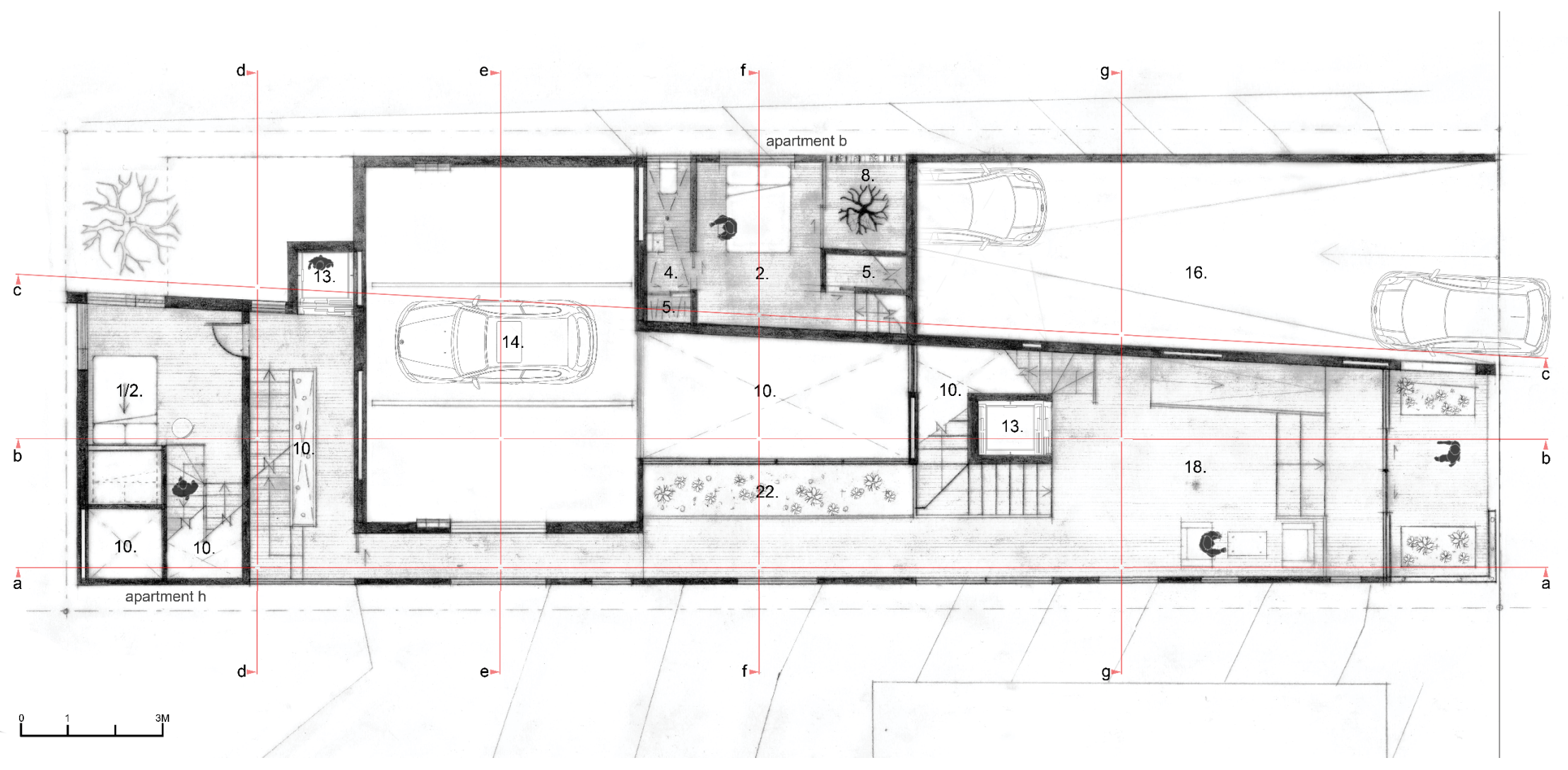

Fig. 5.20 Ground floor plan. 


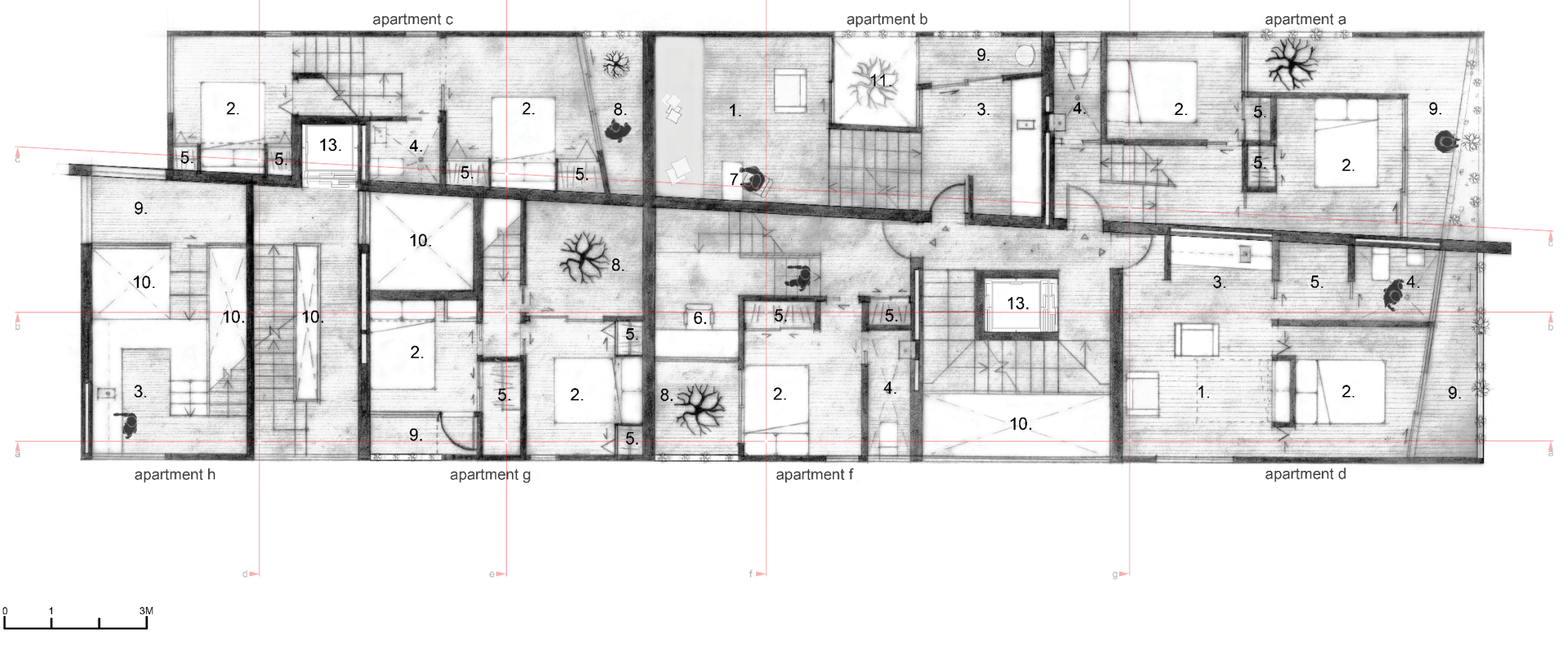




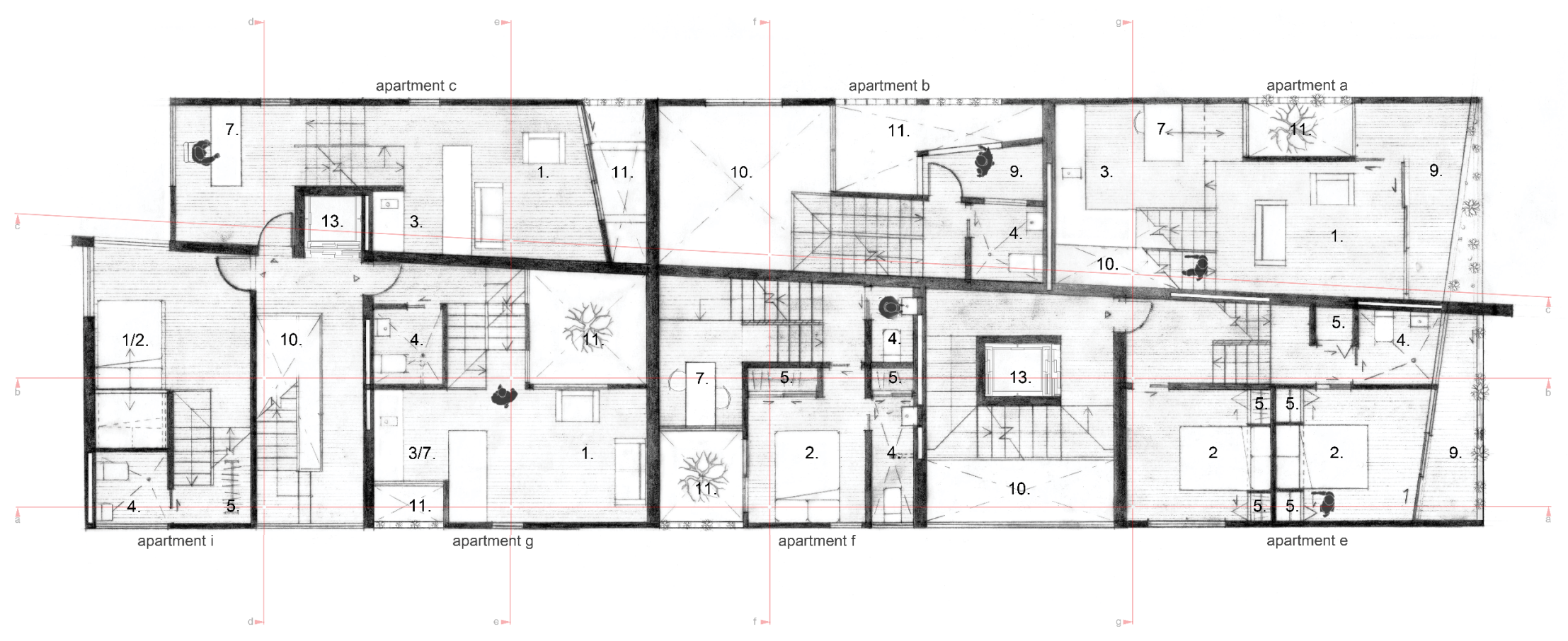

$\theta\left\llcorner i 1^{3 n}\right.$ 

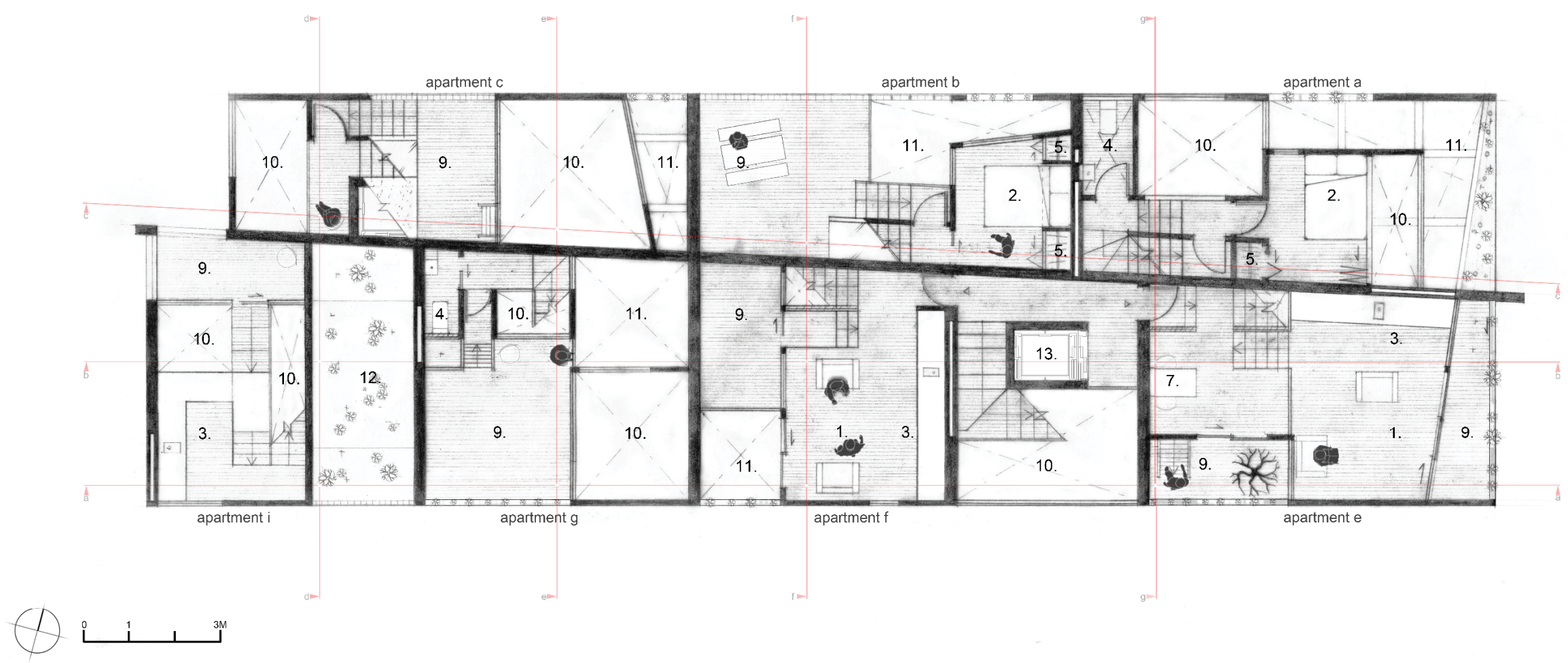


\section{$\underline{\text { Section A-A: }}$}

This section cuts through the primary communal circulation routes. It shows how the horizontal circulation is contained on the lower levels and links vertical cores. It also allows the terracing of the rooftops to be understood, while highlighting the view shafts created across the adjacent apartments and any prospective development to the west of the site.
living
bedroom
kitchen
bathroom
5. closet/storage
study
dining
courtyard
terrace
10. internal void
11. external void
12. roof garden
13. elevator
14. car stacker
15. turning bay
16. vehicle access ramp
17. plant/machine room
18. lobby
19. cycle/storage area
20. rubbish
21. spa
22. residents garden

\section{$\underline{\text { Section B-B: }}$}

In this section, the location of the car stacker within the building can be observed. It's sunken position means it intrudes less on the arrangement of the apartments above. Due to the site's limited footprint, the car stacker's arrangement operates in a vertical dimension to provide nine full sized parks by arranging them in a three-wide, three-high formation.

\section{Section C-C:}

This section reveals the vehicle access ramp leading down to the resident's car parking area. At either end of the steep section of the ramp, a slight change in the gradient creates a more gradual transition to horizontal. This stops vehicles from 'bottoming out'. 


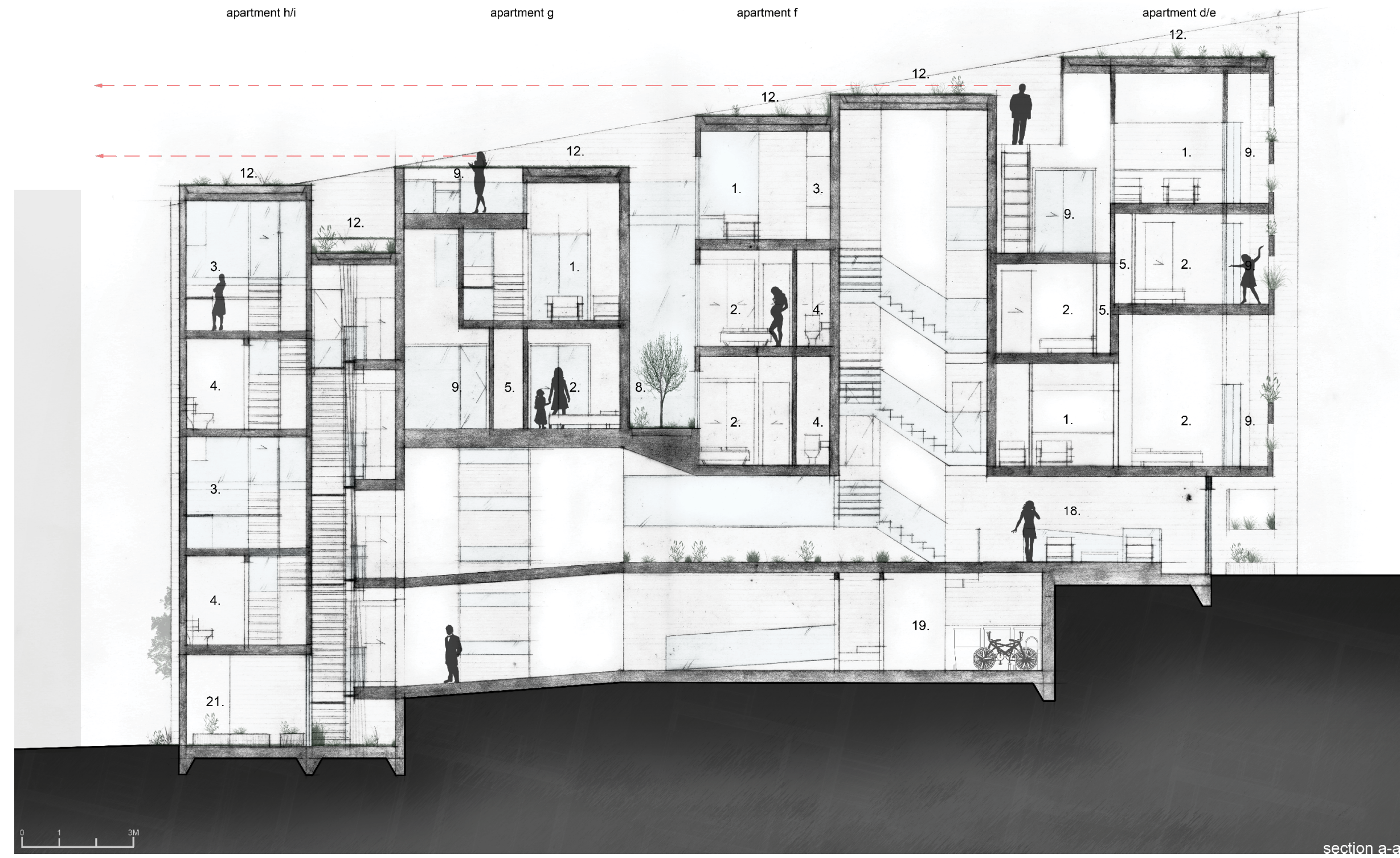


apartment hi

apartment $g$

apartment $\mathrm{f}$

apartment d/e

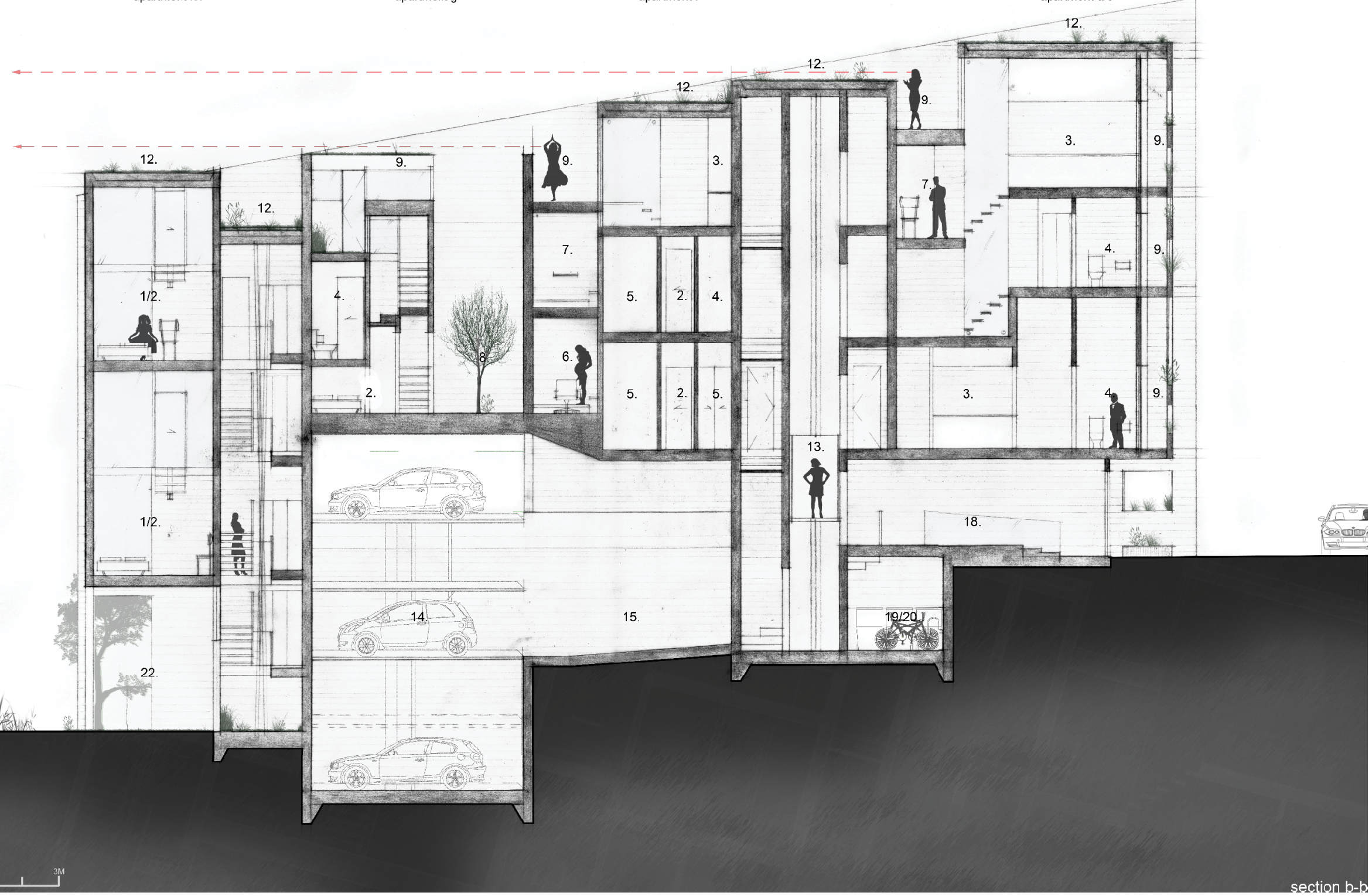

Fig. 5.25 Section B-B. 


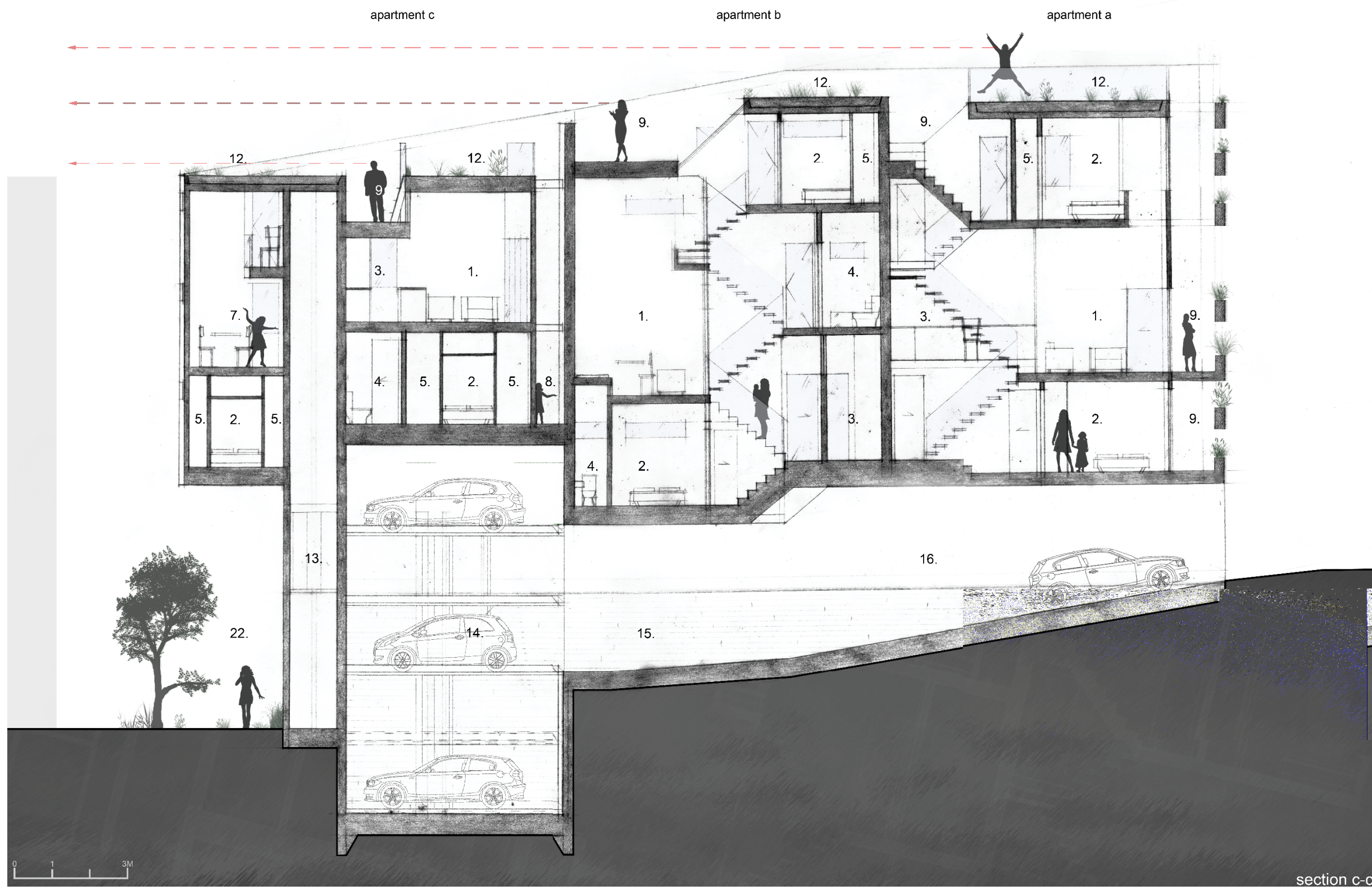




\section{Section D-D:}

Cutting through the eastern circulation core exposes the open tread staircase. The slender structural supports which interlace through the void emulate the trunks of trees supporting the canopy above. This is an abstract reference bringing nature into the building and is emphasised by the plantings growing below. This design motif is repeated throughout the facades. Fig. 5.27 shows the application of strategies observed in the Japanese analysed examples. Here through the use of open risers on stairs, sight-lines are increased and opens up the stairwell, maximizing the apparent dimensions.

\section{Section E-E:}

This view offers a transverse perspective of the car stacker and apartments ' $C$ ' and ' $G$ '. In an attempt to make use of every space available, a small overhead loft space under the stairs provides room for storage in the bedroom of apartment ' $G$ '.

\section{$\underline{\text { Section F-F: }}$}

Positioned above the vehicle turning bay is a small void space which extends the visual backdrop of the internal garden. These internal views help create a legible internal environment by making visual connections between different areas of the building.

\section{Section G-G:}

Section G-G describes the transverse relationship between the vehicle ramp, cycle storage and the communal lobby area. Above, in apartment ' $\mathrm{A}$ ' the cantilevered stairs provide an open, unobtrusive solution to the circulation through the apartment.

Fig. 5.27 Sectional Perspective of western core. 


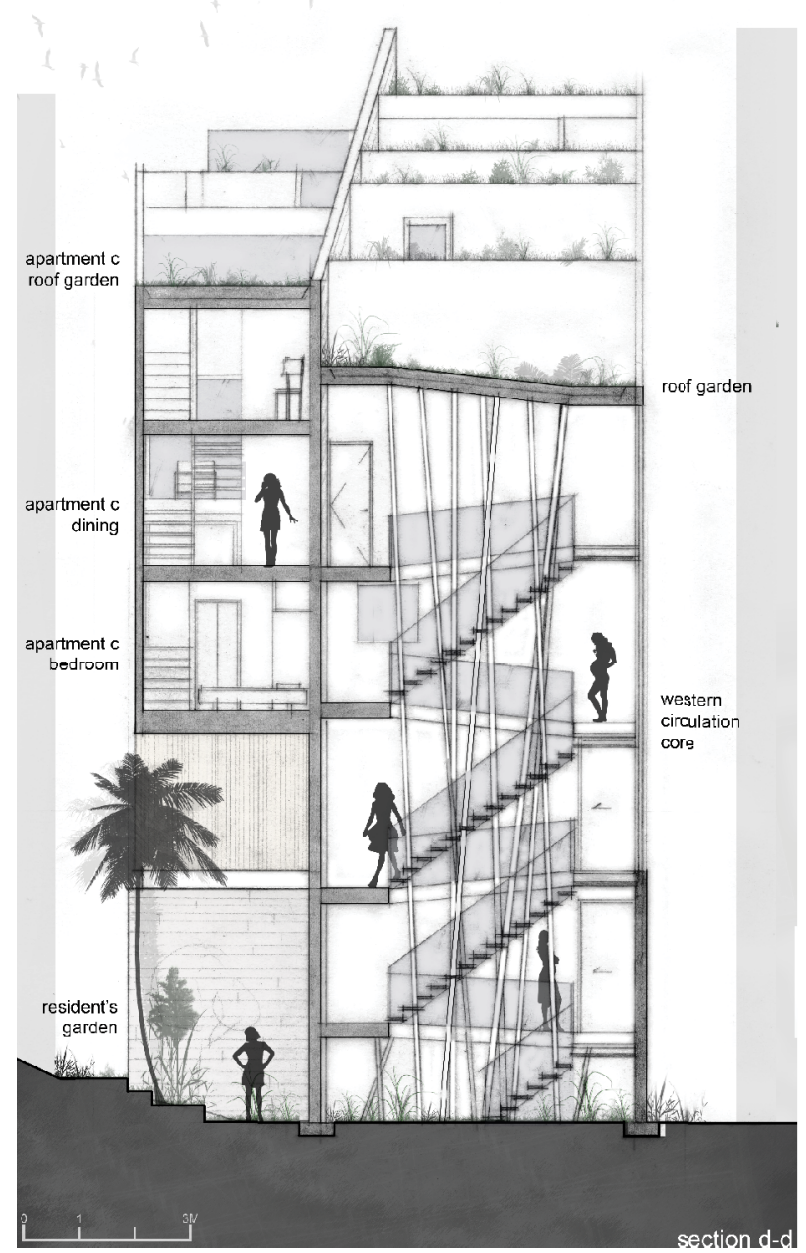

Fig. 5.28 Section D-D.

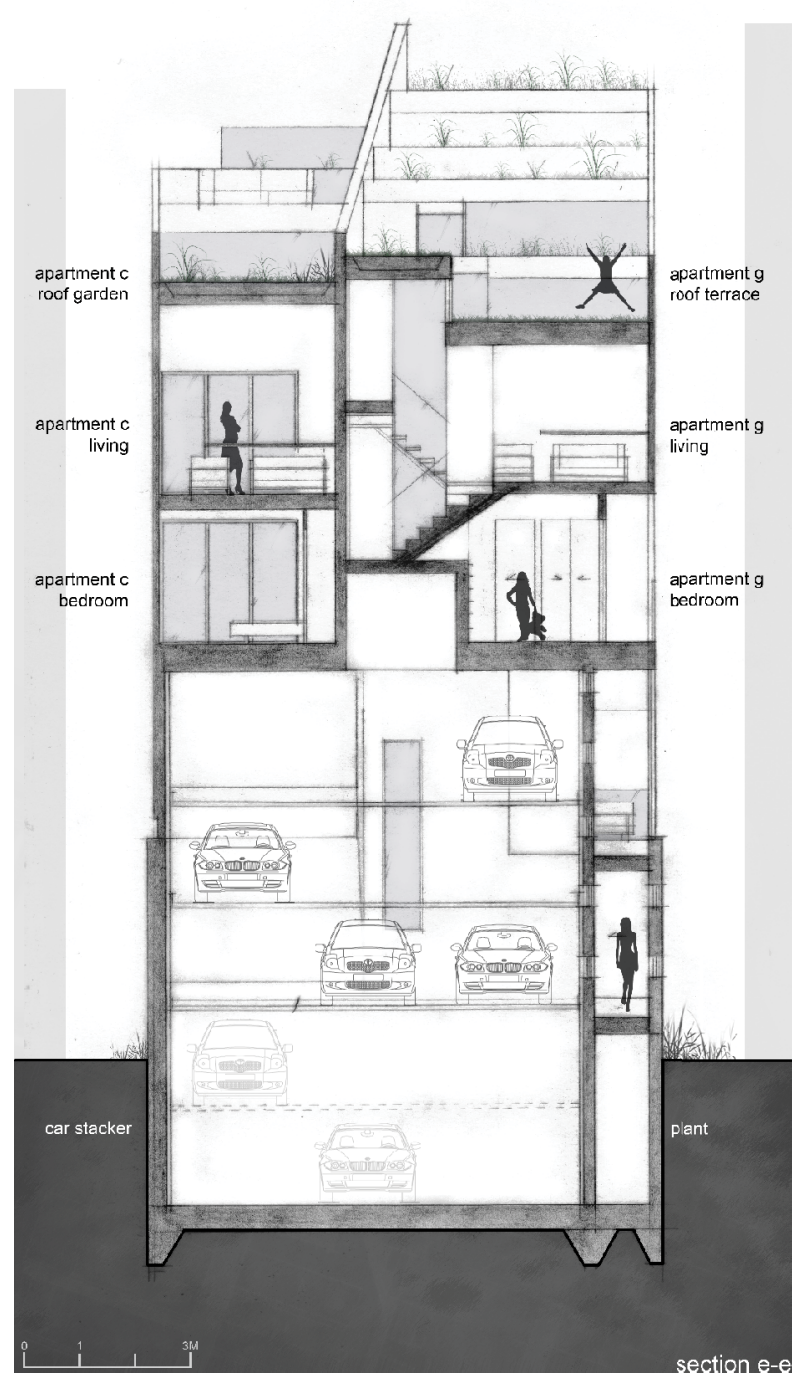

Fig. 5.29 Section E-E. 

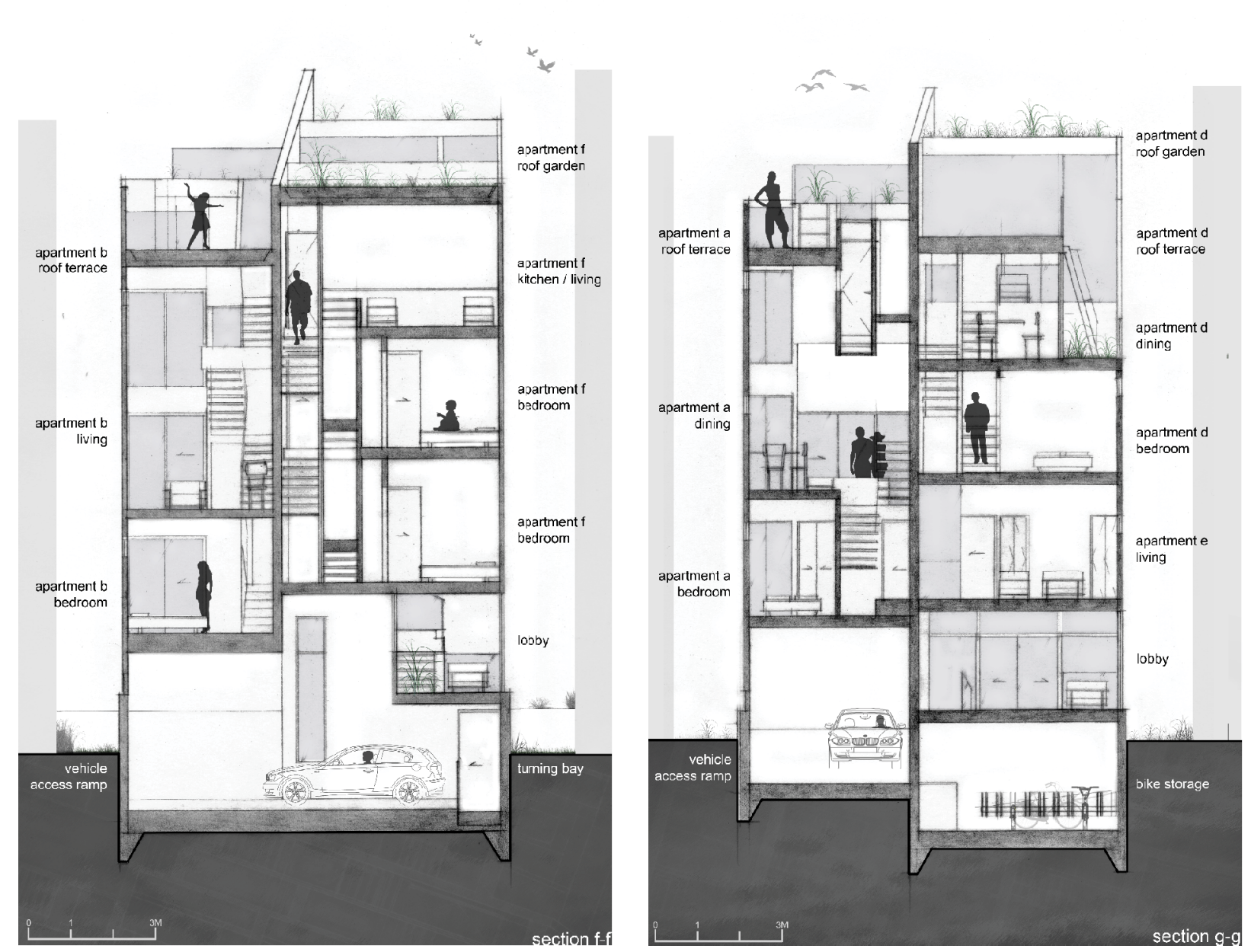

Fig. 5.30 Section F-F.

Fig. 5.31 Section G-G. 


\section{Exterior Perspective:}

The 'spine' of the building is constructed from concrete with the texture created from the horizontal timber shuttering/form-work.

Like the diagonal spine, the same material is used for the 'base' of the three part exterior composition. The solidity of the plinth visually anchors the building on the site and provides contrast to the transparency of the ground floor and lightness of the timber-clad apartments above.

Timber banding across the facade contains planter beds. These small gardens provide inhabitants with an outlook which combines the soft buffer of natural vegetation with controlled views to the streetscape while maintaining privacy within the apartments. This banding is continued as it wraps around the north-east corner of the building and is also featured momentarily along the northern and southern facades where external voids and courtyards are located.

The abstract tree motif represented by the white angled supports, continues the concept discussed earlier and offers the plants a structure to climb with the intention of increasing the density of planting along the facade and improve privacy. They add some informality to the design.

Meanwhile, the glazing along the southern and eastern boundaries of the lobby and circulation space brings diffuse light into the interior. 


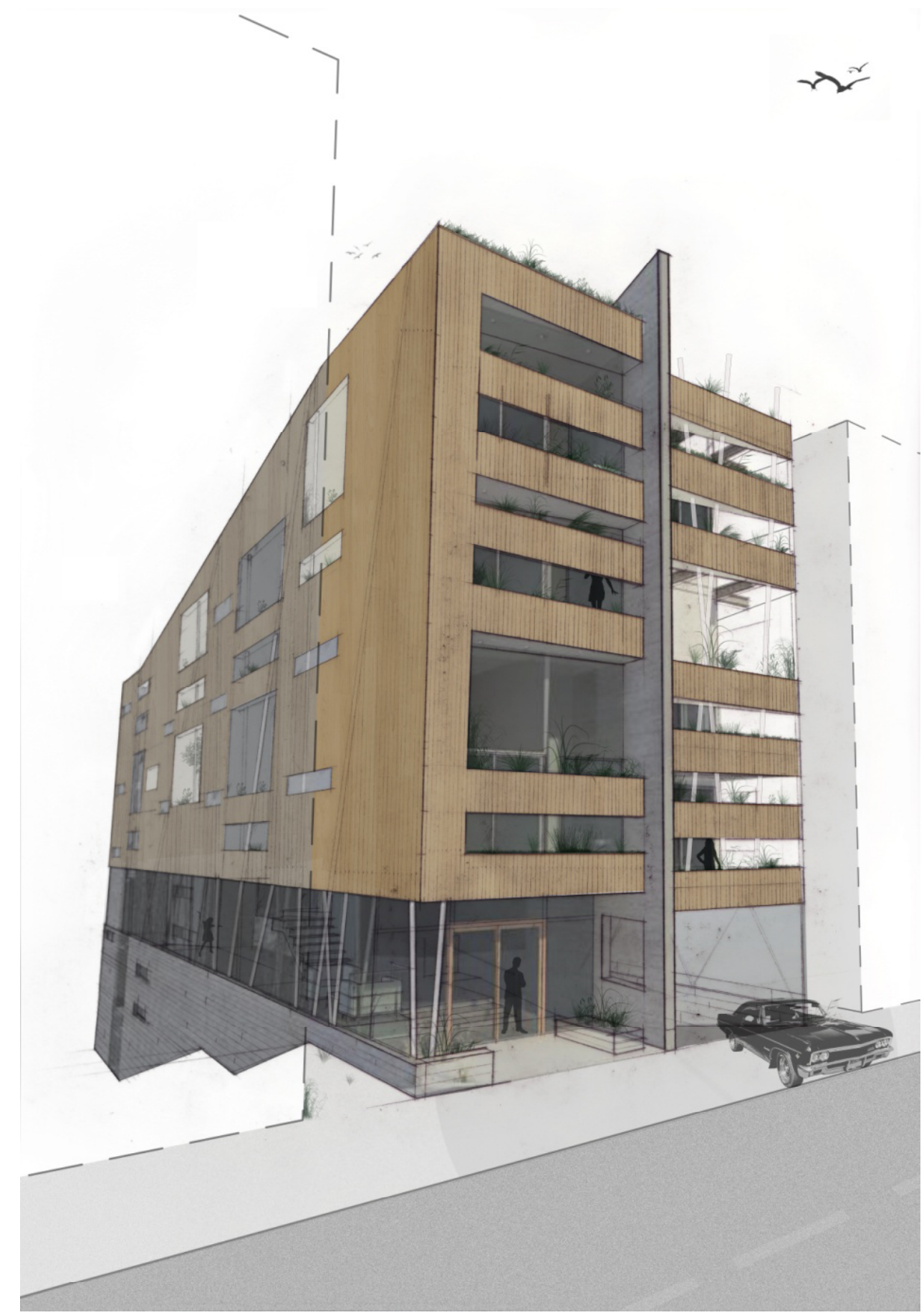




\subsection{3 - Apartment Breakdown:}

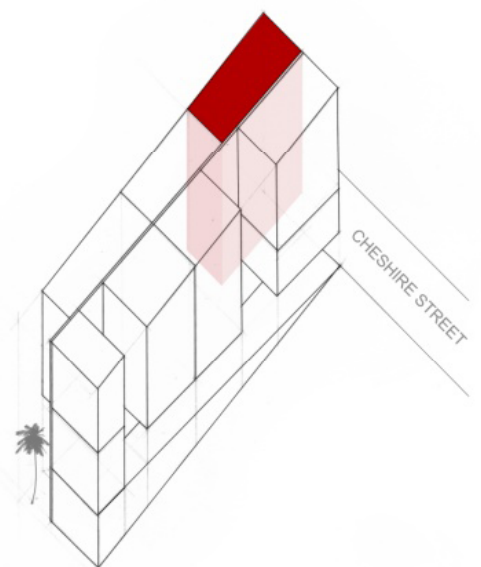

Fig. 5.33 Apartment 'A' location diagram.
In this section the focus is upon the apartments themselves. A more in-depth look at the individual apartments' design will acknowledge the application of the design strategies developed from the analysis of the Japanese precedents.

\section{Apartment 'A':}

Footprint size: $37 \mathrm{sqm} \quad$ Floor size: $116 \mathrm{sqm}$ No. of Bedrooms: 3

- Three bedroom unit on the north-east corner

- Compact bathrooms - fully waterproofed space where there is no defined shower cubical.

- Dining table slides against wall.

- Bedrooms have private outlook to planted terrace.

- Open stairwell acts as void space and creates physical visual links between levels. Enhanced by the skylight at the top of the stairwell.

- Semi-split level design

- The continuity of flooring material from inside to outside...

- Glass doors slide back to expand interior spaces into the exterior

- First floor void on terrace brings light down to level below and opens up space for plantings to grow, giving spaces over multiple levels an increased connection with nature.

- Bands of planters provide a privacy screen and create a self contained focal point for the inhabitants. 
- Elongated view-shafts/sight-lines are created on each level.

- Large sections of floor area are sacrificed for void space to share light between spaces and create visual connections within the apartment.

- The vertical alignment of the kitchen and two bathrooms improves the efficiency of plumbing works.

- Any of the three bedrooms could be used for an alternative function for example a study or second living space.

- The bench top 'floating' over the stairwell makes use of the open space, creating an extra work surface without compromising both floor space, by not encroaching on the kitchen's floor area, or the sense of space above and below the bench.

- Rooftop terrace and garden provides even more private outdoor spaces for the residents to retreat to.

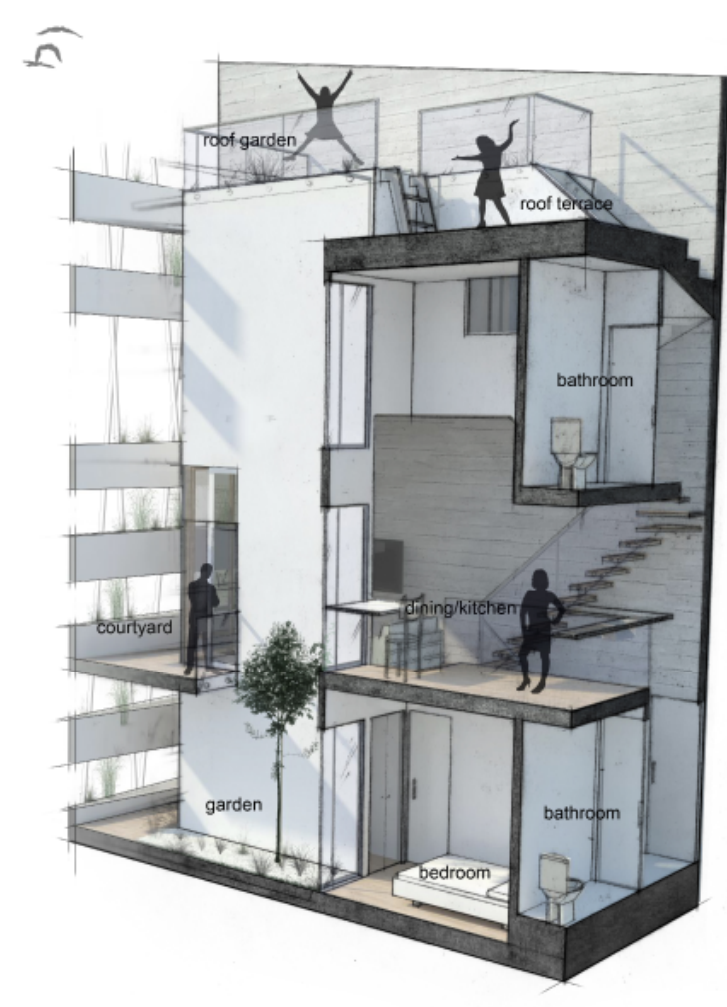

Fig. 5.34 Apartment 'A' sectional perspective. 

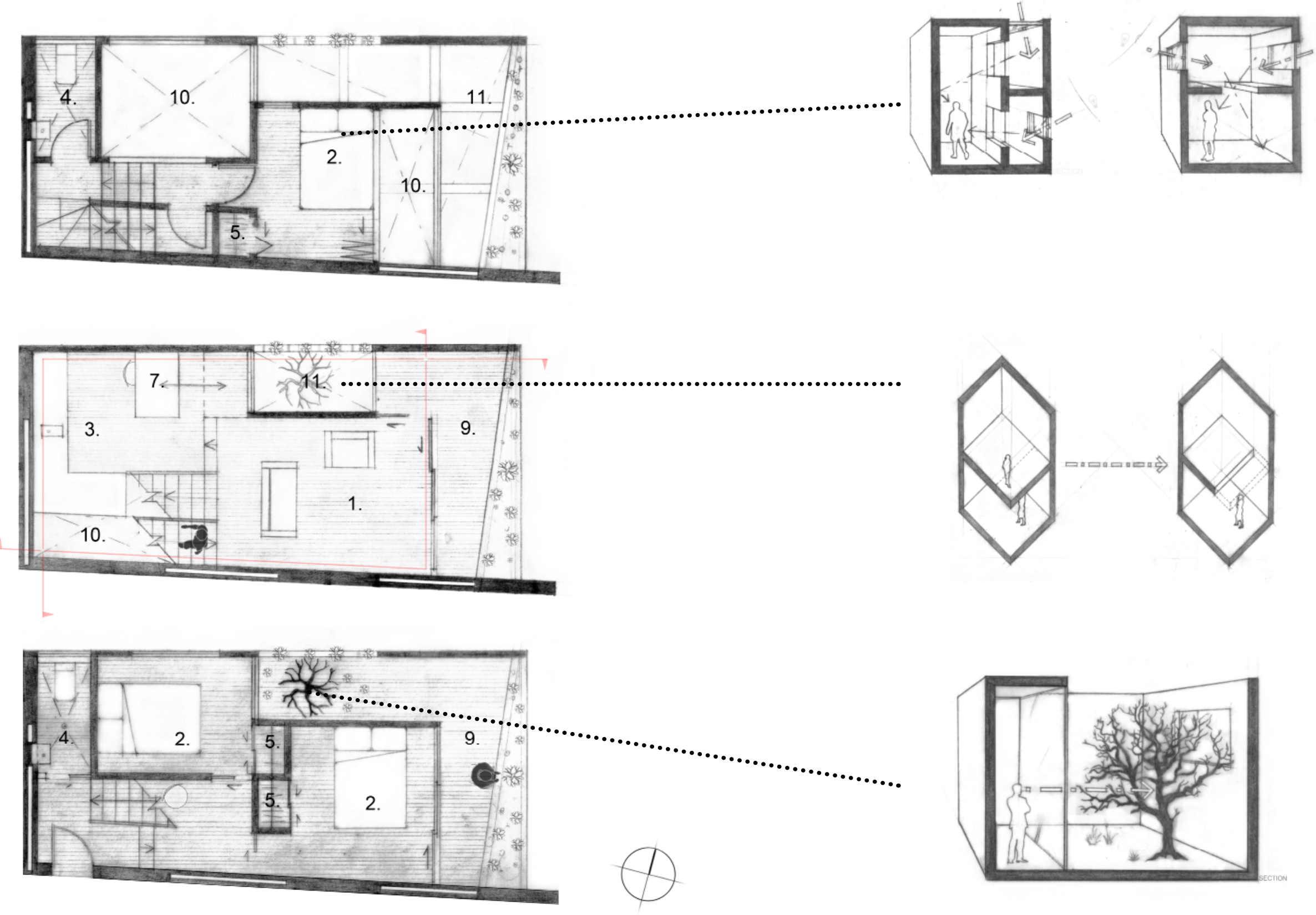

Fig. 5.35 Apartment 'A' floor plans. Scale 1:100 

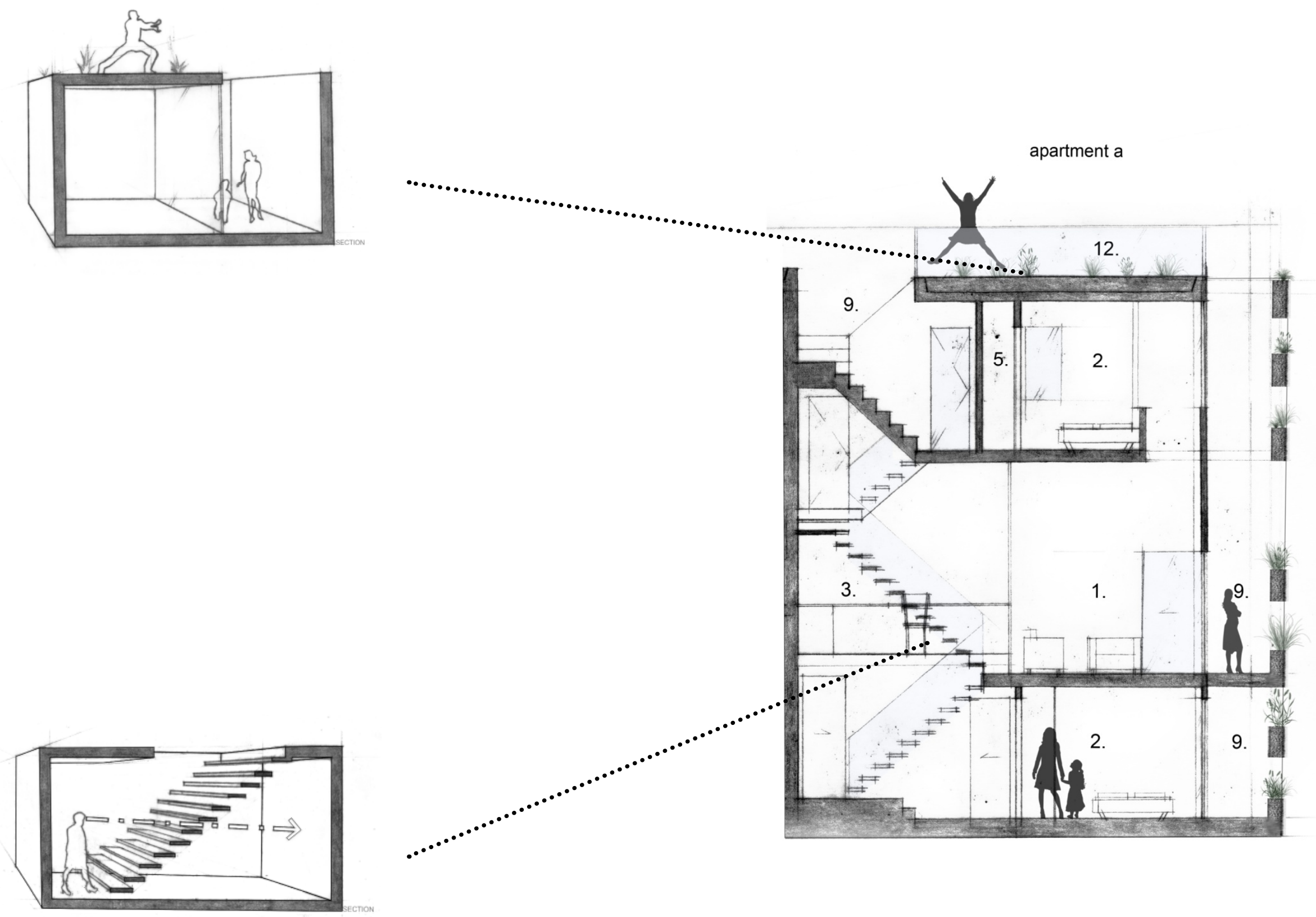

Fig. 5.36 Apartment 'A' section. Scale 1:100 


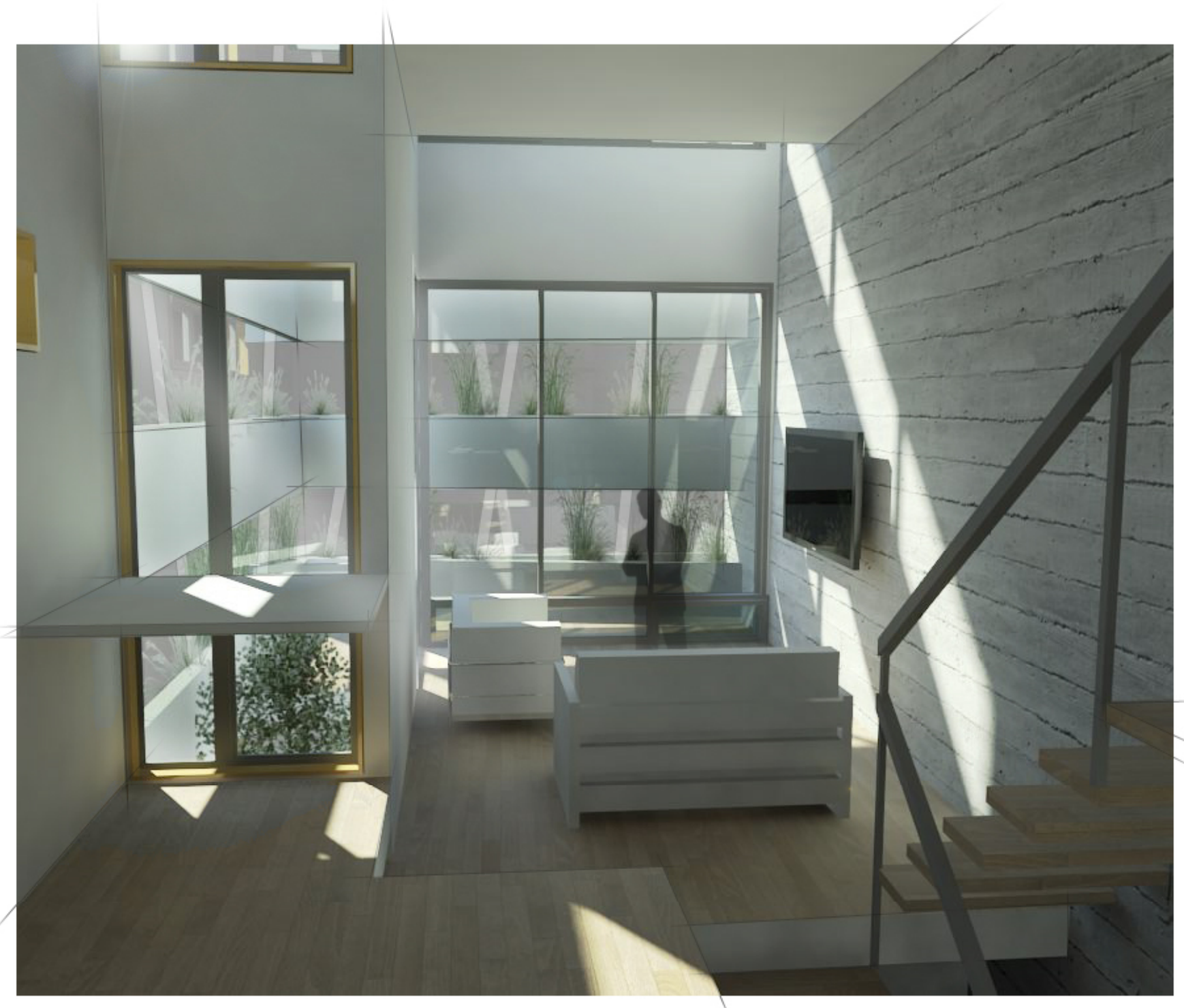

Fig. 5.37 (Opposite) Apartment 'A' Interior Perspective. 


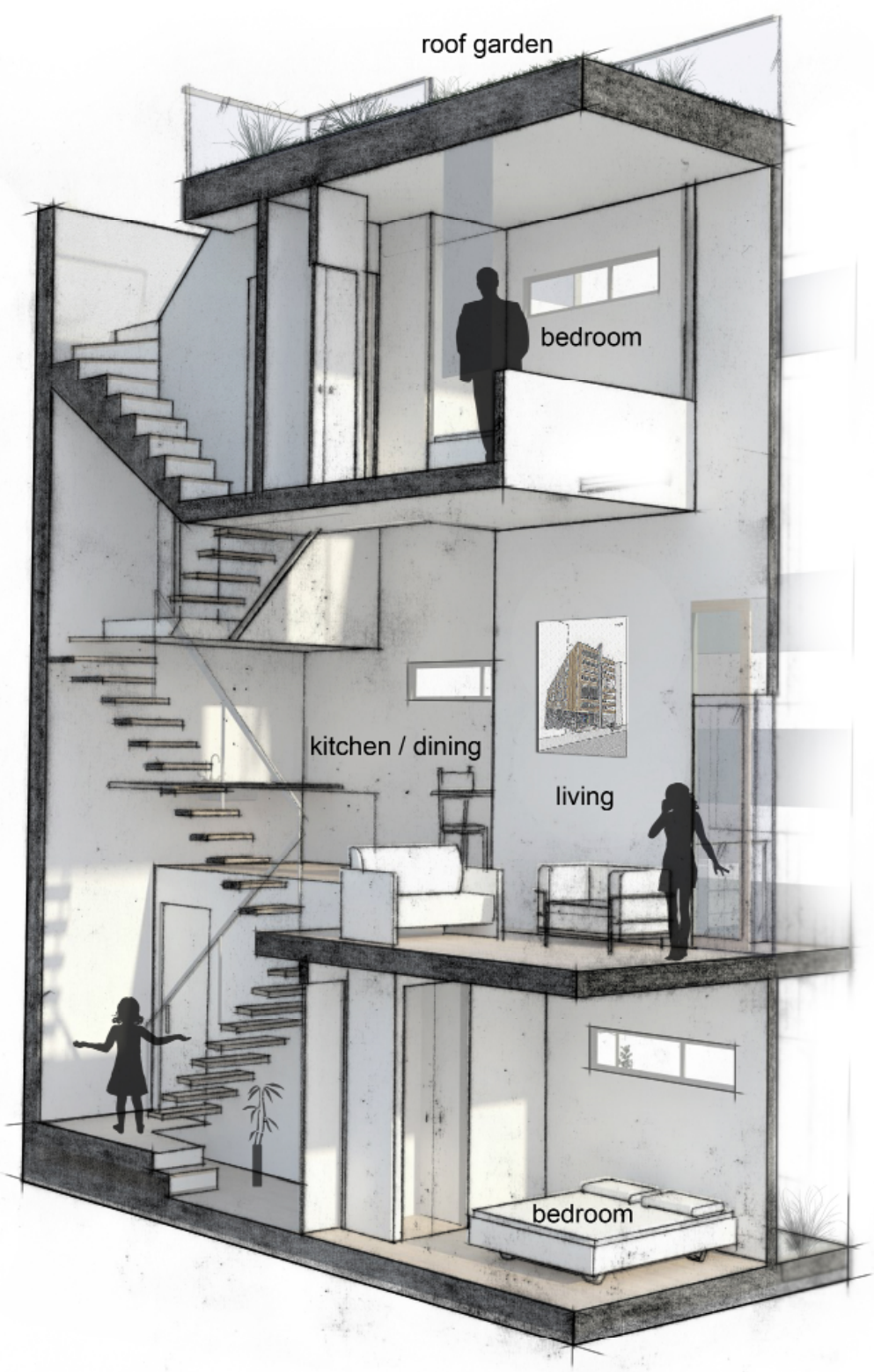

Fig. 5.38 Apartment 'A' sectional perspective. 


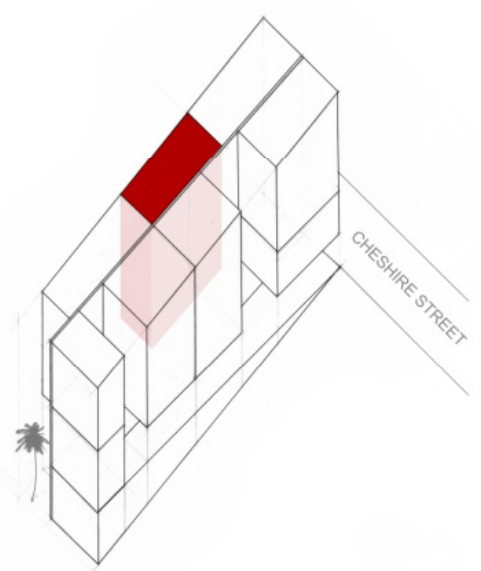

Fig. 5.39 Apartment 'B' location diagram.

\section{Apartment 'B':}

Footprint size: $37 \mathrm{sqm} \quad$ Floor size: $88 \mathrm{sqm}$ No. of Bedrooms: 2

- Split-level two bedroom apartment.

- Narrow ensuite bathroom is compensated by its extra height. This results in built-in seating for the living room above, which can also be used as a temporary sleeping space.

- The built-in bench provides seating for the fold-down dining table.

- Orientated around planted courtyard

- The courtyard gives the adjacent spaces an outlook where the main windows look into this courtyard space as opposed to being positioned along the northern boundary.

- This also creates visual connection between the spaces either side of the courtyard.

- The central stairwell divides spaces while maintaining visual connection and maintaining sight lines across the apartment.

- Every inhabitable room (living spaces, bedrooms) has a connection with an outdoor space.

- Four different outdoor spaces: main courtyard adjacent to master bedroom, small terraces outside kitchen and second bathroom, and the roof terrace. 

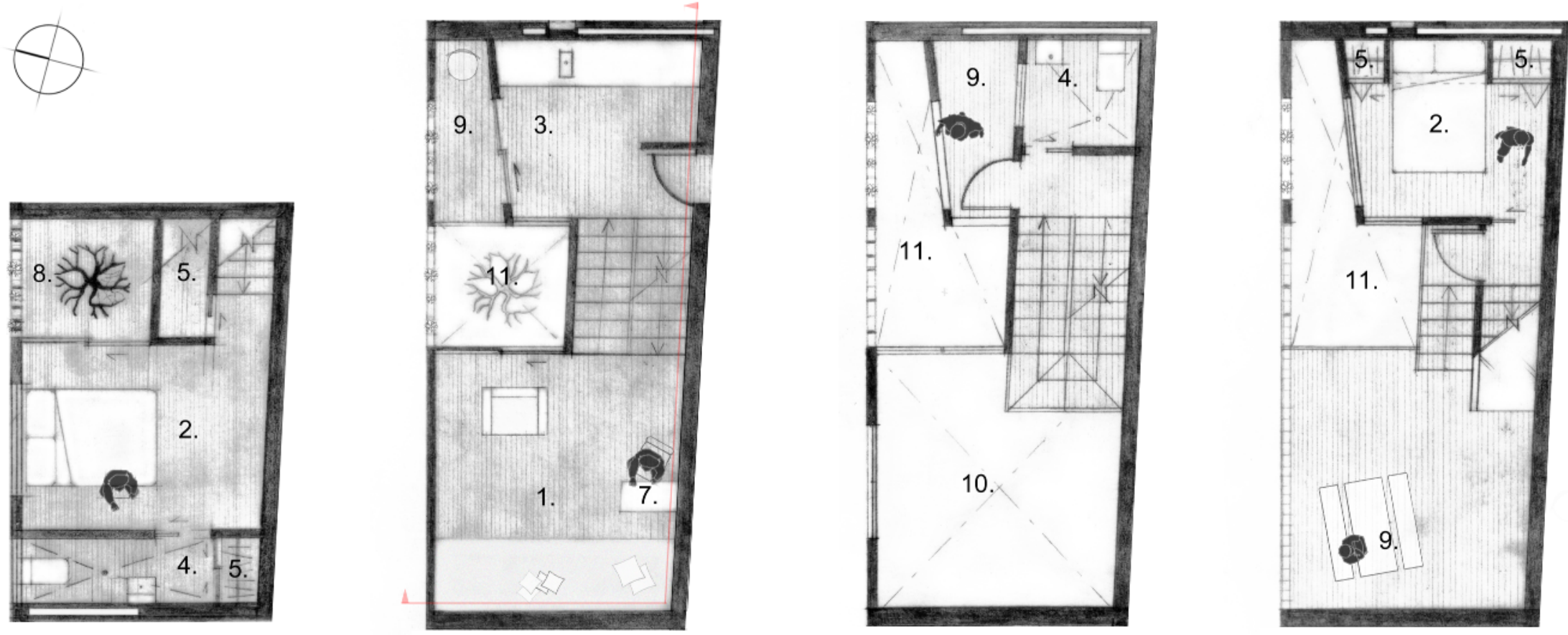

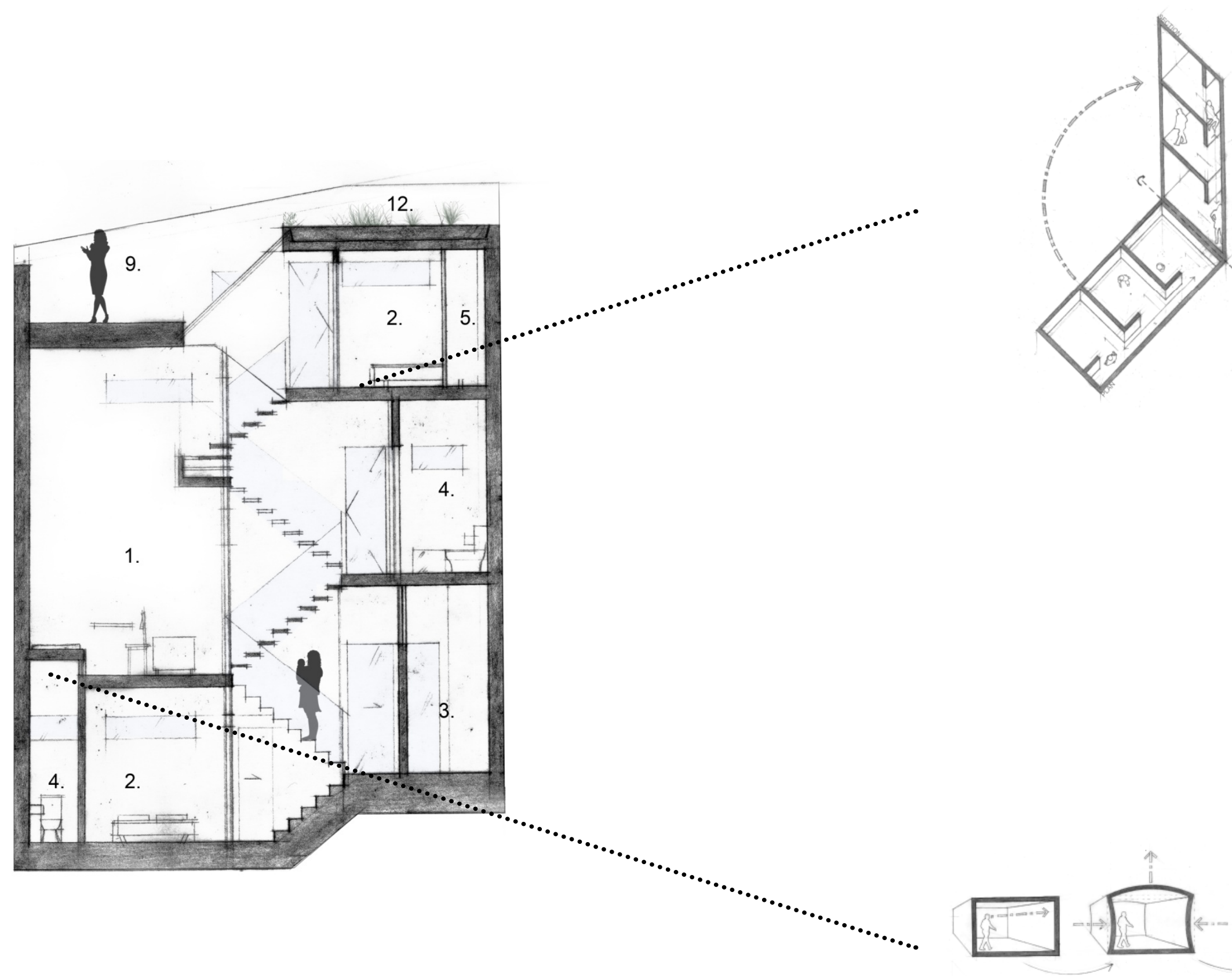

Fig. 5.41 Apartment 'B' section. Scale 1:100. 

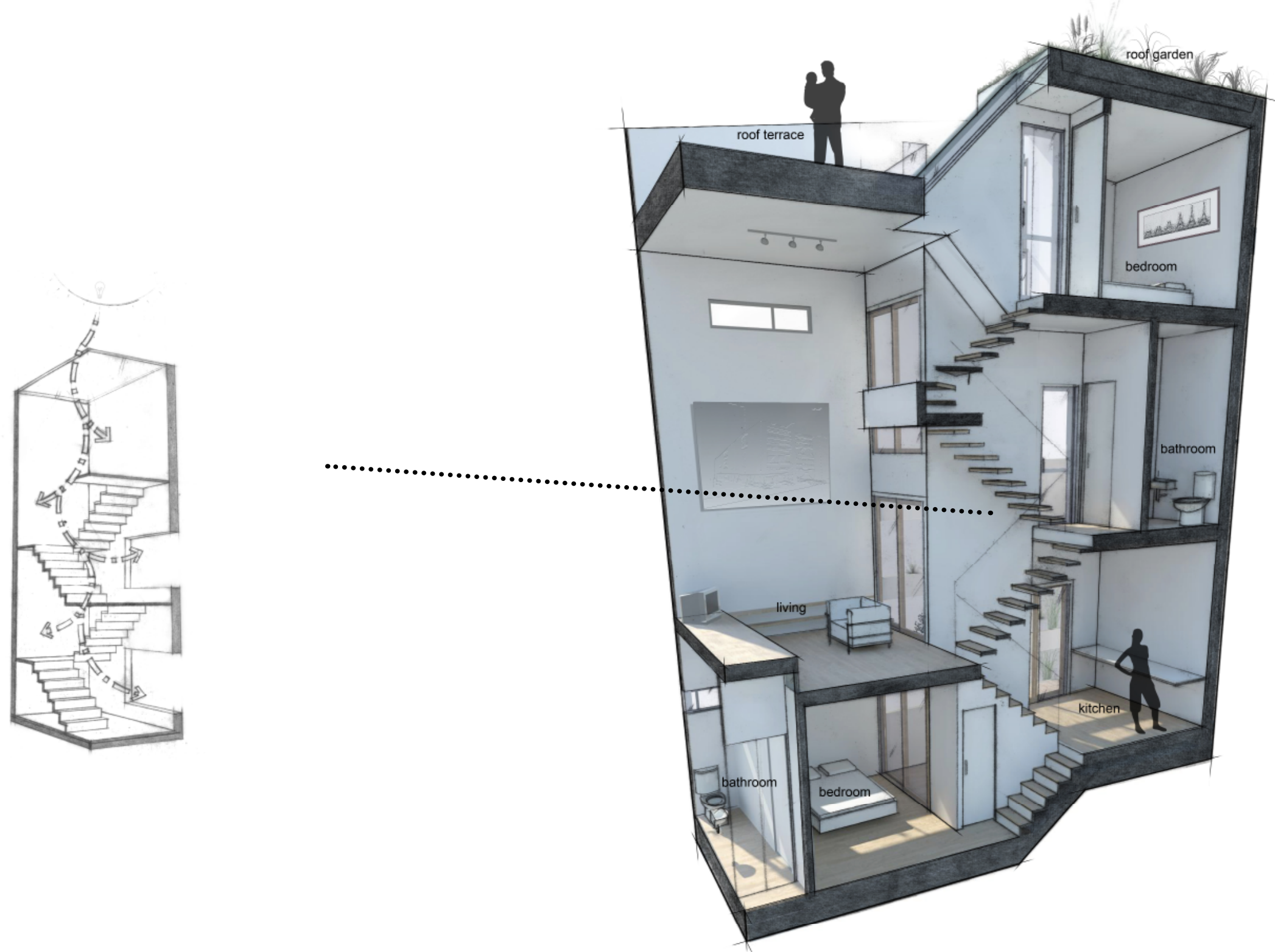

Fig. 5.42 Apartment 'B' sectional perspective. 


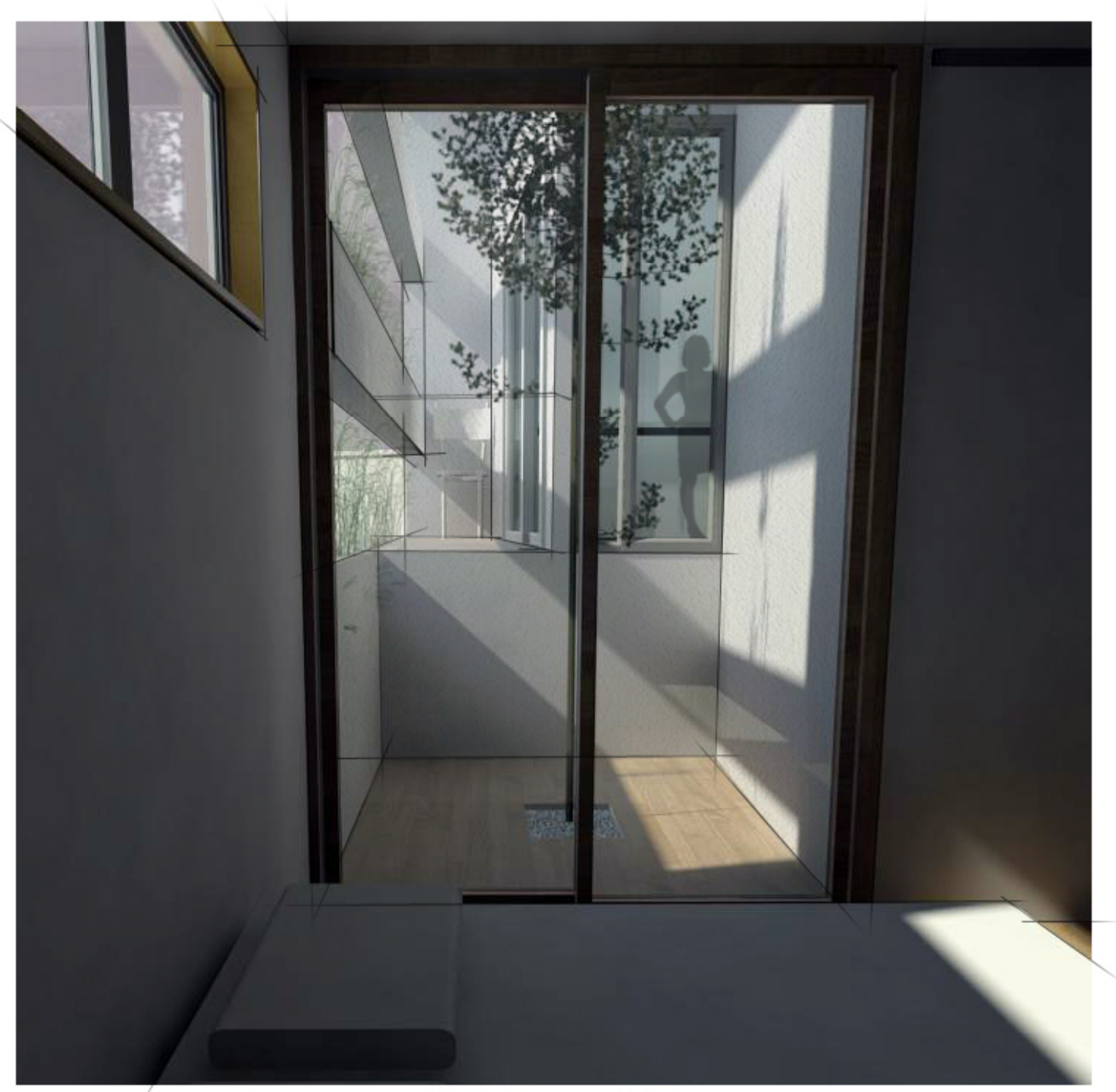

Fig. 5.43 Apartment 'B' Interior Perspective from master bedroom looking at courtyard. 


\section{Apartment 'C':}

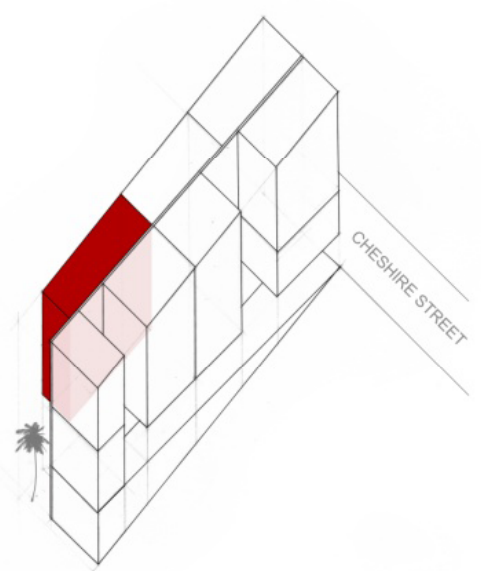

Fig. 5.44 Apartment 'C' location diagram.
Footprint size: $29 \mathrm{sqm} \quad$ Floor size: $74 \mathrm{sqm} \quad$ No. of Bedrooms: 2

- The long thin layout of this apartment contains two bedrooms.

- Entry is into the double height dining room. From here, views are extended right to the opposite end of the apartment.

- The open stair well permits views into adjacent spaces. It also links each split level space in a compact space efficient format.

- Large sliding door into the eastern bedroom can be slid back to open the room up and create a greater connection to the rest of the interior.

- Built-in wardrobes in the bedrooms also contain the fold-down beds. When concealed, this allows these flexible spaces to take on an alternative function.

- The clearstory window above the living room brings light into the space from the west. This is combined with the large sliding doors which face the eastern void, and the smaller window along the northern boundary.

- While dimensionally small, the courtyard provides a private outdoor, day-lit space which the bedroom and living spaces open onto through large windows. This increases the inhabitants' relationship with the outdoor environment. Through the large fenestrations and a continuity of materials, the interior space takes a sense of ownership of the outdoor space; this experiential inclusion extends the perceptive limit of the interior.

- Above the kitchen and living room are habitable roof spaces.

- Once again the plumbing is located within the same wall cavity, increasing its efficiency, and thereby reducing costs. 

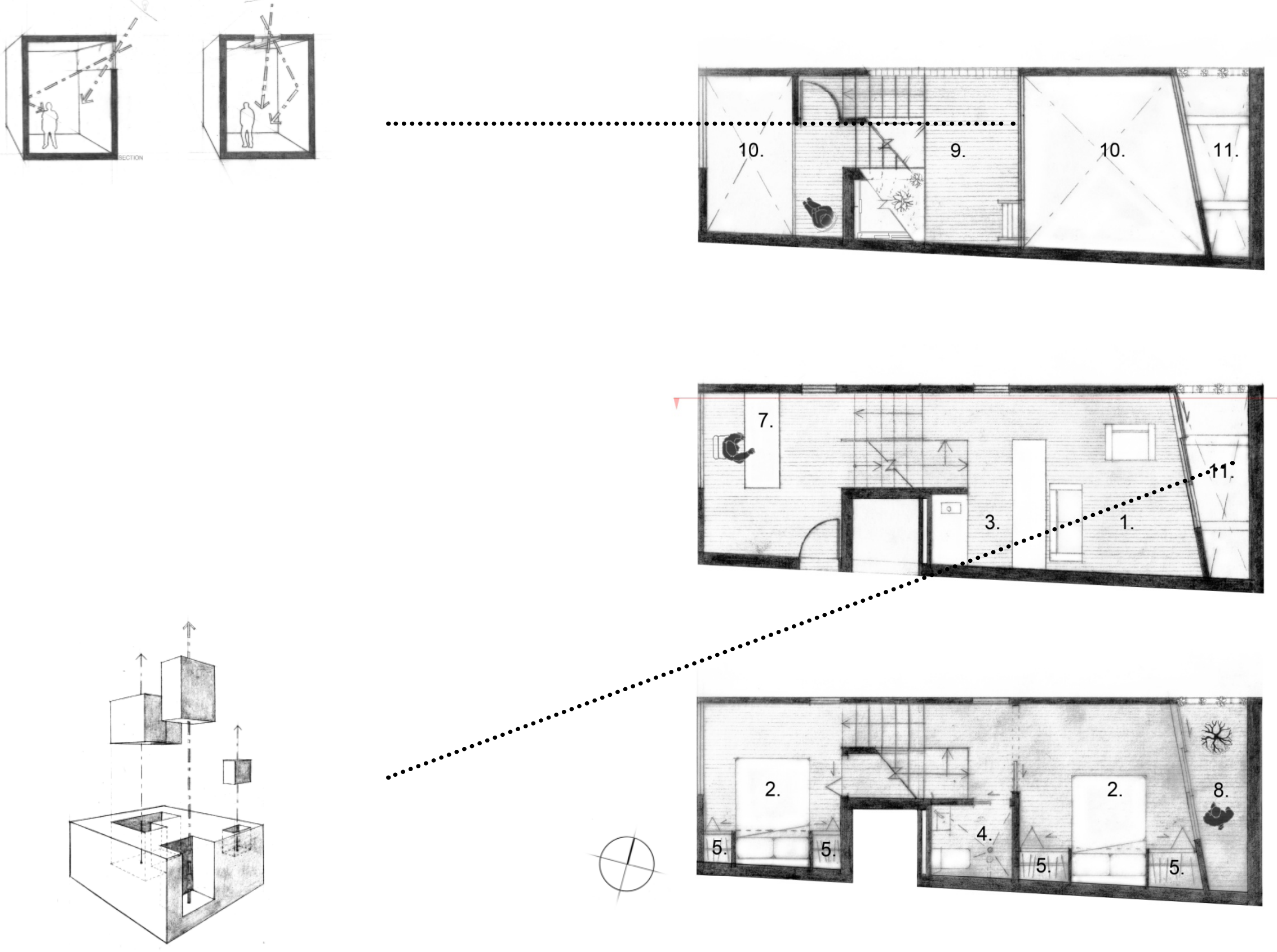

Fig. 5.45 Apartment 'C' floor plans. Scale 1:100. 


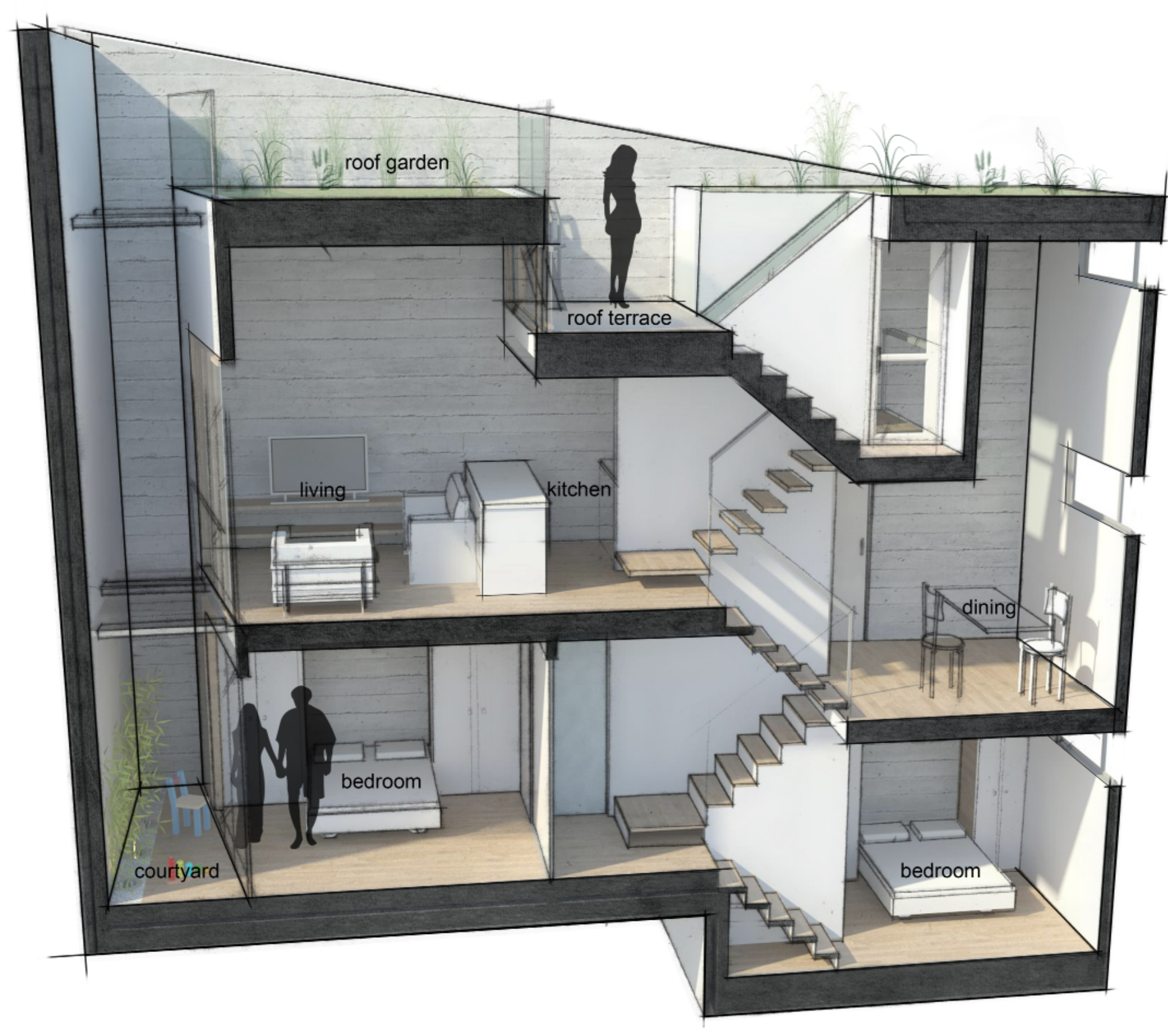

Fig. 5.46 Apartment 'C' Sectional Perspective. 

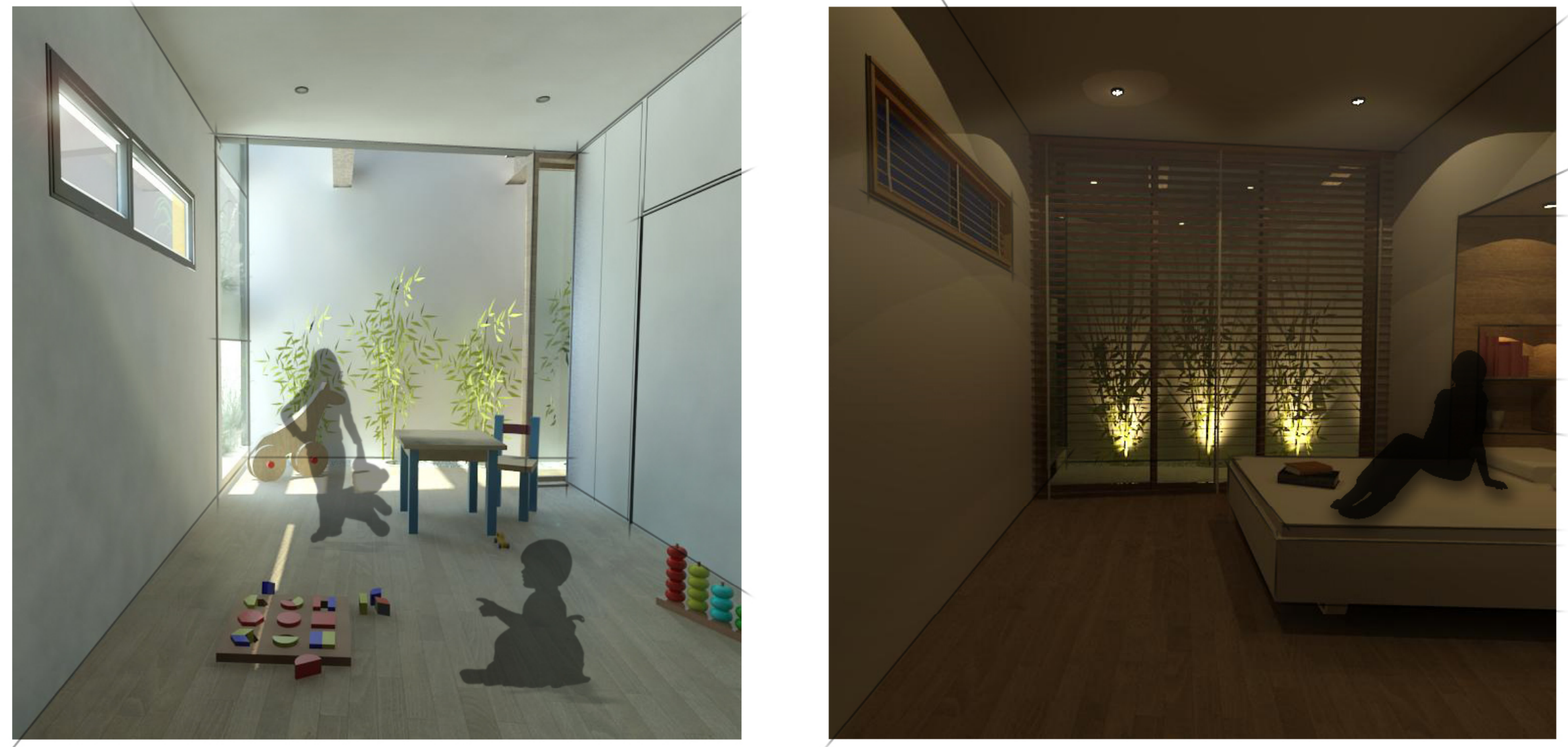

Fig. 5.47 Apartment ' $C$ ' Interior Perspectives illustrating the adaptive use of 'convertible spaces. 


\section{Apartment 'D':}

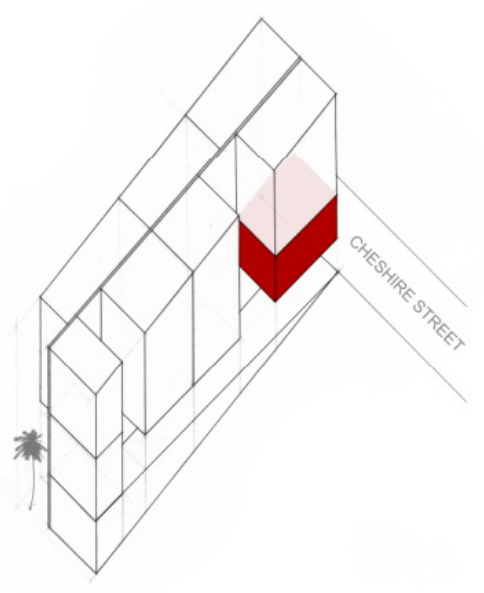

Fig. 5.48 Apartment 'D' location diagram.
Footprint size: $35 \mathrm{sqm}$ Floor size: $35 \mathrm{sqm}$

- This one bedroom apartment can be converted into two, with a fold-down bed, built into the partition between bedroom and living room.

- With the doors between each space slid away, three avenues of sight from the living space to the outdoor space are achieved. This is emphasised by the continuous timber flooring.

- The increased height in section allows for a larger opening at the end of the apartment to help bring more light in form above while not sacrificing privacy from the street below. It also creates a larger volume contained within the same footprint, increasing the spacious feel of the rooms.

- Again, the planting bands, while serving as a privacy screen, create an enhanced connection with nature. 

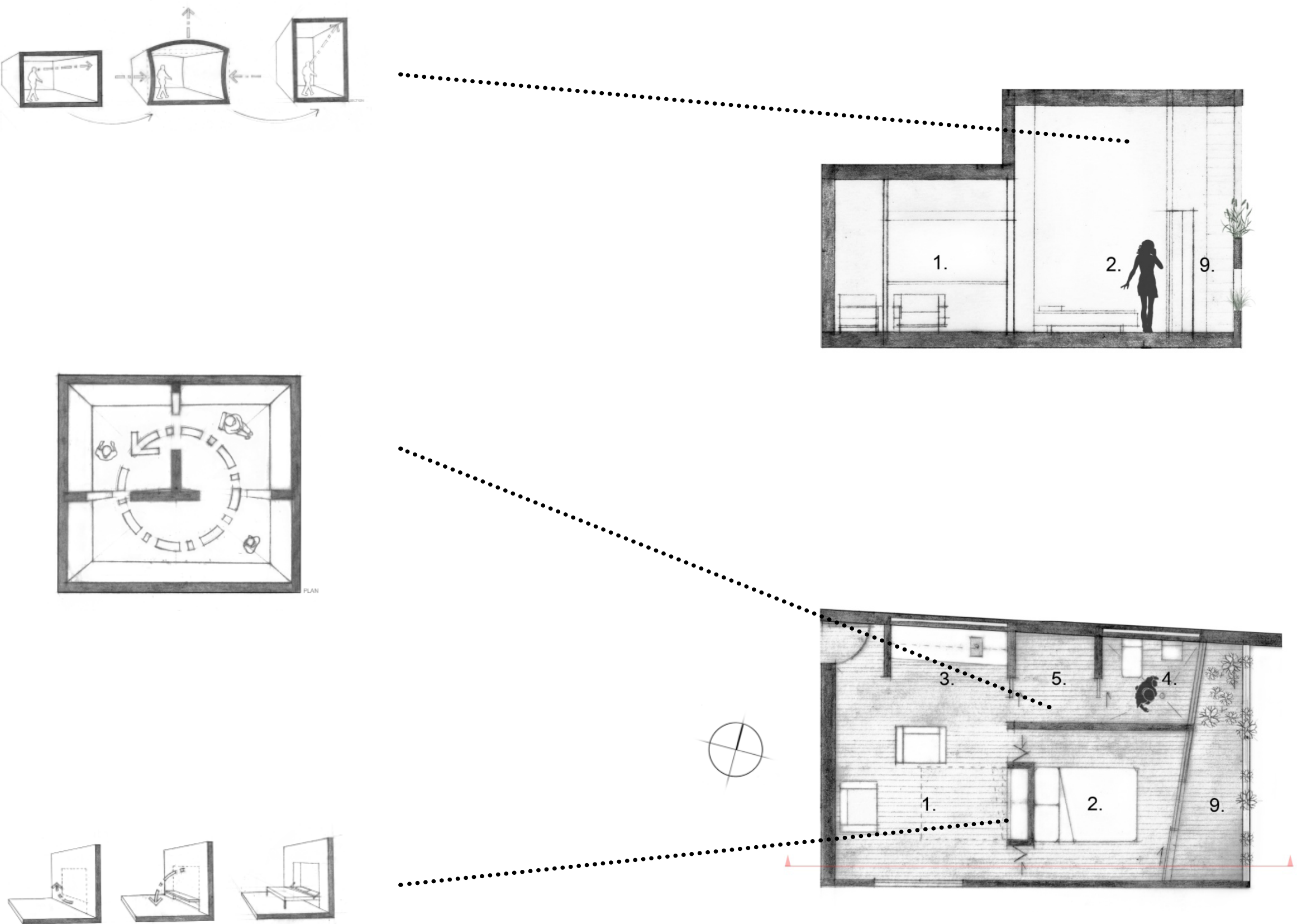

Fig. 5.49 Apartment 'D' section and floor plans. Scale 1:100 


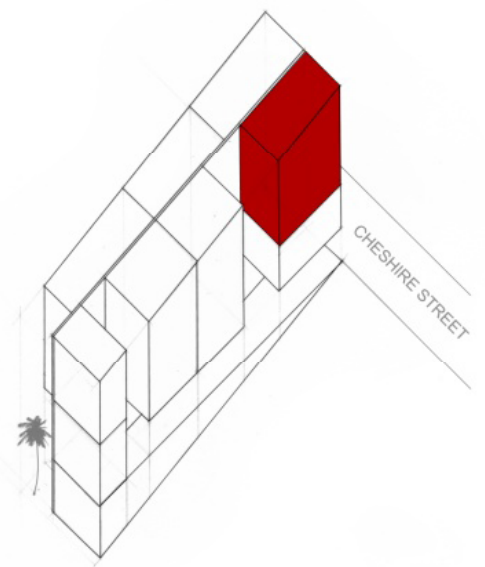

Fig. 5.50 Apartment 'E' location diagram.

\section{Apartment 'E':}

Footprint size: $35 \mathrm{sqm}$ Floor size: $75 \mathrm{sqm}$

No. of Bedrooms: 2

- In this split level apartment, the private spaces are on the lower two levels. The bedrooms integrate wardrobe storage around the 'nook' which the beds are set into.

- Above the bedrooms are living spaces which are conceived as a more open, public environment.

- A secondary entrance provides residents with the option to take the lift further up and enter closer to the living spaces, rather than climb all of the apartment's flights of stairs in inconvenient circumstances, such as when carrying shopping bags.

- From the secondary entrance, there is a small dining space and sitting room which face out into a courtyard.

- This courtyard leads up to the roof terrace where views to Auckland Domain can be captured, yet is connected to the interior through the clearstory window.

- The living room is flanked by private outdoor areas, where multiple connections with nature are captured. 

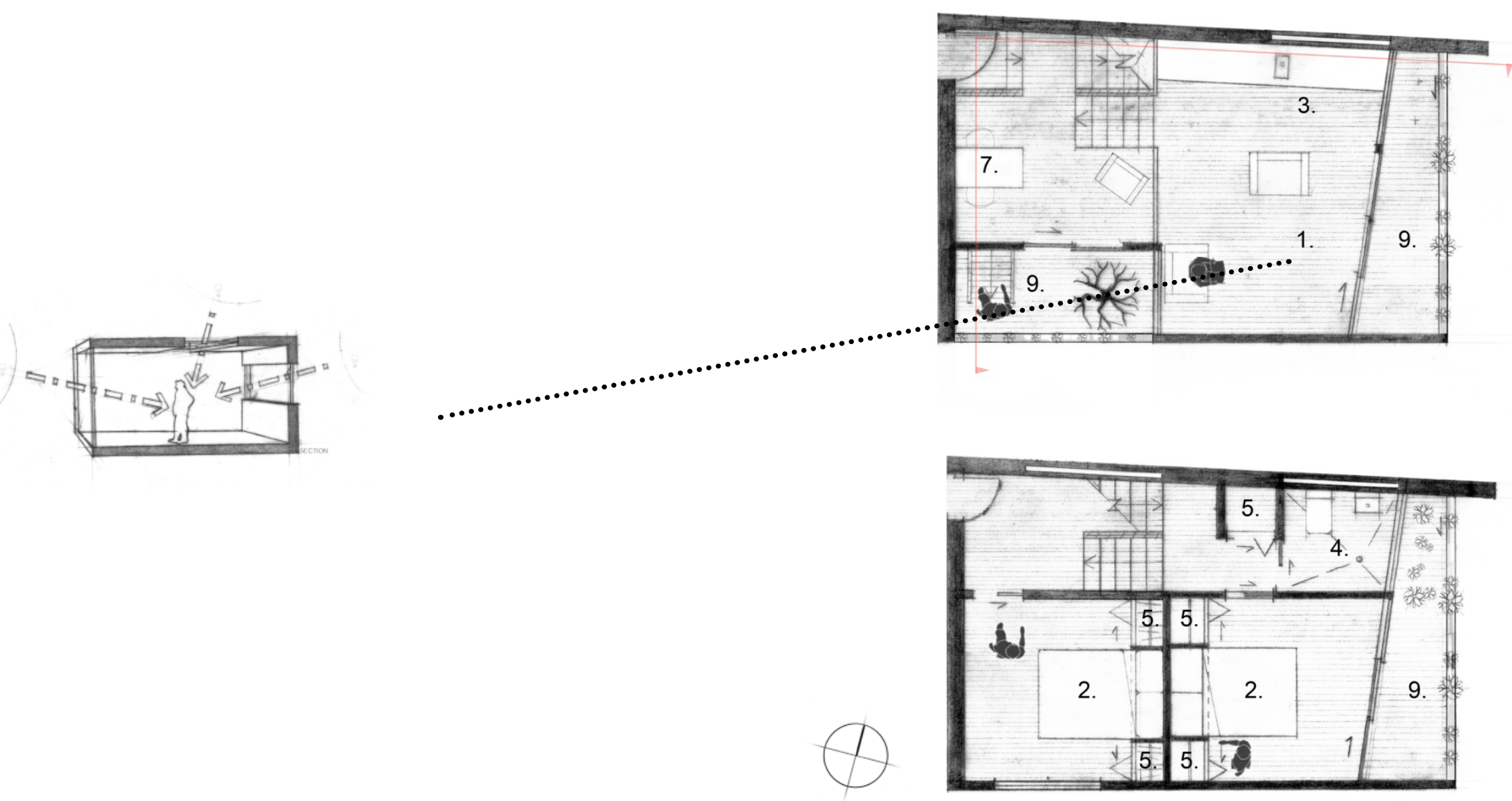

Fig. 5.51 Apartment 'E' floor plans. Scale 1:100. 

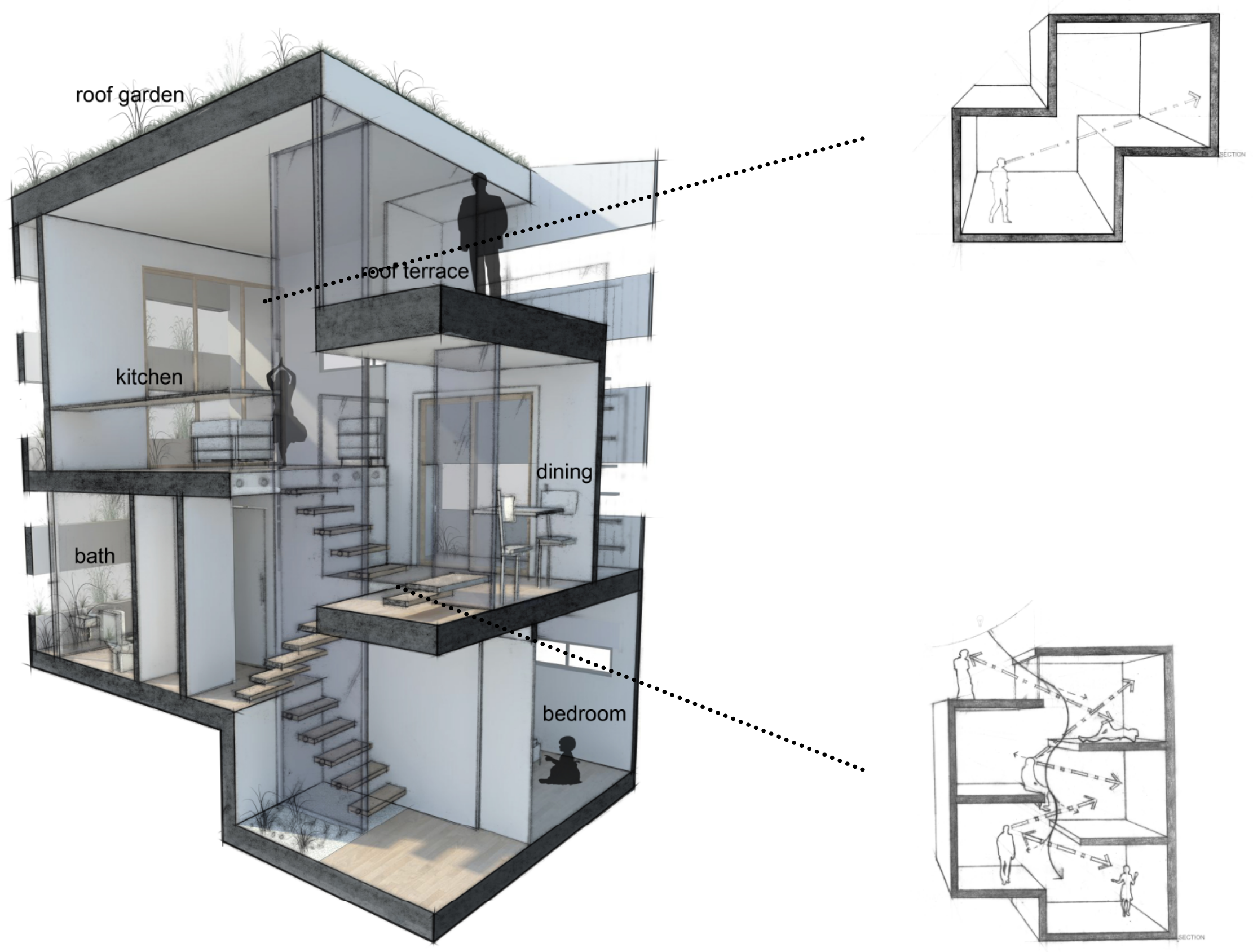

Fig. 5.52 Apartment 'E' Sectional Perspective.

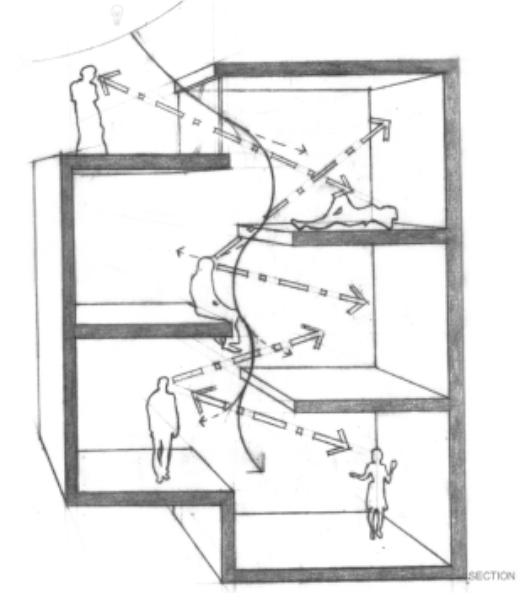




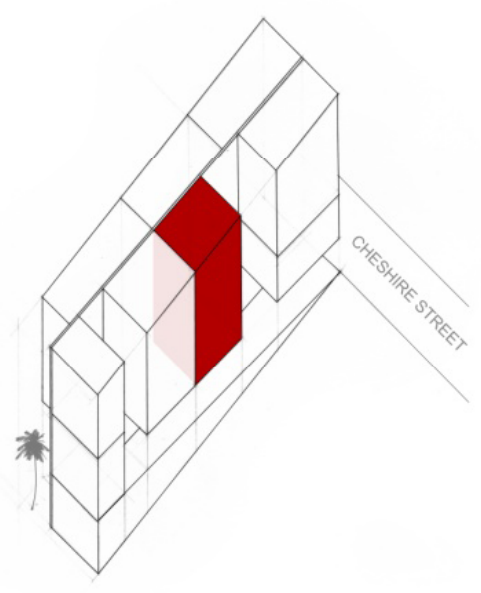

Fig. 5.53 Apartment 'F' location diagram.

\section{Apartment 'F':}

Footprint size: 28 sqm Floor size: 76 sqm

No. of Bedrooms: 2

- The compact footprint of this apartment forces it to expand vertically.

- The 'wet' areas or service spaces are all arranged against the same vertical cavity.

- Elsewhere, the main habitable rooms are arranged around the outdoor courtyard and terrace and are linked by the split level stair case. By orientating the room in such a way where the tree becomes a focal point for the apartment, a heightened connection with nature is achieved and the large fenestrations, which allow light into the interior, are not along the boundary walls where privacy is reduced.

- The long kitchen bench surface extends along the width of the apartment where it becomes part of the living space to provide a surface for such items such as a television.

- Similar to apartment ' $\mathrm{D}$ ', a secondary entrance is provided on the top floor, allowing access directly into the living space. 

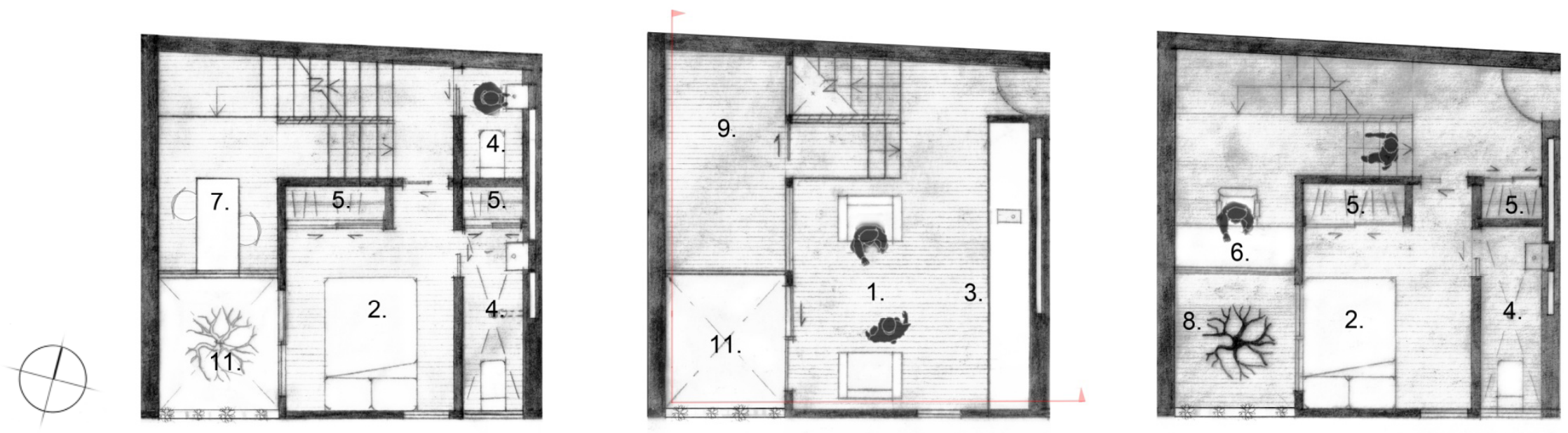

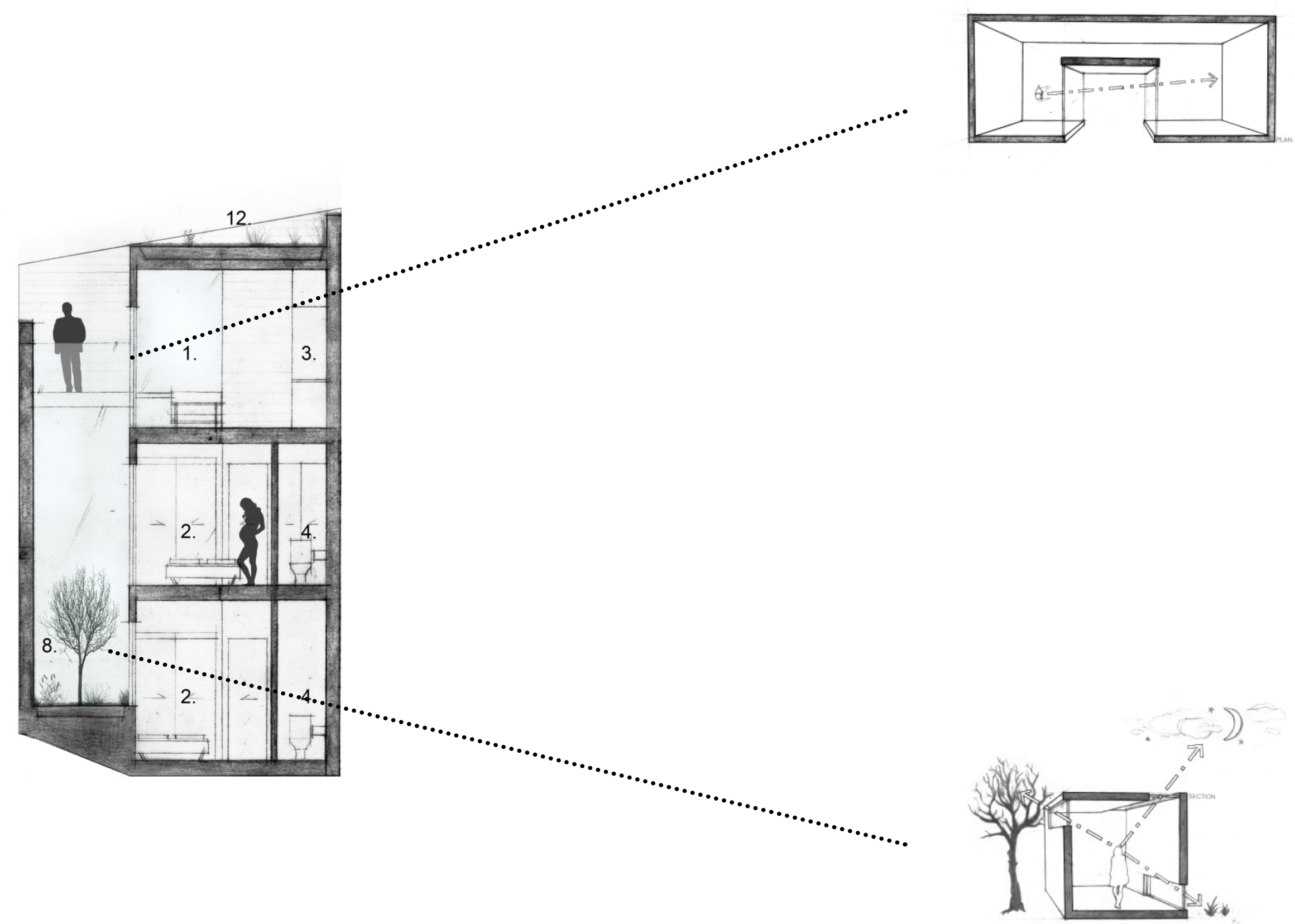

Fig. 5.55 Apartment 'F' section. 1:100 


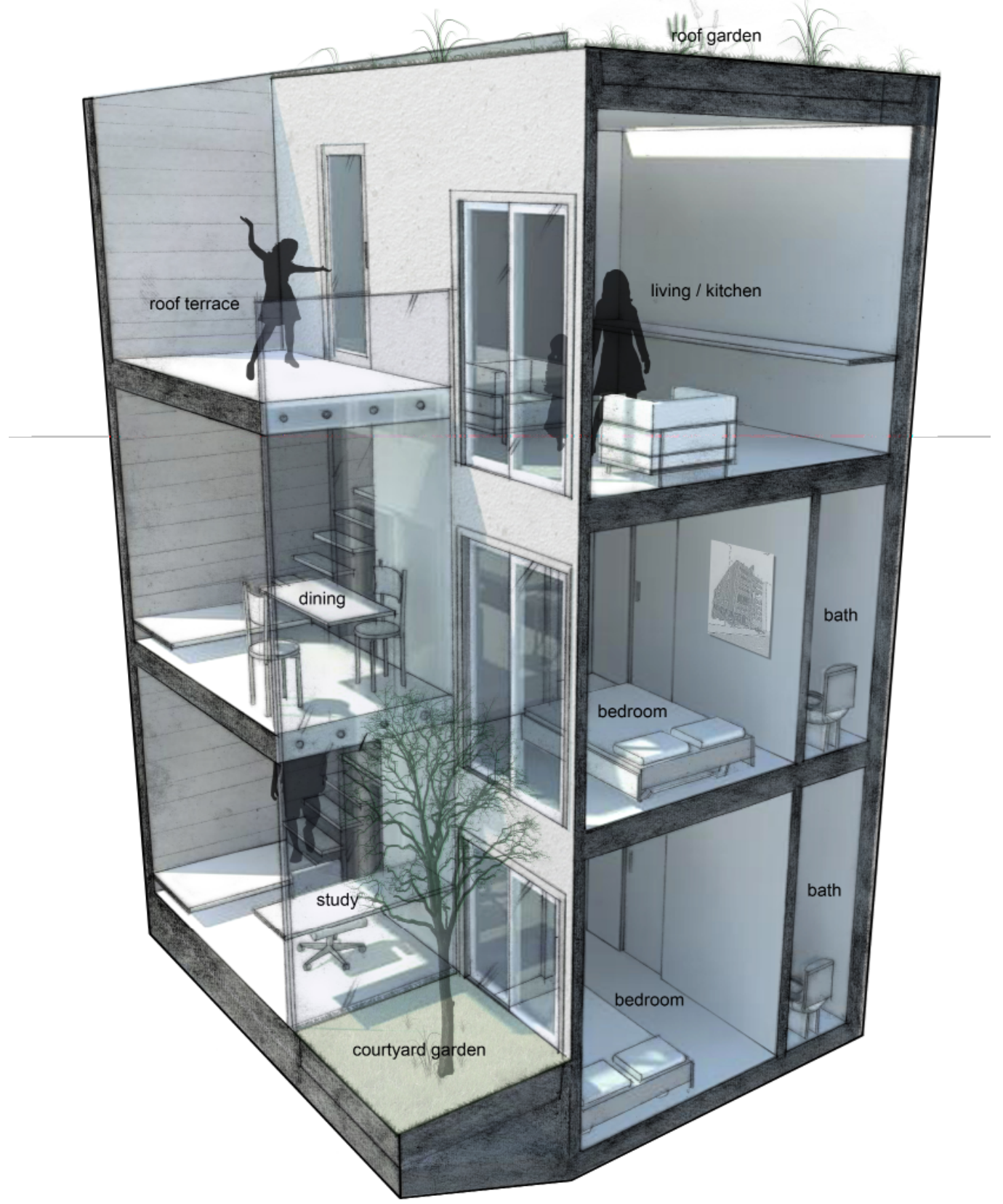

Fig. 5.56 Apartment 'F' sectional perspective. 


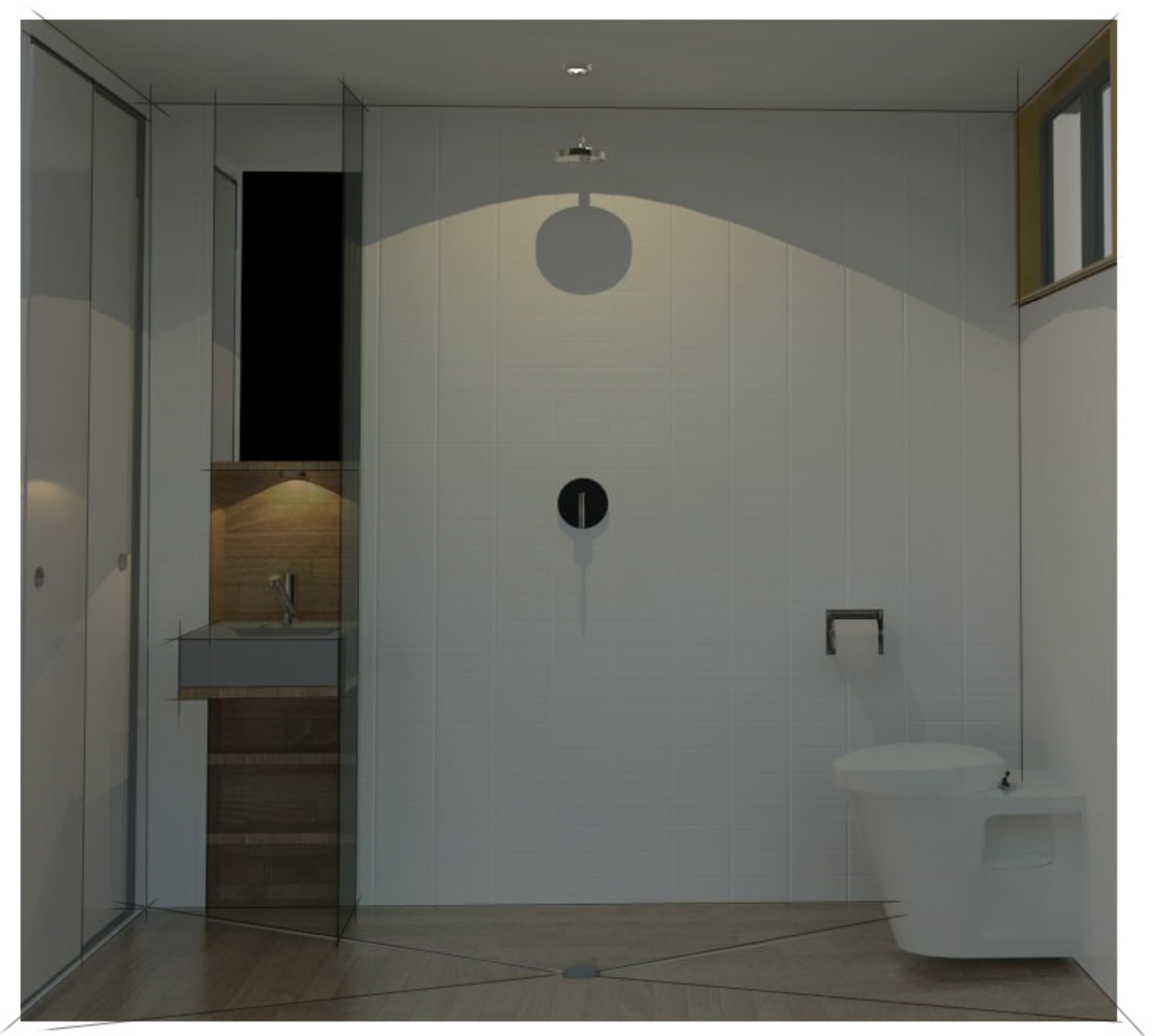

Fig. 5.57 Apartment 'F' interior perspective of bathroom 


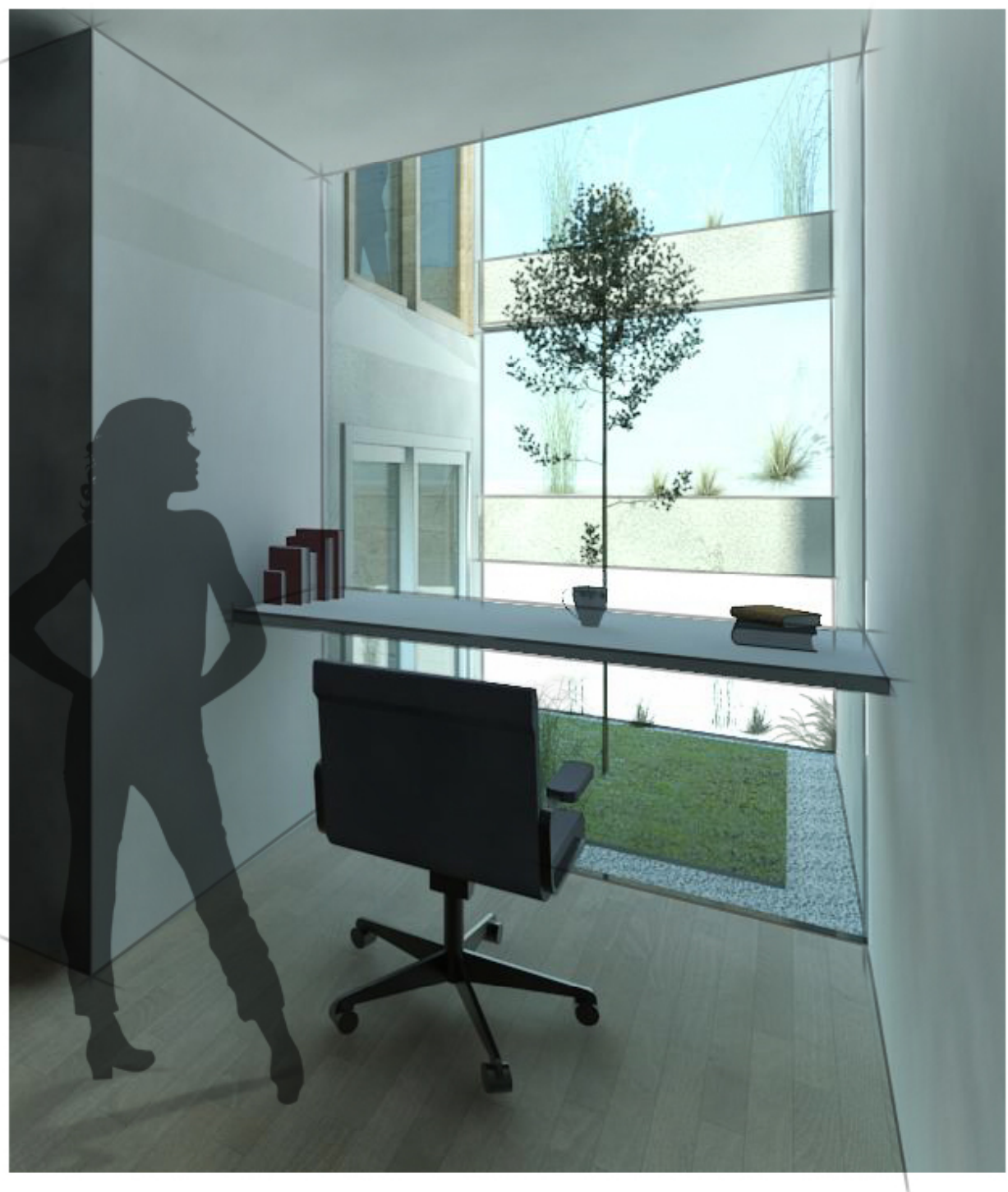

Fig. 5.58 Apartment ' $F$ ' interior perspective from study 


\section{Apartment 'G':}

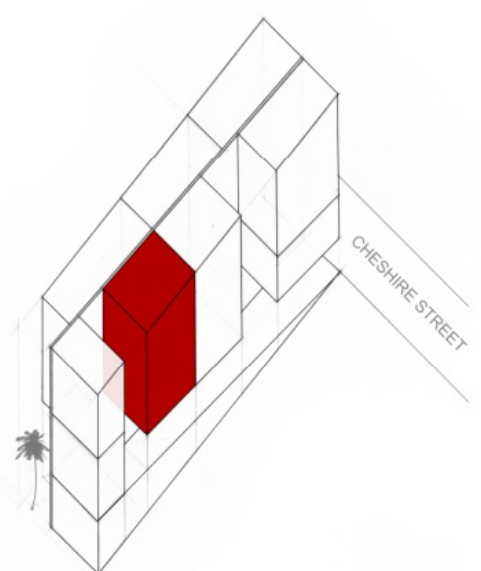

Fig. 5.59 Apartment 'G' location diagram.
Footprint size: 30 sqm Floor size: $68 \mathrm{sqm}$

- The entry of this apartment is located halfway between the private bedrooms below and the living space above. This level also houses the compact bathroom which features a shower space defined only by the water itself, and is not divided or compartmentalised by further partitions within the bathroom. This saves space and maintains an open volume within the room. Examples of this can be seen in Fig. 5.57, Fig. 5.98 and Fig. 5.69.

- An external light-well brings light down to the courtyard below allowing diffuse light to enter the adjacent rooms.

- With the doors open the courtyard feels as though it is part of the same space as the bedroom.

- The kitchen bench doubles as a small dining space.

- A clearstory window in the double height living space hints at the outdoor space through a visual connection.

- Following the stairs to the top reveals a private roof terrace with views to the surrounding roof gardens and the Domain in the distance. 

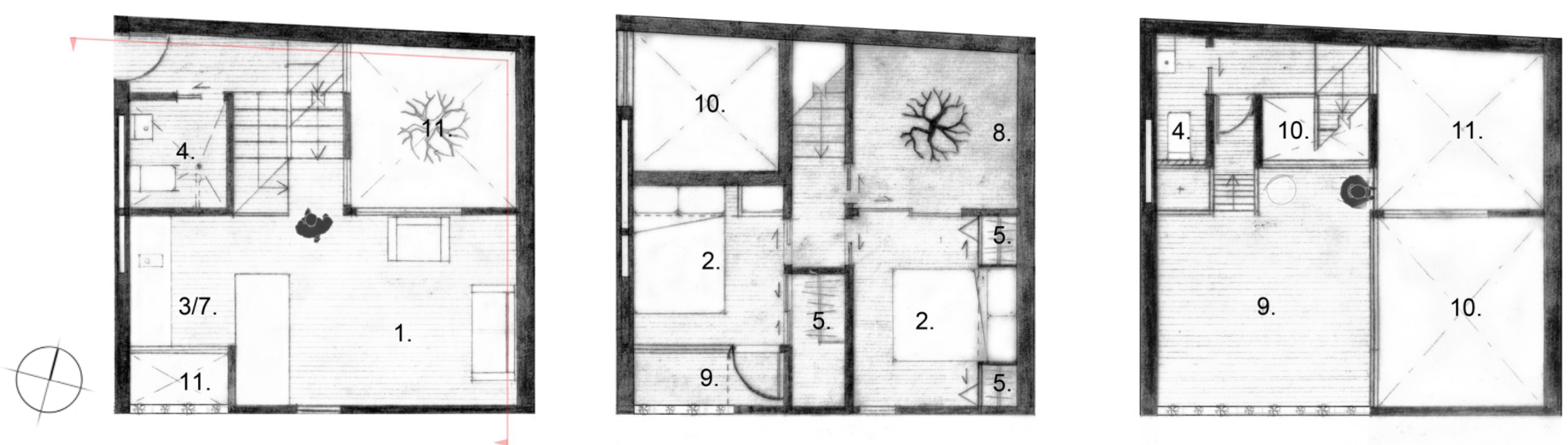

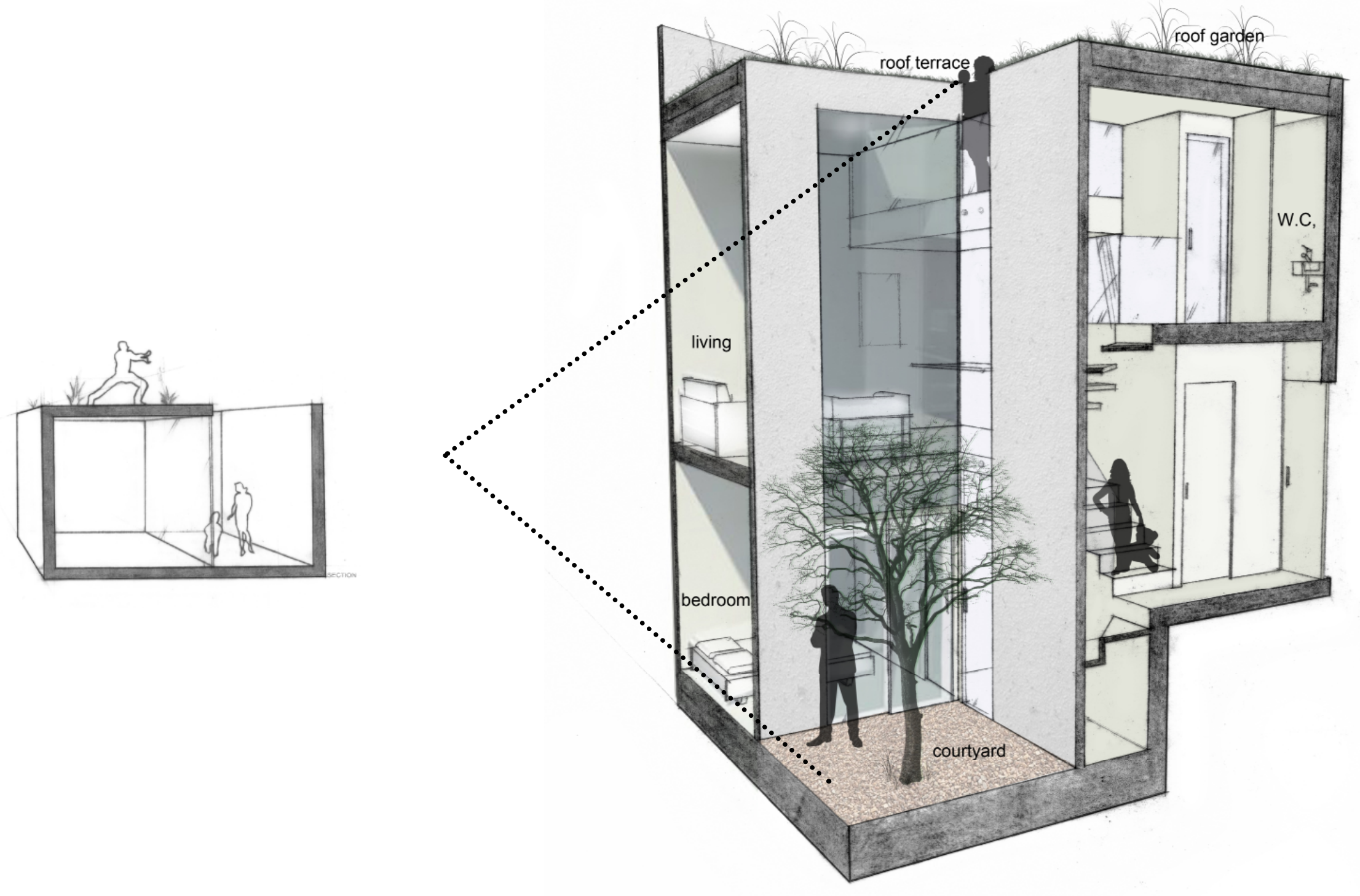

Fig. 5.61 Apartment 'G' sectional perspective. 


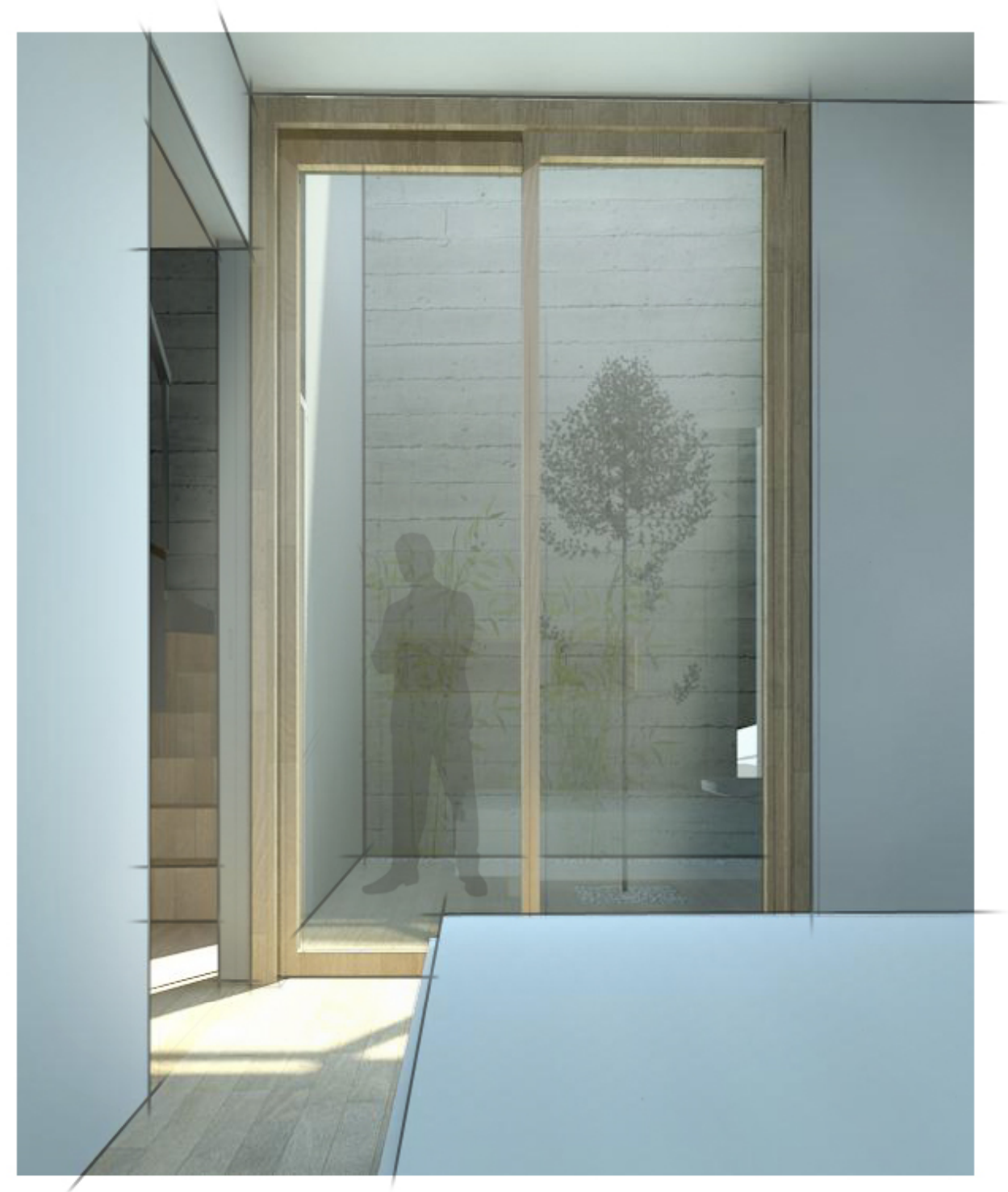

Fig. 5.62 Apartment 'G' interior perspective from bedroom looking to courtyard. 


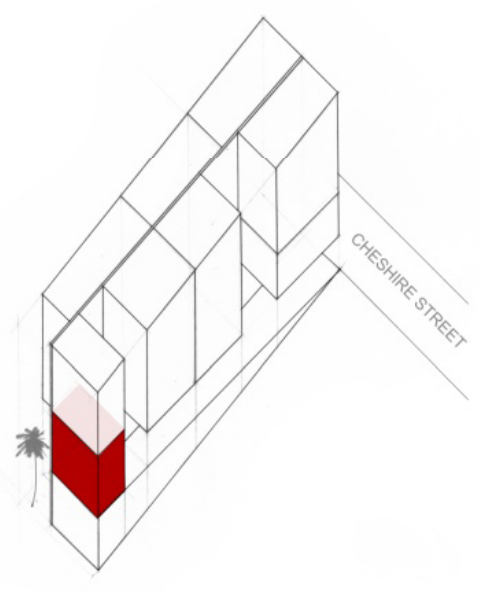

Fig. 5.63 Apartment 'H' location diagram.

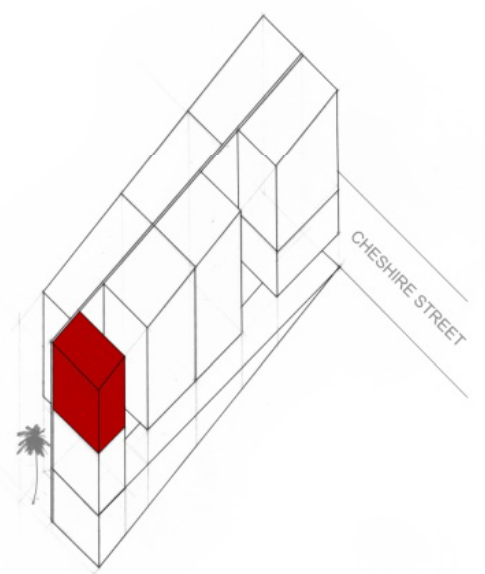

Fig. 5.64 Apartment 'l' location diagram.
Footprint size: 20 sqm Floor size: 34 sqm No. of Bedrooms: 1 (studio)

- While the studio apartments are relatively small in size, particularly in terms of their footprint, a quality and surprisingly spacious environment is achieved.

- The studio footprint remains conservative due to the limited space for horizontal elaboration, yet through arranging spaces in the split level layout, the introduced verticality of the apartment increases the space available for the inhabitant.

- The adaptive furniture also plays a big role. The flexibility of the main space is created by the incorporation of a bed that slides back into a cavity and becomes a couch, thereby increasing the usable floor area during the day while still making use of the semi-exposed bed. Above the bed, storage cupboards are incorporated.

- Down from the living/bedroom space is a wardrobe and storage space efficiently tucked under the stairs.

- Adjacent is the compact bathroom which is fully waterproofed so the whole space can be treated as a shower cubicle, rather than having to further partition the room. This maintains a greater sense of spaciousness, important in such an intimate space.

- Above the bedroom is the kitchen and dining space. The main part of the kitchen (along the western wall) would incorporate all the shelving, cupboards and appliances, whereas the rest of the bench surfaces are floating to either maintain a visual connection from the living space or, in the case of western-most bench surface which floats above the stairs, it allows enough headroom for the stairs below.

- A secondary function of this western bench surface is a transition space which leads up to the terrace. This playful gesture has a sculptural quality as it bridges across the void above 
the living room.

- Despite their small size, these studio apartments have private terraces which are visually connected to the interior through the large glazed partition. This window also brings in light high up in the apartment to diffuse down into the interior below.

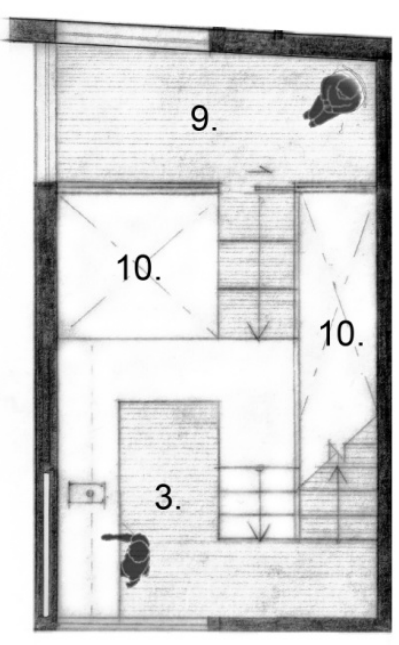

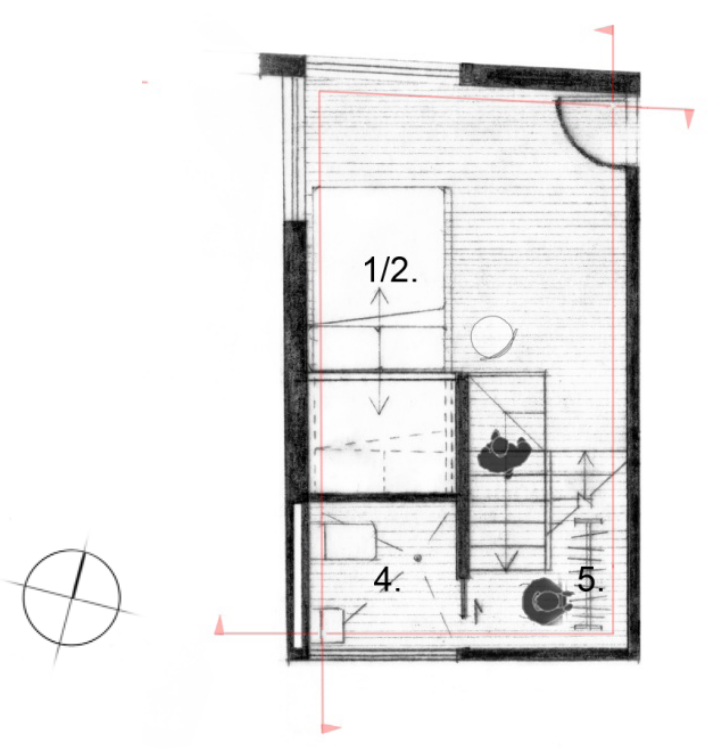

Fig. 5.65 Apartment 'H' and 'I' floor plans. 1:100. 

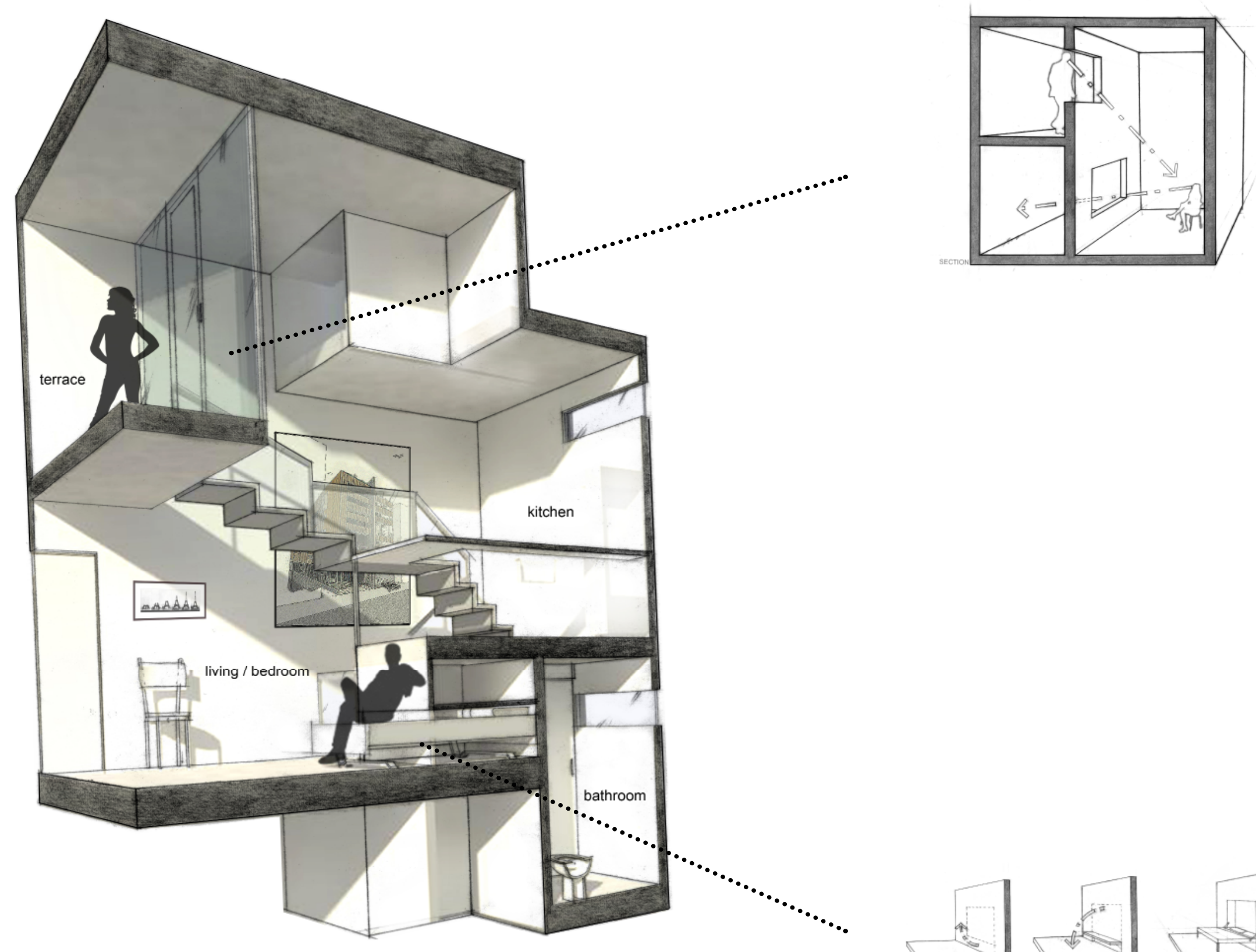

Fig. 5.66 Apartment 'H' sectional perspective. 


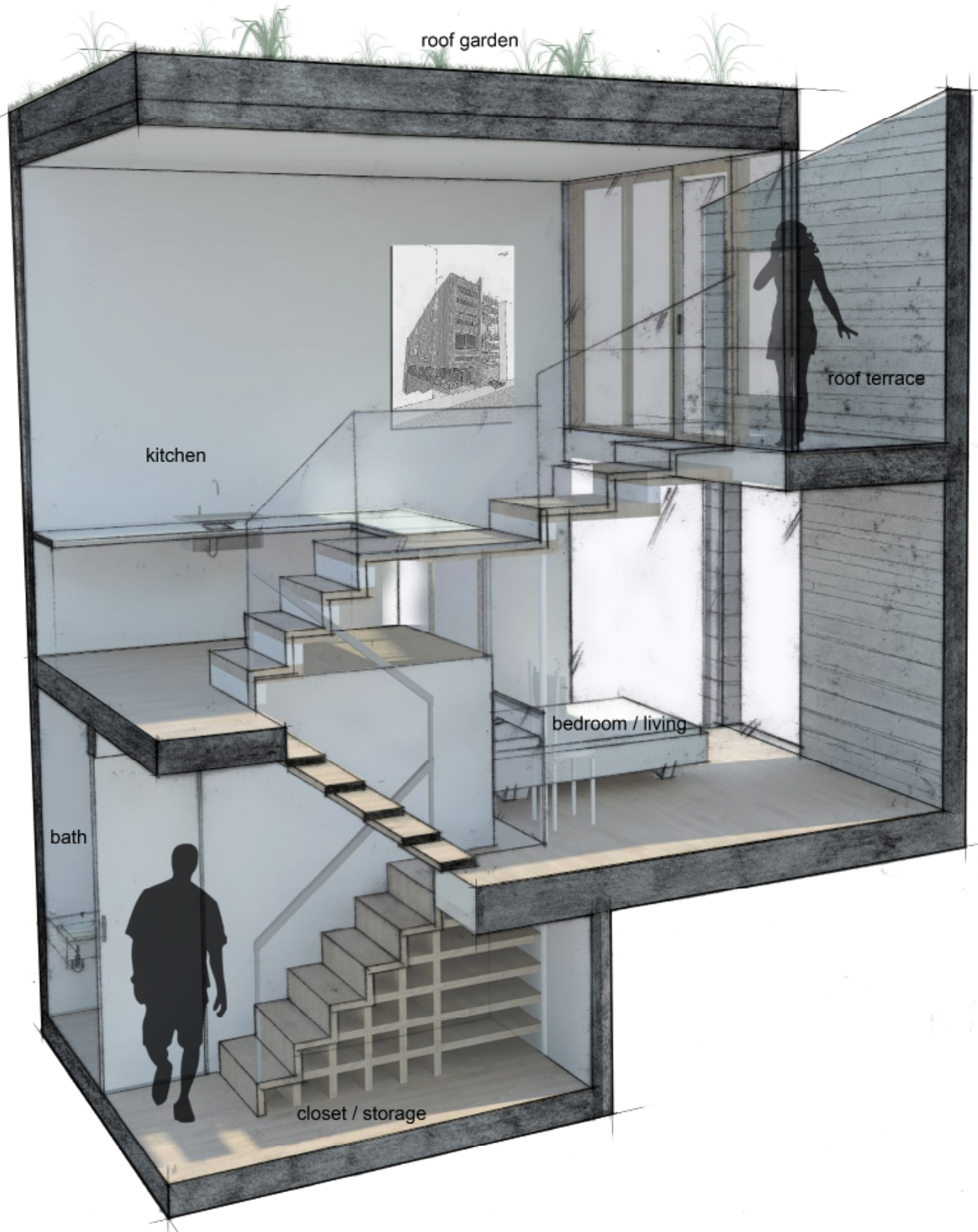

Fig. 5.67 Apartment 'l' sectional perspective. 

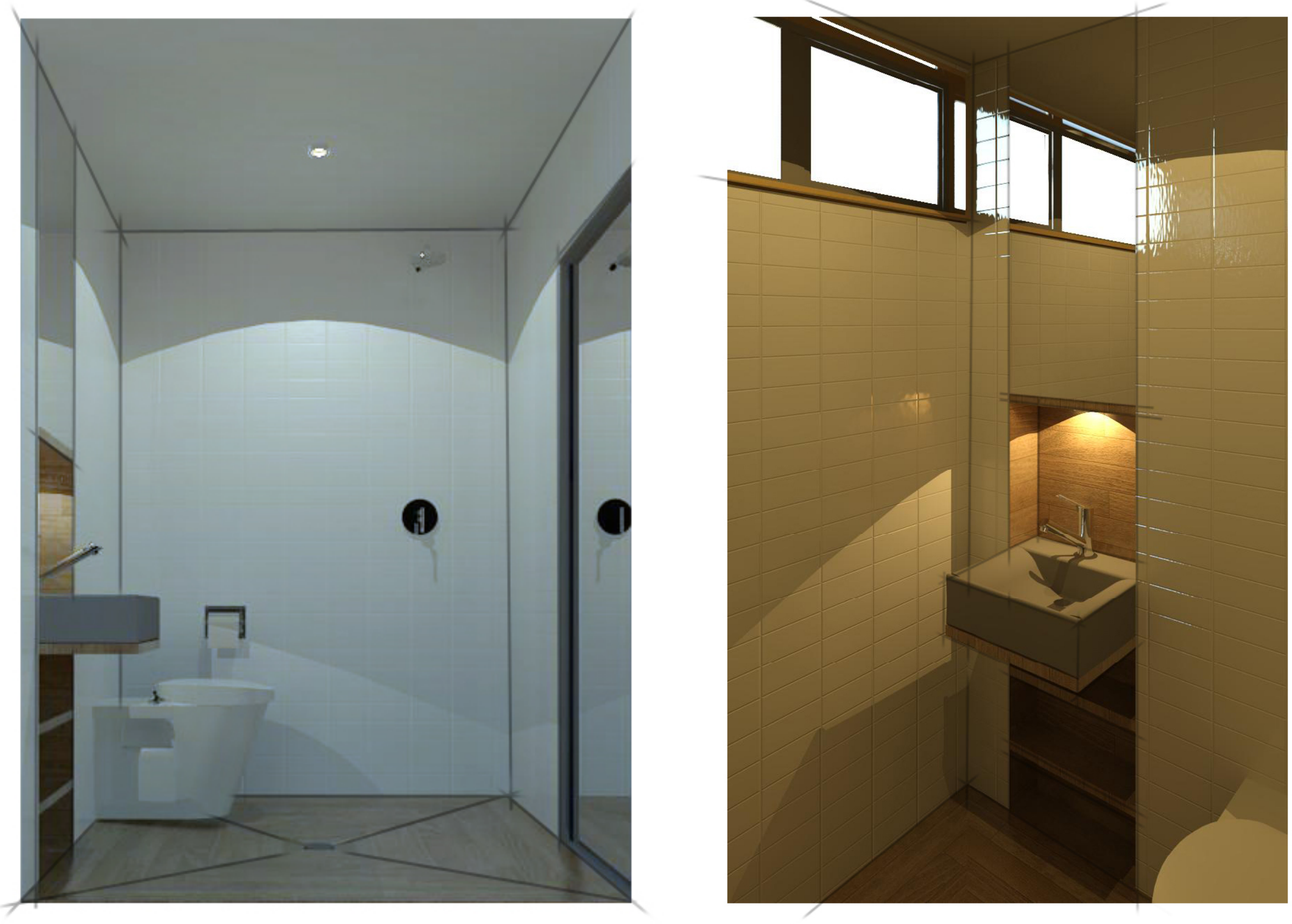
Fig. 5.68 and Fig. 5.69 (Opposite) Compact bathroom. 


\section{5 - Comparative Designs:}

Serving as a reference for comparison, the diagrammatic design solutions below suggest how a more conventional apartment building design may be developed on the same site. These designs are based on the recurring attributes of the models analysed in Chapter Two. Each example is arranged over three floors. The first two examples are based on a two by four grid of apartments, with an exception to the ground floor where, what would be the south-east apartment (adjacent to the street), is replaced by a space allocated for the entry lobby. The second two are arranged in a one deep by six abreast layout. Again, the western-most apartment on the ground floor is replaced by a lobby space. For each layout type a single and double vertical circulation core is represented. Alternative layouts three and four provide some apartments with a dual aspect, beneficial for cross ventilation and offers more external surfaces to introduce daylight into the apartments. No on-site car parking is available in any of these variations due to the small dimensions of the site. The small width of the site does not permit a parking layout where a sufficient number of spaces can be efficiently included, without the use of a car stacker as used in the actual design. Car stackers are not common in conventional apartment complexes and are therefore omitted in these examples. The apartment units, true to convention in New Zealand, are single level apartments. Due to the 'bare-bones' nature of these designs, as well as the removal of on-site car parking, a greater ratio between private and communal space is achieved. The saleable (or rentable) space is more expansive in relation to the overall construction costs when compared to that of the design case study.

Fig. 5.70 Alternative apartment layout 1 diagram.

1. Apartment layout 1: 23 Apartments of approximately 35 square metres.

2. Apartment layout 2: 23 Apartments of approximately 35 square metres.

3. Apartment layout 3: 17 Apartments of approximately 45 square metres.

4. Apartment layout 4: 17 Apartments of approximately 45 square metres. 

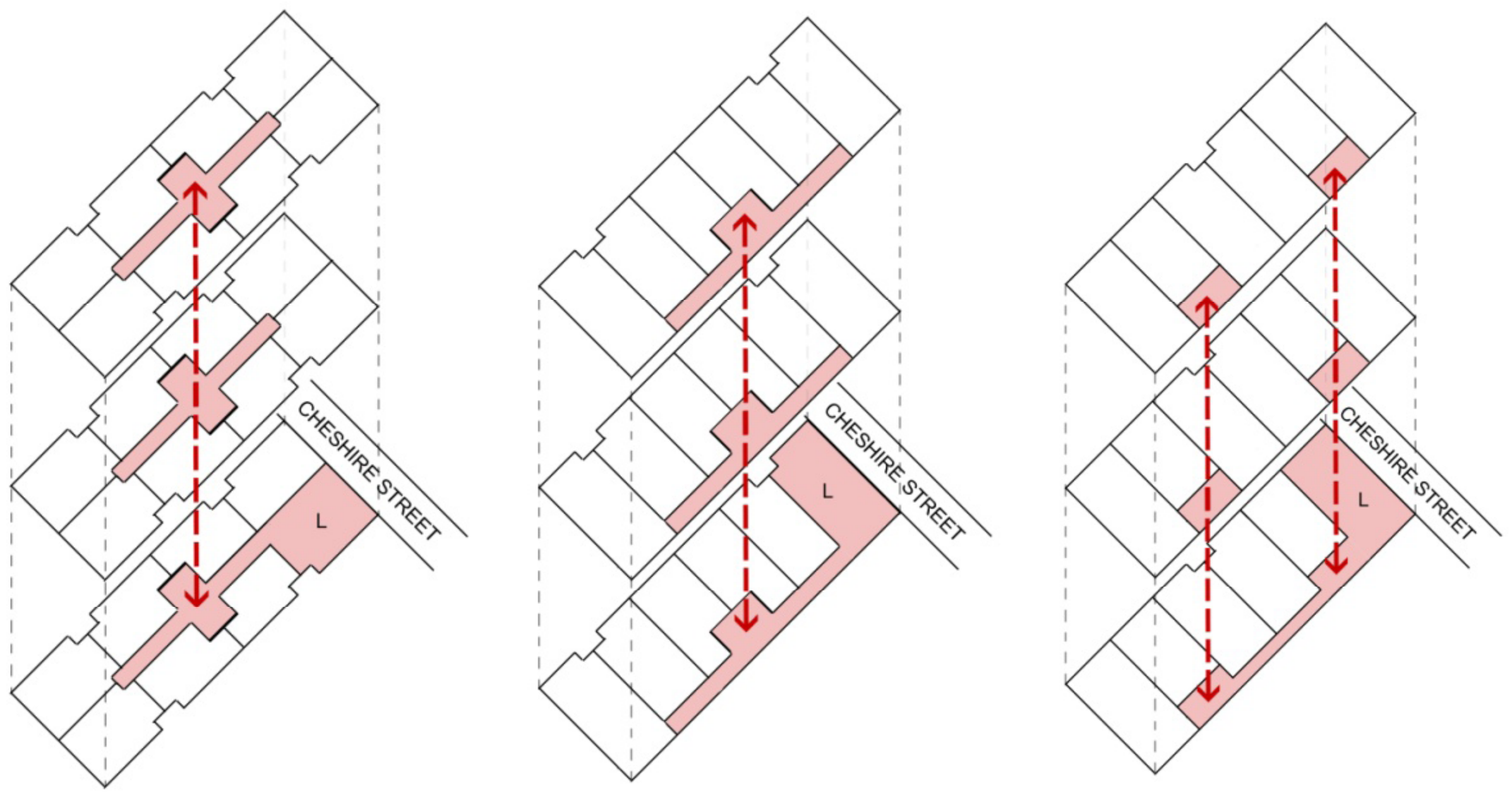
These arrangements are more economical in construction costs due to the repetition of units and the inherent simplicity. The fact that these apartments are compact both in the horizontal and vertical dimensions allows a larger number of units to be 'squeezed' into the small site. The type of units that make up these style of developments are, however, prone to possess the negative attributes and poor quality environments as in those analysed in Chapter Two. This brief comparative design exercise indicates that there is certainly a potential to achieve greater density with alternative design strategies, however the quality of the experience and environments are compromised.

\section{6-Design Discussion:}

This section will reflect on the design outcome. The intention is to discuss the successes, failures and points of interest which have come to light through the design development. The design attempts to provide high-density urban accommodation with apartments which, while maintaining a compact and space efficient size, have a greater sense of spaciousness and higher quality internal environments than the current stock of small apartments in New Zealand. In short, the design achieves that, although there are also some drawbacks and questionable results.

One of the main positive outcomes is the better relationship with nature and the immediate outdoor environments. Following the Japanese precedents, the apartments place a greater emphasis on outdoor space; its inclusion is a high priority. The often perceivably counter-intuitive design decisions, scarce internal floor area sacrificed for outdoor space, results in a better overall environment for the inhabitants. While floor areas may be limited, through extensions of internal spaces to the exterior, the inclusiveness of outdoor spaces within the home gives a perception of greater space. Simultaneously, these carefully designed outdoor spaces afford the inhabitants a private outlook of their own. This is an important feature in the urban areas of New Zealand, where while we need to provide an increasing density of housing, it is this density which limits privacy. These apartments provide their own views to private courtyards and planted terraces. The introverted nature of these homes feels more appropriate in dense urban environments, yet a 
connection to the wider context is still achieved through more controlled views and fenestrations. In this instance, the roof terraces provide more expansive views of the surroundings and the terracing effect of the rooftops helps orientate them to the desirable views of the Auckland Domain at the same time as creating a private outdoor escape from the urban chaos. Nevertheless, the inclusion of roof top terraces, gardens and courtyards are not without their limitations. For an apartment to have direct access to its own rooftop it is necessary for the apartment to be located on the top of building (and also requires additional circulation to reach roof). This restricts the maximum number of apartments able to have rooftop terraces. Similarly, light wells which bring light down from above, are somewhat limited by the location of the apartment they serve; the lower down the space being lit, the longer the light well. With increasing length, the light well becomes less efficient and will take up valuable space. This becomes one of the factors that would ultimately limit the vertical dimension of any given apartment. The design decision to provide numerous small outdoor areas throughout each apartment allowed spaces situated on different levels to have visual or physical access to them. An alternative method would have been to incorporate fewer outdoor areas but make them larger. Benefits from this would likely see a reduction in construction costs and possibly lend to more functional outdoor living spaces as opposed to largely cosmetic exterior focal points.

The main facet of the design that differs significantly from the current examples of apartments in New Zealand is the inherent verticality of the apartments following the precedent set my micro-dwellings in Japan. Through the conceptual translation from stand-alone dwellings to apartments, certain limitations of the application arise and different outcomes are inevitable. Benefits that arise from the stacked configuration of spaces within apartments include the ability to contain the programme within a small footprint. Small footprints allow a dense concentration of apartments within the dimensions of a small site and replace problematic shared circulation areas with private circulation areas. This has also limited the amount of dedicated horizontal circulation. Instead, stairwells link the vertically arranged spaces and provide secondary functions or benefits such as the integration of storage beneath or the ability of the open stairwell to 'share' light between levels. It is recognised that as a result of the greater complexity of the building's unorthodox arrangement of spaces the cost of construction will also be greater when compared 


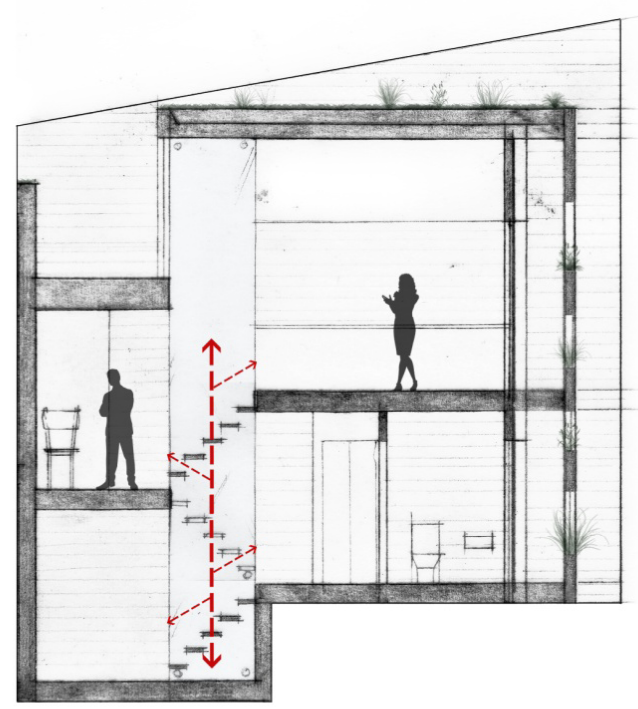

Fig. 5.74 Split-level stair in apartment 'E'. to more conventional apartment design. However, these costs are arguably offset by the better quality environments that result. There is potential for these high costs to decrease over time with subsequent buildings developing time and cost efficient processes to achieve the same or similar results. The most successful stair arrangements within the design are the compact stairwells which are contained within a unified core in the apartment. These stairwells link split levels on either side, typically with smaller spaces like bathrooms or dining rooms on one side and larger space such as living rooms on the other. An example of this is shown in apartment ' $C$ ' (Fig. 5.46) or in apartment 'E' (Fig. 5.74). Through the implementation of the design strategy - increasing height of spaces/rooms as the footprint shrinks - within the design, its limitations became apparent. When the proportions become too extreme, as exemplified in apartment 'B's ensuite (Fig. 5.41), the tall and narrow spaces have the potential to seem 'intimidating' or 'overwhelming', as if the walls are drawing in.

Further conclusions can be drawn from the stacking of programme and extensive use of stairs. In its application, this vertical arrangement is best suited, but not necessarily limited, to studio, one and two bedroom apartments. In this format, an increasing bedroom count will typically lead to an additional floor level. Not only does this increased height affect design elements, such as previously discussed light wells, but the amount of vertical circulation required becomes overwhelming for the inhabitants. To an extent this design addresses this issue through alternative entry points in the larger apartments, allowing the lift in the communal circulation core to be used. This requires the communal core to extend further up in the building volume and in turn creates an inefficiency in circulation as both the communal and the internal circulation of the individual apartments double up in their function. By limiting the number of bedrooms to two or less the small footprints, compact living spaces and the benefits of open stairwells are maintained, while the amount of stairs are kept at a suitable limit, reducing the need for secondary entrances and the extension of communal circulation. Higher numbers of bedrooms are possible through a combination of these strategies and the traditional designs, by expanding both horizontally, for example width of two rooms on one floor. 
Cultural differences between Japan and New Zealand required some compromises when translating the design strategies into the alternative context. For instance, the family dynamics differ; while in Japan it is more accepted for bedrooms to be shared and open to other areas of the home, New Zealanders require rooms which offer more privacy within the household. Consequently the design offers separated bedrooms, with solid partitioning walls. While these partitions enclose the interior spaces more, where practical, sliding doors and walls allow the space to adapt. The bedrooms can be shut off at night and used as public living spaces with greater connections to the rest of the house during the day.

Further critiques of the design are that, while these apartments are conceived more as complete homes, they do not fully address the lack of storage in current apartments. Dwellers of small apartments do not necessarily have proportionally less belongings to dwellers of larger standalone homes. As well as limitations of the size of apartments within a complex, as mentioned above, the size of the complex and the number of apartments is ideally limited to low to medium rise developments. In order to achieve many of the desired spaces and internal conditions, there is a large reliance on the top surface of the apartments to contribute light, views and terraces. With multiple units stacked on top of each other, the complexity, cost and physical feasibility of these design strategies is heavily compromised. However, this does pose a very viable option for vertical extension of existing urban buildings; the addition of smaller scale apartment buildings such as has been designed here, will increase density in central city locations.

One of the early design decisions was to introduce the partition, dividing the volume into two as described in Fig. 5.12 While this gesture achieved its intended purpose it also prevented the inclusion of dual aspect apartments. At the same time, due to the verticality of the individual apartments, introducing dual aspect apartments would limit the number of apartments which have access to the ends of the site, facing the street or valley, as opposed to facing the buildings of the adjacent sites. With a greater understanding on the potential and limits of the strategies and principles, future design iterations would serve less as a 'test bed' and focus on a more realistic and cost efficient design. This would start by increasing the efficiency of circulation through limiting the size and maximum height of individual apartments as discussed above. A 
more consistent design language across all apartments would be necessary, where standardised kitchen and bathroom units could be economically produced to save costs. Similarly, there would be a greater focus on the apartments fitting neatly together in a simplified arrangement, with consistent floor levels. The on-site car parking would also be reconsidered, as in its current state it produces a lot of added cost and spatial inefficiencies. To address this, off-site parking spaces could be introduced on a nearby location or parking foregone altogether (it could be argued the close proximity to amenities and public transport nodes may be sufficient for the residents).

\section{7-Conclusion:}

The intention of the design was to adapt the strategies extracted from the analysis of Japanese micro-architectural precedents and apply them to an apartment development in a New Zealand city. A small site in Parnell, Auckland was selected for its urban location, proximity to amenities and relatively small size (which adds further constraints to the design process). Upon this site a nine apartment complex was designed to address the site constraints and implement the design strategies developed in Chapter Four. Within the chapter the overall design and design process was outlined followed by a more detailed view of the individual apartments and how the strategies were implemented. For the purposes of comparison, a conventional apartment development was also briefly examined. Multiple iterations led to the design as it is featured above, however there are some elements of this design which are more successful than others. Reflection upon the outcome of the design discussed its successes and limitations, particularly in relation to the desired objectives and the implementation of the design strategies. One of the primary conclusions revealed through the design is the physical limitations of these strategies, in terms of the size of both the individual apartments and the overall development. 

CONCLUSION

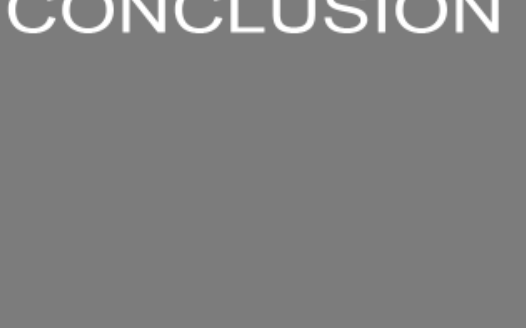

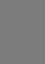

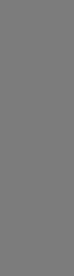




\section{1 - Introduction:}

This thesis investigated how planning and design strategies used in the Japanese architectural movement of Kyosho-Jukatu could be adapted and applied in a New Zealand context to improve the quality of small apartments. This research ultimately led to the design of an apartment building in Central Auckland that tested the strategies within an integrated design. The following sections illustrate the significant conclusions attained from each research stage, how they affected the ensuing design development and the limitations that arose throughout the research process.

\section{2 - Key Findings:}

Chapter Two established the New Zealand context for which this research is sited. Trends showed the continual population increase and urbanisation in New Zealand where, as of 2011, $86 \%$ of the country's population lived in urban centres. As urbanisation increases, growing pressure on innercity land and accommodation necessitates high-density housing solutions, such as apartments. The study of opinion surveys and news articles highlighted New Zealanders' current perceptions towards apartments and apartment living. It suggested that there is generally a negative perception of apartment living resulting in part from the fear of having limited housing options. Additionally, as New Zealanders are typically accustomed to more expansive living environments, exemplified by the quarter acre dream, they are cautious of small apartments and suspect that they produce poor quality dwellings. Analyses of current examples of apartment buildings revealed planning and design flaws which justify the public's perception. Over 60 apartments from 25 different apartment buildings in Wellington and Auckland were analysed with the intention of highlighting recurring problematic planning and poor spatial qualities. The key design problems were then abstracted diagrammatically to establish a series of design issues to be avoided or improved in the design case study. The main issues fall into three categories: uniform sectional layout 
and constant ceiling levels bringing little diversity to the layout of the apartments; circulation addressed in limited ways, with long corridors wasting limited space or living spaces being disrupted through their use as transition zones; the lack of natural light and disconnection with the exterior minimizing the sense and quality of the spaces. This chapter established a need for high-density urban accommodation, and also improvement to the quality and spatial experience of current apartments in New Zealand.

Chapter Three introduced the context which established and validated Japan as an influential precedent and source of inspiration, arguing that Japanese design strategies can be adapted to develop better apartments in New Zealand's evolving urban setting. The phenomenon of Japonisme highlighted the historical influence of Japan on the artistic and architectural endeavours of the Western World, with notable artists and architects such as Van Gogh and Frank Lloyd Wright 'borrowing' from Japanese design. This research followed these precedents. This chapter also looked at Japan's evolution from an agriculture-based society to a highly urbanised country. A parallel can be drawn to New Zealand's current urbanisation, although it is recognised that this occurs at a much slower rate than in Japan. Consequent to the burst of the Japanese economic bubble in the early 1990s, an architectural movement emerged. Kyosho-Jutaku (microliving) took advantage of the small, tightly constrained urban sites throughout Japanese cities to produce comparatively affordable accommodation for individuals and families seeking an urban lifestyle. These dwellings deal with the same issues as apartments, issues of limited floor area, small footprint size, space-efficiency and quality of space. This chapter established a precedent in which to analyse and learn from.

Chapter Four provided a detailed look at the characteristics which define the typology of Japanese micro-architecture. Forty examples were analysed through the redrawing of building plans and sections into a consistent scale and format - consistent with the plans of the New Zealand apartments which aided in comparative study. Primary observational analysis extracted commonalities within the designs pertaining to planning and spatial design strategies which contributed to the successful solutions of size constraints. The analysis led to the production of a series of diagrams which highlighted key strategies employed by Japanese architects in their 
masterful manipulation of small spaces. Diagramming the strategies consolidated the recurring instances into overriding concepts and removed them from their origin, eliminating context and culture. These diagrams discussed the positive implications of the strategies and offered several design options, thus expanding the technique in which the strategy can be explored in different contexts. Strategies can be grouped into three categories: the perceptive extension of space through the use of external sight-lines, the infiltration of natural light and the extension of interior heights; the tight constraints of space maximised through built-in and custom designed furniture to minimise clutter; and the design of circulation extending beyond the horizontal to vertical stacking, mezzanines and split levels.

In Chapter Five, the design phase saw the lessons learned in the previous chapters applied and tested through the design of an apartment building. In essence, the brief was to develop a highdensity urban apartment complex which contained a variety of small apartments. The site, located in Parnell, Auckland, is a small residential lot in a developing mixed-use neighbourhood. The small site produced further constraints appropriate for testing the strategies and resulted in a development where the nine apartments range from studios to three bedroom units. Throughout, the application of the planning and spatial strategies were highlighted. Conclusions drawn from the design phase suggested that while the design successfully employed the strategies to provide quality apartments within a compact volume, there are certain limitations in the transfer of these micro-architecture strategies into a format for apartments. Success was greater for apartments of two bedrooms or less; apartments with larger bedroom counts were likely to require excessive vertical circulation. However, in general the limitations pertained to the complex as a whole. For example, inclusion of light wells and roof terraces, for example, are affected by the number of units stacked upon one another. 
In summary the main findings include:

1) An indication of the need for urban accommodation.

2) Apartments in New Zealand are widely perceived in a negative light.

3) The existing stock of apartments in New Zealand feature many design and planning flaws, and are poor quality living environments.

4) The architectural movement of Kyosho-Jutaku serves as a suitable precedent for how to design quality small spaces.

5) A series of architectural strategies were identified through analysing the Japanese models.

6) While only a limited number of strategies may be suitable for high-rise application, the majority of the principles can be successfully applied to a medium rise apartment building in New Zealand.

7) The stacking of spaces within an apartment serves as practical to a limit of two dedicated bedrooms (more when spaces can be adapted to serve as temporary bedrooms).

8) Such application of the strategies as seen in the design case study is best suited to apartments with direct roof access.

9) Stacking of apartments on top another reduces the efficiency and success of such strategies as top lighting and the inclusion of roof terraces.

10) An increase in construction cost and reduction in apartment numbers is foreseen when compared to more conservative models. 


\section{3-Limitations:}

The translation of the design strategies from stand alone dwellings to apartment buildings offered a challenge. To reduce the effect differing typologies may have on usefulness and applicability, design strategies were abstracted and decontexualised into diagrammatic formats. This elimination of context also addressed the cultural differences between the two countries, where family and societal dynamics differ. Through the design case study, the research concludes that design strategies favour a style of apartment, which is vertical in configuration and relies on roof access and light wells. This is best suited to low or medium-rise apartment complexes, where no more than two apartments are stacked on one another. The apartments designed within the research are therefore more appropriate to urban sites within the inner-city suburbs than to central city high-rise complexes of which made up a significant proportion of the analysed New Zealand examples. It should be mentioned though, that the focus on a medium-rise complex was motivated largely by a desire to test a wide range of strategies, and that high-rise apartments are likely to offer potential to a smaller range of strategies. Throughout the research, the method of analysis consisted largely of qualitative observations. While data such as the quantities of the recurring themes can be measured, the analysis remains somewhat subjective in nature regarding the impact these strategies actually have on the spatial qualities. Complimentary research of the affect of such spatial devices helps support the assumptions made.

\section{4-Closing Comments:}

One can argue success of the overall application of these strategies in a New Zealand context. On the one hand, they provide a quality solution to high density housing in a more quasi-suburban environment where height of the development is limited. However, as far as high-rise apartment complexes are concerned, it is suggested that fewer of the strategies can be employed and perhaps with less efficiency. In this case, the broad definition of an apartment building prevents a comprehensive conclusion. From here, further research could seek to target high-rise apartment buildings specifically, or look further into the cost implications of such design strategies and 
consider the cost versus benefits of their application. Alternatively, research could approach the legislative and regulatory controls which would allow these strategies to be applied easily, as well as prevent further developments of poor quality in the future. Despite limitations, this project has shown how the adaptation of another country's housing techniques can be beneficial in the creation of designs that provide quality living environments. 
Alexander, Christopher. A Pattern Language: Towns, Buildings, Construction. Oxford: Oxford University Press, 1977.

Allinson, G. D. Japan's Postwar History. Cornell University Press, 2004.

Auckland City Council. "Plan modification 77." 22 October 2004. Auckland City Council. August 2011. <http://www.aucklandcity.govt.nz/council/documents/district/updates/ t077/Pm077.pdf>.

Auckland Transport. "Parnell Station Public Information." 15 November 2011. Auckland Transport. November 2011. <http://www.aucklandtransport.govt.nz/improving-transport/ current-projects/Rail/Documents/parnell_station_intial_meeting.pdf >

Auckland UniServices Ltd. Living the Highlife? A Review of Apartment Living in Inner City Auckland. Auckland: Auckland UniServices Ltd., 2004.

Bennett, Jessica. “How Do Apartments Measure Up?” Build, 117, April/May (2010): 72-73.

Bognár, Botond. Beyond the Bubble: The New Japanese Architecture. London: Phaidon Press, 2008.

Chan, Yenna. Small Environments. Gloucester: Rockport Publishers, 2007.

Criscillo, Vic and Howard Tong. Wellington City Apartments :The Survey: "What type of city apartment do you really want?”. Wellington: Moore Warburton Ltd, 1999.

Crockers Property Group. “Crockers Market Research Archives.” 2006-2012. Crockers Property Group. 2 March 2012. <http://www.crockers.co.nz/market-research/market-researcharchive. $\operatorname{aspx}$ ?c=1290>. 
Daniell, T. After the Crash: Architecture in Post-Bubble Japan. New York: Princeton Architectural Press, 2008.

DTZ Research. "Executive Summary of the Auckland Inner City Living Survey." 20 November 2003. Auckland City Council. 3 June 2011. <http://www.aucklandcity.govt.nz/council/ projects/cbdproject/docs/executivesummary.pdf $>$.

Flynn, J.E. and T.J. Spencer. "The Effect of Light Source Color on User Impression and Satisfaction.” Journal of the Illuminating Engineering Society (1977): 167-179.

Freeman, Michael. Space : Japanese Design Solutions for Compact Living. New York: Universe, 2004.

Gates, Charlie. Young Kiwis fear apartment living. 28 April 2011. June 2011. <http://www.stuff. co.nz/national/4934946/Young-Kiwis-fear-apartment-living>.

Hatta, Tatsuo and Takatoshi Tabuchi. "Unipolar Concentration in Tokyo: Causes and Measures." Japanese Economic Studies, Vol. 23, Issue 3 (1995): 74-104.

Jacobs, Jane. The Death and Life of Great American Cities. New York: Modern Library, 1993.

Lambourne, Lionel. Japonisme : cultural crossings between Japan and the West. London: Phaidon, 2005.

Laver, Michael S. The Sakoku Edicts and the Politics of Tokugawa Hegemony. New York: Cambria Press, 2011.

McNeil, Peter. "Myths of Modernism: Japanese Architecture, Interior Design and the West, c. 1920-1940.” Journal of Design History, Vol. 5, No. 4 (1992): 281-294.

Meech-Pekarik, Julia. "Frank Lloyd Wright and Japanese Prints." The Metropolitan Museum of Art Bulletin, Vol. 40, No. 2 (1982): 47-56.

Mera, Koichi. “An Economic Policy Hypothesis of Metropolitan Growth Cycles: A Reflection on 
the Recent Rejuvenation of Tokyo." Review of Urban \& Regional Development Studies, Vol. 1, Issue 1 (1989): 37-46.

Mitchell, Austin. Quarter-acre Pavlova Paradise. Christchurch: Whitcombe and Tombs, 1972.

Miyakawa, Y. “The Location of Modern Industry in Japan.” Gakkai, Nihon Chiri. Geography of Japan. Teikoku-Shoin, 1980. 265-278.

Moore, K., Perkins, H. C., \& Vallance, S. “The results of making a city more compact: neighbours' interpretation of urban infill." Environment and Planning B: Planning and Design, volume 32 (2005): Pg. 718

North Shore City Council. "Urban Design: Apartment Developments (Good Solutions Guide for Apartments).” 20 March 2007. Auckland City Council. 1 August 2011. <http://www.northshorecity.govt.nz/YourCouncil/Planning/UrbanDesign/Pages/ UrbanDesignApartmentDevelopments.aspx>.

Nute, Kevin. Frank Lloyd Wright and Japan: The Role of Traditional Japanese Art and Architecture in the Work of Frank Lloyd Wright. London: Routledge, 2000.

Smith, Norman. Small Space Living: Design. Rockport: Rockport Publishers, 1995.

Smith, Patrick. Japan: A Reinterpretation. New York: Pantheon Books, 1997.

Sorensen, A. The Making of Urban Japan - Cities and Planning from Edo to the Twenty-first Century. New York: Routledge, 2002.

Statistics New Zealand. Apartment Dwellers: 2006 Census. Wellington: Statistics New Zealand, 2010.

—. Building Consents Statistics for New Apartment Buildings 1992 - 2012. Wellington, 05 April 2012.

—. Long-term Data Series - Population Estimates in NZ. 2011. 20 February 2012. <http:// 
www.stats.govt.nz/infoshare/SelectVariables.aspx?pxID=85d52c37-a2cd-49e4-9fa9bd42c39c1123>.

—. Population: Demography Dwelling and Household Estimates. Wellington, 05 June 2011.

Stewart, K., \& Donn, M. "New Zealand Daylight Code Compliance Tool: Development and Implementation." PLEA 2008 - 25th Conference on Passive and Low Energy Architecture. Dublin: Passive and Low Energy Architecture, 2008. 1-6.

Tamborini, Susanne. Living in a Small Space : Experimental Projects From Four Continents. Stuttgart: Edition Axel Menges, 1999.

Tashiro, Kazui. "Foreign Relations During the Edo Period: Sakoku Reexamined." Journal of Japanese Studies. Vol. 8, No. 2 (1982): 288-290.

The World Bank. World Development Report 2011: Conflict, Security, and Development. Washington: The International Bank for Reconstruction and Development / The World Bank, n.d.

Thiel, Philip. "Review: Japanese Influences on Western Architecture." The Journal of Asian Studies, Vol. 16, No. 2 (1957): 271-274.

United Nations Environment Programme, Task Force on Sustainable Lifestyles. Visions For Change: Country Papers. Paris: UNEP Division of Technology, Industry \& Economics, 2011.

—.Visions for Change: Recommendations for Effective Policies on Sustainable Lifestyles. Paris: UNEP Division of Technology, Industry \& Economics, 2011.

United Nations, Department of Economic and Social Affairs, Population Division. World Urbanization Prospects: The 2011 Revision. New York: United Nations Department of Economic and Social Affairs, 2012.

Wellington City Council. "Central City Apartment Dwellers Survey - A Summary of Results." 
14 April 2009. Wellington City Council. 4 June 2011. <http://www.wellington.govt.nz/ services/urban/pdfs/apartment-survey-report.pdf>.

-. Urban Development Strategy: Directing Growth and Delivering Quality. Wellington: Wellington City Council, 2006.

Wright, Frank Lloyd. “The Japanese Print: An Interpretation.” Pfeiffer, Ed. Bruce Brooks. Frank Llyod Wright Collected Writings Vol. 1. 1894-1930. New York: Rizzoli, 1992. 116-125. 


\section{Chapter Two:}

Fig. 2.0 Graph of New Zealand's increasing population over a 60 year period. Image by Author.

Fig. 2.1 Graph showing popular reasons for living in apartments. Adapted from DTZ Research. "Executive Summary of the Auckland Inner City Living Survey." 20 November 2003. Auckland City Council. 3 June 2011. <http://www.aucklandcity.govt.nz/council/projects/ cbdproject/docs/executivesummary.pdf $>$.

Fig. 2.2 Graph illustrating the percentage of apartment building consents issued out of all residential consents over the last two decades. Image by Author.

Fig. 2.3, 2.4, 2.5, 2.6, 2.7, 2.8, 2.9, 2.10 and 2.11 Apartment plans from Auckland and Wellington apartment buildings. 1:200 scale. Images by Author.

Fig. 2.12 Analysis examples. Image by Author.

Fig. 2.13 Analysis examples. Image by Author.

Fig. 2.14 Diagram illustrating apartments' complex plans and simple sectional layouts. Image by Author.

Fig. 2.15 Diagram illustrating low monotonous ceilings. Image by Author.

Fig. 2.16 Diagram illustrating dedicated circulation and cellular living. Image by Author.

Fig. 2.17 Diagram illustrating living space serving as primary circulation/transition zone. Image by Author.

Fig. 2.18 Diagram illustrating apartments or rooms being lit by a single source of natural light. Image by Author.

Fig. 2.19 Diagram illustrating rooms with no windows. Image by Author.

Fig. 2.20 Diagram illustrating poor connections with nature and external environments.

Image by Author.

Fig. 2.21 Diagram illustrating the lack of dedicated outdoor space. Image by Author. 


\section{Chapter Three:}

Fig. 3.0 Ukiyo-e print; "Great Bridge, Sudden Shower at Atake" by Hiroshige. Retrieved from: http://commons.wikimedia.org/wiki/File\%3AHiroshige_-_Evening_Shower_at_Atake_ and_the_Great_Bridge.jpg)

Fig. 3.1 The Ho-oden Hall at the Chicago 1893 World Fair. Retrieved from: http://www. discovernikkei.org/en/journal/2012/4/5/meeting-of-the-twain/)

Fig. 3.2. The 'Tokaido Megalopolis': Industry was concentrated along the Pacific Belt Region, spanning from Tokyo to northern Kyushu. Image by Author.

Fig. 3.3 Exterior views of Japanese-micro houses. Image by Author.

Fig. 3.4 Exterior views of Japanese-micro houses. Image by Author.

\section{Chapter Four:}

Fig. 4.0, 4.1, 4.2, 4.3, 4.4, 4.5, 4.6, 4.7, 4.8, 4.9, 4.10, 4.11 and 4.12 Plans and sections of Kyosho-Jutaku precedents. 1:200 scale. Images by Author.

Fig. 4.13 Analytical observations of House in Hiro by Suppose Design Office. Image by Author.

Fig. 4.14 Analytical observations of Magritte's by Atelier Tekuto. Image by Author.

Fig. 4.15 Analytical observations of House in Fukawa by Suppose Design Office. Image by Author.

Fig. 4.16 Analytical observations of Skytrace by Amorphe. Image by Author.

Fig. 4.17 Analytical observations of House in Sakuragawa by Suppose Design Office. Image by Author.

Fig. 4.18 Analytical observations of Love House by Takeshi Hosaka Architects. Image by Author.

Fig. 4.19 Analytical observations of House in Minamimachi 3 by Suppose Design Office. Image by Author.

Fig. 4.20 Analytical observations of Garden House by Takeshi Hosaka Architects. Image by Author. 
Fig. 4.21 and Fig. 4.22 Analytical observations of House in Showa-Cho by FujiwaraMuro

Architects. Images by Author.

Fig. 4.23 Internal sight-line diagram. Image by Author.

Fig. 4.24, Fig. 4.25, Fig. 4.26 and Fig. 4.27 Internal sight-line diagrams. Images by Author.

Fig. 4.28, Fig. 4.29, Fig. 4.30 and Fig. 4.31 External sight-line diagrams. Images by Author.

Fig. 4.32 Increasing height of spaces diagram. Image by Author.

Fig. 4.33 Vertical stacking configuration diagram. Image by Author.

Fig. 4.34 Vertical circulation diagram. Image by Author.

Fig. 4.35 Split-level diagram. Image by Author.

Fig. 4.36 Rooms as circulation space diagram. Image by Author.

Fig. 4.37 Internal void diagram. Image by Author.

Fig. 4.38 External void diagram. Image by Author.

Fig. 4.39 Top lighting diagram. Image by Author.

Fig. $4.40 \quad$ Borrowed light diagram. Image by Author.

Fig. 4.41 Light from multiple directions diagram. Image by Author.

Fig. 4.42 Translucent and perforated screening diagram. Image by Author.

Fig. 4.43 Convertible furniture/space diagram. Image by Author.

Fig. 4.44 Built-in furniture diagram. Image by Author.

\section{Chapter Five:}

Fig. 5.1 Site location within Auckland. Image by Author.

Fig. 5.2 Parnell heritage and character buildings. Image by Author.

Fig. 5.3 Parnell topography map. Image by Author.

Fig. 5.4 Figure-ground maps. Image by Author.

Fig. 5.5 Street grid maps. Image by Author.

Fig. 5.6 Site location within Parnell. Image by Author.

Fig. 5.7 Site plan. Image by Author.

Fig. 5.8 Photographs looking at site from Cheshire Street. Photographs by Author. 
Fig. 5.9

Fig. 5.10

Fig. 5.11

Fig. 5.12

Fig. 5.13

Fig. 5.14

Fig. 5.15

Fig. 5.16

Fig. 5.17

Fig. 5.18

Fig. 5.19

Fig. 5.20

Fig. 5.21

Fig. 5.22
Stage one diagram: Site extrusion. Image by Author.

Sloping height plane diagram. Image by Author.

Stage two diagram: Insertion of car stacker. Image by Author.

Stage three diagram: Diagonal division. Image by Author.

Dividing wall separating pedestrian and vehicular access. Image by Author.

Stage four diagram: Circulation routes established. Image by Author.

Stage five diagram. Garden void created. Image by Author.

Stage six diagram: Division of volume into apartments. Image by Author.

Stage seven diagram: Sloped roofs formed into terraces. Image by Author.

Basement 2 plan. Image by Author.

Basement plan. Image by Author.

Ground floor plan. Image by Author.

First floor plan. Image by Author.

Second floor plan. Image by Author.

Third floor plan. Image by Author.

Section A-A. Image by Author.

Section B-B. Image by Author.

Section C-C. Image by Author.

Sectional Perspective of western core. Image by Author.

Section D-D. Image by Author.

Section E-E. Image by Author.

Section F-F. Image by Author.

Section G-G. Image by Author.

Exterior Perspective. Image by Author.

Apartment 'A' location diagram. Image by Author.

Apartment 'A' sectional perspective. Image by Author.

Apartment 'A' floor plans. 1:100. Image by Author.

Apartment 'A' section. 1:100. Image by Author.

Fig. 5.36

Apartment 'A' Interior Perspective. Image by Author. 
Fig. 5.38 Apartment 'A' sectional perspective. Image by Author.

Fig. 5.39 Apartment 'B' location diagram. Image by Author.

Fig. 5.40 Apartment 'B' floor plans. 1:100. Image by Author.

Fig. 5.41 Apartment 'B' section. 1:100. Image by Author.

Fig. 5.42 Apartment 'B' sectional perspective. Image by Author.

Fig. 5.43 Apartment ' $\mathrm{B}$ ' Interior Perspective from master bedroom looking at courtyard.

Image by Author.

Fig. 5.44 Apartment 'C' location diagram. Image by Author.

Fig. 5.45 Apartment ' $C$ ' floor plans. 1:100. Image by Author.

Fig. 5.46 Apartment 'C' Sectional Perspective. Image by Author.

Fig. 5.47 Apartment ' $C$ ' Interior Perspectives illustrating the adaptive use of 'convertible spaces. Image by Author.

Fig. 5.48 Apartment 'D' location diagram. Image by Author.

Fig. 5.49 Apartment ' $D$ ' section and floor plans. 1:100. Image by Author.

Fig. 5.50 Apartment 'E' location diagram. Image by Author.

Fig. 5.51 Apartment 'E' floor plans. 1:100. Image by Author.

Fig. 5.52 Apartment 'E' Sectional Perspective. Image by Author.

Fig. 5.53 Apartment 'F' location diagram. Image by Author.

Fig. 5.54 Apartment 'F' floor plans. 1:100. Image by Author.

Fig. 5.55 Apartment ' $F$ ' section. 1:100. Image by Author.

Fig. 5.56 Apartment 'F' sectional perspective. Image by Author.

Fig. 5.57 Apartment ' $F$ ' interior perspective of bathroom. Image by Author.

Fig. 5.58 Apartment ' $F$ ' interior perspective from study. Image by Author.

Fig. 5.59 Apartment ' $G$ ' location diagram. Image by Author.

Fig. 5.60 Apartment ' $G$ ' floor plans. 1:100. Image by Author.

Fig. 5.61 Apartment ' $G$ ' sectional perspective. Image by Author.

Fig. 5.62 Apartment ' $G$ ' interior perspective from bedroom looking to courtyard. Image by

Author.

Fig. 5.63 Apartment 'H' location diagram. Image by Author. 
Fig. 5.64 Apartment 'I' location diagram.

Fig. 5.65 Apartment ' $H$ ' and 'I' floor plans. 1:100.

Fig. 5.66 Apartment ' $H$ ' sectional perspective.

Fig. 5.67 Apartment 'I' sectional perspective.

Fig. 5.68 and Fig. $5.69 \quad$ Compact bathroom.

Fig. 5.70 Alternative apartment layout 1 diagram.

Fig. 5.71 Alternative apartment layout 2 diagram.

Fig. 5.72 Alternative apartment layout 3 diagram.

Fig. 5.73 Alternative apartment layout 4 diagram.

Fig. 5.74 Split-level stair in apartment 'E'. 